\title{
Overcoming Limitations in Dual Photoredox/Nickel catalyzed C-N Cross-Couplings due to Catalyst Deactivation
}

\author{
Sebastian Gisbertz, Susanne Reischauer, Bartholomäus Pieber
}

Submitted date: 13/11/2019 - Posted date: 25/11/2019

Licence: CC BY-NC-ND 4.0

Citation information: Gisbertz, Sebastian; Reischauer, Susanne; Pieber, Bartholomäus (2019): Overcoming Limitations in Dual Photoredox/Nickel catalyzed C-N Cross-Couplings due to Catalyst Deactivation. ChemRxiv. Preprint. https://doi.org/10.26434/chemrxiv.10298735.v1

Dual photoreodox/nickel catalyzed $\mathrm{C}-\mathrm{N}$ cross-couplings are an attractive alternative to the palladium catalyzed Buchwald-Hartwig reaction, but are limited to aryl halides containing electron-withdrawing groups. We show that the formation of catalytically inactive nickel-black is responsible for this limitation. Deposition of nickel-black further deactivates heterogeneous photocatalysts restricting their recyclability. We demonstrate that catalyst deactivation can be avoided by the combination of nickel catalysis and a carbon nitride semiconductor. The broad absorption range of the organic, heterogeneous photocatalyst enables a wavelength dependent reactivity control to prevent nickel-black formation. A second approach is to run the reactions at high concentrations to increase the formation of nickel-amine complexes that reduce nickel-black formation. This allows reproducible, selective $\mathrm{C}-\mathrm{N}$ cross-couplings of electron-rich aryl bromides.

File list (2)

manuscript.pdf (1.56 MiB)

view on ChemRxiv - download file

SI.pdf (8.70 MiB)

view on ChemRxiv - download file 


\title{
ARTICLE
}

\section{Overcoming Limitations in Dual Photoredox/Nickel catalyzed $\mathbf{C}-\mathbf{N}$ Cross-Couplings due to Catalyst Deactivation}

Sebastian Gisbertz, ${ }^{1,2}$ Susanne Reischauer ${ }^{1,2} \&$ Bartholomäus Pieber ${ }^{1 *}$

${ }^{1}$ Department of Biomolecular Systems, Max-Planck-Institute of Colloids and Interfaces, Am Mühlenberg 1, 14476 Potsdam, Germany

${ }^{2}$ Department of Chemistry and Biochemistry, Freie Universität Berlin, Arnimallee 22, 14195 Berlin, Germany

*Corresponding author

Email: bartholomaeus.pieber@mpikg.mpg.de

\begin{abstract}
Dual photoreodox/nickel catalyzed $\mathrm{C}-\mathrm{N}$ cross-couplings are an attractive alternative to the palladium catalyzed Buchwald-Hartwig reaction, but are limited to aryl halides containing electron-withdrawing groups. Here we show that the formation of catalytically inactive nickelblack is responsible for this limitation and causes severe reproducibility issues. Deposition of nickel-black further deactivates heterogeneous photocatalysts restricting their recyclability. We demonstrate that catalyst deactivation can be avoided by the combination of nickel catalysis and a carbon nitride semiconductor. The broad absorption range of the organic, heterogeneous photocatalyst enables a wavelength dependent reactivity control to prevent nickel-black formation. A second approach, that is applicable to a broader set of substrates, is to run the reactions at high concentrations to increase the formation of nickel-amine complexes that reduce nickel-black formation. This allows reproducible, highly selective $\mathrm{C}-\mathrm{N}$ cross-couplings of electron rich aryl bromides and enables efficient reactions of aryl chlorides.
\end{abstract}




\section{MAIN}

The palladium-catalyzed formation of carbon-nitrogen bonds (Buchwald-Hartwig) ranks among the most widely applied reactions in synthetic chemistry. ${ }^{1}$ Nickel is an attractive alternative to palladium due to its higher abundance, but the air-sensitive $\mathrm{Ni}(0)$ complexes, sophisticated ligands, strong reductants, and bases required for $\mathrm{C}-\mathrm{N}$ bond formations have hampered its use..$^{2-4}$ Air-stable nickel pre-catalysts have been developed, but require harsh conditions and have a limited substrate scope (Figure 1, a). ${ }^{5-8}$ In combination with electrochemistry, ligated $\mathrm{Ni}$ (II) salts catalyze the $\mathrm{C}-\mathrm{N}$ cross-coupling under mild conditions (Figure 1, b).${ }^{910}$ Ligand-free Ni(II) salts were used together with UV light $(365 \mathrm{~nm}),{ }^{11}$ or visible light photoredox catalysis $(\mathrm{PRC})^{12-16}$ in a similar approach (Figure 1,c). Although synthetically attractive, electro- and photochemically mediated, nickel-catalyzed C-N couplings are limited to electron-poor aryl halides. Aryl halides that do not contain electron withdrawing groups are usually either unreactive, ${ }^{15}$ or give low yields, ${ }^{10-12,16}$ and only a few examples with a good isolated yield are reported (for a detailed analysis, see the Supplementary Information). ${ }^{13,17}$ Electro- and photochemically mediated methods rely on the initial reduction of the $\mathrm{Ni}$ (II) catalyst to a low valent $\left(\mathrm{Ni}^{0}\right.$ or $\left.\mathrm{Ni}^{\mathrm{I}}\right)$ species, followed by oxidative addition that is slow for electron-rich aryl halides. ${ }^{10,18}$ This potentially leads to the accumulation of nickel(0) species that aggregate, resulting in catalyst deactivation. In the electrochemically driven, nickelcatalyzed aryl amination, nickel-black deposition was observed on the cathode and could be avoided by using $\mathrm{Ni}(\mathrm{bpy})_{3} \mathrm{Br}_{2}$ (bpy $=2,2$ ' bipyridine) instead of a 1:1 mixture of $\mathrm{NiBr}_{2} \cdot$ glyme and dtbbpy (4,4'-di-tert-butyl-2,2'-bipyridine), thereby expanding the scope to a few electronrich heteroaryl halides. ${ }^{10}$ Stabilizing ligands are unsuitable for light mediated, nickel-catalyzed $\mathrm{C}-\mathrm{N}$ cross-couplings, ${ }^{11-16}$ but catalyst deactivation or nickel-black formation was not reported. It is, however, well known that $\mathrm{Ni}(\mathrm{II})$ salts - in presence of amines as sacrificial electron donors (SED) - can be used intentionally for the photochemical preparation of $\mathrm{Ni}(0)$ nanoparticles (Figure 1, d). ${ }^{19-21}$ 

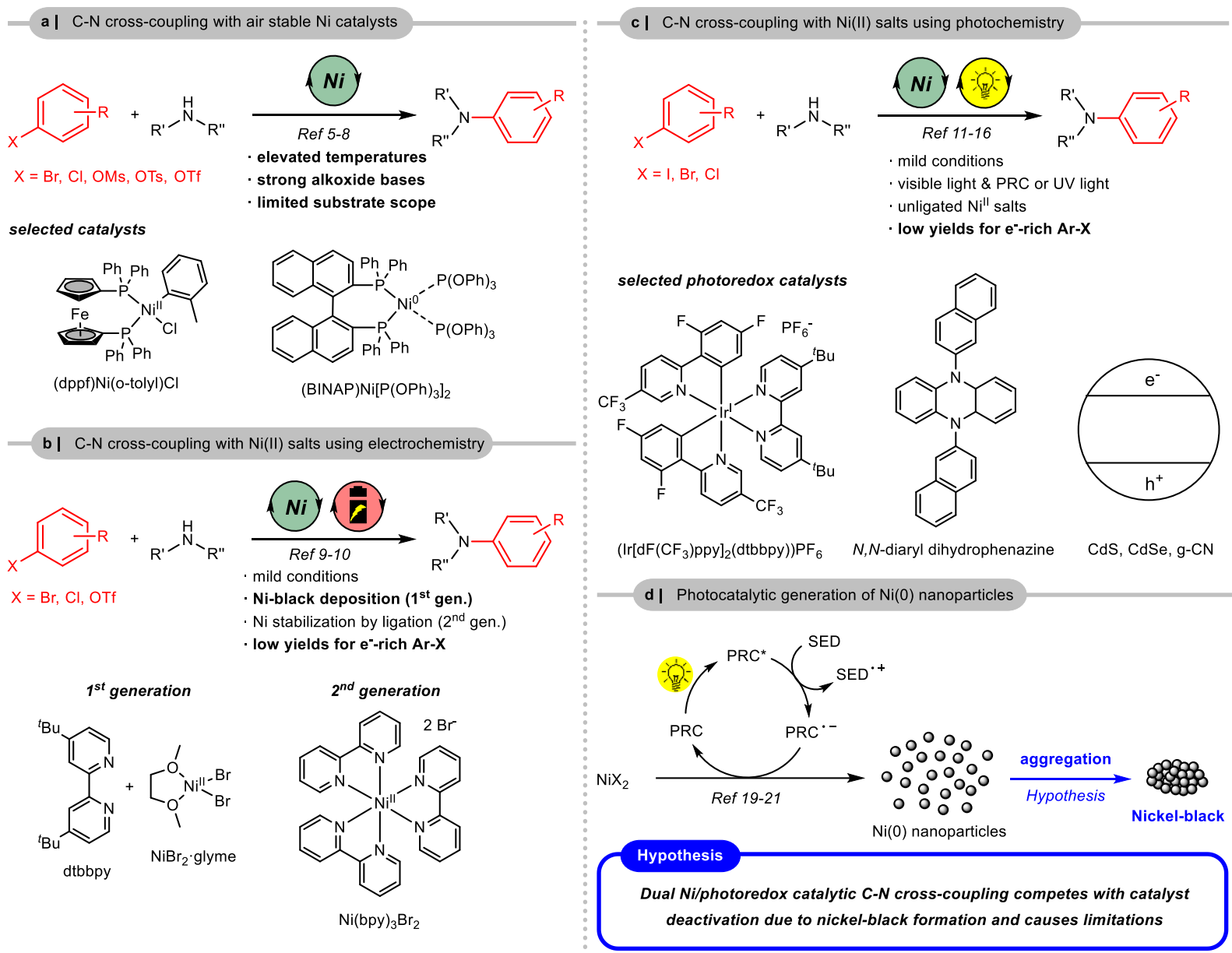

Figure 1 | Nickel catalyzed $\mathbf{C}-\mathbf{N}$ cross-coupling reactions. a, air stable Ni precatalysts require harsh conditions. b, electrochemically enabled $\mathrm{Ni}$-catalyzed aminations and; c, photochemically driven Ni-catalyzed aminations are limited to electron-poor aryl halides. d, photocatalytic reduction of $\mathrm{Ni}$ (II) salts for is used for nanoparticle formation potentially leads to nickel-black formation in catalysis.

Here, we show that catalyst deactivation via nickel-black formation is responsible for low yields for electron-rich aryl halides in dual photoredox/nickel catalyzed $\mathrm{C}-\mathrm{N}$ cross-couplings. Deposition of the catalytically inactive, low-valent nickel species further deactivates a heterogeneous photocatalyst, hampering its recyclability. We demonstrate that nickel-black formation can be avoided by controlling the reactivity of a carbon nitride photocatalyst, or the reduction of catalyst-solvent interactions. The resulting protocols enable selective and reproducible couplings of electron-rich aryl halides, efficient reactions using aryl chlorides, and allow recycling of the heterogeneous photocatalyst. 


\section{Results}

Our investigations started by optimizing the dual nickel/photoredox catalyzed amination of methyl 4-bromobenzoate with pyrrolidine using CN-OA-m, a carbon nitride derivative prepared from urea and oxamide (see Supplementary Information for details). ${ }^{22-24}$ Nearly quantitative formation of the desired alkyl aryl amine (1) was obtained within $8 \mathrm{~h}$ when $\mathrm{CN}$ OA-m $\left(3.33 \mathrm{mg} \mathrm{mL}^{-1}\right), \mathrm{NiBr}_{2} \cdot 3 \mathrm{H}_{2} \mathrm{O}(2.5 \mathrm{~mol} \%)$ and three equivalents of the amine were used without any additional base in dimethylacetamide (DMAc) as solvent (Table 1, Entry 1-2). ${ }^{17}$ The reaction was easily scaled up by increasing the reaction time, affording $\mathbf{1}$ on a gram scale within 14 hours (see Supplementary Information). Aside from aryl bromides, aryl iodides coupled with similar efficiency and selectivity (Entry 3). The optimized protocol further enabled $\mathrm{C}-\mathrm{N}$ couplings using aryl chlorides and aryl triflates, but these reactions did not go to completion (Entry 4-5).

Table 1 | Optimized conditions and control experiments using white LEDs (RGB) ${ }^{[a]}$

\begin{tabular}{|c|c|c|c|c|c|c|}
\hline \multirow[b]{2}{*}{ Entry } & \multirow[b]{2}{*}{$\mathbf{X}$} & \multirow{2}{*}{$\begin{array}{c}+\bigsqcup_{3.0 \text { equiv }}^{\mathrm{N}} \\
\text { Conditions }\end{array}$} & $\begin{array}{l}\mathrm{CN}-\mathrm{OA}-\mathrm{m}\left(3.33 \mathrm{mg} \mathrm{mL}^{-1}\right) \\
\mathrm{NiBr}_{2} \cdot 3 \mathrm{H}_{2} \mathrm{O}(2.5 \mathrm{~mol} \%) \\
\mathrm{DMAc} \text { (deg.), } 8 \mathrm{~h} \\
\text { white LEDs, } 40^{\circ} \mathrm{C}\end{array}$ & & $\begin{array}{l}2, R=H \\
3, R=O H\end{array}$ & \multirow[b]{2}{*}{$3[\%]^{\mathrm{c}}$} \\
\hline & & & Conversion $[\%]^{b}$ & $1[\%]^{\mathrm{c}}$ & $2[\%]^{\mathrm{c}}$ & \\
\hline 1 & $\mathrm{Br}$ & as shown & quant. & 98 & 2 & n.d. \\
\hline 2 & $\mathrm{Br}$ & $1.66 \mathrm{mg} \mathrm{mL}^{-1} \mathrm{CN}-\mathrm{OA}-\mathrm{n}$ & quant. & 96 & 2 & 1 \\
\hline 3 & I & as shown & quant. & 99 & 1 & n.d. \\
\hline 4 & $\mathrm{Cl}$ & $168 \mathrm{~h}$ & 76 & 72 & 4 & n.d. \\
\hline 5 & OTf & $72 \mathrm{~h}$ & 75 & 67 & 5 & 2 \\
\hline 6 & $\mathrm{Br}$ & no CN-OA-m & 5 & n.d. & 2 & 1 \\
\hline 7 & $\mathrm{Br}$ & no $\mathrm{NiBr}_{2} \cdot 3 \mathrm{H}_{2} \mathrm{O}$ & 5 & n.d. & n.d. & n.d. \\
\hline 8 & $\mathrm{Br}$ & no light & $<1$ & n.d. & n.d. & n.d. \\
\hline 9 & $\mathrm{Br}$ & no degassing & 10 & 10 & n.d. & n.d. \\
\hline
\end{tabular}

aReaction conditions: methyl 4-bromobenzoate $(1.2 \mathrm{mmol})$, pyrrolidine $(3.6 \mathrm{mmol}), \mathrm{NiBr}_{2} \cdot 3 \mathrm{H}_{2} \mathrm{O}(2.5 \mathrm{~mol} \%), \mathrm{CN}-\mathrm{OA}-\mathrm{m}$ (20 mg), DMAc (anhydrous, $6 \mathrm{~mL}$ ), white LEDs (RGB) at $40{ }^{\circ} \mathrm{C}$ for $8 \mathrm{~h} .{ }^{\mathrm{b}} \mathrm{Conversion}$ aryl halide determined by ${ }^{1} \mathrm{H}-\mathrm{NMR}$ using 1,3,5-trimethoxybenzene as internal standard. ${ }^{\mathrm{C}} \mathrm{NMR}$ yields were determined by ${ }^{1} \mathrm{H}-\mathrm{NMR}$ using $1,3,5-$ trimethoxybenzene as internal standard. n.d. = not detected. dtbbpy $=4,4^{\prime}$-di-tert-butyl-2,2'-bipyridine 
With the optimized conditions in hand, the versatility of the semiheterogeneous catalytic system was evaluated (Table 2). The reaction of methyl 4-bromobenzoate with cyclic secondary amines generally gave high yields for the corresponding aryl amines (1, 4-7). A secondary amine with low steric hindrance also resulted in the desired aryl amine (8), but the majority of acyclic secondary amines did not react under these conditions (see Supplementary Information). Aliphatic and aromatic primary amines reacted efficiently (9-11). Aryl halides containing electron-withdrawing groups coupled with high selectivity; Nitriles (12-14), carbonyl groups $(\mathbf{1}, \mathbf{1 5}, \mathbf{2 3 - 2 4})$, trifluoromethyl- (15) as well as methylsulfonyl-groups (16), halides (17-18), boronic acid pinacol esters $(\mathbf{2 2})$, and heteroaromatic bromides $(\mathbf{2 5}, \mathbf{2 6})$ were tolerated in the dual catalytic amination. 1,4-dibromobenze can undergo selective mono- (20) or diamination (21) by varying the reaction time and stoichiometry of the amine coupling partner. Similar to related $\mathrm{C}-\mathrm{O}$ bond formations, ${ }^{22,23}$ a carbonyl-group in the 2-position only gave moderate yield (16).

Although good isolated yields were obtained for 1-bromo-4-fluorobenzene (27), ${ }^{25}$ bromobenzene (28), and aryl bromides with electron donating substituents (29-31), these values are not representative and these substrates suffered from severe reproducibility issues. The reactions frequently resulted in low yields and the heterogeneous PRC became black. High amounts of deposited nickel were detected on the recovered carbon nitride by ICP-OES analysis, indicating nickel-black formation (see Supplementary Information). Deactivation of metal catalysts via deposition is a common problem in palladium catalysis (Pd-black formation) and can be addressed by avoiding high concentrations of $\operatorname{Pd}(0)$ species that agglomerate. ${ }^{26}$ In light-mediated, nickel catalyzed $\mathrm{C}-\mathrm{N}$ cross-couplings, a $\mathrm{Ni}(0)$ complex was proposed to be the catalytically active species that is $i$ ) initially formed via a photoredox-catalyzed hydrogen atom transfer (HAT), and $i$ ) regenerated in the last step of the catalytic cycle via a SET reduction of a $\mathrm{Ni}(\mathrm{I})$ intermediate by the PRC. ${ }^{18}$ Consequently, we assumed that controlling the reactivity of the photocatalytic system could enable us to decrease the accumulation of unstabilized $\mathrm{Ni}(0)$ 
Table 2 | Scope of the semi-heterogeneous amination of amines and aryl bromides. ${ }^{\text {[a] }}$

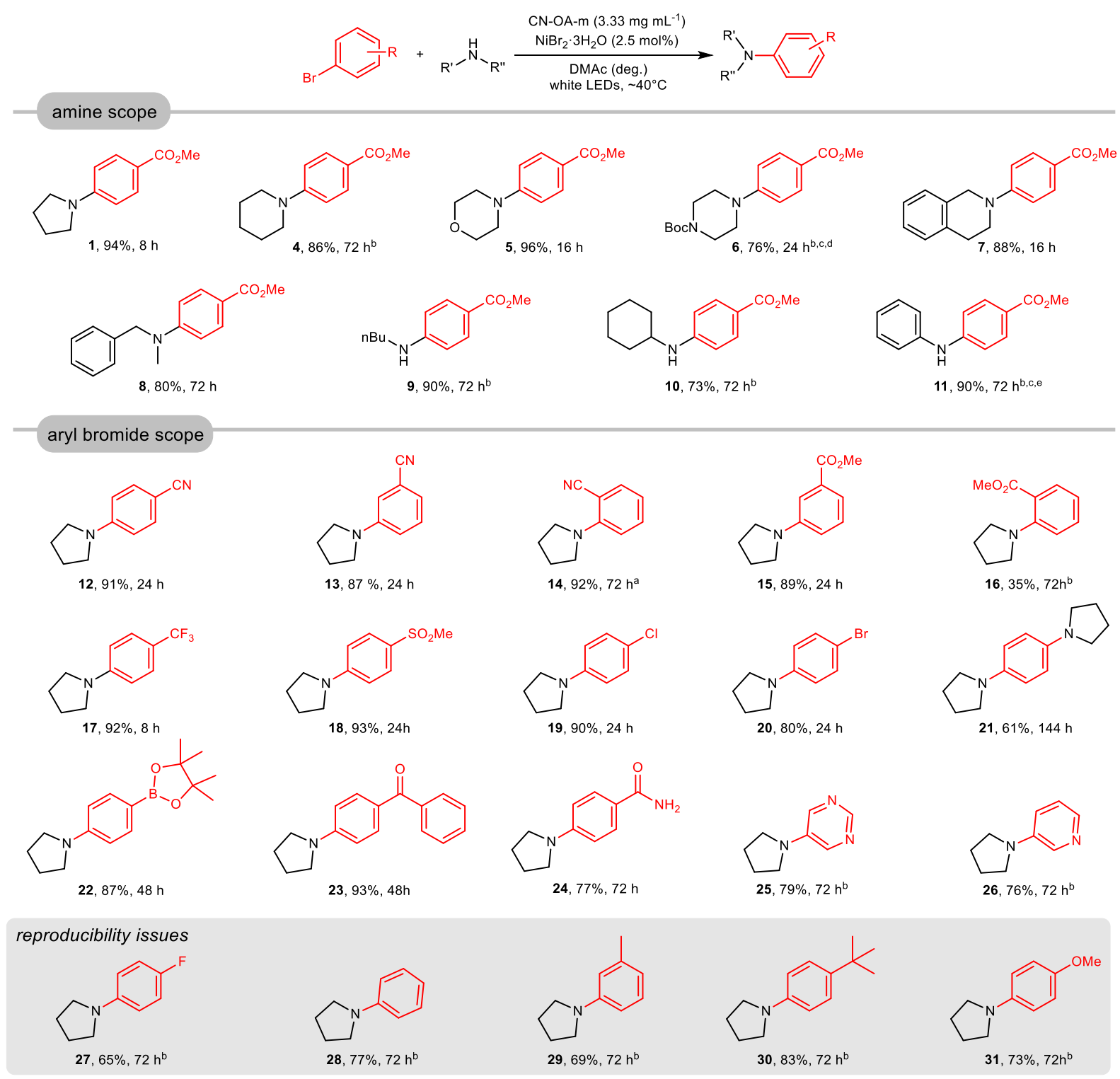

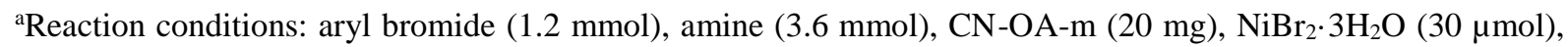
DMAc (anhydrous, $6.0 \mathrm{~mL}$ ), white LEDs at $40{ }^{\circ} \mathrm{C}$. ${ }^{b} 5 \mathrm{~mol} \% \mathrm{NiBr}_{2} \cdot 3 \mathrm{H}_{2} \mathrm{O}$ were used. ${ }^{\mathrm{c}} 10 \mathrm{~mol} \%$ pyrrolyidine were added. ${ }^{\mathrm{d}}$ The reaction was carried out on a $0.6 \mathrm{mmol}$ scale. ${ }^{\text {e}} 3$ equivalents $N$-tert-butylisopropylamine were added. Isolated yields are reported. For experimental details, see the Supplementary Information.

species, avoiding their aggregation. We hypothesized that this can be achieved using higher wavelengths as $\mathrm{CN}-\mathrm{OA}-\mathrm{m}$ has an extended visible light absorption that enables catalytic crosscouplings using green light. ${ }^{23}$ The coupling of pyrollidine and 1-bromo-4-fluorobenzene was indeed highly selective and reproducible using $520 \mathrm{~nm}$ LEDs (Method B), and the desired compound (27) was obtained in $85-91 \%$ in six parallel experiments (Figure 2, a). The same set of experiments using blue LEDs ( $450 \mathrm{~nm}$, Method A) exhibited large variations in yield. While 
five experiments gave $60-70 \%$ of $\mathbf{2 7}$, only $5-6 \%$ of the desired amine were formed for two reactions where the reaction mixture turned black. Careful analysis of the heterogeneous material recovered from the low yielding reactions identified the nature and quantity of the deposited Ni species (see Supplementary Information). ICP-OES analysis showed a Ni concentration of $126 \mathrm{mg} \mathrm{g}^{-1}$ for the reaction irradiated with blue light and only $36 \mathrm{mg} \mathrm{g}^{-1}$ for the material after an experiment using green LEDs. Elemental analysis via energy-dispersive X-ray spectroscopy (EDX) is in agreement with these results. X-ray powder diffraction (XRD) confirmed the deposition of low valent nickel species, with a significantly higher concentration on the material irradiated with blue light. High resolution X-ray photoelectron spectroscopy (XPS) for core levels of $\mathrm{Ni} 2 \mathrm{p}_{3 / 2}$ spectrum of the recovered $\mathrm{CN}-\mathrm{OA}-\mathrm{m}$ from experiments using $450 \mathrm{~nm}$ LEDs (Method A) showed two main deconvoluted peaks located at $853.7( \pm 0.02) \mathrm{eV}$ and $852.5( \pm 0.02) \mathrm{eV}$ that can be assigned to the binding energy of $\mathrm{Ni}(\mathrm{II})$ and $\mathrm{Ni}(0)$ species, respectively. Only $\mathrm{Ni}(\mathrm{II})$ was detected on the material recovered from experiments using 520 nm LEDs (Method B) by XPS. Scanning transmission electron microscopy (STEM) was used to visualize nickel particles on the surface of the recovered $\mathrm{CN}-\mathrm{OA}-\mathrm{m}$ from both methods. High-angle annular dark-field (HAADF) images show a high amount of nickel particles that agglomerated (nickel-black) on the CN-OA-m recovered from experiments using $450 \mathrm{~nm}$ LEDs (Method A), whereas the material from experiments using $520 \mathrm{~nm}$ LEDs (Method B) contained almost no agglomerates (Figure 2, a).

Nickel-black formation was also shown to be responsible for low yields using other lightmediated protocols for the same model reaction (Figure 2,b). Using 1 mol\% of the homogeneous $\mathrm{PRC}\left(\operatorname{Ir}\left[\mathrm{dF}_{\left(\mathrm{CF}_{3}\right)} \mathrm{ppy}\right]_{2}(\mathrm{dtbbpy})\right) \mathrm{PF}_{6},{ }^{12}$ resulted in low selectivity towards the desired coupling product $(\mathbf{2 5}, 33 \%$ yield $)$, and small amounts of a black precipitate were formed during the reaction. Decreasing the amount of $\left(\operatorname{Ir}\left[\mathrm{dF}_{\left(\mathrm{CF}_{3}\right)} \mathrm{ppy}\right]_{2}(\mathrm{dtbbpy})\right) \mathrm{PF}_{6}$ to $0.02 \mathrm{~mol} \%$ increased the yield of $\mathbf{2 7}$ significantly (77\%) and no particle formation was observed. Here, the 
amount of the PRC plays a crucial role to avoid nickel-black formation and the optimal catalyst loading needs to be determined for each substrate individually. The PRC-free, UV light-

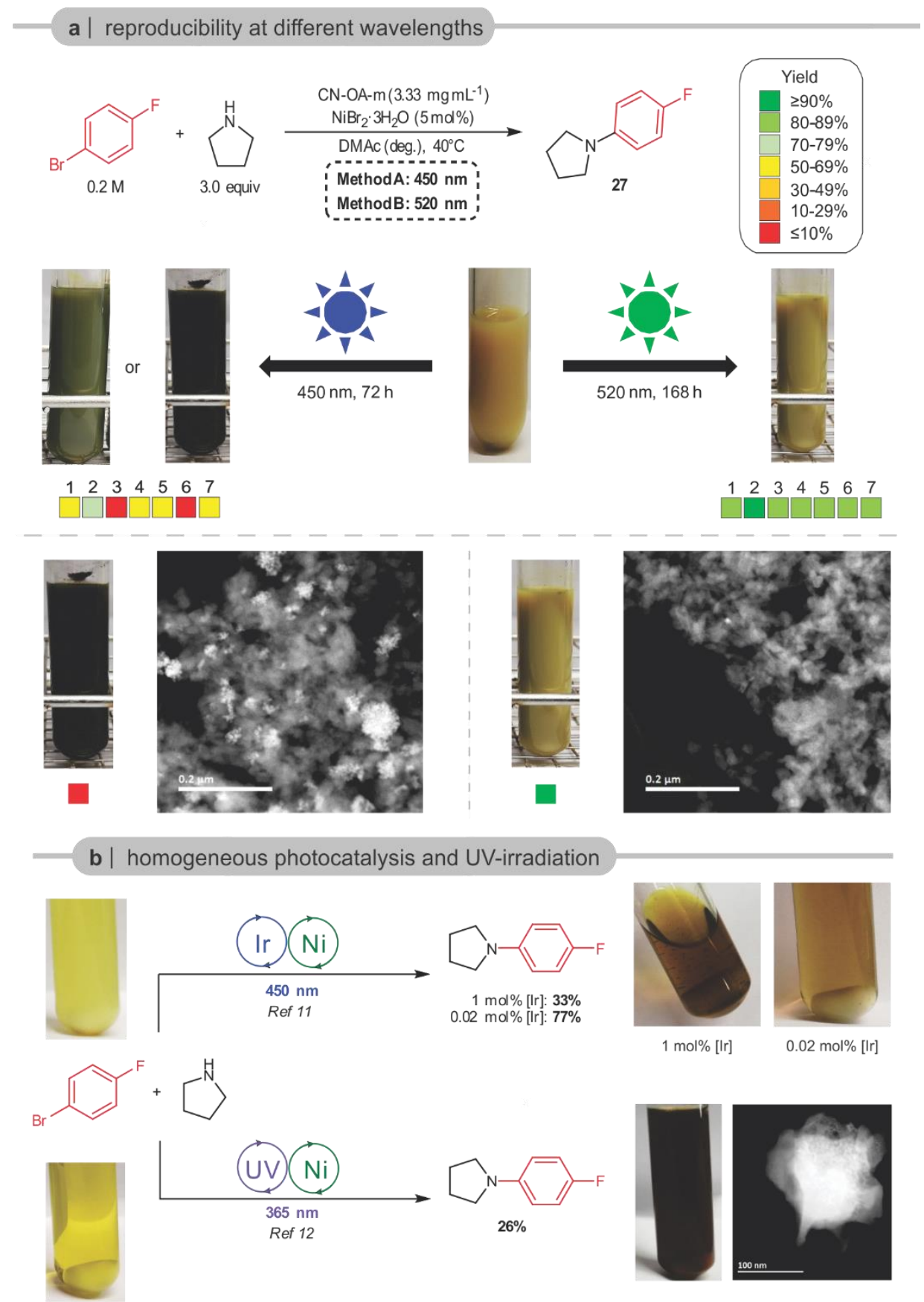

Figure 2 Catalyst deactivation during the reaction of 4-bromofluorobenzene with pyrrolidine. a, Reproducibility using blue $(450 \mathrm{~nm})$ and green $(520 \mathrm{~nm})$ LED irradiation. The reaction mixture turned dark green or black and suffered from severe reproducibility issues at $450 \mathrm{~nm}$, whereas almost no color change and reproducible results were obtained at $520 \mathrm{~nm}$. HAADF-STEM images show nickel particle agglomerates (bright spots) on CN-OA-m recovered the experiment using blue light and almost no agglomerates when $520 \mathrm{~nm}$ were used. c, Nickel-black formation was also observed using the homogeneous $\left(\operatorname{Ir}\left[\mathrm{dF}\left(\mathrm{CF}_{3}\right)\right.\right.$ ppy $]_{2}(\mathrm{dtbbpy}) \mathrm{PF}_{6}(=[\mathrm{Ir}])$ photocatalyst and in the PRC-free reaction using UV light. For experimental details, see the Supplementary Information. 
mediated protocol ${ }^{11}$ resulted in no more than $26 \%$ of 27 and a black precipitate was formed in high amounts (Figure 2, c). STEM imaging and EDX spectroscopy confirmed that these solids consist of nickel and organic matter that is presumably resulting from substrate/product degradation by the high-energy light source (see Supplementary Information for details).

The dual carbon nitride/nickel catalyzed protocol using green light (520 nm, Method B) did also enable selective, reproducible $\mathrm{C}-\mathrm{N}$ cross-couplings of bromobenzene (26), and 3bromotoluene (27) with pyrrolidine, but did not eliminate catalyst deactivation issues in the cases of 1-bromo-4-tert-butylbenzene (28), and 4-bromoanisole (29) (Figure 3, a). Although almost quantitative product formation was observed in some cases, the reactions sometimes gave low yields and black reaction mixtures. In the case of 1-bromo-4-tert-butylbenzene, for example, six parallel reactions using $450 \mathrm{~nm}$ (Method A) gave $52-70 \%$ of the desired product (28), whereas up to $92 \%$ as well as only $28 \%$ were obtained under identical conditions using $520 \mathrm{~nm}$ (Method B). Efforts to increase the reproducibility and to minimize the nickel-black formation by changing the light intensity, distance between the reaction mixture and light source, varying the amount of both catalysts, changing the solvent or nickel catalyst, and adding $\mathrm{MTBD}^{12}$ or dtbbpy to stabilize intermediate nickel species were not successful. We hypothesized that the formation of $\mathrm{Ni}(0)$ agglomerates is not only caused by the photon energy and activity of the photocatalyst but also results from competitive binding of the amine and the solvent (DMAc) with the nickel salt. In palladium catalyzed cross couplings, for example, PdArylXL $_{n}$ intermediates, are known to form complexes with various solvents, including DMAc, that undergo $\beta$-hydride elimination followed by the formation of $\operatorname{Pd}(0)$ and Aryl- $\mathrm{H}^{27}$ Although pyrrolidine was shown to be the most favorable ligand in light-mediated, nickel catalyzed aminations,${ }^{18}$ the high excess of DMAc likely leads to a significant amount of solventcatalyst complexes. Indeed, running the reaction at $1.2 \mathrm{M}$ instead of $0.2 \mathrm{M}$ resulted in reproducible reactions and the desired products (28-31) were obtained in high yields even at $450 \mathrm{~nm}$ (Method C). These results could not be further improved using $520 \mathrm{~nm}$ irradiation, 
suggesting that the photochemical nickel-black formation can be outpaced at high concentrations independent of the photon energy in our semiheterogeneous catalytic system (see Supplementary Information). ${ }^{28}$

a | reproducibility - aryl bromides without EWGs

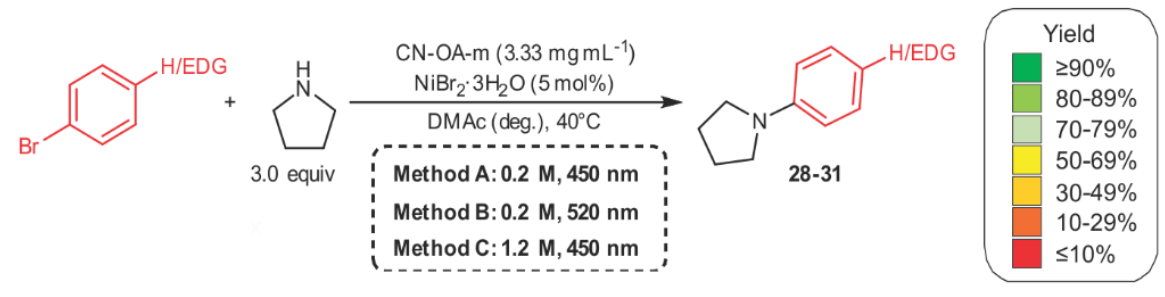

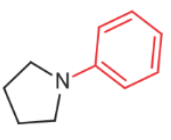

28

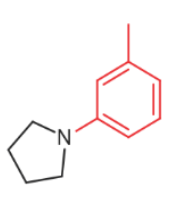

29

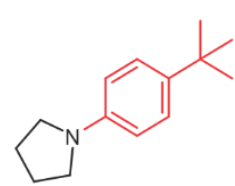

30

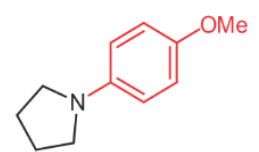

31

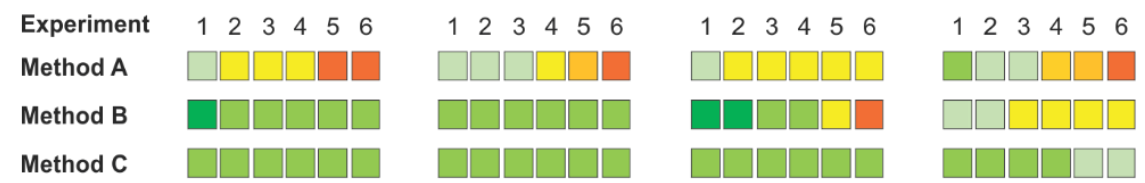

b | method evaluation - aryl chloride

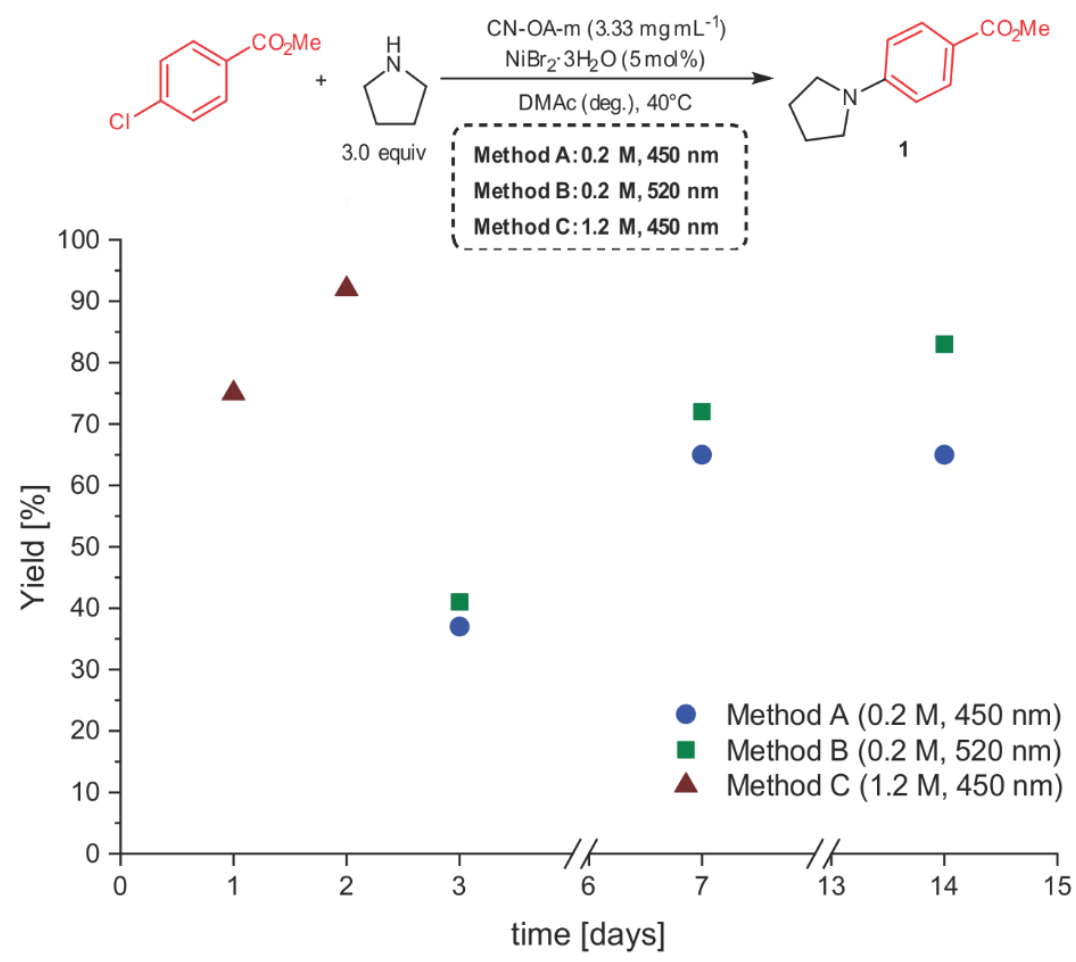

Figure 3 Evaluation of different coupling protocols for non-activated aryl bromides and an aryl chloride. a, Reproducibility study for aryl bromides without electron withdrawing groups using different $\mathrm{C}-\mathrm{N}$ coupling protocols $\mathbf{B}$, Comparison of the different coupling protocols for the reaction of methyl 4-chlorobenzoate and pyrrolidine. 
A reinvestigation of the coupling of methyl 4-chlorobenzoate with pyrrolidine was carried out using all protocols (Figure 3, b), as this reaction did not go to completion using the initially optimized conditions (Table 1, Entry 3). The standard protocol (Method A) afforded the desired coupling product (1) in 65\% within seven days. Longer irradiation did not result in higher yields and only increased the amount of the dehalogenated side product, indicating complete catalyst deactivation (see Supplementary Information). With green light (Method B), 83\% of 1 were obtained within 14 days. The optimized method using $450 \mathrm{~nm}$ LEDs and a lower amount of solvent (Method C) significantly enhanced the $\mathrm{C}-\mathrm{N}$ coupling and resulted in $92 \%$ of 1 within two days.

Finally, we sought to study if the deposition of nickel-black also affects the recyclability of CNOA-m by altering its photocatalytic activity. During the coupling of pyrolidine with methyl 4bromobenzoate using white (RGB) LEDs, the reaction mixture became greenish-brown (Figure 4, a). ICP-OES analysis of the heterogeneous material showed a nickel content of $\sim 14 \mathrm{mg} \mathrm{g}^{-1}$. The product formation decreased significantly when the heterogeneous PRC was recycled (Figure 4, b). ${ }^{29}$ Further, the yellow PRC turned dark green to black and the amount of deposited $\mathrm{Ni}$ rose to $\sim 61 \mathrm{mg} \mathrm{g}^{-1}$ over five recycling experiments. At higher wavelengths (520 nm, Method B), the model reaction required $48 \mathrm{~h}$ instead of $8 \mathrm{~h}$ for full conversion (Figure 4 , a). Although the reaction mixture did not change its color, the amount of deposited Ni was similar to the white LED experiment $\left(\sim 14 \mathrm{mg} \mathrm{g}^{-1}\right)$. The photocatalyst did, however, not lose its catalytic activity during five recycling experiments and was recovered as a yellow solid that contained a lower amount of deposited nickel $\left(\sim 39 \mathrm{mg} \mathrm{g}^{-1}\right)$ compared to the white light experiment (Figure 4, b). Scanning transmission electron microscopy (STEM) of CN-OA-m from both recycling studies showed a significant amount of nickel agglomerates (nickel-black) for CN-OA-m from the experiments using white LEDs, whereas almost no agglomerates were detected on the semiconductor recovered from the recycling study using green LEDs (see Supplementary Information). 


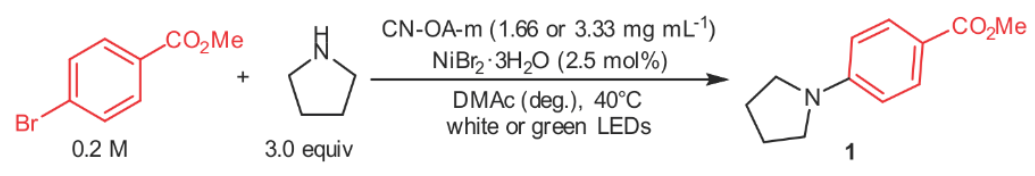

a | time study

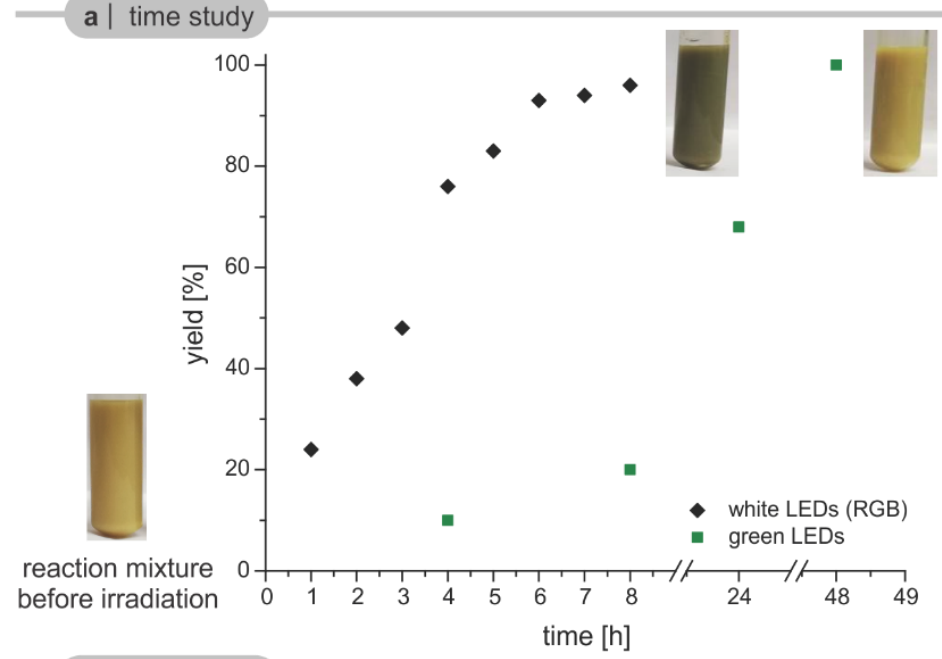

b | recyclability

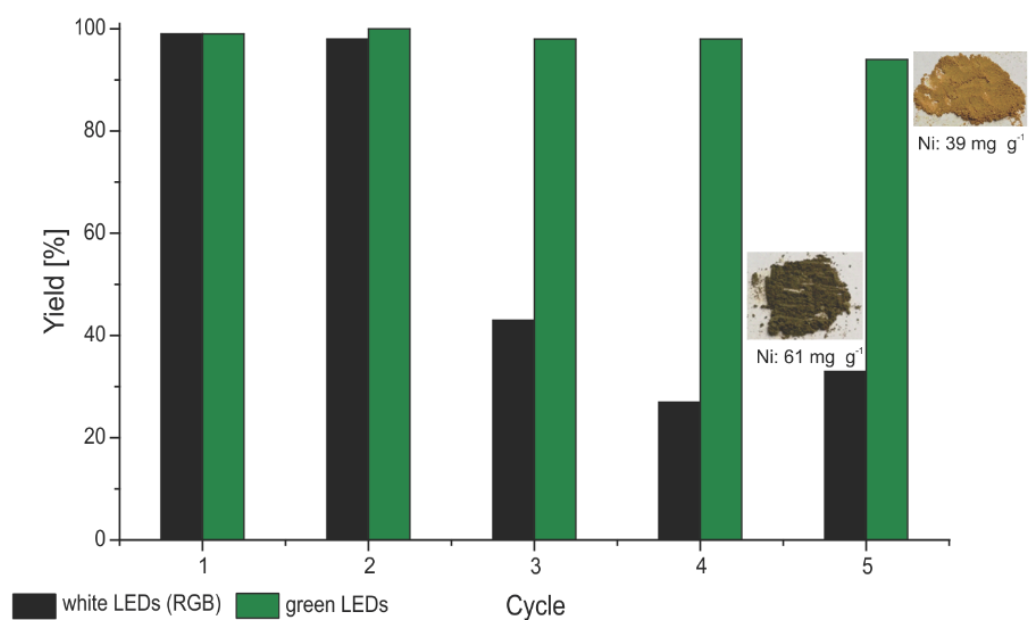

Figure 4 | Reduction of catalyst deactivation using higher wavelengths. a, Time study for the coupling of methyl 4-bromobenzoate and pyrrolidine using white (RGB) and green $(\sim 520 \mathrm{~nm})$ LED irradiation. The heterogeneous photocatalyst turned green using white light (RGB) irradiation whereas no color change was observed when green light $(\sim 520 \mathrm{~nm})$ was used. b, The recyclability of CN-OA-m is excellent using green $(\sim 520 \mathrm{~nm})$ LEDs. Deactivation of the PRC by nickel-black depositions was observed using white (RGB) LEDs. For experimental details, see the Supplementary Information.

\section{Conclusion}

The formation of nickel-black limits the applicability of light-mediated, nickel catalyzed $\mathrm{C}-\mathrm{N}$ cross-couplings. In particular, aryl halides lacking electron withdrawing groups suffer from reproducibility problems due to deactivation of the nickel catalyst. Deposition of agglomerated 
nickel particles (nickel-black) not only deactivates the homogeneous nickel catalyst, but also the heterogeneous carbon nitride photocatalyst. Careful studies using dual carbon nitride/nickel catalysis showed that nickel-black formation can be avoided by wavelength dependent reactivity control to avoid agglomeration of low valent nickel species. For homogeneous PRCs this requires tedious screenings to identify a suitable stoichiometry of the photocatalyst. In case of carbon nitride materials the cross-couplings can be carried out at longer wavelengths due to their broad absorption spectrum. A second, more generally applicable approach is to run the reactions at higher concentrations. This increases the overall reaction rate and likely reduces the formation of nickel-solvent interactions that likely facilitate nickel-black formation. This method resulted in reproducible, highly selective $\mathrm{C}-\mathrm{N}$ cross-couplings of aryl bromides and enables efficient reactions of aryl chlorides.

\section{Methods}

\section{General procedure for light-mediated $\mathrm{C}-\mathrm{N}$ cross-couplings using $\mathrm{CN}-\mathrm{OA}-\mathrm{m}$ and $\mathrm{Ni}$}

catalysis. An oven dried vial $(19$ x $80 \mathrm{~mm})$ equipped with a stir bar was charged with CN-OAm (20 mg), aryl bromide (1.2 mmol, 1.0 equiv.) and $\mathrm{NiBr}_{2} \cdot 3 \mathrm{H}_{2} \mathrm{O}(16.4 \mathrm{mg}, 60 \mu \mathrm{mol}, 5.0 \mathrm{~mol} \%)$. Subsequently, pyrrolidine ( $256.0 \mathrm{mg}, 295.6 \mu \mathrm{l}, 3.6 \mathrm{mmol}, 3.0$ equiv.) and DMAc (anhydrous, Method A and B: $6 \mathrm{~mL}$, Method C: $1 \mathrm{~mL}$ ) were added and the vial was sealed with a septum and Parafilm. The reaction mixture was sonicated for 5-10 min until fine dispersion of the solids was achieved and the mixture was then degassed by bubbling $\mathrm{N}_{2}$ for $10 \mathrm{~min}$. The mixture was irradiated in the photoreactor (Method A and C: $450 \mathrm{~nm}$, Method B: $520 \mathrm{~nm}$, see Supplementary Information for details) at $40{ }^{\circ} \mathrm{C}$. After the respective reaction time, one equivalent of $1,3,5-$ trimethoxybenzene $(202.0 \mathrm{mg}, 1.2 \mathrm{mmol}$, internal standard) was added. An aliquot $(\sim 300 \mu \mathrm{L})$ of the reaction mixture was diluted with DMSO- $\mathrm{d}_{6}$ and subjected to ${ }^{1} \mathrm{H}-\mathrm{NMR}$ analysis. After full consumption of the arene starting material, the liquid phase was diluted with $\mathrm{H}_{2} \mathrm{O}(40 \mathrm{~mL})$ and extracted with ethyl acetate $(3 \times 30 \mathrm{~mL})$. The combined organic phases were washed with 
$\mathrm{H}_{2} \mathrm{O}(40 \mathrm{~mL}), \mathrm{NaHCO}_{3}$ solution $(40 \mathrm{ml})$ and brine $(40 \mathrm{~mL})$, dried over $\mathrm{Na}_{2} \mathrm{SO}_{4}$ and concentrated. The crude product was purified by flash column chromatography $\left(\mathrm{SiO}_{2}\right.$, Hexane/EtOAc, dichloromethane/EtOAc or dichloromethane/MeOH) on a Grace ${ }^{\mathrm{TM}}$ Reveleris ${ }^{\mathrm{TM}}$ system using a $12 \mathrm{~g}$ cartridge to afford the desired product. The final product was characterized by ${ }^{1} \mathrm{H}-\mathrm{NMR},{ }^{13} \mathrm{C}-\mathrm{NMR},{ }^{19} \mathrm{~F}-\mathrm{NMR}$ and HRMS (ESI-TOF).

\section{References}

1 Roughley, S. D. \& Jordan, A. M. The Medicinal Chemist's Toolbox: An Analysis of Reactions Used in the Pursuit of Drug Candidates. J. Med. Chem. 54, 3451-3479 (2011).

2 Wolfe, J. P. \& Buchwald, S. L. Nickel-Catalyzed Amination of Aryl Chlorides. J. Am. Chem. Soc. 119, 6054-6058 (1997).

3 Ge, S., Green, R. A. \& Hartwig, J. F. Controlling First-Row Catalysts: Amination of Aryl and Heteroaryl Chlorides and Bromides with Primary Aliphatic Amines Catalyzed by a BINAP-Ligated Single-Component Ni(0) Complex. J. Am. Chem. Soc. 136, 16171627 (2014).

4 Tassone, J. P., England, E. V., MacQueen, P. M., Ferguson, M. J. \& Stradiotto, M. PhPAd-DalPhos: Ligand-Enabled, Nickel-Catalyzed Cross-Coupling of (Hetero)aryl Electrophiles with Bulky Primary Alkylamines. Angew. Chem. Int. Ed. 58, 2485-2489 (2019).

5 Kelly, R. A., Scott, N. M., Díez-González, S., Stevens, E. D. \& Nolan, S. P. Simple Synthesis of $\mathrm{CpNi}(\mathrm{NHC}) \mathrm{Cl}$ Complexes $(\mathrm{Cp}=$ Cyclopentadienyl; $\mathrm{NHC}=\mathrm{N}-$ Heterocyclic Carbene). Organometallics 24, 3442-3447 (2005).

6 Park, N. H., Teverovskiy, G. \& Buchwald, S. L. Development of an Air-Stable Nickel Precatalyst for the Amination of Aryl Chlorides, Sulfamates, Mesylates, and Triflates. Org. Lett. 16, 220-223 (2014). 
7 Kampmann, S. S., Skelton, B. W., Wild, D. A., Koutsantonis, G. A. \& Stewart, S. G. An Air-Stable Nickel(0) Phosphite Precatalyst for Primary Alkylamine C-N CrossCoupling Reactions. Eur. J. Org. Chem. 2015, 5995-6004 (2015).

8 Shields, J. D., Gray, E. E. \& Doyle, A. G. A Modular, Air-Stable Nickel Precatalyst. Org. Lett. 17, 2166-2169 (2015).

9 Li, C., Kawamata, Y., Nakamura, H., Vantourout, J. C., Liu, Z., Hou, Q., Bao, D., Starr, J. T., Chen, J., Yan, M. \& Baran, P. S. Electrochemically Enabled, Nickel-Catalyzed Amination. Angew. Chem. Int. Ed. 56, 13088-13093 (2017).

10 Kawamata, Y., Vantourout, J. C., Hickey, D. P., Bai, P., Chen, L., Hou, Q., Qiao, W., Barman, K., Edwards, M. A., Garrido-Castro, A. F., deGruyter, J. N., Nakamura, H., Knouse, K., Qin, C., Clay, K. J., Bao, D., Li, C., Starr, J. T., Garcia-Irizarry, C., Sach, N., White, H. S., Neurock, M., Minteer, S. D. \& Baran, P. S. Electrochemically Driven, Ni-Catalyzed Aryl Amination: Scope, Mechanism, and Applications. J. Am. Chem. Soc. 141, 6392-6402 (2019).

11 Lim, C.-H., Kudisch, M., Liu, B. \& Miyake, G. M. C-N Cross-Coupling via Photoexcitation of Nickel-Amine Complexes. J. Am. Chem. Soc. 140, 7667-7673 (2018).

12 Corcoran, E. B., Pirnot, M. T., Lin, S., Dreher, S. D., DiRocco, D. A., Davies, I. W., Buchwald, S. L. \& MacMillan, D. W. C. Aryl amination using ligand-free Ni(II) salts and photoredox catalysis. Science 353, 279-283 (2016).

13 Du, Y., Pearson, R. M., Lim, C.-H., Sartor, S. M., Ryan, M. D., Yang, H., Damrauer, N. H. \& Miyake, G. M. Strongly Reducing, Visible-Light Organic Photoredox Catalysts as Sustainable Alternatives to Precious Metals. Chem. Eur. J. 23, 10962-10968 (2017).

14 Caputo, J. A., Frenette, L. C., Zhao, N., Sowers, K. L., Krauss, T. D. \& Weix, D. J. General and Efficient C-C Bond Forming Photoredox Catalysis with Semiconductor Quantum Dots. J. Am. Chem. Soc. 139, 4250-4253 (2017). 
15 Liu, Y.-Y., Liang, D., Lu, L.-Q. \& Xiao, W.-J. Practical heterogeneous photoredox/nickel dual catalysis for $\mathrm{C}-\mathrm{N}$ and $\mathrm{C}-\mathrm{O}$ coupling reactions. Chem. Commun. 55, 4853-4856 (2019).

16 Ghosh, I., Khamrai, J., Savateev, A., Shlapakov, N., Antonietti, M. \& König, B. Organic semiconductor photocatalyst can bifunctionalize arenes and heteroarenes. Science $\mathbf{3 6 5}$, 360-366 (2019).

17 Bulky, secondary amines such as $N$-tert-butylisopropylamine and 2,2,6,6tetramethylpiperidine do not couple with aryl halides and can be used as a base if 1.5 equivalents of pyrrolidine are used (see Supplementary Information).

18 Qi, Z.-H. \& Ma, J. Dual Role of a Photocatalyst: Generation of Ni(0) Catalyst and Promotion of Catalytic C-N Bond Formation. ACS Catal. 8, 1456-1463 (2018).

19 Wang, C., Cao, S. \& Fu, W.-F. A stable dual-functional system of visible-light-driven Ni(ii) reduction to a nickel nanoparticle catalyst and robust in situ hydrogen production. Chem. Commun. 49, 11251-11253 (2013).

20 Rodríguez, J. L., Valenzuela, M. A., Pola, F., Tiznado, H. \& Poznyak, T. Photodeposition of $\mathrm{Ni}$ nanoparticles on $\mathrm{TiO} 2$ and their application in the catalytic ozonation of 2,4-dichlorophenoxyacetic acid. J. Mol. Catal. A: Chem. 353-354, 29-36 (2012).

21 Indra, A., Menezes, P. W., Kailasam, K., Hollmann, D., Schröder, M., Thomas, A., Brückner, A. \& Driess, M. Nickel as a co-catalyst for photocatalytic hydrogen evolution on graphitic-carbon nitride (sg-CN): what is the nature of the active species? Chem. Commun. 52, 104-107 (2016).

22 Cavedon, C., Madani, A., Seeberger, P. H. \& Pieber, B. Semiheterogeneous Dual Nickel/Photocatalytic (Thio)etherification Using Carbon Nitrides. Org. Lett. 21, 53315334 (2019). 
23 Pieber, B., Malik, J. A., Cavedon, C., Gisbertz, S., Savateev, A., Cruz, D., Heil, T., Zhang, G. \& Seeberger, P. H. Semi-Heterogeneous Dual Nickel/Photo-catalysis using Carbon Nitrides: Esterification of Carboxylic Acids with Aryl Halides. Angew. Chem. Int. Ed. 58, 9575-9580.

24 Zhang, G., Li, G., Lan, Z.-A., Lin, L., Savateev, A., Heil, T., Zafeiratos, S., Wang, X. \& Antonietti, M. Optimizing Optical Absorption, Exciton Dissociation, and Charge Transfer of a Polymeric Carbon Nitride with Ultrahigh Solar Hydrogen Production Activity. Angew. Chem. Int. Ed. 56, 13445-13449 (2017).

25 The strong strong resonance donating effect of fluorine appears sufficient to counteract the inductive withdrawing effect in dual photoredox/nickel catalyzed cross-couplings resulting in low reactivity (see Refs. 22-23).

26 Crabtree, R. H. Deactivation in Homogeneous Transition Metal Catalysis: Causes, Avoidance, and Cure. Chem. Rev. 115, 127-150 (2015).

27 Molina de la Torre, J. A., Espinet, P. \& Albéniz, A. C. Solvent-Induced Reduction of Palladium-Aryls, a Potential Interference in Pd Catalysis. Organometallics 32, 54285434 (2013).

28 It has to be noted that a higher concentration does not increase the yield in case of $\left(\operatorname{Ir}\left[\mathrm{dF}\left(\mathrm{CF}_{3}\right) \mathrm{ppy}\right]_{2}(\mathrm{dtbbpy})\right) \mathrm{PF}_{6}$.

29 When no $\mathrm{NiBr}_{2} \cdot 3 \mathrm{H}_{2} \mathrm{O}$ is added to the recovered $\mathrm{CN}-\mathrm{OA}-\mathrm{m}$ material containing deposited nickel, only trace amounts of the C-N coupling product were observed (see Supplementary Information).

\section{Acknowledgments}

We gratefully acknowledge the Max-Planck Society for generous financial support. S.G. and B.P. thank the International Max Planck Research School on Multiscale Bio-Systems for funding. B.P. und S.R. acknowledge financial support by a Liebig Fellowship of the German 
Chemical Industry Fund (Fonds der Chemischen Industrie, FCI). B.P. thanks the Deutsche Forschungsgemeinschaft (DFG, German Research Foundation) under Germany’s Excellence Strategy - EXC 2008/1 (UniSysCat) - 390540038 for financial support. We thank our colleagues Prof. Peter H. Seeberger, Dr. Jamal Malik, Dr. Kerry Gilmore, Dr. Tobias Heil, Dr. Daniel Cruz, Heike Runge, Rona Pitschke, Jessica Brandt and Katharina ten Brummelhuis (all MPIKG), for scientific, technical and analytical support. 


\section{Supplementary Materials for}

\section{Overcoming Limitations in Dual Photoredox/Nickel catalyzed $\mathbf{C}-\mathbf{N}$ Cross-Couplings due to Catalyst Deactivation}

Sebastian Gisbertz, ${ }^{1,2}$ Susanne Reischauer ${ }^{1,2} \&$ Bartholomäus Pieber ${ }^{1 *}$

${ }^{1}$ Department of Biomolecular Systems, Max-Planck-Institute of Colloids and Interfaces, Am Mühlenberg 1, 14476 Potsdam, Germany

${ }^{2}$ Department of Chemistry and Biochemistry, Freie Universität Berlin, Am Mühlenberg 1, 14476 Potsdam, Germany

*Corresponding author

Email: bartholomaeus.pieber@mpikg.mpg.de 


\section{TABLE OF CONTENTS}

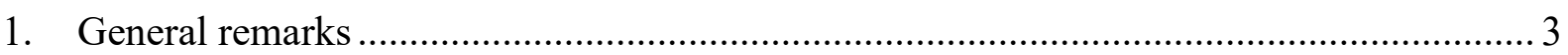

2. Literature analysis: aryl halides without electron withdrawing groups ........................... 5

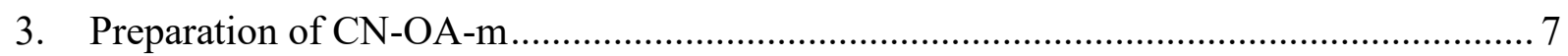

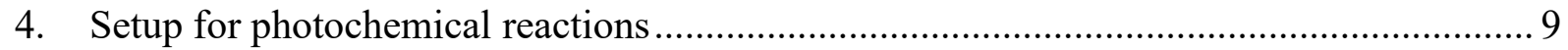

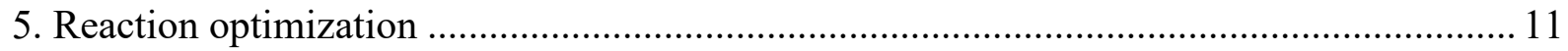

5.1 General experimental procedure for screening experiments .................................... 11

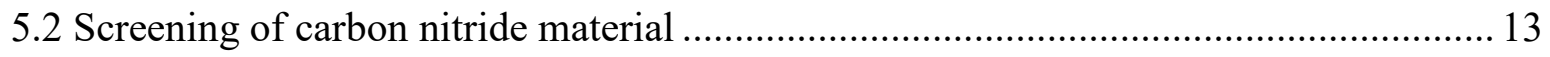

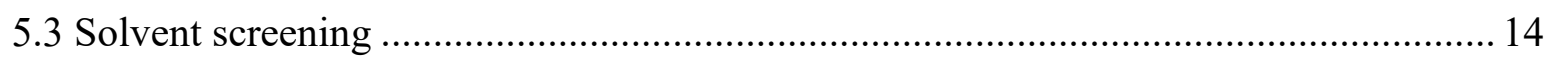

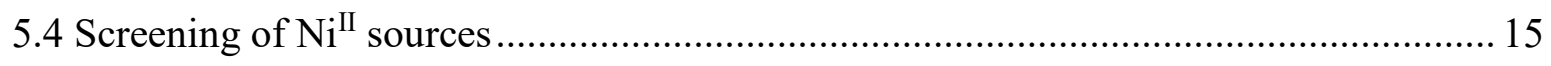

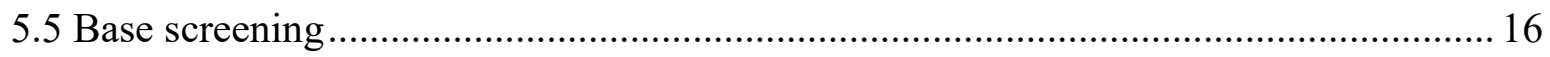

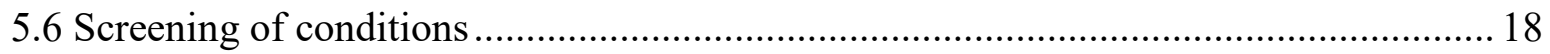

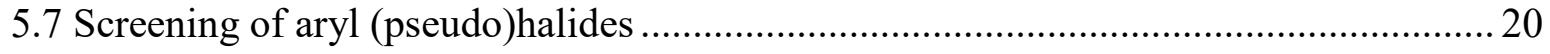

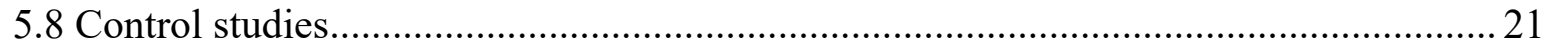

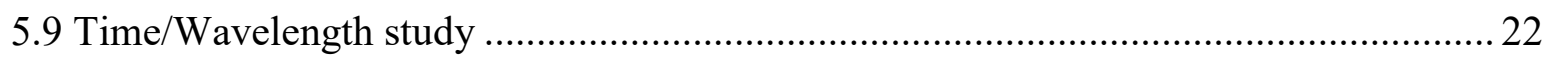

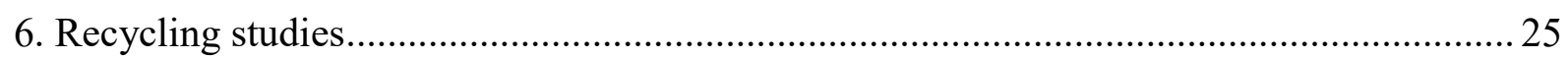

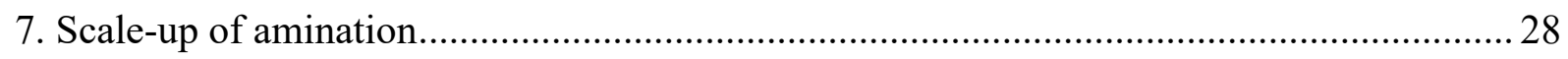

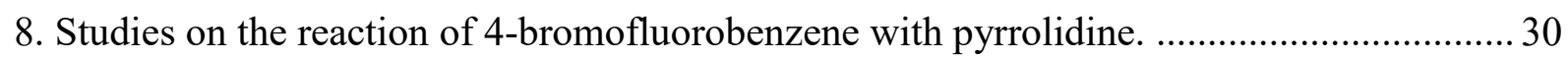

8.1 Powder X-ray diffraction (XRD) and X-ray photoelectron spectroscopy (XPS) .......... 34

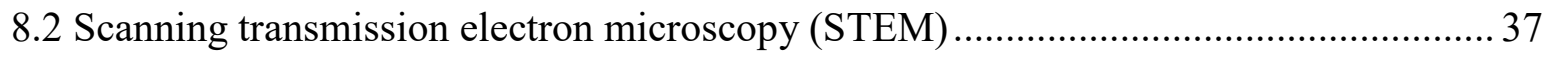

8.2.1 CN-OA-m recovered from method A (blue LEDs) and method B (green LEDs) ...... 37

8.2.2 Heterogeneous material generated during experiments using the UV method

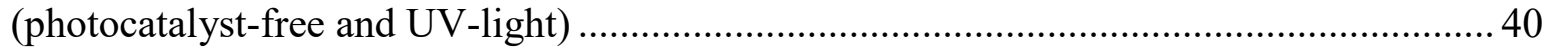

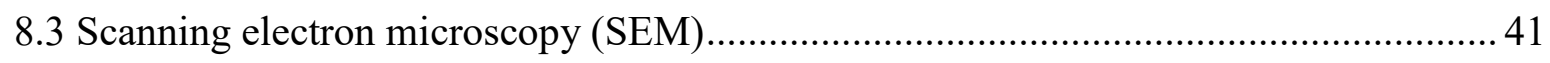

8.4 Energy-dispersive X-ray spectroscopy (EDX) and inductively coupled plasma atomic

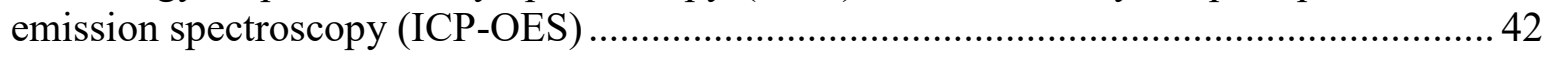

8.5 Fourier-transform infrared spectroscopy (FTIR) and Ultraviolet-visible spectroscopy (UV-VIS)

9. Studies on the reaction of bromobenzene, 3-bromotoluene, 1-bromo-4-tert-butylbenzene, and

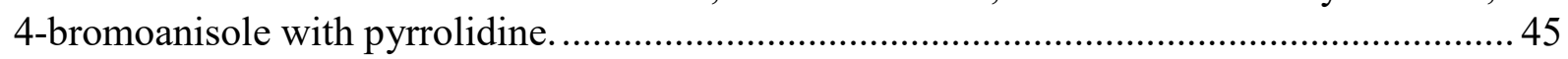

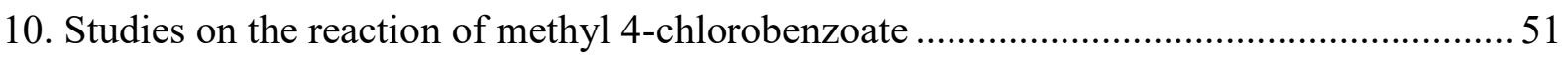

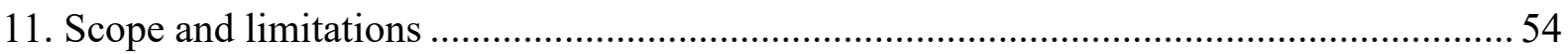

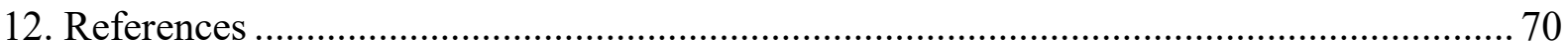

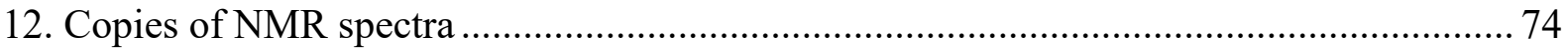




\section{General remarks}

Substrates, reagents, and solvents were purchased from commercial suppliers and used without further purification. Methyl 4-(trifluoromethylsulfonyloxy)benzoate, ${ }^{1}$ methyl 4(tosyloxy)benzoate ${ }^{2}$, methyl 4-((methylsulfonyl)oxy)benzoate ${ }^{3}$ and N-tertbutylisopropylamine (BIPA) ${ }^{4}$ were prepared according to literature procedures. ${ }^{1} \mathrm{H}$-, ${ }^{13} \mathrm{C}$ - and ${ }^{19}$ F-NMR spectra were obtained using a Varian 400 spectrometer (400 MHz, Agilent), an Ascend $^{\mathrm{TM}} 400$ spectrometer (400 MHz, cryoprobe, Bruker) and a Varian 600 spectrometer (600 $\mathrm{MHz}$, Agilent) at $298 \mathrm{~K}$, and are reported in ppm relative to the residual solvent peaks. Peaks are reported as: $\mathrm{s}=$ singlet, $\mathrm{d}=$ doublet, $\mathrm{t}=$ triplet, $\mathrm{q}=$ quartet, $\mathrm{m}=$ multiplet or unresolved, with coupling constants in Hz. Analytical thin layer chromatography (TLC) was performed on pre-coated TLC-sheets, ALUGRAM Xtra SIL G/UV 254 sheets (Macherey-Nagel) and visualized with $254 \mathrm{~nm}$ light or staining solutions followed by heating. Purification of final compounds was carried out by flash chromatography on the Reveleris X2 Flash Chromatography System from GRACE using prepacked columns with $40 \mu \mathrm{m}$ silica gel. Silica $60 \mathrm{M}(0.04-0.063 \mathrm{~mm})$ silica gel (Sigmal Aldrich) was used for dry loading of the crude compounds on the flash chromatography system. Centrifugation was carried out using an Eppendorf 5430 centrifuge. High-resolution mass spectral data were obtained using a Waters XEVO G2-XS 4K spectrometer with the XEVO G2-XS QTOF capability kit. Emission spectra of LED lamps were recorded using $10 \mathrm{in.}(24.5 \mathrm{~cm})$ integrating sphere (Labsphere, Inc. Model LMS 1050) equipped with a diode array detector (International Light, Model RPS900). The $\mathrm{UV} / \mathrm{Vis}$ spectrum of $\operatorname{Ir}(\mathrm{ppy})_{2}(\mathrm{dtbbpy}) \mathrm{PF}_{6}$ was recorded using a UVmini-1240 spectrometer (Shimadzu).Inductively coupled plasma - optical emission spectrometry (ICP-OES) was carried out using a Horiba Ultra 2 instrument equipped with photomultiplier tube detection. FTIR spectra were recorded on a Thermo Scientific Nicolet iD5 spectrometer. Diffuse reflectance UV/Vis spectra of powders were recorded on a Shimadzu UV-2600 spectrometer equipped with an integrating sphere. For XRD measurements, a Bruker D8 Advanced X-ray diffractometer with $\mathrm{Cu} \mathrm{K} \alpha$ radiation was used. Scanning electron microscopy (SEM) images were obtained on a LEO 1550-Gemini microscope. Energy-dispersive X-ray (EDX) investigations were conducted on a Link ISIS-300 system (Oxford Microanalysis Group) equipped with a $\mathrm{Si}(\mathrm{Li})$ detector and an energy resolution of $133 \mathrm{eV}$. X-ray photoelectron spectroscopic (XPS) measurements were carried out with a CISSY set-up, equipped with a SPECS XR 50 X-ray gun with $\mathrm{Mg} \mathrm{K \alpha}$ excitation radiation (1254.6 eV) and combined with a lens analyzer module (CLAM) under ultra-high vacuum (UHV, 1.5x10-8 Pa). The calibration was performed using 
the $\mathrm{Au} 4 \mathrm{f} 7 / 2(84.0 \mathrm{eV})$ binding energy scale as reference. Quantitative analysis and decovolution were achieved using "peakfit" and "Igor" software with Lorenzian-Gaussian functions and Shirley background deletion in photoemission spectra. The STEM images were acquired using a double-corrected Jeol ARM200F, equipped with a cold field emission gun. For the investigation, the acceleration voltage was set to $200 \mathrm{kV}$, the emission was put to $5 \mu \mathrm{A}$ and a condenser aperture with a diameter of $20 \mu \mathrm{m}$ was used. With these settings, the microscope reaches a lattice resolution below $1 \AA$. The STEM specimens were prepared by dissolving a powder sample of the material in ethanol, sonicating the solution for 15 minutes and finally dropping a few drops onto a copper TEM grid coated with holey carbon film. Once the solution had dried off, the specimens were investigated. 


\section{Literature analysis: aryl halides without electron withdrawing groups}

a) Electrochemically driven, Ni-catalyzed amination ${ }^{5}$
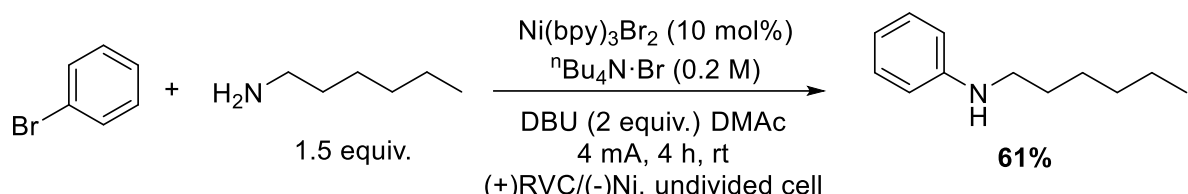

$(+) \mathrm{RVC} /(-) \mathrm{Ni}$, undivided cell

b) UV-light mediated, Ni-catalyzed amination ${ }^{6}$

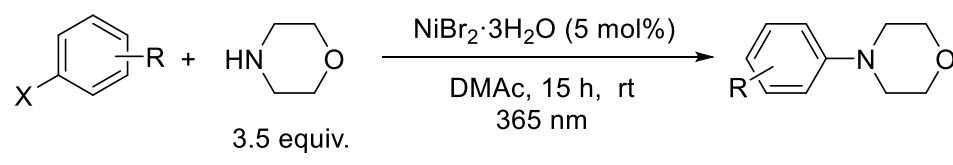

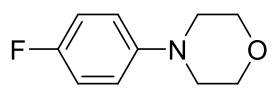

$\mathrm{X}=\mathrm{Br}, 38 \%$

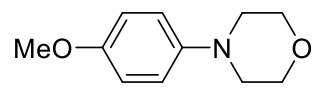

$X=1,26 \%$

$\mathrm{X}=\mathrm{Br}, 7 \%$

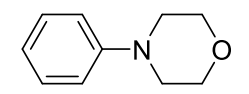

$X=1,66 \%$

$\mathrm{X}=\mathrm{Br}, 53 \%$

$\mathrm{MeO}$

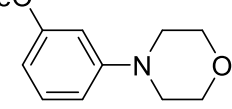

$X=B r, 59 \%$

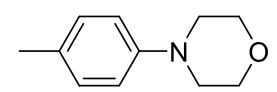

$\mathrm{X}=\mathrm{Br}, 33 \%$

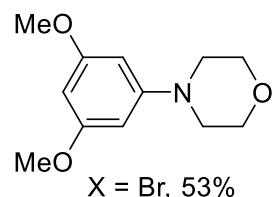

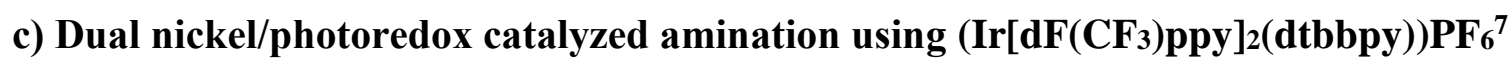

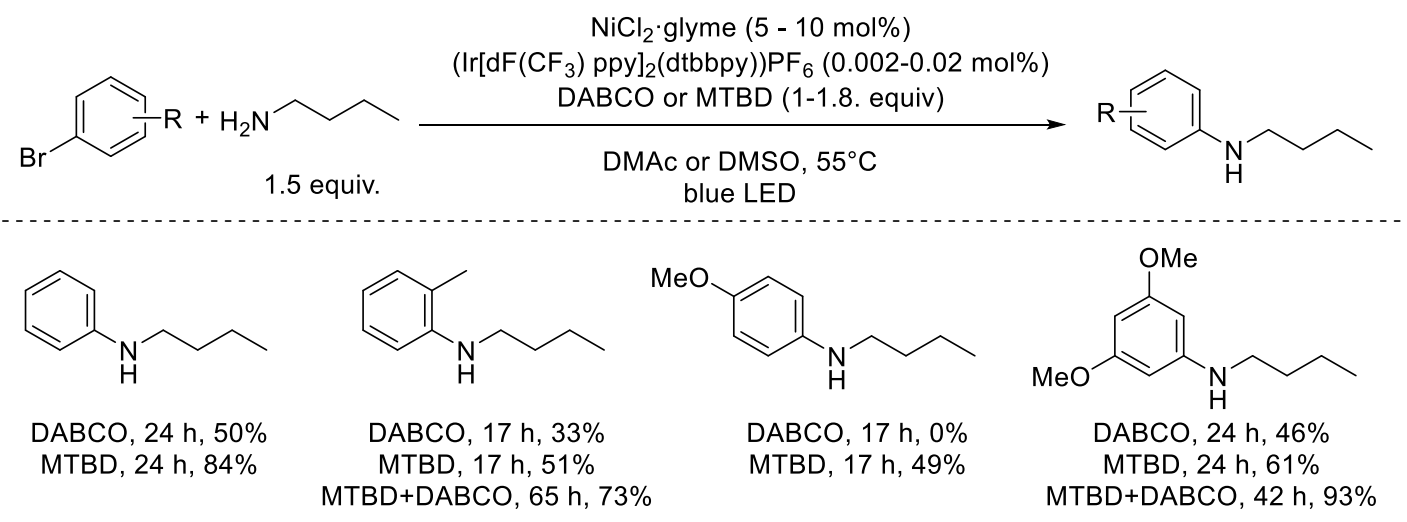


d) Dual nickel/photoredox catalyzed amination using organic dyes ${ }^{8}$

\section{$\mathrm{NiBr}_{2} \cdot$ glyme $(5 \mathrm{~mol} \%)$}

$\mathrm{N}, \mathrm{N}-5,10-$ di(2-naphthalene)-5,10-dihydrophenazine or

3,7-(4-biphenyl)-1-naphthalene-10-phenoxazine $(0.4 \mathrm{~mol} \%)$

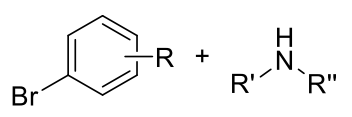
$\mathrm{DABCO}$ (1.8. equiv)

1.5 equiv.

DMAc , $25-60^{\circ} \mathrm{C}, 24 \mathrm{~h}$

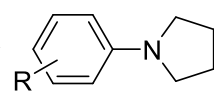
white LED<smiles>CCCNc1ccc(-c2ccccc2)cc1</smiles>

$68 \%$<smiles>c1ccc2cc(N3CCCC3)ccc2c1</smiles>

$85 \%$

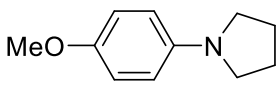

$96 \%$

e) Dual nickel/photoredox catalyzed amination using $\mathrm{CdS}^{9}$

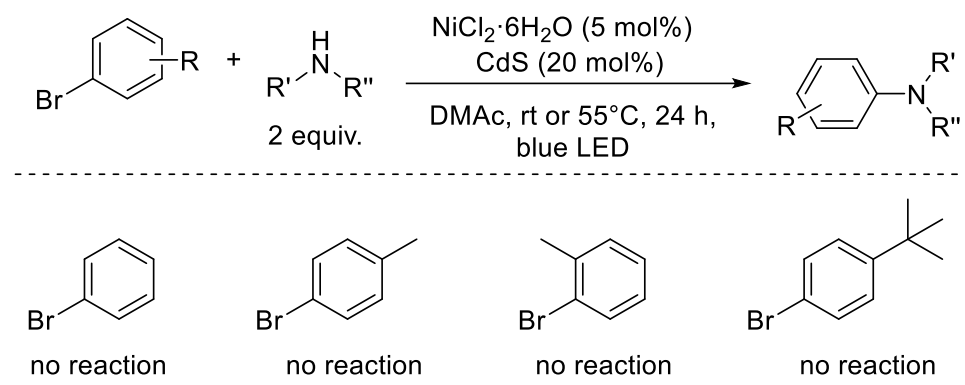

e) Dual nickel/photoredox catalyzed amination using mpg-CN ${ }^{10}$

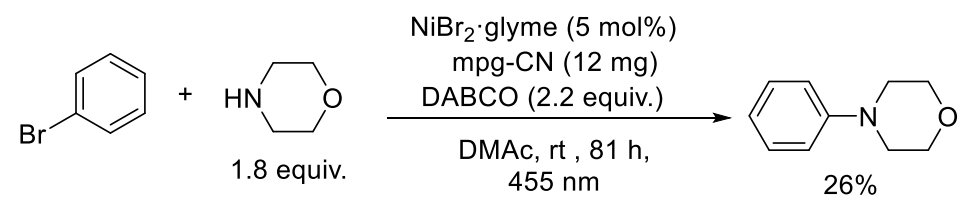




\section{Preparation of $\mathrm{CN}-\mathrm{OA}-\mathrm{m}$}

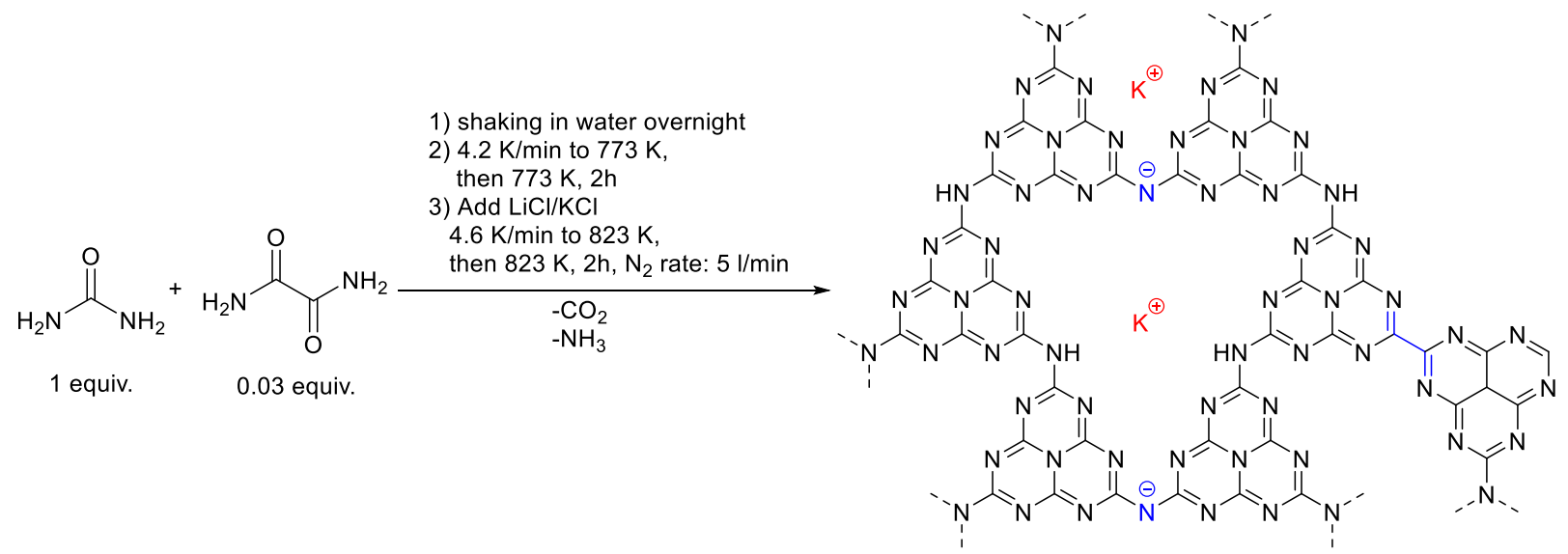

Scheme S1. Synthesis of CN-OA-m

The synthesis for CN-OA-m was carried out using a slightly adapted version of the literature procedure (Scheme S1) ${ }^{11}$ : For each batch of the photocatalyst, urea $(10 \mathrm{~g}, 166.5 \mathrm{mmol})$ and oxamide $(0.5 \mathrm{~g}, 5.7 \mathrm{mmol})$ were mixed in $10 \mathrm{ml}$ of DI water to generate a homogeneous mixture. After drying at $373 \mathrm{~K}$, the resulting solids were grinded, transferred into a crucible with a cover and heated up in an air-oven with a heating rate of $4.3 \mathrm{~K} / \mathrm{min}$ to $773 \mathrm{~K}$. After keeping the mixture for $2 \mathrm{~h}$ at $773 \mathrm{~K}$, the sample was allowed to cool to room temperature. Subsequently, $\mathrm{KCl}(3.3 \mathrm{~g}, 44.3 \mathrm{mmol})$ and $\mathrm{LiCl}(2.7 \mathrm{~g}, 63.7 \mathrm{mmol})$ were added and the solids were grinded to obtain a homogeneous mixture which was heated in an inert atmosphere $\left(\mathrm{N}_{2}\right.$ flow: $\left.5 \mathrm{~mL} / \mathrm{min}\right)$ to $823 \mathrm{~K}$ with a heating rate of $4.6 \mathrm{~K} / \mathrm{min}$. After keeping the mixture for $2 \mathrm{~h}$ at $823 \mathrm{~K}$, the sample was allowed to cool to room temperature and the resulting solids were collected on a filter paper and washed with $\mathrm{H}_{2} \mathrm{O}(3 \times 100 \mathrm{~mL})$. The resulting yellow material was dried at $373 \mathrm{~K}$ (average yield per batch: $\sim 425 \mathrm{mg}$ ). All analytical data (FTIR, UV/Vis, XRD, SEM, etc.; see Section 7) are in full agreement with those published in the literature. ${ }^{11}$

The cost of CN-OA-m was calculated to be $4.0 € \mathrm{~g}^{-1}$ based on the prices of urea, oxamide, $\mathrm{LiCl}$ and $\mathrm{KCl}$ from Sigma-Aldrich (Merck). ${ }^{12}$ As a comparison, the price of $\left(\operatorname{Ir}\left[\mathrm{dF}\left(\mathrm{CF}_{3}\right) \text { ppy }\right]_{2}(\mathrm{dtbpy})\right) \mathrm{PF}_{6}$ is $883 € \mathrm{~g}^{-1} \cdot{ }^{12}$

The UV/Vis spectrum of CN-OA-m shows a strong absorption up to $\sim 460 \mathrm{~nm}$ and a comparably weaker absorption band up to $700 \mathrm{~nm}$ (Figure S1, A) which are attributed to the $\pi-\pi^{*}$ electron transition of the $\mathrm{sp}^{2}$ hybridization of $\mathrm{C}$ and $\mathrm{N}$ in the heptazine framework and $\mathrm{n}-\pi^{*}$ electron transition involving the lone pairs of the edge nitrogen atoms in the heptazine units, 
respectively. ${ }^{11}$ The capability of harvesting low energy light is therefore superior compared to Ir and $\mathrm{Ru}$ photocatalysts (see Figure $\mathrm{S} 1, \mathrm{~B}$ for the UV/Vis spectrum of $\operatorname{Ir}\left[\mathrm{dF}\left(\mathrm{CF}_{3}\right) \mathrm{ppy}\right]_{2}(\mathrm{dtbbpy}) \mathrm{PF}_{6}$ as a representative example) which have only a low absorption band between 400 and $500 \mathrm{~nm}$ in the visible region, which corresponds to the metal-to-ligand charge transfer transition.

A

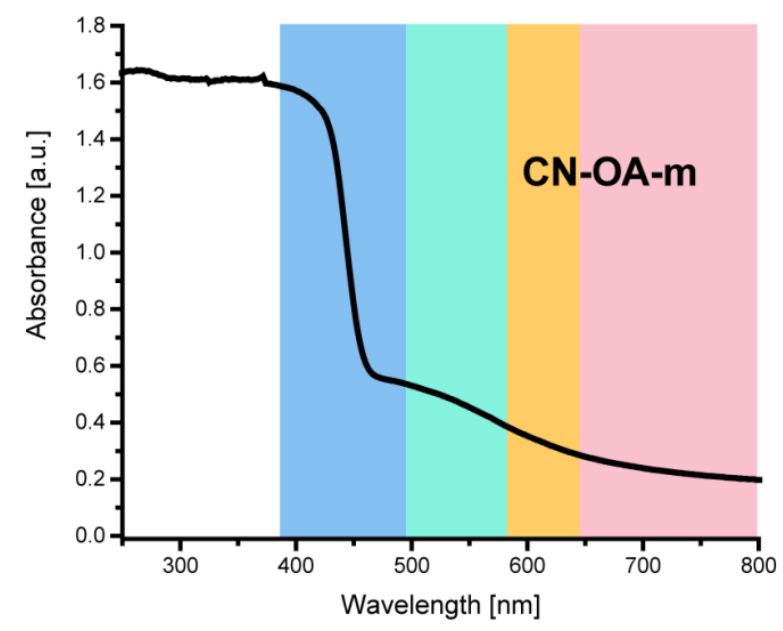

B

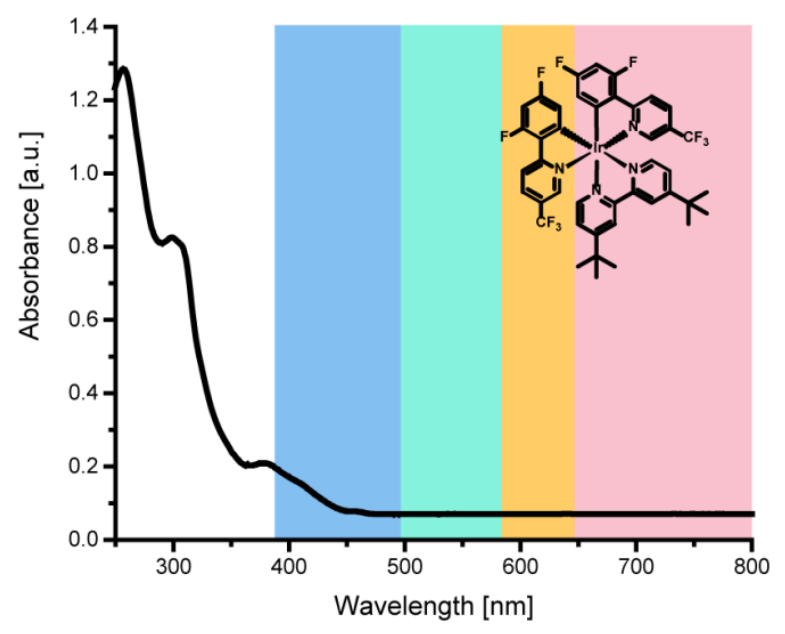

Figure S1. UV/VIS-absorption spectra of CN-OA-m $(\mathbf{A})$ and $\operatorname{Ir}\left[\mathrm{dF}\left(\mathrm{CF}_{3}\right) \text { ppy }\right]_{2}(\mathrm{dtbbpy}) \mathrm{PF}_{6}(\mathbf{B})$. 


\section{Setup for photochemical reactions}

A flexible, red/green/blue LED strip ${ }^{13}$ (RGB, 5m, $24 \mathrm{~W} /$ strip; Tween Light, BAHAG AG, Germany) was wrapped around a $115 \mathrm{~mm}$ borosilicate crystallization dish (Figure S2, A). Blue, green, red or white (illumination of all three LED colors - red/green/blue) light was used at full power for all experiments (For emission spectra of a single diode, see Figure S3). The evaporating dish was filled with ethylene glycol and the temperature was set to $40^{\circ} \mathrm{C}$ to maintain a constant temperature. The sealed, cylindrical reaction vessels $(16 \times 100 \mathrm{~mm})$ were placed at the same distance from the LED strip during all experiments (Figure S2, A). All reactions were performed with a stirring speed of $600(1 \mathrm{~mL})$ or $1400 \mathrm{rpm}(3$ or $6 \mathrm{~mL})$. For large scale aminations a flexible, red/green/blue LED strip (RGB, 5m, 24 W/strip; Tween Light, BAHAG AG, Germany) was wrapped around a mm borosilicate beaker (Figure S2, B). The scale-up reaction was performed in a sealed, cylindrical reaction vessel $(25 \times 140 \mathrm{~mm})$ with a stirring speed of $700 \mathrm{rpm}$ and without additional heating (Figure S2, B).

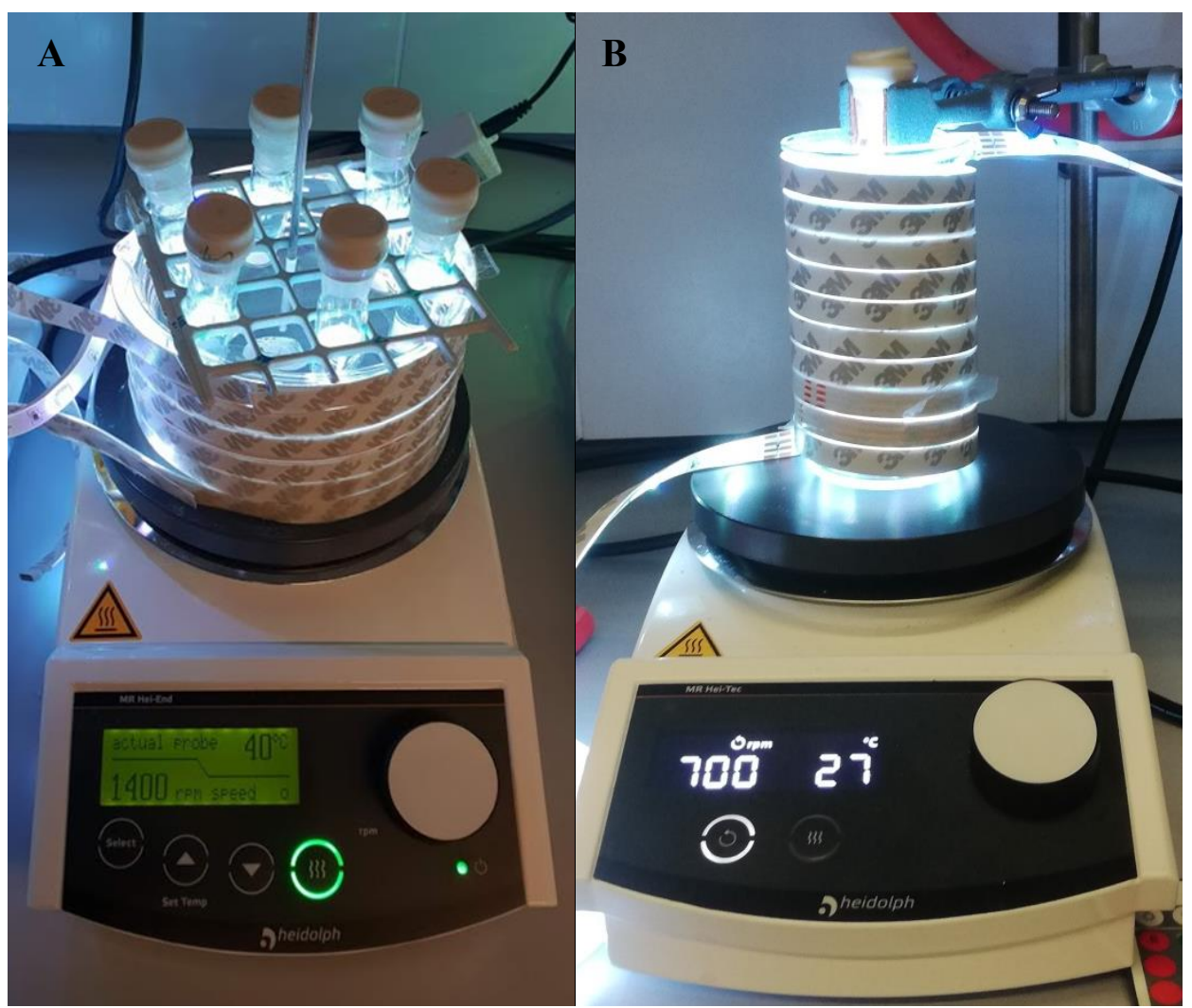

Figure S2. Experimental setup for general photochemical reactions (A) and for the scale-up reaction (B). 

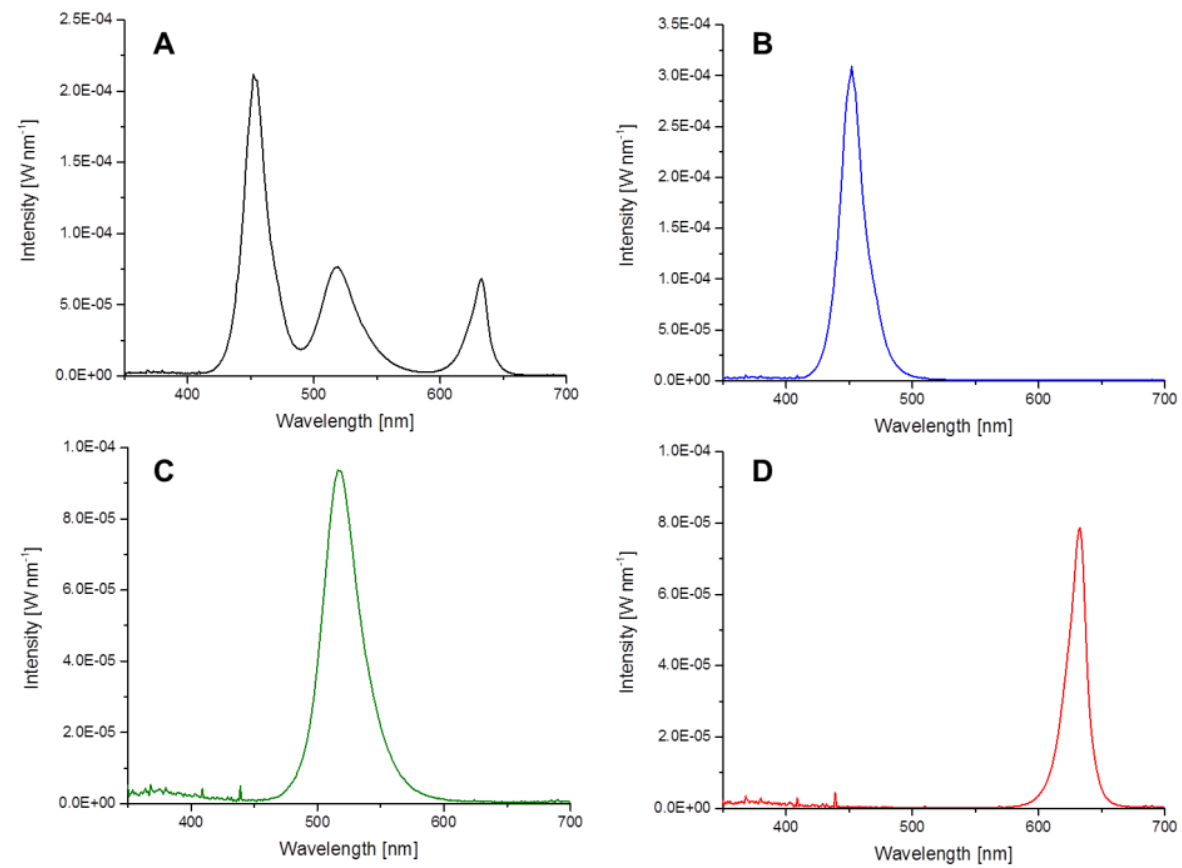

Figure S3. Emission spectra of the LED strips used for photochemical reactions. All experiments were carried out at maximum power. A: white light. B: blue light only. C: green light only. D: red light only.

A Kessil ${ }^{\circledR}$ PR 160-370nm lamp, a stir plate and a fan for cooling was used for UV-light experiments (Figure S4, A). All experiments were carried out with maximum lamp power. The sealed reaction vessels $(16 \times 100 \mathrm{~mm})$ were placed at the same distance $(4 \mathrm{~cm})$ from the light source during all experiments. All reactions were performed with vigorous stirring.
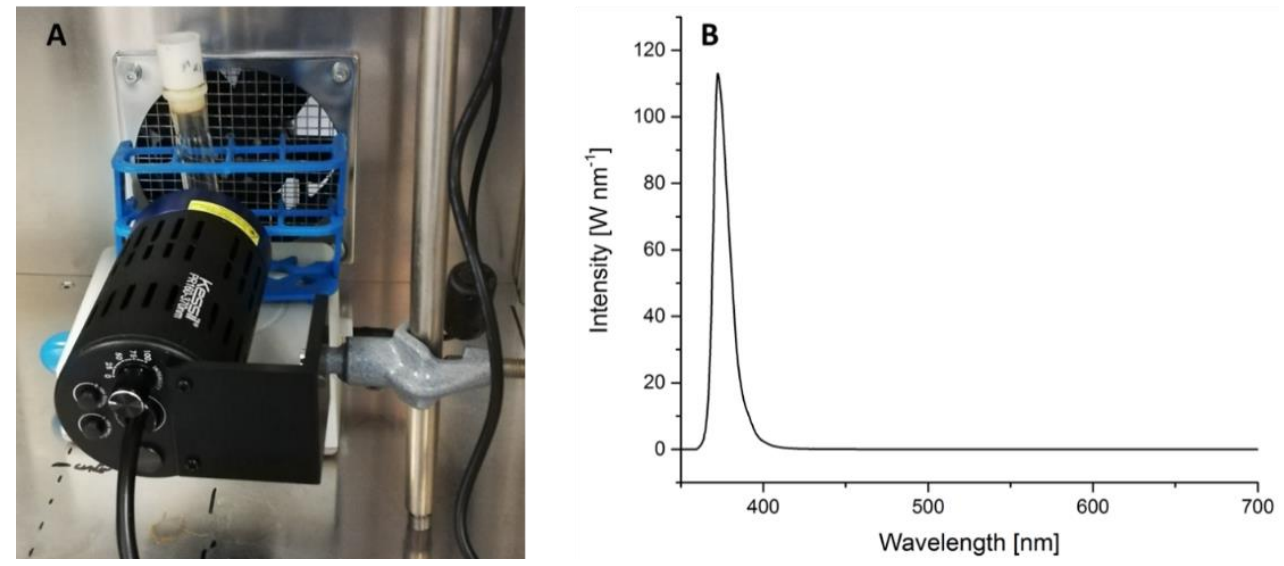

Figure S4. A: Picture of the Set-up for UV-light experiments B: Emission spectra of the Kessil ${ }^{\circledR}$ PR 160-370nm lamp used for photochemical reactions. All experiments were carried out at maximum power. 


\section{Reaction optimization}

\subsection{General experimental procedure for screening experiments}

An oven dried vial (16 x $100 \mathrm{~mm})$ equipped with a stir bar was charged with methyl 4bromobenzoate $(0.3 \mathrm{mmol}, 64.5 \mathrm{mg}, 1$ equiv. $)$, the base ( $0.9 \mathrm{mmol}, 3.0$ equiv. $)$, the $\mathrm{Ni}^{\mathrm{II}}$ catalyst (30 $\mu \mathrm{mol}, 10 \mathrm{~mol} \%)$ and the carbon nitride material $(10 \mathrm{mg})$. Subsequently, pyrrolidine $(0.45$ mmol, $37.0 \mu \mathrm{L}, 1.5$ equiv.) and the solvent (anhydrous, $3 \mathrm{~mL}$ ) were added and the vial was sealed with a septum and Parafilm. The reaction mixture was sonicated for 5-10 min followed by stirring for 5 min until a fine dispersion of the solids was achieved and the mixture was then degassed by bubbling $\mathrm{N}_{2}$ for $10 \mathrm{~min}$. The mixture was irradiated in the photoreactor at $40{ }^{\circ} \mathrm{C}$ with rapid stirring $(1400 \mathrm{rpm})$. After the respective reaction time, one equivalent of 1,3,5trimethoxybenzene $(0.3 \mathrm{mmol}, 50.5 \mathrm{mg})$ was added. An aliquot of the reaction mixture $(\sim 300 \mu \mathrm{L})$ was filtered, diluted with DMSO-d 6 and subjected to ${ }^{1} \mathrm{H}-\mathrm{NMR}$ analysis. (Alternatively, $1.5 \mathrm{~mL} \mathrm{CDCl}_{3}$ and $3 \mathrm{~mL} \mathrm{H}_{2} \mathrm{O}$ were added and the vial was sealed and vigorously shaken. After phase separation, the $\mathrm{CDCl}_{3}$ layer was carefully removed using a syringe, filtered, and analyzed by ${ }^{1}$ H-NMR.) For representative NMR spectra, see Figure S5. 

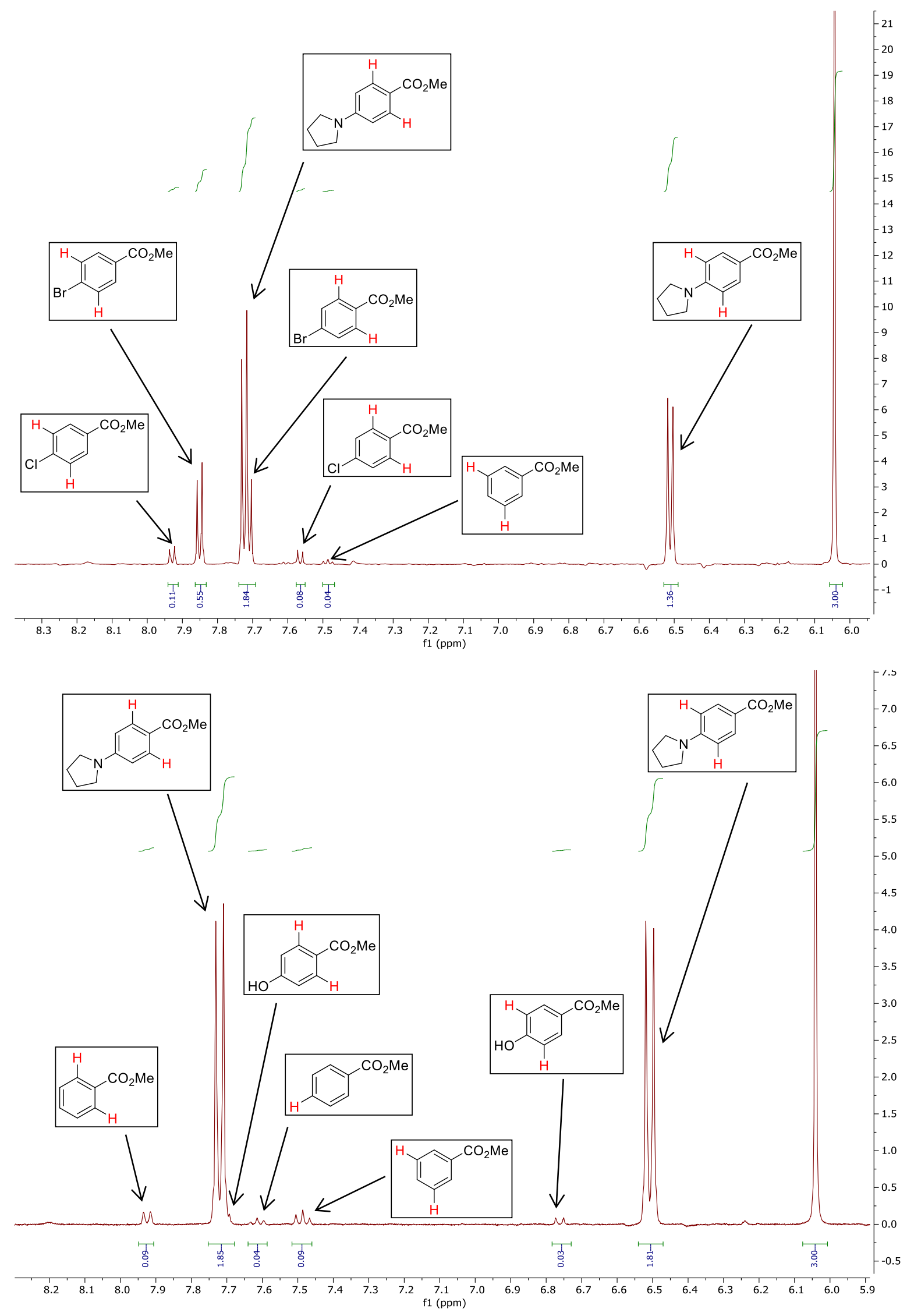

Figure S5. Examples of ${ }^{1} \mathrm{H}-\mathrm{NMR}$ spectra for determining NMR yields. 


\subsection{Screening of carbon nitride material}

Table S1. Screening of carbon nitride materials. ${ }^{\mathrm{a}}$

\begin{tabular}{|c|c|c|c|c|c|}
\hline $0.1 \mathrm{M}$ & $+\underbrace{\mathrm{H}}_{1.5 \text { equiv. }}$ & 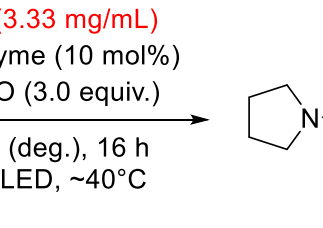 & 1 & 2 & 4 \\
\hline Entry & CN catalyst & Conversion $[\%]^{b}$ & $1[\%]^{\mathrm{c}}$ & $2[\%]^{\mathrm{c}}$ & $4[\%]^{\mathrm{c}}$ \\
\hline 1 & CN-OA-m & 73 & 65 & 2 & 5 \\
\hline 2 & $\mathrm{CMB}_{0.05}-\mathrm{CN}$ & 25 & 21 & 2 & trace \\
\hline 3 & mpg-CN & 23 & 19 & trace & trace \\
\hline 4 & PHIK & 18 & 14 & trace & trace \\
\hline 5 & $\mathrm{CNS}_{600}$ & 9 & 6 & trace & trace \\
\hline
\end{tabular}

${ }^{a}$ Reaction conditions: methyl 4-bromobenzoate $(0.3 \mathrm{mmol})$, pyrrolidine $(0.45 \mathrm{mmol}), \mathrm{NiCl}_{2} \cdot \mathrm{glyme}(10 \mathrm{~mol} \%)$, DABCO (0.9 mmol), carbon nitride $\left(10 \mathrm{mg}\right.$ ), DMAc (anhydrous, $3 \mathrm{~mL}$ ), white LEDs at $40{ }^{\circ} \mathrm{C}$ for $16 \mathrm{~h}$. ${ }^{\mathrm{b}}$ Conversion of methyl $4-$ bromobenzoate determined by ${ }^{1} \mathrm{H}$-NMR using 1,3,5-trimethoxybenzene as internal standard. ${ }^{\mathrm{c}} \mathrm{NMR}$ yields determined by ${ }^{1} \mathrm{H}-\mathrm{NMR}$ using $1,3,5$-trimethoxybenzene as internal standard.

Several carbon nitride materials were tested: Mesoporous graphitic carbon nitride (mpg-CN), ${ }^{14}$ a modified carbon nitride derived from a cyanuric acid/melamide/barbituric acid complex $\left(\mathrm{CMB}_{0.05}-\mathrm{CN}\right),{ }^{15}$ a sulfur-doped material $\left(\mathrm{CNS}_{600}\right),{ }^{16}$ a strongly oxidizing potassium poly(heptazine imide) (K-PHI), ${ }^{17}$ and a carbon nitride derivative prepared via co-condensation of urea and oxamide followed by post-calcination in a molten salt (CN-OA-m), ${ }^{11}$ all using white LED (RGB) irradiation at a constant temperature of $40{ }^{\circ} \mathrm{C}$. 


\subsection{Solvent screening}

Table S2. Solvent screening. ${ }^{\mathrm{a}}$

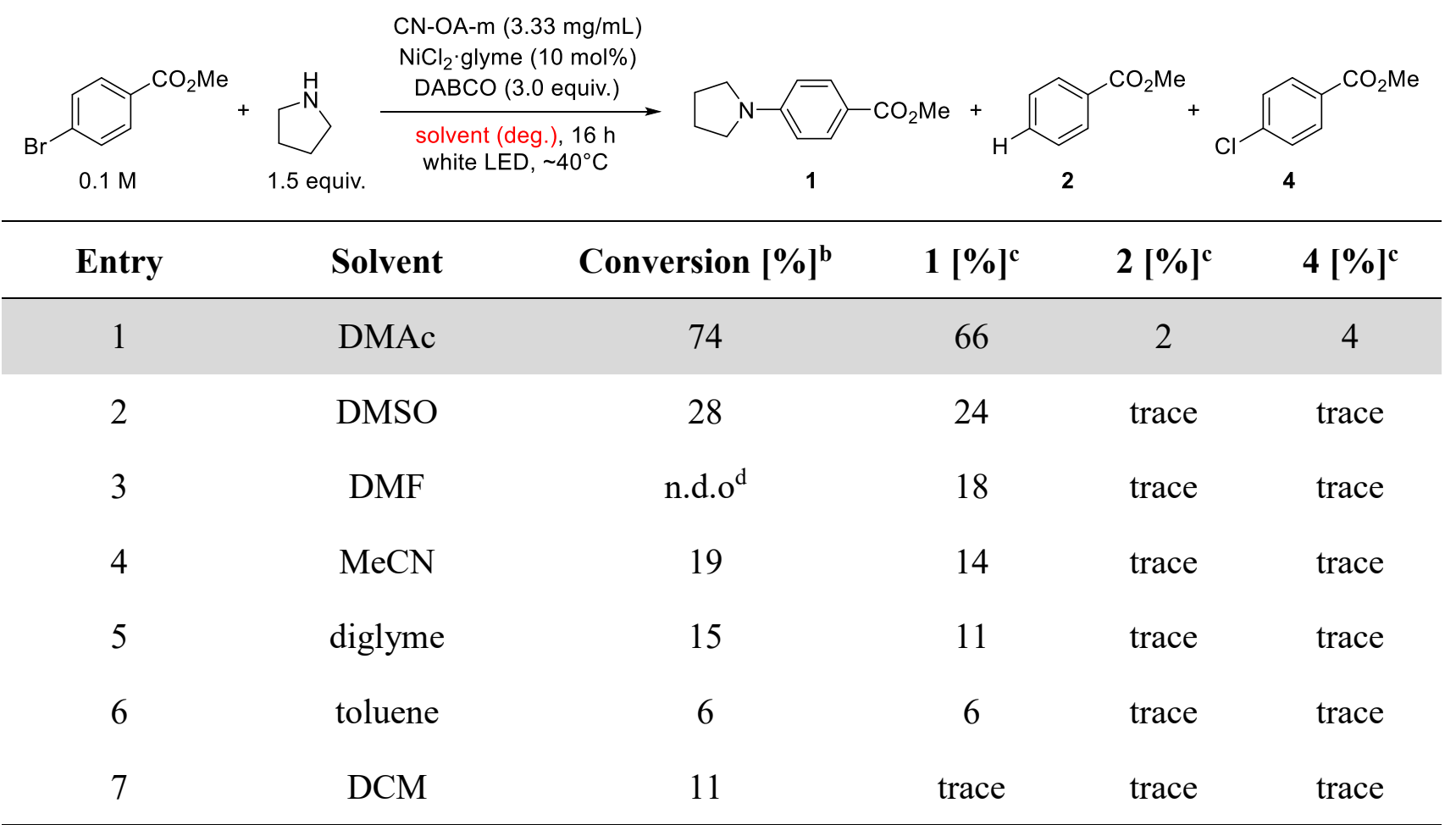

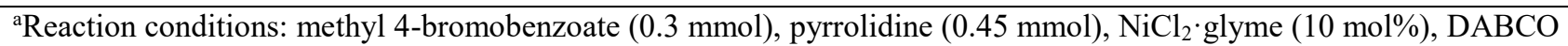
$(0.9 \mathrm{mmol})$, CN-OA-m $(10 \mathrm{mg})$, solvent (anhydrous, $3 \mathrm{~mL})$, white LEDs at $40{ }^{\circ} \mathrm{C}$ for $16 \mathrm{~h} .{ }^{\mathrm{b}}$ Conversion of methyl $4-$ bromobenzoate determined by ${ }^{1} \mathrm{H}-\mathrm{NMR}$ using 1,3,5-trimethoxybenzene as internal standard. ${ }^{\mathrm{C}} \mathrm{NMR}$ yields determined by ${ }^{1} \mathrm{H}$-NMR using 1,3,5-trimethoxybenzene as internal standard. ${ }^{\mathrm{d}}$ not detected due to overlapping peaks. 


\subsection{Screening of $\mathrm{Ni}^{\mathrm{II}}$ sources}

Table S3. Screening Ni ${ }^{\mathrm{II}}$ sources. ${ }^{\mathrm{a}}$

\begin{tabular}{|c|c|c|c|c|c|c|}
\hline $0.1 \mathrm{M}$ & $+{ }_{1.5 \text { equiv. }}^{\mathrm{e}}$ & $\begin{array}{l}\mathrm{N}-\mathrm{OA}-\mathrm{m}(3.33 \mathrm{mg} / \mathrm{mL}) \\
\text { Nill salt }(10 \mathrm{~mol} \%) \\
\text { DABCO }(3.0 \text { equiv. }) \\
\begin{array}{l}\text { DMAc (deg.), } 16 \mathrm{~h} \\
\text { white LED, } \sim 40^{\circ} \mathrm{C}\end{array}\end{array}$ & 1 & & & 4 \\
\hline Entry & $\mathrm{Ni}^{\mathrm{II}}$ catalyst & $\begin{array}{c}\text { Conversion } \\
{[\%]^{b}} \\
\end{array}$ & $\begin{array}{c}1 \\
{[\%]^{\mathrm{c}}}\end{array}$ & $\begin{array}{c}2 \\
{[\%]^{\mathrm{c}}}\end{array}$ & $\begin{array}{c}4 \\
{[\%]^{\mathrm{c}}} \\
\end{array}$ & $\begin{array}{c}\text { Price } \\
{\left[€ \mathrm{~mol}^{-1}\right]^{\mathrm{d}}} \\
\end{array}$ \\
\hline 1 & $\mathrm{NiI}_{2}$ & 90 & 86 & 2 & n.d. & 2063 \\
\hline 2 & $\mathrm{NiBr}_{2} \cdot$ glyme & 87 & 80 & 3 & n.d. & 10431 \\
\hline 3 & $\mathrm{NiCl}_{2}$ & 85 & 76 & 4 & 5 & 110 \\
\hline 4 & $\mathrm{NiBr}_{2}$ & 74 & 72 & trace & n.d. & 411 \\
\hline 5 & $\mathrm{NiBr}_{2} \cdot 3 \mathrm{H}_{2} \mathrm{O}$ & 71 & 68 & 3 & n.d. & 116 \\
\hline 6 & $\mathrm{NiCl}_{2} \cdot$ glyme & 74 & 66 & trace & 9 & 4161 \\
\hline 7 & $\mathrm{Ni}\left(\mathrm{ClO}_{4}\right)_{2} \cdot 6 \mathrm{H}_{2} \mathrm{O}$ & 62 & 59 & trace & n.d. & 171 \\
\hline 8 & $\mathrm{Ni}\left(\mathrm{NO}_{3}\right)_{2} \cdot 6 \mathrm{H}_{2} \mathrm{O}$ & 52 & 52 & trace & n.d. & 49 \\
\hline 9 & $\mathrm{Ni}(\mathrm{OTf})_{2}$ & 55 & 51 & 3 & n.d. & 12917 \\
\hline 10 & $\mathrm{NiCl}_{2} \cdot 6 \mathrm{H}_{2} \mathrm{O}$ & 45 & 35 & 4 & 2 & 71 \\
\hline 11 & $\mathrm{Ni}\left(\mathrm{BF}_{4}\right)_{2} \cdot 6 \mathrm{H}_{2} \mathrm{O}$ & 24 & 23 & 2 & n.d. & 223 \\
\hline 12 & $\mathrm{Ni}(\mathrm{TMHD})_{2}$ & 10 & 5 & 2 & n.d. & 35294 \\
\hline 13 & $\mathrm{Ni}(\mathrm{OAc})_{2} \cdot 4 \mathrm{H}_{2} \mathrm{O}$ & 9 & 5 & 4 & n.d. & 28 \\
\hline 14 & $\mathrm{Ni}\left(\mathrm{SO}_{4}\right) 2 \cdot 6 \mathrm{H}_{2} \mathrm{O}$ & 9 & 4 & 2 & n.d. & 41 \\
\hline 15 & $\mathrm{Ni}(\mathrm{acac})_{2}$ & 3 & n.d. & trace & n.d. & 620 \\
\hline
\end{tabular}

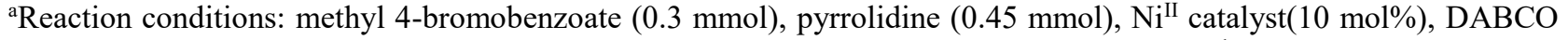
$(0.9 \mathrm{mmol}), \mathrm{CN}-\mathrm{OA}-\mathrm{m}(10 \mathrm{mg})$, DMAc (anhydrous, $3 \mathrm{~mL})$, white LEDs at $40{ }^{\circ} \mathrm{C}$ for $16 \mathrm{~h} .{ }^{\mathrm{b}}$ Conversion of methyl $4-$ bromobenzoate determined by ${ }^{1} \mathrm{H}-\mathrm{NMR}$ using 1,3,5-trimethoxybenzene as internal standard. ${ }^{\mathrm{c}} \mathrm{NMR}$ yields determined by ${ }^{1} \mathrm{H}-\mathrm{NMR}$ using 1,3,5-trimethoxybenzene as internal standard. ${ }^{\mathrm{d}}$ Prices according to Sigma Aldrich (Merck) ${ }^{\mathrm{x}}$.

$\mathrm{NiBr}_{2} \cdot 3 \mathrm{H}_{2} \mathrm{O}$ gave the best combination of price, selectivity (chloride formation in case of $\left.\mathrm{NiCl}_{2}\right)$, activity and handling $\left(\mathrm{NiI}_{2}\right.$ and $\mathrm{NiBr}_{2}$ are highly hygroscopic). 


\subsection{Base screening}

Table S4. Base screening. ${ }^{\text {a }}$

\begin{tabular}{|c|c|c|c|c|c|}
\hline $0.1 \mathrm{M}$ & 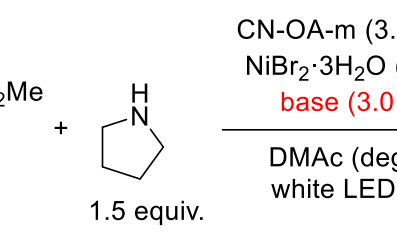 & $\begin{array}{l}3 \mathrm{mg} / \mathrm{mL} \text { ) } \\
0 \mathrm{~mol} \%) \\
\text { quiv.) } \\
\qquad \begin{array}{l}16 \mathrm{~h} \\
-40^{\circ} \mathrm{C}\end{array}\end{array}$ & & 2 & 3 \\
\hline Entry & Base & Conversion $[\%]^{b}$ & $1[\%]^{\mathrm{c}}$ & $2[\%]^{\mathrm{c}}$ & $3[\%]^{\mathrm{c}}$ \\
\hline 1 & $\mathrm{TMP}^{\mathrm{d}}$ & quant. & 91 & 3 & 2 \\
\hline 2 & $\mathrm{BIPA}^{\mathrm{e}}$ & 90 & 89 & trace & n.d. ${ }^{f}$ \\
\hline 3 & $\mathrm{DABCO}^{\mathrm{g}}$ & 71 & 68 & 3 & trace \\
\hline 4 & $\mathrm{~K}_{2} \mathrm{HPO}_{4}$ & 68 & 63 & 4 & trace \\
\hline 5 & dimethylaniline & 59 & 62 & n.d. & n.d. \\
\hline 6 & $\mathrm{CaCO}_{3}$ & 65 & 61 & trace & trace \\
\hline 7 & 2,6-lutidine & 62 & 60 & 3 & n.d. \\
\hline 8 & without base & 65 & 58 & 4 & trace \\
\hline 9 & tetramethylguanidine & 53 & 43 & n.d. & n.d. \\
\hline 10 & DIPEA $^{\mathrm{h}}$ & 49 & 42 & 6 & n.d. \\
\hline 11 & $\mathrm{Et}_{3} \mathrm{~N}$ & 42 & 35 & 5 & trace \\
\hline 12 & DMAP $^{\mathrm{i}}$ & 43 & 31 & 6 & trace \\
\hline 13 & $\mathrm{~K}_{3} \mathrm{PO}_{4}$ & 33 & 21 & trace & trace \\
\hline 14 & $\mathrm{DBU}^{\mathrm{j}}$ & 27 & 19 & trace & trace \\
\hline 15 & $\mathrm{Na}_{2} \mathrm{CO}_{3}$ & 17 & 14 & trace & trace \\
\hline 16 & $\mathrm{NaHCO}_{3}$ & 14 & 8 & 4 & trace \\
\hline 17 & $\mathrm{NaO} t \mathrm{Bu}$ & 29 & 5 & trace & trace \\
\hline 18 & $\mathrm{KOH}$ & quant. & 4 & n.d. & n.d. \\
\hline 19 & $\mathrm{NaOH}$ & quant. & n.d. & n.d. & n.d. \\
\hline 20 & $\mathrm{~K}_{2} \mathrm{CO}_{3}$ & 8 & n.d. & trace & n.d. \\
\hline 21 & $\mathrm{NaH}_{2} \mathrm{PO}_{4}$ & 10 & n.d. & n.d. & n.d. \\
\hline
\end{tabular}




\begin{tabular}{cccccc}
\hline Entry & Base & Conversion [\%] & $\mathbf{1}[\%]^{\mathbf{c}}$ & $\mathbf{2}[\mathbf{\%}]^{\mathbf{c}}$ & $\mathbf{3}[\mathbf{\%}]^{\mathbf{c}}$ \\
\hline 22 & $\mathrm{LiOH}$ & 43 & n.d. & n.d. & n.d. \\
23 & $\mathrm{Cs}_{2} \mathrm{CO}_{3}$ & 11 & n.d. & 5 & trace \\
24 & $\mathrm{CsF}$ & 7 & n.d. & trace & n.d. \\
25 & $\mathrm{CsOAc}$ & 2 & n.d. & n.d. & n.d. \\
26 & $\mathrm{HMDS}^{\mathrm{k}}$ & quant. & n.d. & n.d. & n.d. \\
\hline
\end{tabular}

${ }^{\mathrm{a}}$ Reaction conditions: methyl 4-bromobenzoate $(0.3 \mathrm{mmol})$, pyrrolidine $(0.45 \mathrm{mmol}), \mathrm{NiBr}_{2} \cdot 3 \mathrm{H}_{2} \mathrm{O}(10 \mathrm{~mol} \%)$, base $(0.9 \mathrm{mmol}), \mathrm{CN}-\mathrm{OA}-\mathrm{m}(10 \mathrm{mg})$, DMAc (anhydrous, $3 \mathrm{~mL})$, white LEDs at $40{ }^{\circ} \mathrm{C}$ for $16 \mathrm{~h}$. ${ }^{\mathrm{b}} \mathrm{Conversion}$ of methyl 4-bromobenzoate determined by ${ }^{1} \mathrm{H}-\mathrm{NMR}$ using 1,3,5-trimethoxybenzene as internal standard. ${ }^{\mathrm{C}} \mathrm{NMR}$ yields determined by ${ }^{1} \mathrm{H}-\mathrm{NMR}$ using 1,3,5-trimethoxybenzene as internal standard. ${ }^{\mathrm{d}} 2,2,6,6-$ tetramethylpiperidin ${ }^{\mathrm{e}} N$-tert-butylisopropylamine. ${ }^{\mathrm{f}}$ not detected. ${ }_{\mathrm{g}}$ 1,4-diazabicyclo[2.2.2] $\mathrm{octane}^{\mathrm{h}} N, N$ diisopropylethylamine. i4-(dimethylamino)pyridine.

${ }^{j} 1,8$-diazabicyclo[5.4.0]undec-7-ene.

${ }^{\mathrm{k}}$ Gexamethyldisilazane

$N$-tert-butylisopropylamine (BIPA) and 2,2,6,6-tetramethylpiperidine (TMP) gave best results. No C-N coupling between the aryl halide and these secondary, sterically hindered amines was observed. The absence of a base resulted in 58\% yield indicating that the amine substrate can play several roles simultaneously (substrate, ligand, base). All other tested bases did not significantly increase the yield compared to the base-free method. 


\subsection{Screening of conditions}

Table S5. Screening of amine equivalents for the base-free method.

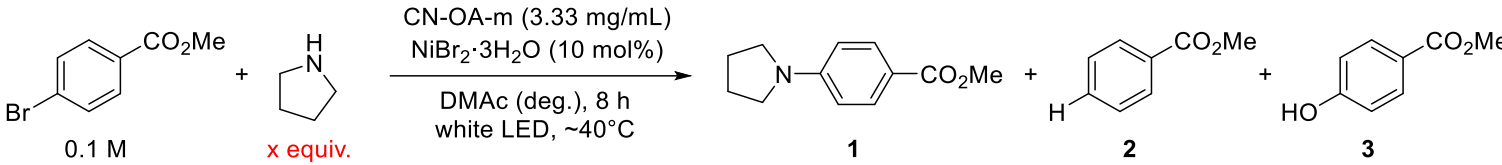

\begin{tabular}{cccccc}
\hline Entry & Pyrrolidine [equiv.] & $\begin{array}{c}\text { Conversion } \\
{[\mathbf{\%}]^{\mathbf{b}}}\end{array}$ & $\begin{array}{c}\mathbf{1} \\
{[\mathbf{\%}]^{\mathbf{c}}}\end{array}$ & $\begin{array}{c}\mathbf{2} \\
{[\mathbf{\%}]^{\mathbf{c}}}\end{array}$ & $\begin{array}{c}\mathbf{3} \\
{[\mathbf{\%}]^{\mathbf{c}}}\end{array}$ \\
\hline 1 & 1 & 33 & 24 & 4 & 1 \\
2 & 1.5 & 53 & 43 & 6 & 1 \\
3 & 2.0 & 67 & 59 & 7 & 1 \\
4 & 2.5 & 91 & 83 & 6 & 2 \\
6 & 3.0 & quant. & 94 & 5 & 2 \\
\hline
\end{tabular}

${ }^{a}$ Reaction conditions: methyl 4-bromobenzoate $(0.3 \mathrm{mmol})$, pyrrolidine (x equiv.), $\mathrm{NiBr}_{2} \cdot 3 \mathrm{H}_{2} \mathrm{O}(10 \mathrm{~mol} \%)$, CN-OA$\mathrm{m}(10 \mathrm{mg})$, DMAc (anhydrous, $3 \mathrm{~mL}$ ), white LEDs at $40{ }^{\circ} \mathrm{C}$ for $8 \mathrm{~h}$. ${ }^{\mathrm{b}}$ Conversion of methyl 4-bromobenzoate determined by ${ }^{1} \mathrm{H}$-NMR using 1,3,5-trimethoxybenzene as internal standard. ${ }^{\mathrm{C}} \mathrm{NMR}$ yields determined by ${ }^{1} \mathrm{H}-\mathrm{NMR}$ using 1,3,5-trimethoxybenzene as internal standard.

Table S6. Screening of base (BIPA) equivalents for reactions with 1.5 equiv. pyrrolidine. ${ }^{\mathrm{a}}$

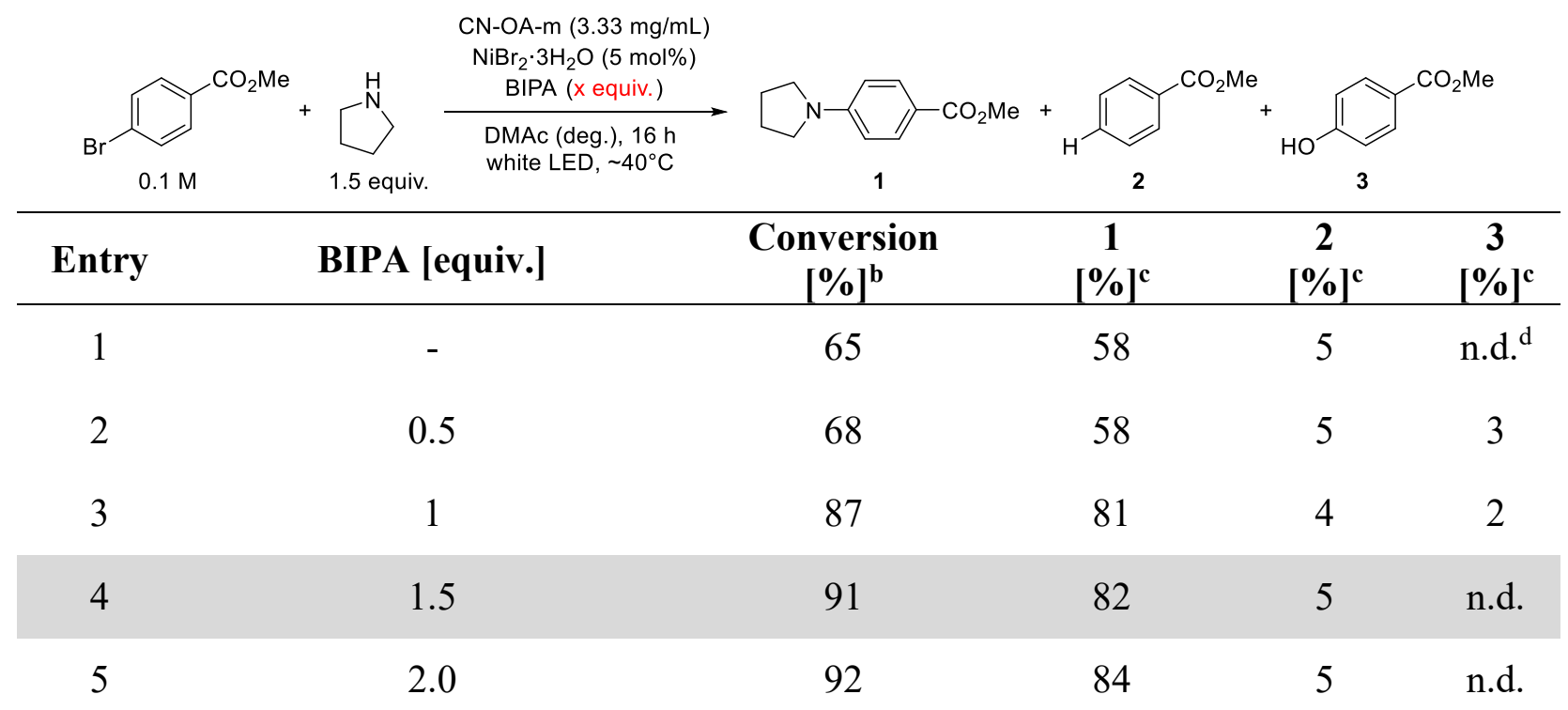

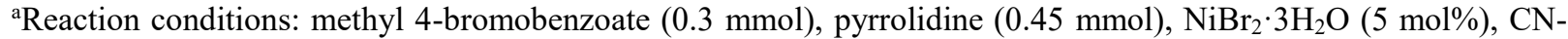
OA-m (10 mg), BIPA (0-2 equiv.), DMAc (anhydrous, $3 \mathrm{~mL}$ ), white LEDs at $40{ }^{\circ} \mathrm{C}$ for $16 \mathrm{~h}$. ${ }^{\mathrm{b}}$ Conversion of methyl 4-bromobenzoate determined by ${ }^{1} \mathrm{H}-\mathrm{NMR}$ using 1,3,5-trimethoxybenzene as internal standard. ${ }^{\mathrm{C}} \mathrm{NMR}$ yields determined by ${ }^{1} \mathrm{H}$-NMR using 1,3,5-trimethoxybenzene as internal standard. ${ }^{\mathrm{d}}$ not detected. 
Table S7. Effect of the amount of $\mathrm{NiBr}_{2} \cdot 3 \mathrm{H}_{2} \mathrm{O}$ and CM-OA-m on the yield of 1 . $^{\mathrm{a}}$

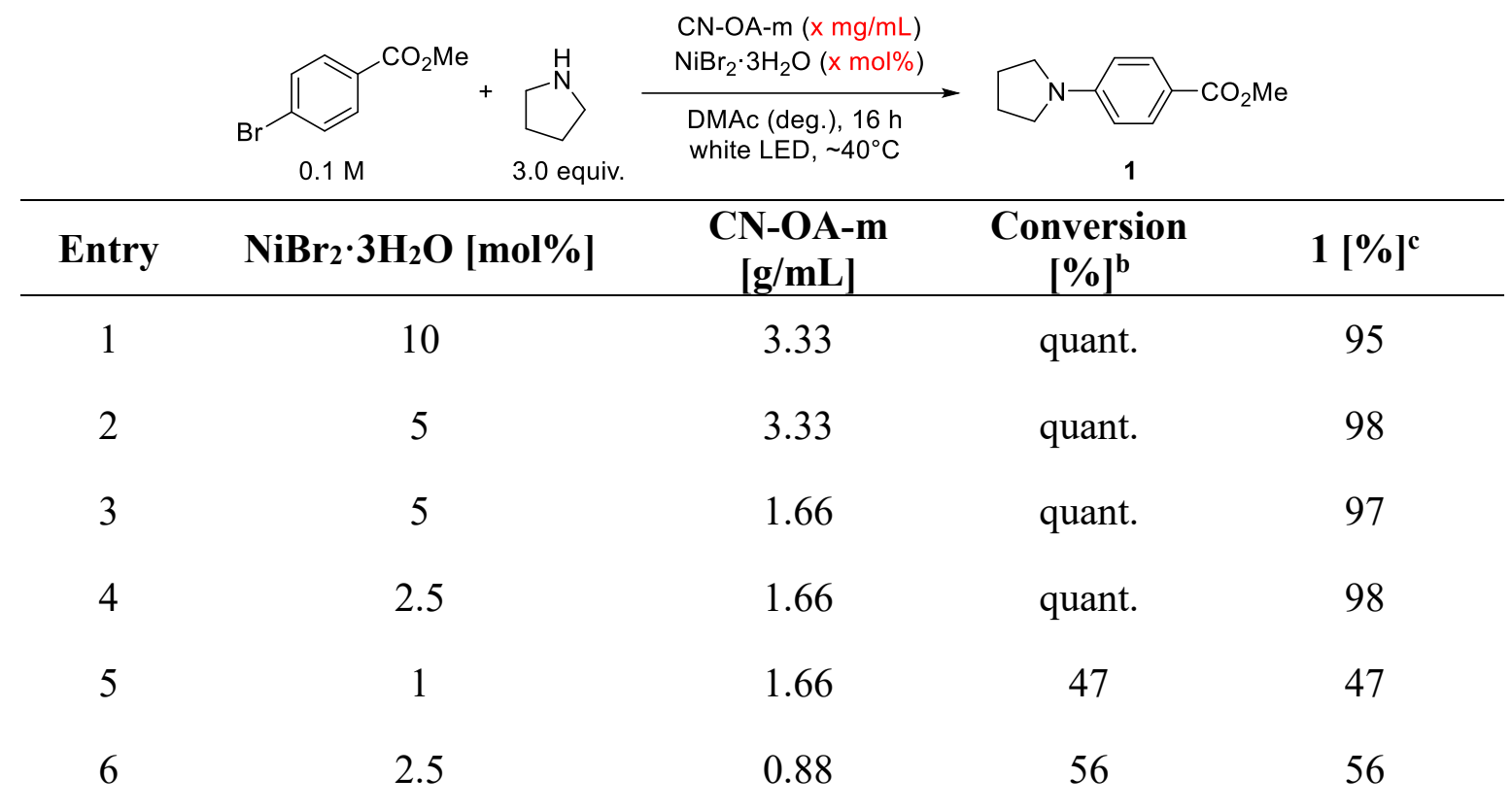

${ }^{a}$ Reaction conditions: methyl 4-bromobenzoate $(0.3 \mathrm{mmol})$, pyrrolidine $(0.9 \mathrm{mmol}), \mathrm{NiBr}_{2} \cdot 3 \mathrm{H}_{2} \mathrm{O}$ (y mol\%), base $(0.9 \mathrm{mmol}), \mathrm{CN}-\mathrm{OA}-\mathrm{m}(\mathrm{x} \mathrm{mg})$, DMAc (anhydrous, $3 \mathrm{~mL}$ ), white LEDs at $40{ }^{\circ} \mathrm{C}$ for $16 \mathrm{~h} .{ }^{\mathrm{b}}$ Conversion of methyl 4-bromobenzoate determined by ${ }^{1} \mathrm{H}-\mathrm{NMR}$ using 1,3,5-trimethoxybenzene as internal standard. ${ }^{\mathrm{C}} \mathrm{NMR}$ yields determined by ${ }^{1} \mathrm{H}-\mathrm{NMR}$ using 1,3,5-trimethoxybenzene as internal standard. 


\subsection{Screening of aryl (pseudo)halides}

Table S8. Screening of aryl (pseudo)halides. ${ }^{a}$

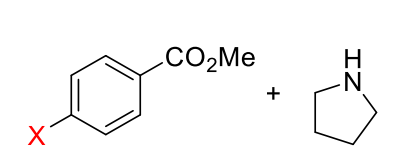

$0.1 \mathrm{M}$

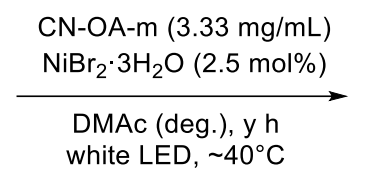

3.0 equiv.

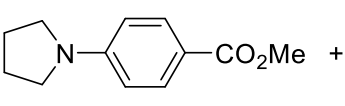

1

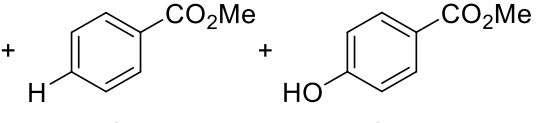

\begin{tabular}{ccccccc} 
Entry & $\mathbf{X}$ & Time $[\mathbf{h}]$ & Conversion $[\mathbf{\%}]^{\mathbf{b}}$ & $\mathbf{1}[\mathbf{\%}]^{\mathbf{c}}$ & $\mathbf{2}[\mathbf{\%}]^{\mathbf{c}}$ & $\mathbf{3}[\mathbf{\%}]^{\mathbf{c}}$ \\
\hline 1 & I & 8 & quant. & 99 & 1 & n.d. \\
2 & Br & 8 & quant. & 98 & 2 & 1 \\
3 & Cl & 168 & 76 & 72 & 4 & n.d. \\
4 & OTf & 72 & 75 & 67 & 5 & 2 \\
5 & OTs & 16 & 2 & n.d. & n.d. & n.d. \\
6 & OMs & 16 & 5 & n.d. & n.d. & 4 \\
\hline
\end{tabular}

${ }^{a}$ Reaction conditions: aryl (pseudo)halide $(0.3 \mathrm{mmol})$, pyrrolidine $(0.9 \mathrm{mmol}), \mathrm{NiBr}_{2} \cdot 3 \mathrm{H}_{2} \mathrm{O}(2.5 \mathrm{~mol} \%), \mathrm{CN}-\mathrm{OA}-\mathrm{m}$ (10 mg), DMAc (anhydrous, $3 \mathrm{~mL}$ ), white LEDs at $40{ }^{\circ} \mathrm{C}$ for $\mathrm{x} \mathrm{h} .{ }^{\mathrm{b}}$ Conversion of methyl 4-bromobenzoate determined by ${ }^{1} \mathrm{H}-\mathrm{NMR}$ using $1,3,5$-trimethoxybenzene as internal standard. ${ }^{\mathrm{c}} \mathrm{NMR}$ yields determined by ${ }^{1} \mathrm{H}-\mathrm{NMR}$ using $1,3,5$ trimethoxybenzene as internal standard. ${ }^{\mathrm{d}}$ not detected. 


\subsection{Control studies}

Table S9. Control studies. ${ }^{a}$

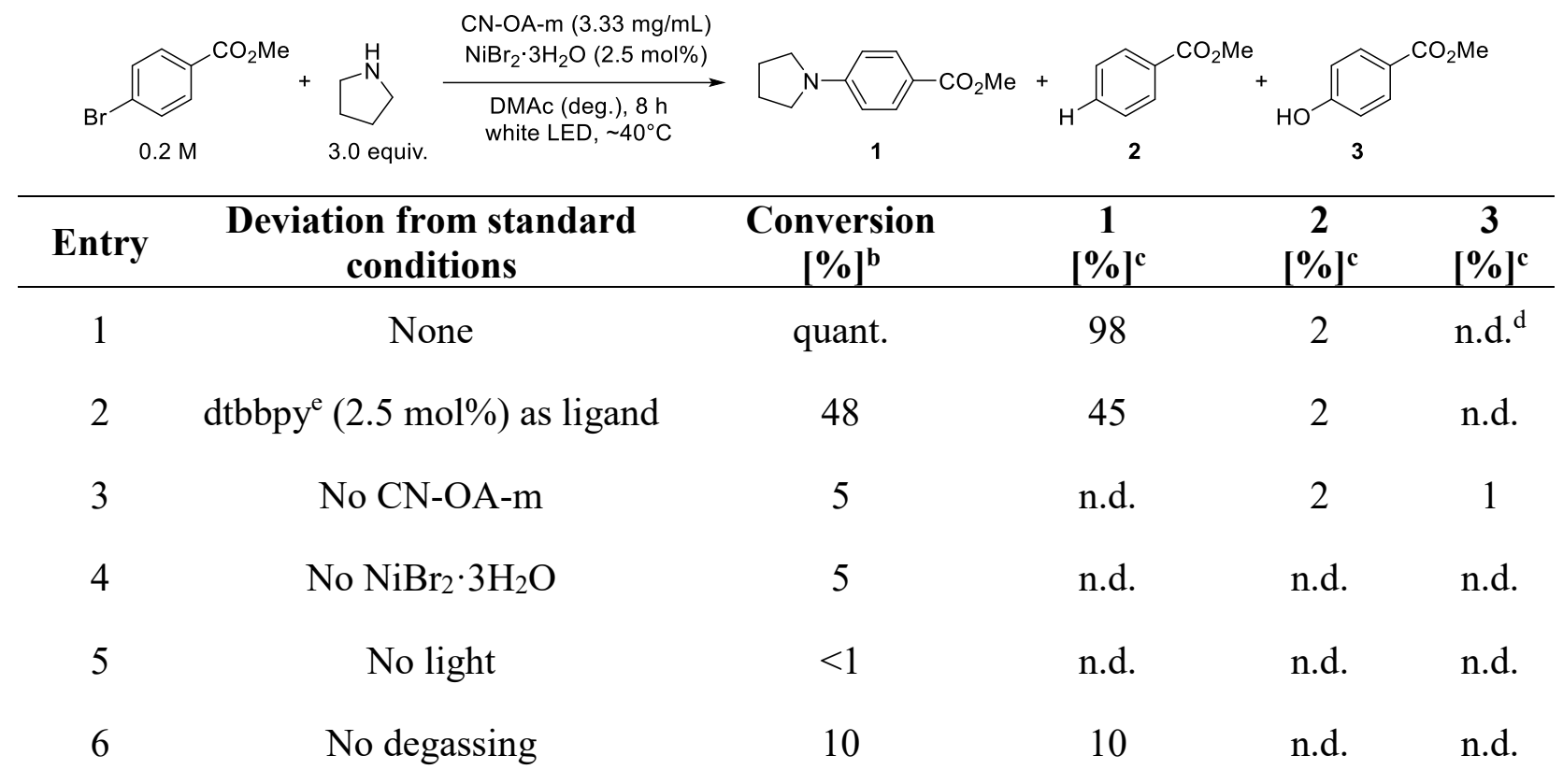

${ }^{a}$ Reaction conditions: methyl 4-bromobenzoate $(1.2 \mathrm{mmol})$, pyrrolidine $(3.6 \mathrm{mmol}), \mathrm{NiBr}_{2} \cdot 3 \mathrm{H}_{2} \mathrm{O}(2.5 \mathrm{~mol} \%), \mathrm{CN}-$ OA-m (20 mg), DMAc (anhydrous, $6 \mathrm{~mL}$ ), white LEDs at $40{ }^{\circ} \mathrm{C}$ for $8 \mathrm{~h}$. ${ }^{\text {b} C o n v e r s i o n ~ o f ~ m e t h y l ~ 4-b r o m o b e n z o a t e ~}$ determined by ${ }^{1} \mathrm{H}-\mathrm{NMR}$ using 1,3,5-trimethoxybenzene as internal standard. ${ }^{\mathrm{c}} \mathrm{NMR}$ yields determined by ${ }^{1} \mathrm{H}-\mathrm{NMR}$ using 1,3,5-trimethoxybenzene as internal standard. 'not detected. ${ }^{\mathrm{e}} 4,4^{\prime}$-Di-tert-butyl-2,2'-bipyridyl. 


\subsection{Time/Wavelength study}

Table S10. Time study using white light.

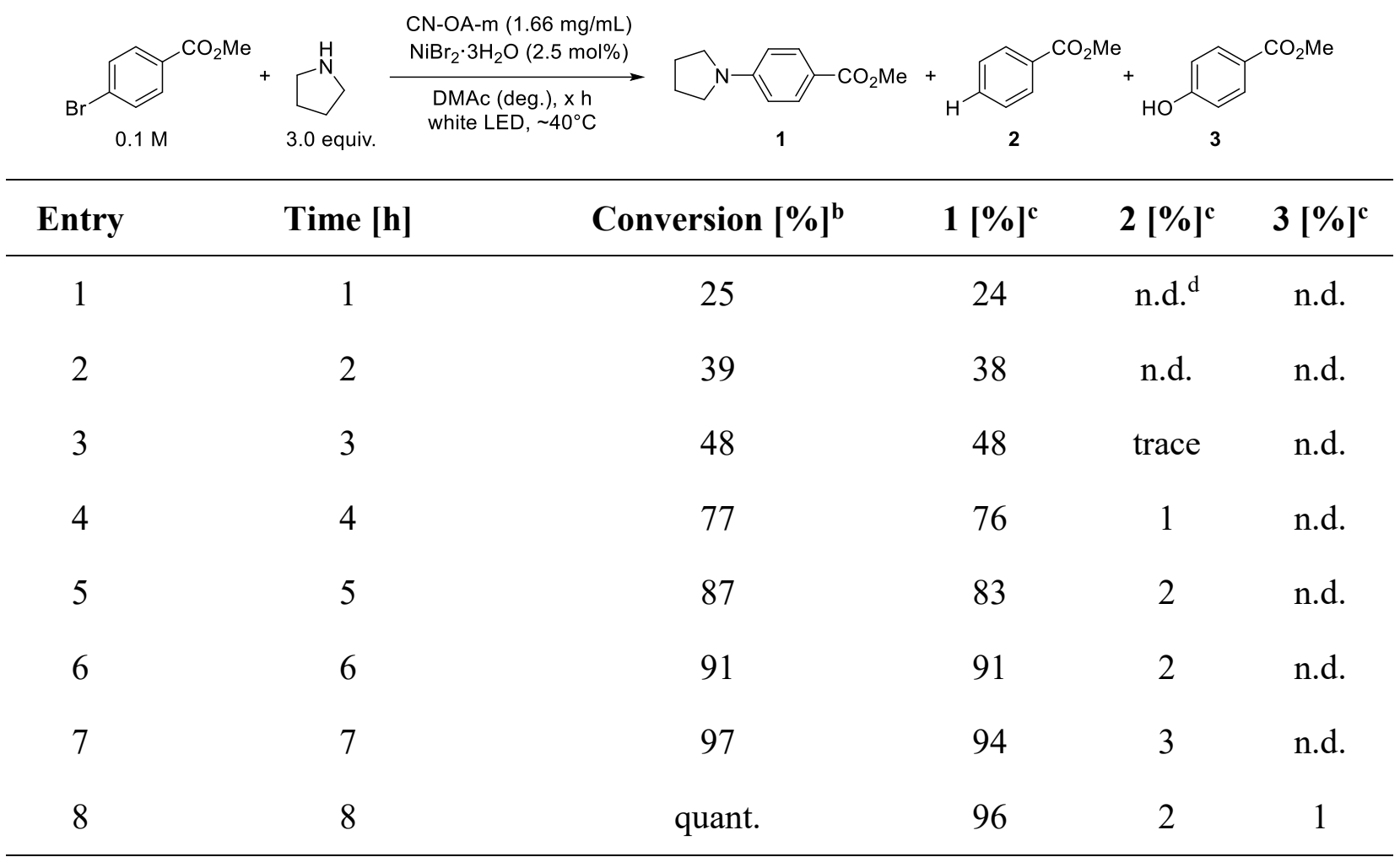

${ }^{a}$ Reaction conditions: methyl 4-bromobenzoate $(0.6 \mathrm{mmol})$, pyrrolidine $(1.8 \mathrm{mmol}), \mathrm{NiBr}_{2} \cdot 3 \mathrm{H}_{2} \mathrm{O}(2.5 \mathrm{~mol} \%), \mathrm{CN}-$ OA-m (10 mg), DMAc (anhydrous, $6 \mathrm{~mL}$ ), white LEDs at $40{ }^{\circ} \mathrm{C}$ for $\mathrm{x} \mathrm{h} .{ }^{\mathrm{b}} \mathrm{Conversion}$ of methyl 4-bromobenzoate determined by ${ }^{1} \mathrm{H}-\mathrm{NMR}$ using $1,3,5$-trimethoxybenzene as internal standard. ${ }^{\mathrm{C}} \mathrm{NMR}$ yields determined by ${ }^{1} \mathrm{H}-\mathrm{NMR}$ using 1,3,5-trimethoxybenzene as internal standard. ${ }^{\mathrm{d}}$ not detected.

Table S11. Time study using blue light.

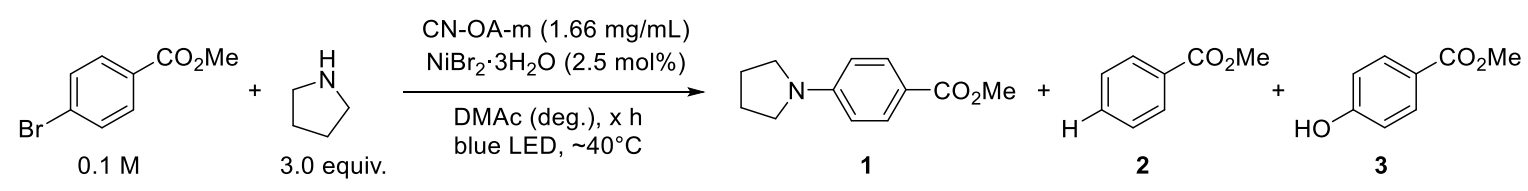

\begin{tabular}{cccccc}
\hline Entry & Time $[\mathbf{h}]$ & Conversion $[\%]^{\mathbf{b}}$ & $\mathbf{1}[\mathbf{\%}]^{\mathbf{c}}$ & $\mathbf{2}[\mathbf{\%}]^{\mathbf{c}}$ & $\mathbf{3}[\mathbf{\%}]^{\mathbf{c}}$ \\
\hline 1 & 2 & 51 & 51 & n.d. & n.d. \\
2 & 4 & 77 & 80 & trace & n.d. \\
3 & 5.5 & quant. & $>99$ & trace & n.d.
\end{tabular}

aReaction conditions: methyl 4-bromobenzoate $(0.6 \mathrm{mmol})$, pyrrolidine $(1.8 \mathrm{mmol}), \mathrm{NiBr}_{2} \cdot 3 \mathrm{H}_{2} \mathrm{O}(2.5 \mathrm{~mol} \%), \mathrm{CN}-$ OA-m (10 mg), DMAc (anhydrous, $6 \mathrm{~mL}$ ), blue LEDs at $40{ }^{\circ} \mathrm{C}$ for $\mathrm{x} \mathrm{h}$. ${ }^{\mathrm{b}}$ Conversion of methyl 4-bromobenzoate determined by ${ }^{1} \mathrm{H}$-NMR using 1,3,5-trimethoxybenzene as internal standard. ${ }^{c} \mathrm{NMR}$ yields determined by ${ }^{1} \mathrm{H}-\mathrm{NMR}$ using 1,3,5-trimethoxybenzene as internal standard. ${ }^{d}$ not detected. 
Table S12. Time study using green light.

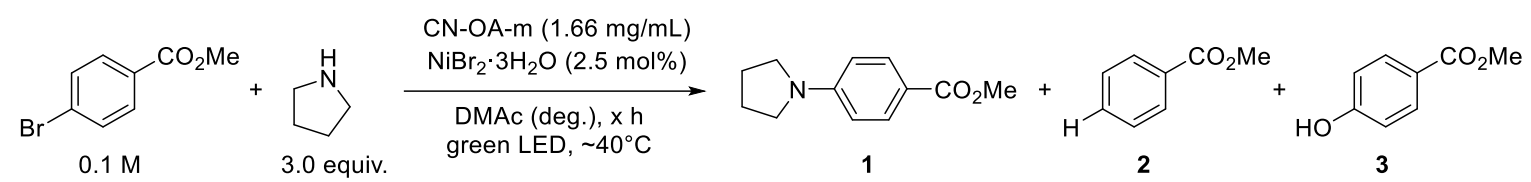

\begin{tabular}{|c|c|c|c|c|c|}
\hline Entry & Time [h] & Conversion $[\%]^{b}$ & $1[\%]^{\mathrm{c}}$ & $2[\%]^{\mathrm{c}}$ & $3[\%]^{\mathrm{c}}$ \\
\hline 1 & 4 & 10 & 10 & n.d. ${ }^{d}$ & n.d. \\
\hline 2 & 8 & 21 & 20 & n.d. & n.d. \\
\hline 3 & 24 & 69 & 68 & n.d. & n.d. \\
\hline 4 & 48 & quant. & $>99$ & n.d. & n.d. \\
\hline
\end{tabular}

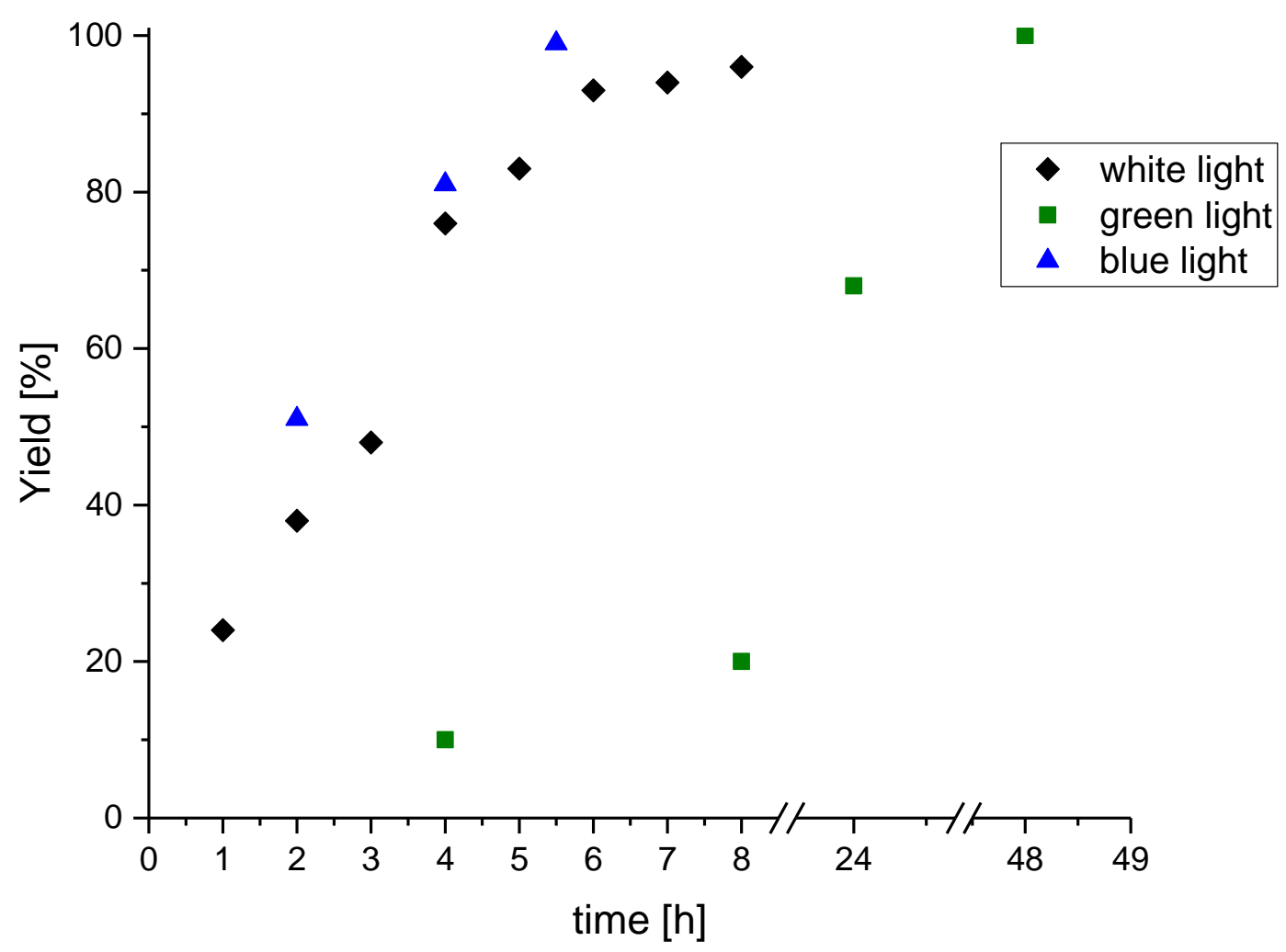

Figure S6. Time study using blue, green and white light for model reaction. 
For ICP-OES experiments, the reaction mixture was centrifuged at $3000 \mathrm{rpm}$ for $20 \mathrm{~min}$ and the liquid phase was carefully separated and analyzed by ${ }^{1} \mathrm{H}-\mathrm{NMR}$. The carbon nitride was washed with DMAc (anhydrous, $6 \mathrm{~mL}$, followed by centrifugation at $3000 \mathrm{rpm}$ for $20 \mathrm{~min}$ and separation of the liquid phase), water ( $6 \mathrm{~mL}$, followed by centrifugation at $3000 \mathrm{rpm}$ for $20 \mathrm{~min}$ and separation of the liquid phase) and lyophilized (overnight) before analysis.

Table S13: ICP-OES measurements of the nickel content on the new and recovered CN-OA$\mathrm{m}$ after $8 \mathrm{~h}$ white light and $48 \mathrm{~h}$ green light standard reaction.

\begin{tabular}{ccc}
\hline Sample & $\mathrm{Ni}[\mathrm{mg} / \mathrm{g} \mathrm{CN}]$ & \% adsorbed Ni \\
\hline CN-OA-m new & 0.117 & $/$ \\
$\begin{array}{c}\text { CN-OA-m white light } \\
\text { standard reaction 1 }\end{array}$ & 14.2 & 16.1 \\
$\begin{array}{c}\text { CN-OA-m green light } \\
\text { standard reaction }\end{array}$ & 13.8 & 15.7 \\
\hline
\end{tabular}

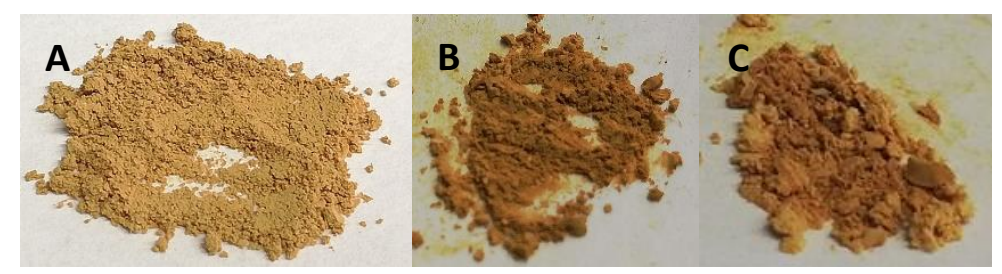

Figure S7. Fresh CN-OA-m (A), CN-OA-m after $8 \mathrm{~h}$ white light irradiation for standard reaction $(\mathbf{B})$ and $\mathrm{CN}-\mathrm{OA}-\mathrm{m}$ after $48 \mathrm{~h}$ green light irradiation for standard reaction $(\mathbf{C})$.

Note: Although $1.66 \mathrm{mg} \mathrm{mL}^{-1}$ of CN-OA-m is suitable for the C-N cross-coupling, a higher loading (3.33 mg mL $\mathrm{m}^{-1}$ ) was used for further experiments in order to obtain enough material for material characterization (ICP-OES, EDX, SEM, TEM, etc). 


\section{Recycling studies}

An oven dried vial (13 x $80 \mathrm{~mm})$ equipped with a stir bar was charged with CN-OA-m $(20 \mathrm{mg})$, 4-bromomethylbenzoate (258.0 mg, $1.2 \mathrm{mmol}, 1.0$ equiv.) and $\mathrm{NiBr}_{2} \cdot 3 \mathrm{H}_{2} \mathrm{O}(8.2 \mathrm{mg}, 30 \mu \mathrm{mol}$, $2.5 \mathrm{~mol} \%$ ). Subsequently, pyrrolidine (256.0 mg, $295.6 \mu 1,3.6 \mathrm{mmol}, 3.0$ equiv.) and DMAc (anhydrous, $6 \mathrm{~mL}$ ) were added and the vial was sealed with a septum and Parafilm. The reaction mixture was sonicated for 5-10 min followed by stirring for $5 \mathrm{~min}$ until fine dispersion of the solids was achieved and the mixture was then degassed by bubbling $\mathrm{N}_{2}$ for $10 \mathrm{~min}$. The mixture was irradiated in the photoreactor (white light or green light) at $40{ }^{\circ} \mathrm{C}$ with rapid stirring $(1400$ $\mathrm{rpm})$. After the respective reaction time, one equivalent of 1,3,5-trimethoxybenzene (202.0 mg, $1.2 \mathrm{mmol}$ ) was added and the mixture was stirred for $5 \mathrm{~min}$. The reaction mixture was centrifuged at $3000 \mathrm{rpm}$ for $20 \mathrm{~min}$ and the liquid phase was carefully separated and analyzed by ${ }^{1} \mathrm{H}-\mathrm{NMR}$. The carbon nitride was washed with DMAc (anhydrous, $6 \mathrm{~mL}$, followed by centrifugation at $3000 \mathrm{rpm}$ for $20 \mathrm{~min}$ and separation of the liquid phase), lyophilized (overnight) and reused in the next reaction.

Table S14. Reusability of CN-OA-m using white light. ${ }^{a}$

\begin{tabular}{cc} 
Cycle & $\begin{array}{c}\text { 1 } \\
{[\%]^{\mathbf{b}}}\end{array}$ \\
\hline 1 & 99 \\
2 & 98 \\
3 & $\begin{array}{l}\mathrm{CN}-\mathrm{OA}-\mathrm{m}(3.33 \mathrm{mg} / \mathrm{mL}) \\
\mathrm{NiBr}_{2} \cdot 3 \mathrm{H}_{2} \mathrm{O}(2.5 \mathrm{~mol} \%) \\
\text { white LED, } \sim 40^{\circ} \mathrm{C}\end{array}$ \\
4 & 27 \\
5 & 33
\end{tabular}

a Reaction conditions: methyl 4-bromobenzoate (1.2 mmol), pyrrolidine (3.6 mmol), $\mathrm{NiBr}_{2} \cdot 3 \mathrm{H}_{2} \mathrm{O}$ (2.5 mol\%), CN-OA-m (20 mg - reused), DMAc (anhydrous, $6 \mathrm{~mL}$ ), white LEDs at $40{ }^{\circ} \mathrm{C}$ for $16 \mathrm{~h}$. bNMR yields determined by ${ }^{1} \mathrm{H}-\mathrm{NMR}$ using 1,3,5-trimethoxybenzene as internal standard. 
Table S15. Reusability of CN-OA-m without additional $\mathrm{NiBr}_{2} \cdot 3 \mathrm{H}_{2} \mathrm{O}$ using white light. ${ }^{\mathrm{a}}$

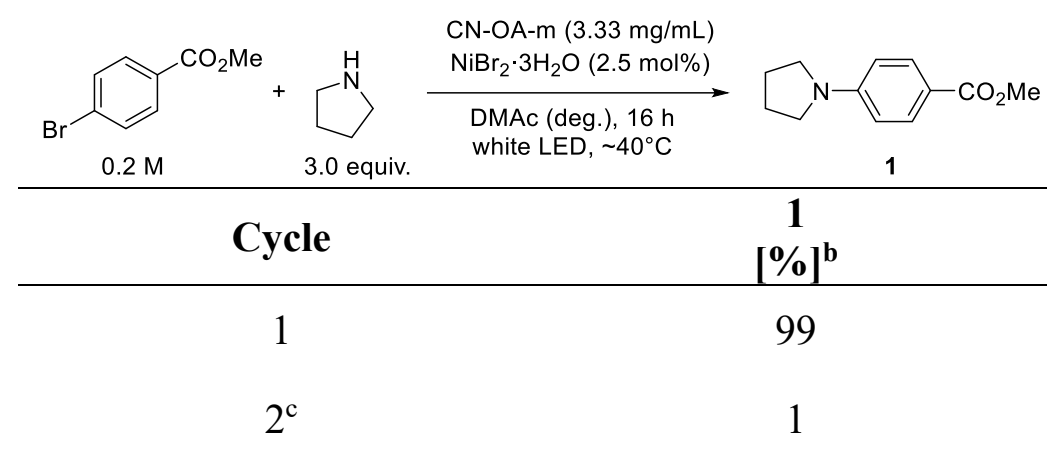

${ }^{\text {a}}$ Reaction conditions: methyl 4-bromobenzoate (1.2 mmol), pyrrolidine (3.6 mmol), $\mathrm{NiBr}_{2} \cdot 3 \mathrm{H}_{2} \mathrm{O}$ (2.5 mol\%), CN-OA-m (20 mg - reused), DMAc (anhydrous, $6 \mathrm{~mL}$ ), white LEDs at $40{ }^{\circ} \mathrm{C}$ for $16 \mathrm{~h} .{ }^{\mathrm{b}} \mathrm{NMR}$ yields determined by ${ }^{1} \mathrm{H}-\mathrm{NMR}$ using 1,3,5-trimethoxybenzene as internal standard. ${ }^{\mathrm{N}} \mathrm{No} \mathrm{NiBr}_{2} \cdot 3 \mathrm{H}_{2} \mathrm{O}$ added.

Table S16. Reusability of CN-OA-m using green light. ${ }^{a}$

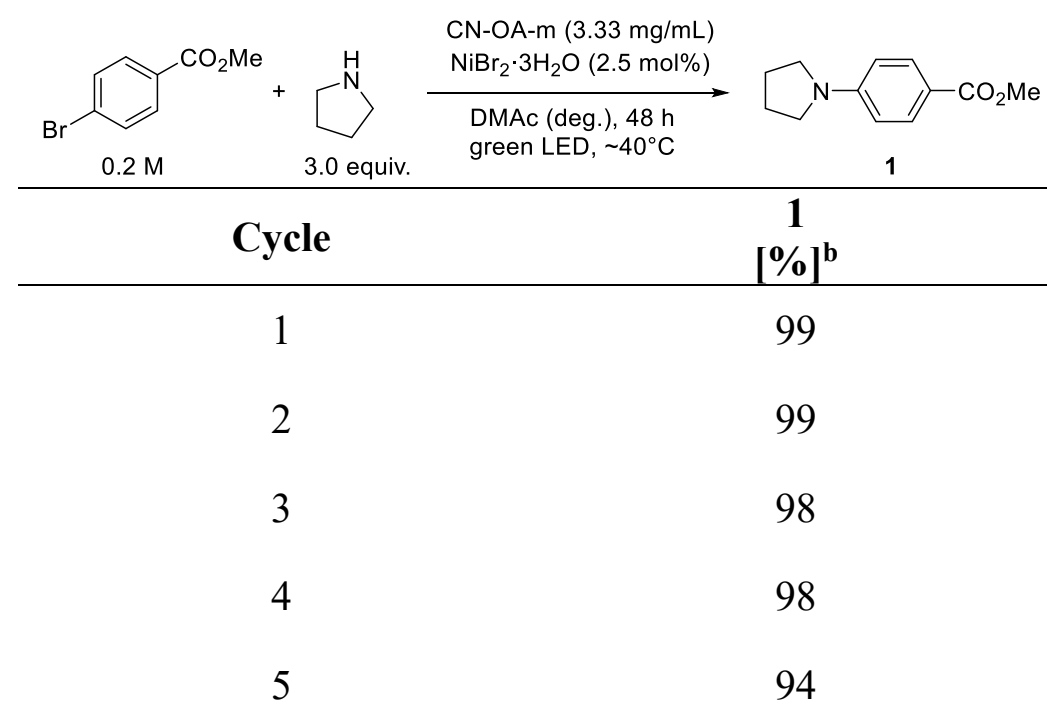

${ }^{a}$ Reaction conditions: methyl 4-bromobenzoate $(1.2 \mathrm{mmol})$, pyrrolidine (3.6 mmol), $\mathrm{NiBr}_{2} \cdot 3 \mathrm{H}_{2} \mathrm{O}$ (2.5 mol\%), CN-OA-m (20 mg - reused), DMAc (anhydrous, $6 \mathrm{~mL}$ ), green LEDs at $40{ }^{\circ} \mathrm{C}$ for $48 \mathrm{~h}$. bNMR yields determined by ${ }^{1} \mathrm{H}$-NMR using 1,3,5-trimethoxybenzene as internal standard. 
Table S17: ICP-OES measurements of the nickel content on recovered CN-OA-m after white light and green light recyclability tests.

\begin{tabular}{ccc}
\hline Sample & $\mathrm{Ni}[\mathrm{mg} / \mathrm{g} \mathrm{CN}]$ & \% adsorbed $\mathrm{Ni}$ \\
\hline $\begin{array}{c}\text { CN-OA-m white light } \\
\text { recyclability tests }\end{array}$ & 60.5 & 13.7 \\
$\begin{array}{c}\text { CN-OA-m green light } \\
\text { recyclability tests }\end{array}$ & 38.8 & 8.8 \\
\hline
\end{tabular}
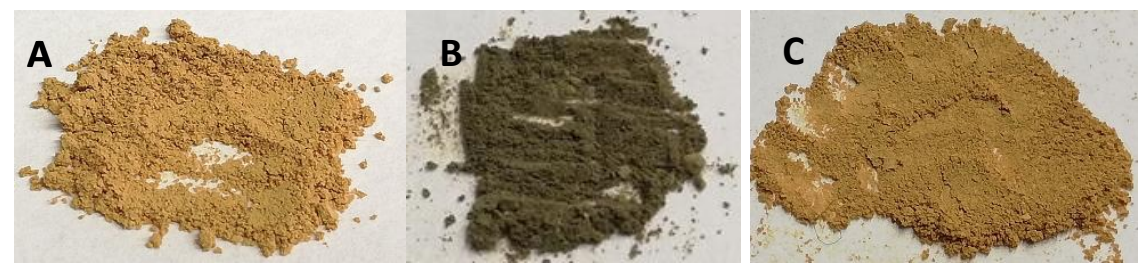

Figure S8. Fresh CN-OA-m (A), CN-OA-m after recyclability tests with white light irradiation (B) and CN-OA-m after recyclability tests with green light irradiation (C).

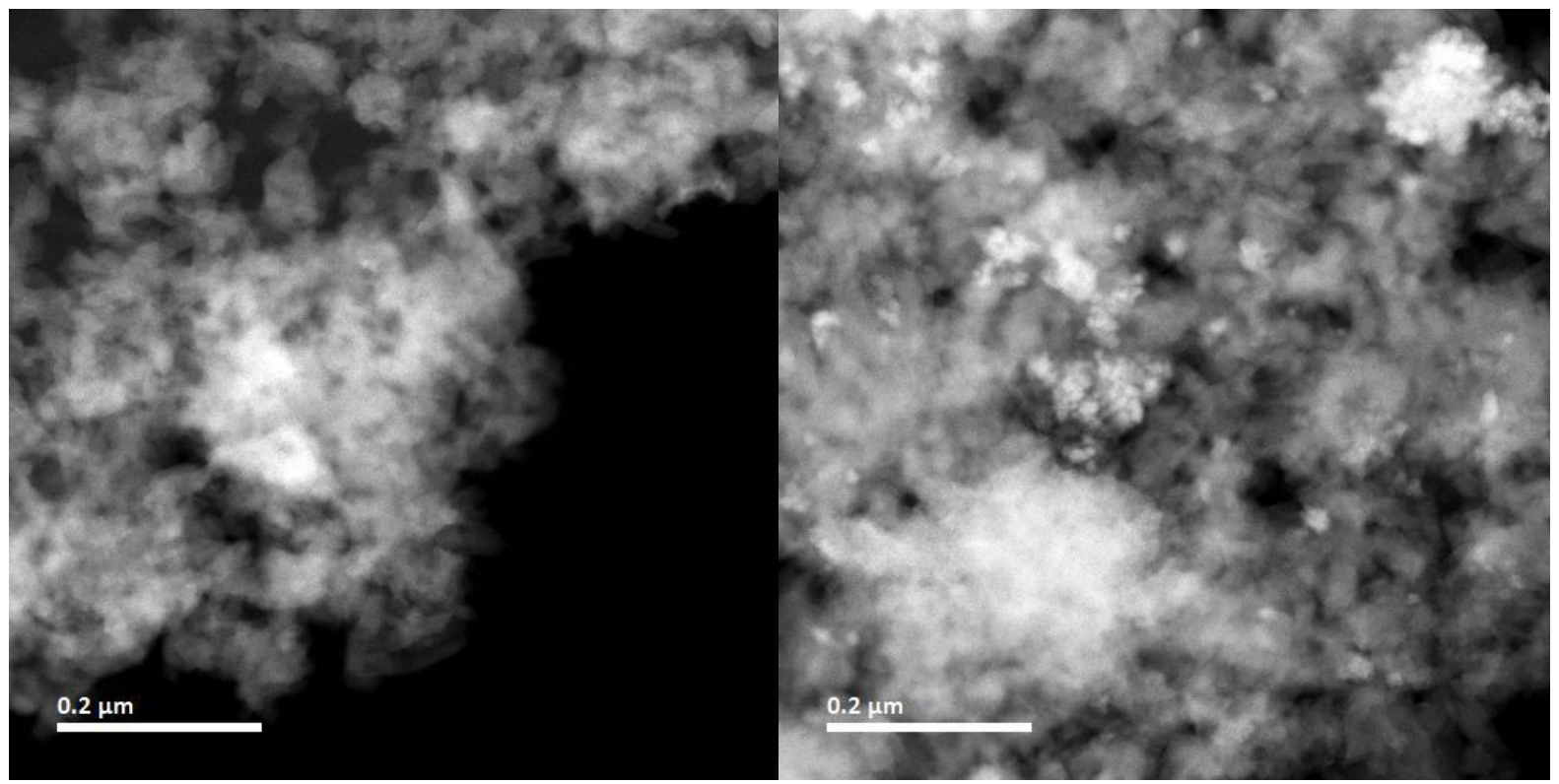

Figure S9. HAADF-STEM brightfield images show almost no nickel particle agglomerates (bright spots) on CN-OA-m after recyclability tests with green light irradiation (left) and a significant amount of agglomerates after recyclability tests with white light irradiation (right). 


\section{Scale-up of amination}

An oven dried vial (25 x $140 \mathrm{~mm}$ ) (Figure S10, A) equipped with a stir bar was charged with $\mathrm{NiBr}_{2} \cdot 3 \mathrm{H}_{2} \mathrm{O}$ (54.5 mg, $0.2 \mathrm{mmol}, 2.5 \mathrm{~mol} \%$ ), methyl 4-bromobenzoate (1.720 g, $8.0 \mathrm{mmol}$, 1 equiv.) and CN-OA-m (133.3 mg). Subsequently, pyrrolidine (1.706 g, $1.97 \mathrm{ml}, 24.0 \mathrm{mmol}$, 3 equiv.) and DMAc (anhydrous, $6 \mathrm{~mL}$ ) were added and the vial was sealed with a septum and parafilm. The reaction mixture was sonicated for $10 \mathrm{~min}$ and the mixture was then degassed by bubbling $\mathrm{N}_{2}$ for $30 \mathrm{~min}$ and stirring the reaction mixture. The mixture was irradiated in a beaker wrapped with a LED-band (Figure S2, B) at $\sim 40^{\circ} \mathrm{C}$ with rapid stirring (700 rpm). The completion of the reaction ( $14 \mathrm{~h}$ ) was confirmed by taking an aliquot and measuring ${ }^{1} \mathrm{H}-\mathrm{NMR}$ of the crude mixture in DMSO- $\mathrm{d}^{6}$. The catalyst was removed by centrifugation $(3000 \mathrm{rpm}, 20$ min) and the liquid phase was diluted with $\mathrm{H}_{2} \mathrm{O}(200 \mathrm{~mL})$ and extracted with ethyl acetate $(3 \mathrm{x}$ $200 \mathrm{~mL})$. The combined organic phases were washed with $\mathrm{H}_{2} \mathrm{O}(200 \mathrm{~mL})$, a sat. $\mathrm{NaHCO}_{3}$ solution $(200 \mathrm{ml})$, and brine $(200 \mathrm{~mL})$, dried over $\mathrm{Na}_{2} \mathrm{SO}_{4}$ and concentrated. The crude product was purified by flash column chromatography $\left(\mathrm{SiO}_{2}\right.$, Hexane/EtOAc; gradient $0-5 \%$ ethyl acetate in hexane; 2. Isocratic 5\% ethyl acetate in hexane)) on a Grace ${ }^{\mathrm{TM}}$ Reveleris ${ }^{\mathrm{TM}}$ system using a $24 \mathrm{~g}$ cartridge to afford (1-(4-methylbenzoate)pyrrolidine) (1) in $93 \%$ (1.5338 g, $7.47 \mathrm{mmol}$ ) as a white solid (Figure S11).

${ }^{1} \mathrm{H}$ NMR (400 MHz, Chloroform- $d$ ) $\delta 7.88(\mathrm{~d}, J=8.7 \mathrm{~Hz}, 2 \mathrm{H}), 6.46(\mathrm{~d}, J=8.7 \mathrm{~Hz}, 2 \mathrm{H}), 3.83$ (s, 3H), $3.40-3.09(\mathrm{~m}, 4 \mathrm{H}), 2.05-1.86(\mathrm{~m}, 4 \mathrm{H}) .{ }^{13} \mathrm{C}$ NMR (101 MHz, Chloroform- $d$ ) $\delta=$ 167.57, 150.79, 131.31, 116.16, 110.62, 51.37, 47.47, 25.41. HRMS (ESI-TOF) m/z calcd. for $\mathrm{C}_{12} \mathrm{H}_{16} \mathrm{NO}_{2}\left[(\mathrm{M}+\mathrm{H})^{+}\right]: 206.1176$; found: 206.116.

These data are in full agreement with those previously published in the literature. ${ }^{18}$ 


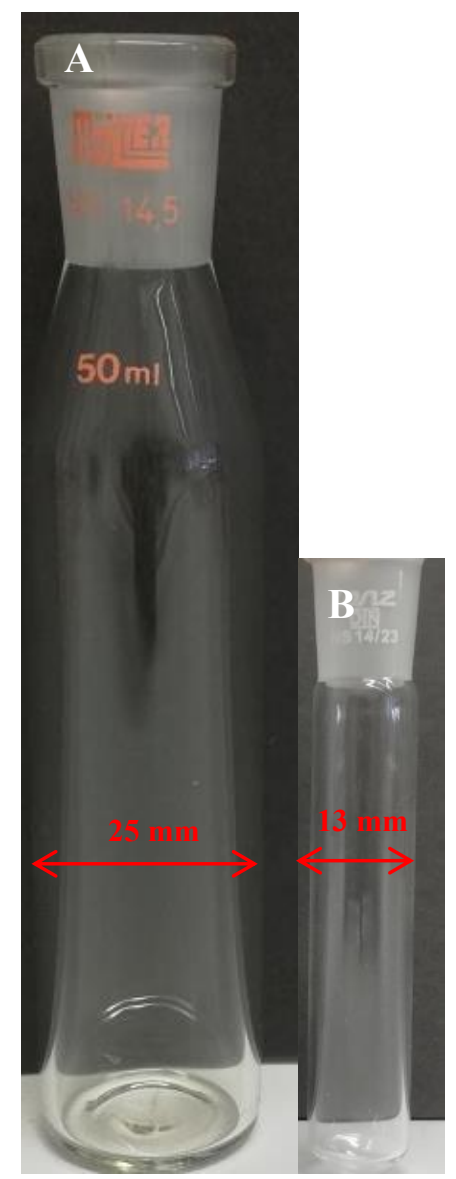

Figure S10. Vessel dimensions of vial for scale-up reaction (A) and vial for "standard scale" reactions $(\mathbf{B})$.

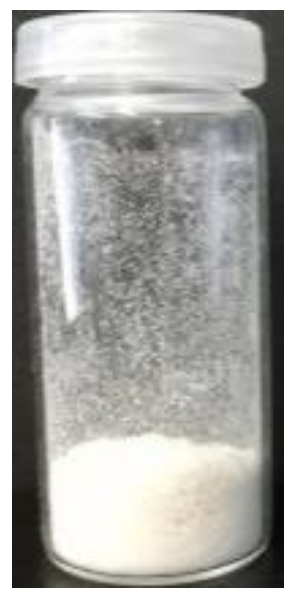

Figure S11. Isolated product (1-(4-methylbenzoate)pyrrolidine) (1) from $8 \mathrm{mmol}$ scale. 


\section{Studies on the reaction of 4-bromofluorobenzene with pyrrolidine.}

\section{Procedure A: Dual CN-OA-m/Ni catalysis with irradiation at $450 \mathrm{~nm}$}

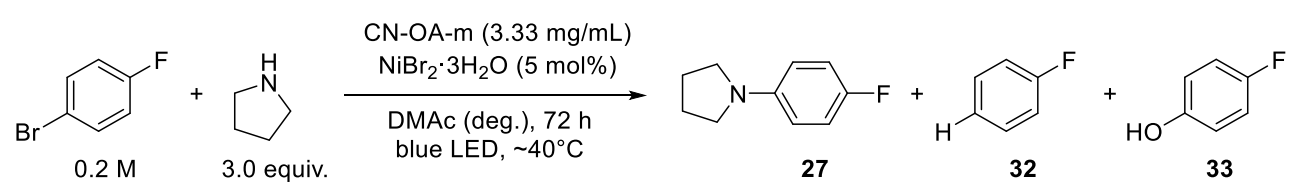

An oven dried vial $(19 \times 80 \mathrm{~mm})$ equipped with a stir bar was charged with the CN-OA-m (20 mg), 4-bromofluorobenzene (210.0 mg, $131.8 \mu \mathrm{l}, 1.2 \mathrm{mmol}, 1.0$ equiv.) and $\mathrm{NiBr}_{2} \cdot 3 \mathrm{H}_{2} \mathrm{O}$ (16.4 mg, $60 \mu \mathrm{mol}, 5.0 \mathrm{~mol} \%$ ). Subsequently, pyrrolidine $(256.0 \mathrm{mg}, 295.6 \mu 1,3.6 \mathrm{mmol}, 3.0$ equiv.) and DMAc (anhydrous, $6 \mathrm{~mL}$ ) were added and the vial was sealed with a septum and Parafilm. The reaction mixture was sonicated for 5-10 min followed by stirring for $5 \mathrm{~min}$ until fine dispersion of the solids was achieved and the mixture was then degassed by bubbling $\mathrm{N}_{2}$ for $10 \mathrm{~min}$. The mixture was irradiated in the photoreactor (blue light function of RGB LED strip) at $40{ }^{\circ} \mathrm{C}$ with rapid stirring (1400 rpm). After $72 \mathrm{~h}$, one equivalent of 1,3,5trimethoxybenzene $(1.2 \mathrm{mmol})$ was added and the mixture was stirred for $5 \mathrm{~min}$. An aliquot of the reaction mixture $(\sim 300 \mu \mathrm{L})$ was filtered, diluted with DMSO- $\mathrm{d}_{6}$ and subjected to ${ }^{1} \mathrm{H}-\mathrm{NMR}$ analysis.

\section{Procedure B: Dual CN-OA-m/Ni catalysis with irradiation at 520 nm}

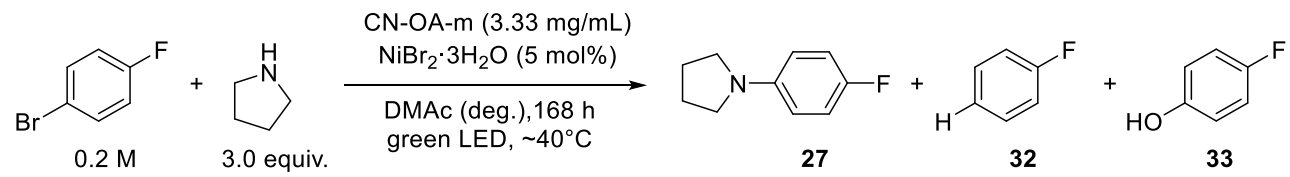

An oven dried vial $(19 \times 80 \mathrm{~mm})$ equipped with a stir bar was charged with the CN-OA-m (20 mg), 4-bromofluorobenzene (210.0 mg, $131.8 \mu 1,1.2 \mathrm{mmol}, 1.0$ equiv.) and (16.4 mg, 60 $\mu \mathrm{mol}, 5.0 \mathrm{~mol} \%)$. Subsequently, pyrrolidine (256.0 mg, $295.6 \mu 1,3.6 \mathrm{mmol}, 3.0$ equiv.) and DMAc (anhydrous, $6 \mathrm{~mL}$ ) were added and the vial was sealed with a septum and Parafilm. The reaction mixture was sonicated for 5-10 min followed by stirring for 5 min until fine dispersion of the solids was achieved and the mixture was then degassed by bubbling $\mathrm{N}_{2}$ for $10 \mathrm{~min}$. The mixture was irradiated in the photoreactor (green light function of RGB LED strip) at $40{ }^{\circ} \mathrm{C}$ with rapid stirring $(1400 \mathrm{rpm})$. After $168 \mathrm{~h}$, one equivalent of 1,3,5-trimethoxybenzene (1.2 mmol) was added and the mixture was stirred for $5 \mathrm{~min}$. An aliquot of the reaction mixture $(\sim 300 \mu \mathrm{L})$ was filtered, diluted with DMSO- $\mathrm{d}_{6}$ and subjected to ${ }^{1} \mathrm{H}-\mathrm{NMR}$ analysis. 


\section{Procedure Ir: Dual Ir/Ni catalysis with irradiation at $420 \mathrm{~nm}$}

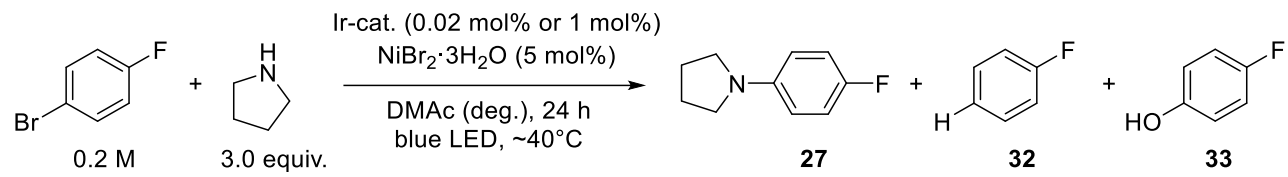

Ir1: An oven dried vial $(19$ x $80 \mathrm{~mm})$ equipped with a stir bar was charged with 4bromofluorobenzene (210.0 mg, $131.8 \mu \mathrm{l}, 1.2 \mathrm{mmol}, 1.0$ equiv.) and $\mathrm{NiBr}_{2} \cdot 3 \mathrm{H}_{2} \mathrm{O}(16.4 \mathrm{mg}, 60$ $\mu \mathrm{mol}, 5.0 \mathrm{~mol} \%)$ and a solution of $\operatorname{Ir}\left[\mathrm{dF}\left(\mathrm{CF}_{3}\right) \text { ppy }\right]_{2}(\mathrm{dtbbpy}) \mathrm{PF}_{6}(0.27 \mathrm{mg}, 0.02 \mathrm{~mol} \%)$. in DMAc (48 $\mu$ l). Subsequently, pyrrolidine $(256.0 \mathrm{mg}, 295.6 \mu 1,3.6 \mathrm{mmol}, 3.0$ equiv.) and DMAc (anhydrous, $6 \mathrm{~mL}$ ) were added and the vial was sealed with a septum and Parafilm.

Ir2: An oven dried vial $(19$ x $80 \mathrm{~mm})$ equipped with a stir bar was charged with 4bromofluorobenzene (52.5 mg, $33.0 \mu \mathrm{l}, 0.3 \mathrm{mmol}, 1.0$ equiv.), $\mathrm{NiBr}_{2} \cdot 3 \mathrm{H}_{2} \mathrm{O}$ (4.1 mg, $15 \mu \mathrm{mol}$, $5.0 \mathrm{~mol} \%)$ and a solution of $\operatorname{Ir}\left[\mathrm{dF}\left(\mathrm{CF}_{3}\right) \text { ppy }\right]_{2}(\mathrm{dtbbpy}) \mathrm{PF}_{6}(3.37 \mathrm{mg}, 1 \mathrm{~mol} \%)$. in DMAc (600 $\mu 1)$. Subsequently, pyrrolidine (64.0 mg, $73.9 \mu 1,0.9 \mathrm{mmol}, 3.0$ equiv.) and DMAc (anhydrous, $2.4 \mathrm{~mL}$ ) were added and the vial was sealed with a septum and Parafilm.

The reaction mixture was sonicated for 5-10 min followed by stirring for $5 \mathrm{~min}$ and the mixture was then degassed by bubbling $\mathrm{N}_{2}$ for $10 \mathrm{~min}$. The mixture was irradiated in the photoreactor (blue light function of LED-band) at $40{ }^{\circ} \mathrm{C}$ with rapid stirring (1400 rpm). After $24 \mathrm{~h}$, one equivalent of 1,3,5-trimethoxybenzene (Ir1: $202.0 \mathrm{mg}, 1.2 \mathrm{mmol} / \mathrm{Ir} 2: 50.5 \mathrm{mg}, 0.3 \mathrm{mmol}$ ) was added and the mixture was stirred for $5 \mathrm{~min}$. An aliquot of the reaction mixture $(\sim 300 \mu \mathrm{L})$ was filtered, diluted with DMSO- $\mathrm{d}_{6}$ and subjected to ${ }^{1} \mathrm{H}-\mathrm{NMR}$ analysis.

Note: In case if procedure $\mathrm{C} 2$, the formation of small amounts of black particles was observed after the reaction. 


\section{Procedure UV: Ni catalysis with irradiation at $370 \mathrm{~nm}$}

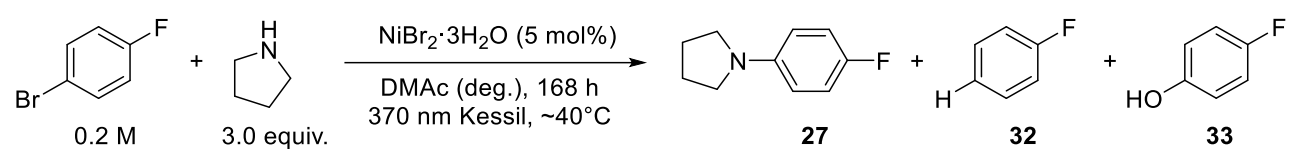

An oven dried vial (19 x $80 \mathrm{~mm})$ equipped with a stir bar was charged 4-bromofluorobenzene (210.0 mg, $131.8 \mu \mathrm{l}, 1.2 \mathrm{mmol}, 1.0$ equiv.) and $\mathrm{NiBr}_{2} \cdot 3 \mathrm{H}_{2} \mathrm{O}$ (16.4 mg, $60 \mu \mathrm{mol}, 5.0 \mathrm{~mol} \%$ ). Subsequently, pyrrolidine (256.0 mg, $295.6 \mu 1,3.6 \mathrm{mmol}, 3.0$ equiv.) and DMAc (anhydrous, $6 \mathrm{~mL}$ ) were added and the vial was sealed with a septum and Parafilm. The reaction mixture was sonicated for 5-10 min followed by stirring for $5 \mathrm{~min}$ and the mixture was then degassed by bubbling $\mathrm{N}_{2}$ for $10 \mathrm{~min}$. The mixture was irradiated with UV light using the Kessil ${ }^{\circledR}$ PR 160$370 \mathrm{~nm}$ lamp with rapid stirring ( $~ 800 \mathrm{rpm})$ and cooling by a fan. After $3 \mathrm{~h}$ (UV1), $15 \mathrm{~h}$ (UV2), $72 \mathrm{~h}$ (UV3) and $168 \mathrm{~h}$ (UV4) one equivalent of 1,3,5-trimethoxybenzene (202.0 mg, $1.2 \mathrm{mmol}$ ) was added and the mixture was stirred for $5 \mathrm{~min}$. An aliquot of the reaction mixture $(\sim 300 \mu \mathrm{L})$ was filtered, diluted with DMSO- $\mathrm{d}_{6}$ and subjected to ${ }^{1} \mathrm{H}-\mathrm{NMR}$ analysis.

Note: The color of the reaction solution changed from yellowish to black and a significant amount of black particles was formed.

The reaction mixtures of procedure A, B, and D were centrifuged at $3000 \mathrm{rpm}$ for $20 \mathrm{~min}$. The carbon nitride from the blue (procedure A) and green light experiment (procedure B) and the black particles formed during the UV-light experiment (procedure D) were washed with DMAc (anhydrous $6 \mathrm{~mL}$, followed by centrifugation at $3000 \mathrm{rpm}$ for $20 \mathrm{~min}$ and separation of the liquid phase) and acetone $(6 \mathrm{~mL}$, followed by centrifugation at $3000 \mathrm{rpm}$ for $20 \mathrm{~min}$ and separation of the liquid phase), lyophilized (overnight) and subjected to FTIR, UV-Vis, XRD, UV-Vis, ICP-OES, EDX, XPS as well as SEM and TEM analysis. For comparison, an unused sample of CN-OA-m from the same batch was also analyzed. 
Table S18. Coupling of 4-bromofluorobenzene and pyrrolidine using different light sources and catalysts.

\begin{tabular}{|c|c|c|c|c|c|}
\hline & $+\square_{3.0 \text { equiv. }}^{\mathrm{H}}$ & $\begin{array}{c}\text { Method } \mathrm{A} / \mathrm{B} / \mathrm{C} / \mathrm{D} \\
\mathrm{NiBr}_{2} \cdot 3 \mathrm{H}_{2} \mathrm{O}(5 \mathrm{~mol} \%)\end{array}$ & 27 & 32 & 3 \\
\hline Entry & Procedure & Conversion $[\%]^{\mathrm{a}}$ & $27[\%]^{b}$ & $32[\%]^{b}$ & $33[\%]^{b}$ \\
\hline 1 & A & 93 & 70 & 6 & 9 \\
\hline 2 & A & 92 & 69 & 7 & 8 \\
\hline 3 & A & 91 & 68 & 6 & 9 \\
\hline 4 & A & 92 & 63 & 7 & 6 \\
\hline 5 & A & 87 & 60 & 7 & 9 \\
\hline 6 & A & 18 & 6 & 2 & n.d. ${ }^{\mathrm{c}}$ \\
\hline 7 & A & 22 & 5 & n.d. & 3 \\
\hline 8 & B & quant. & 91 & 5 & 2 \\
\hline 9 & B & quant. & 89 & 1 & 10 \\
\hline 10 & B & quant. & 89 & 9 & 1 \\
\hline 11 & B & 99 & 86 & 9 & 2 \\
\hline 12 & B & quant. & 88 & 1 & 10 \\
\hline 13 & $\mathrm{~B}$ & 97 & 86 & 2 & 9 \\
\hline 14 & B & quant. & 84 & 9 & n.d. \\
\hline 15 & $\operatorname{Ir} 1$ & quant. & 77 & 7 & 4 \\
\hline 16 & $\operatorname{Ir} 2$ & 79 & 33 & 20 & 13 \\
\hline 17 & UV1 & 18 & 7 & 3 & n.d. \\
\hline 18 & UV2 & 39 & 17 & 9 & 4 \\
\hline 19 & UV3 & 94 & 26 & 32 & 16 \\
\hline 20 & UV4 & quant. & 10 & 23 & 9 \\
\hline
\end{tabular}

${ }^{a}$ Conversion of 4-bromofluorobenzene determined by ${ }^{1} \mathrm{H}-\mathrm{NMR}$ using 1,3,5-trimethoxybenzene as internal standard. ${ }^{b} \mathrm{NMR}$ yields determined by ${ }^{1} \mathrm{H}-\mathrm{NMR}$ using $1,3,5$-trimethoxybenzene as internal standard. ${ }^{\mathrm{c}}$ not detected. 


\subsection{Powder X-ray diffraction (XRD) and X-ray photoelectron spectroscopy (XPS)}

The powder X-ray diffraction spectra (PXRD) of the black material generated during the UVlight experiment (Table S18, Entry 17) showed diffraction peaks at $44^{\circ}, 51^{\circ}$ and $76^{\circ}$ that could be assigned to the (lll 111$),\left(\begin{array}{lll}2 & 0 & 0\end{array}\right),\left(\begin{array}{lll}2 & 2 & 0\end{array}\right)$ planes of nickel(0) (Figure S12). Spectra of the recovered CN-OA-m (Table 17, Entry $7 \& 8$ ) materials show a characteristic peak at $27.4^{\circ}$, which corresponds to the in-planar structural packing and inter-planar stacking peaks of the aromatic systems of CN-OA-m. Nickel(0) (diffraction peaks at $44^{\circ}, 51^{\circ}$ and $76^{\circ}$ ) was detected in the material recovered from experiment using blue LEDs (Method A), and, although in significantly lower quantity, in the material recovered from the experiment using green LEDs (Method B).

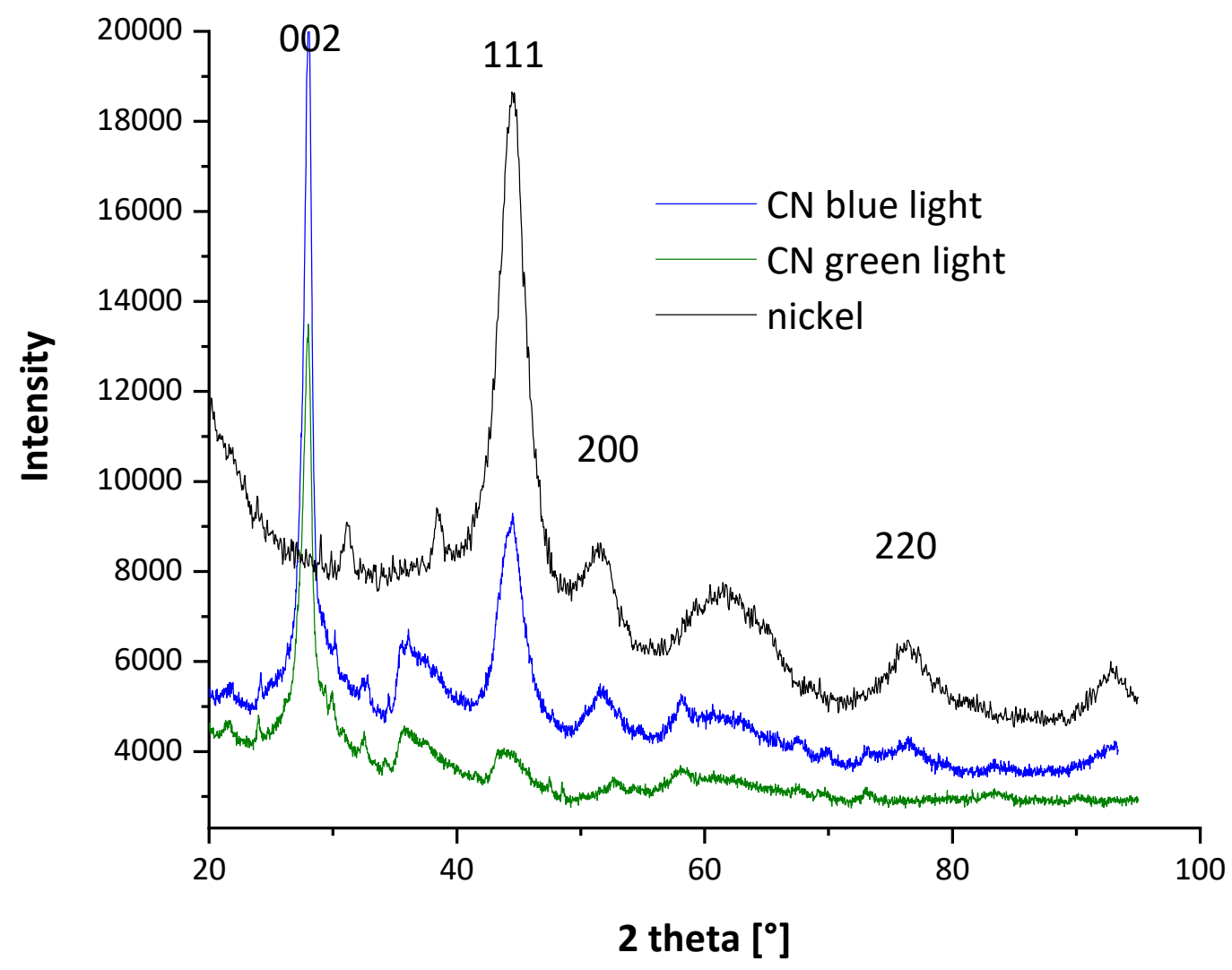

Figure S12. XRD measurements of the material generated by UV-light (black line), CN-OA$\mathrm{m}$ after method $\mathrm{A}$ with blue light irradiation (blue line) and CN-OA-m after method $\mathrm{B}$ with green light irradiation (green line). 
XPS scans of the solid material generated during UV light experiments and CN-OA-m recovered from the experiments using blue (Method A) and green LED (Method B) irradiation confirmed the presence of nickel in both samples (Figure S13). High-resolution XPS analysis spectra for core levels of $\mathrm{Ni} 2 \mathrm{p}$ confirm the presence of $\mathrm{Ni}^{2+}$ and $\mathrm{Ni}^{0}$ at $854.6( \pm 0.02) \mathrm{eV}$ and $852.3( \pm 0.02) \mathrm{eV}$, for CN-OA-m recovered from method A (blue light) and the material generated during UV light irradiation (Figure S13, A). Only $\mathrm{Ni}^{2+}(854.6( \pm 0.02) \mathrm{eV})$ species were detected in the CN-OA-m sample recovered from the experiment using method B (green light).The high-resolution XPS spectra of the C 1s core level spectra shows typical C-C and N$\mathrm{C}=\mathrm{N}$ bonding signals for all CN-OA-m samples (Figure S13, B). The $\mathrm{N}$ 1s spectra contain two main peaks that are typical for carbon nitrides and can be assigned to i) sp2 bonded nitrogen in tri-s-triazine groups $(\mathrm{C}-\mathrm{N}=\mathrm{C})$, and ii) sp3 amino groups $(\mathrm{C}-\mathrm{NH})$ for all $\mathrm{CN}-\mathrm{OA}-\mathrm{m}$ samples. The calculated elemental composition indicates a two times higher concentration of nickel on $\mathrm{CN}$ OA-m recovered from method A (blue light) compared to CN-OA-m recovered from method B (green light) (Table S19). 
A
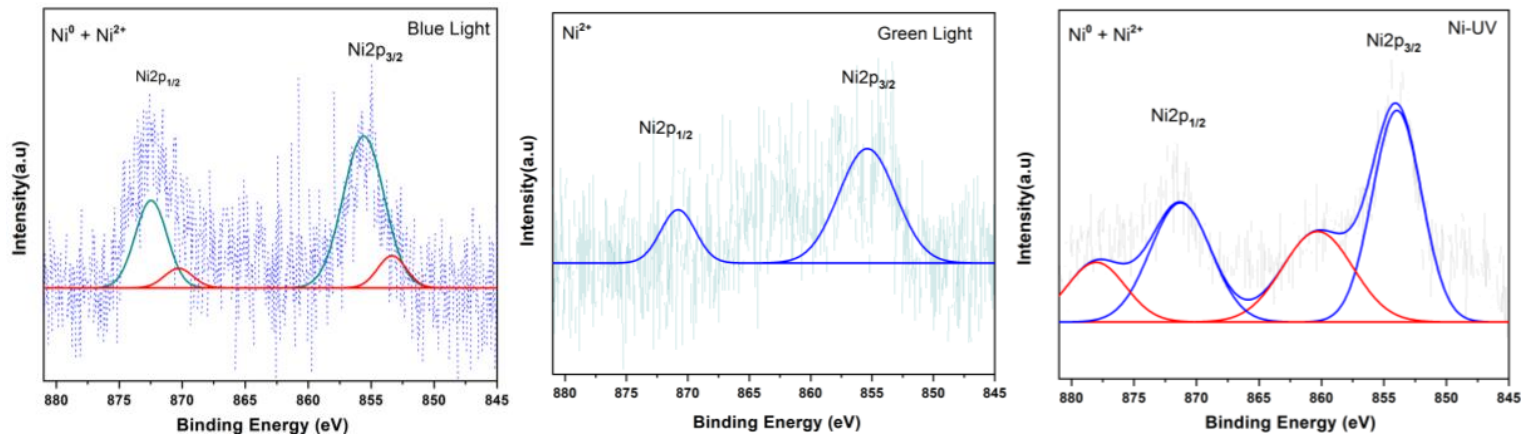

B
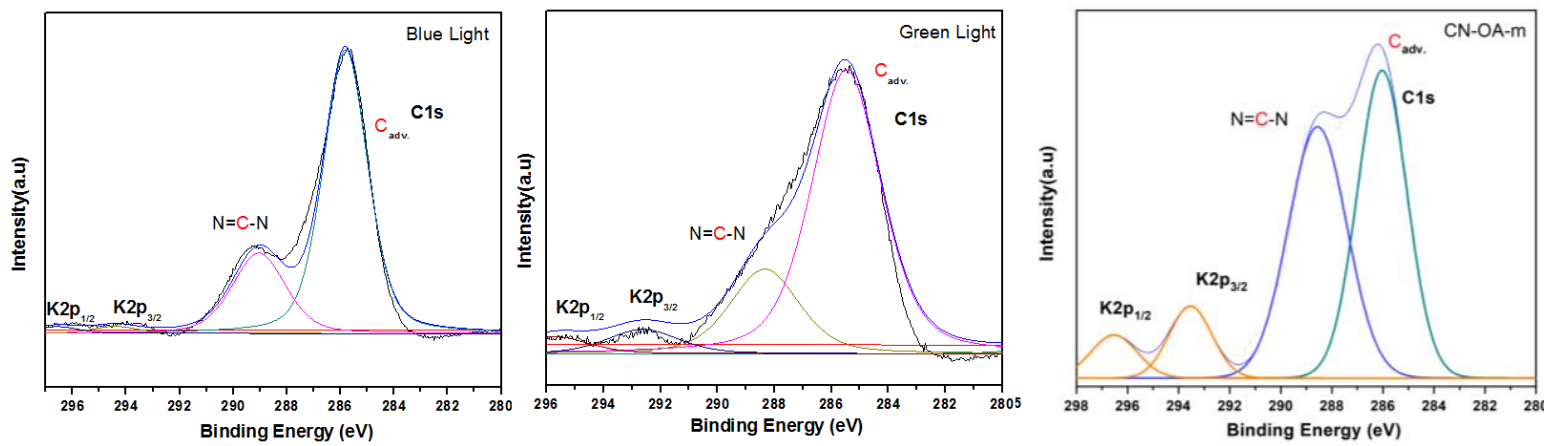

C
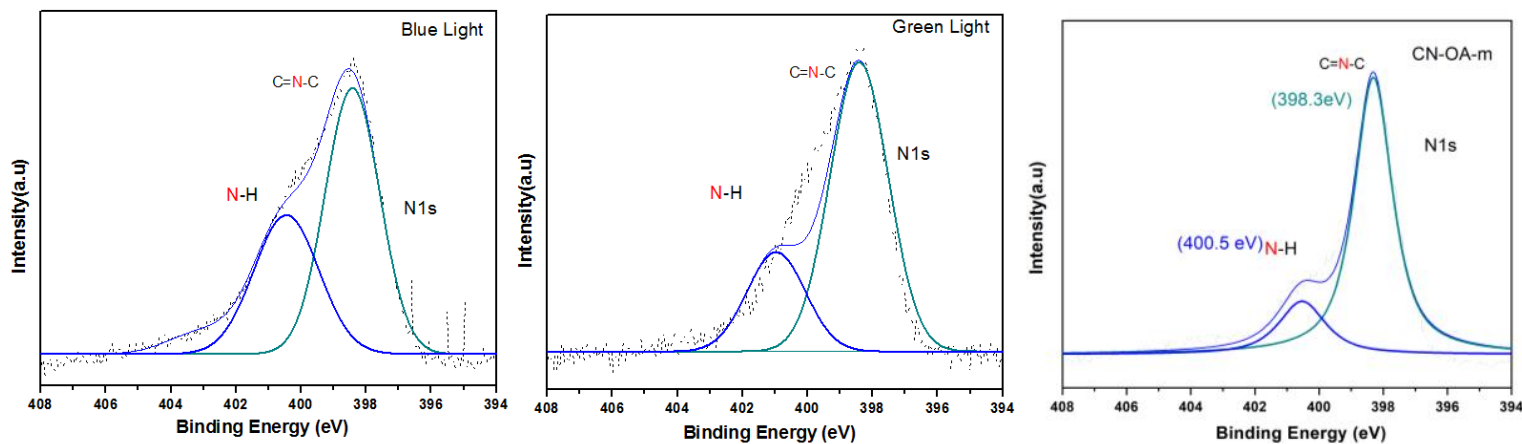

Figure S13. A) High-resolution XPS analysis spectra for core levels of Ni 2p $p_{3 / 2}$ : CN-OA-m recovered from experiments using method A (blue light) and method B (green light), and the heterogeneous material generated during UV-light experiments(Ni-UV). B) High-resolution XPS analysis spectra for core levels of $\mathrm{C} 1 \mathrm{~s}$ : CN-OA-m recovered from experiments using method A (blue light) and method B (green light), and unused CN-OA-m. C) High-resolution XPS analysis spectra for core levels of $\mathrm{N} \mathrm{1s}$ : CN-OA-m recovered from experiments using method A (blue light) and method B (green light), and unused CN-OA-m. has been deconvoluted using Lorenzian-Gaussian peak fitting functions with Shirley background deletion. 
Table S19. XPS Elemental composition of CN-OA-m and CN-OA-m recovered from experiments using method $\mathrm{A}$ and $\mathrm{B}$.

\begin{tabular}{|c|c|c|c|c|}
\hline Sample & $\% \mathrm{w} / \mathrm{w} \mathrm{N}$ & $\% \mathrm{w} / \mathrm{w} \mathrm{C}$ & $\% \mathrm{w} / \mathrm{w} \mathrm{K}$ & $\% \mathrm{w} / \mathrm{w} \mathrm{Ni}$ \\
\hline CN-OA-m & 57.257 & 41.191 & 1.552 & --- \\
\hline CN-OA-m blue light ${ }^{\mathrm{a}}$ & 61.094 & 37.718 & 0.365 & 0.822 \\
\hline CN-OA-m green light ${ }^{b}$ & 59.021 & 39.983 & 0.709 & 0.377 \\
\hline
\end{tabular}

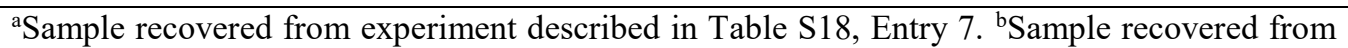
experiment described in Table S18, Entry 8.

\subsection{Scanning transmission electron microscopy (STEM)}

\subsubsection{CN-OA-m recovered from method A (blue LEDs) and method B (green LEDs)}

Scanning transmission electron microscopy (STEM) was used to visualize nickel particles on the surface of the recovered CN-OA-m. High-angle annular dark-field (HAADF) images show round- to oval-shaped particles with sizes ranging 10-20 nm. The polycrystalline particle consist of smaller ones (1-5 nm), which agglomerated on the surface (Figure S14 and S15). The images show the porous structure of $\mathrm{CN}-\mathrm{OA}-\mathrm{m}$ containing particles that show a diffraction pattern indicating Ni-species deposition. The exact lattice of a selected nickel particle is shown in higher resolution. The STEM images of CN-OA-m recovered from experiments using method B (green LED) (Figure S15) show a significantly lower amount of (agglomerated) nickel particles compared to using method A (blue LED, Figure S14). This confirms the results obtained using XRD (Figure S12), XPS (Figure S13), EDX (Table S20) and ICP-OES (Table S21) analysis. 


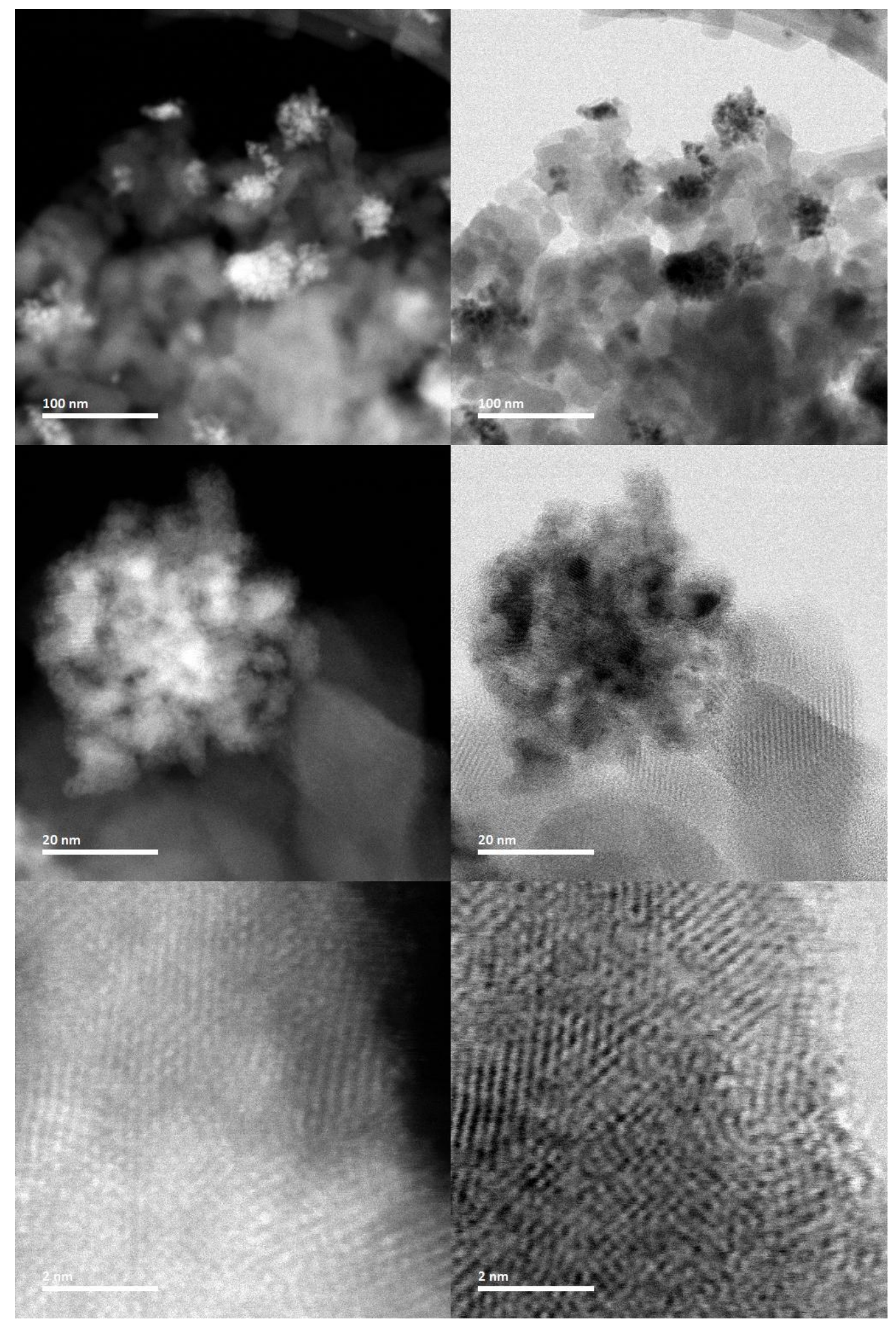

Figure S14. HAADF-STEM brightfield (left)/darkfield (right) images showing nickel particles (bright spots in brightfield and dark spots in darkfield) on CN-OA-m recovered from the experiment using method A (blue LED). 


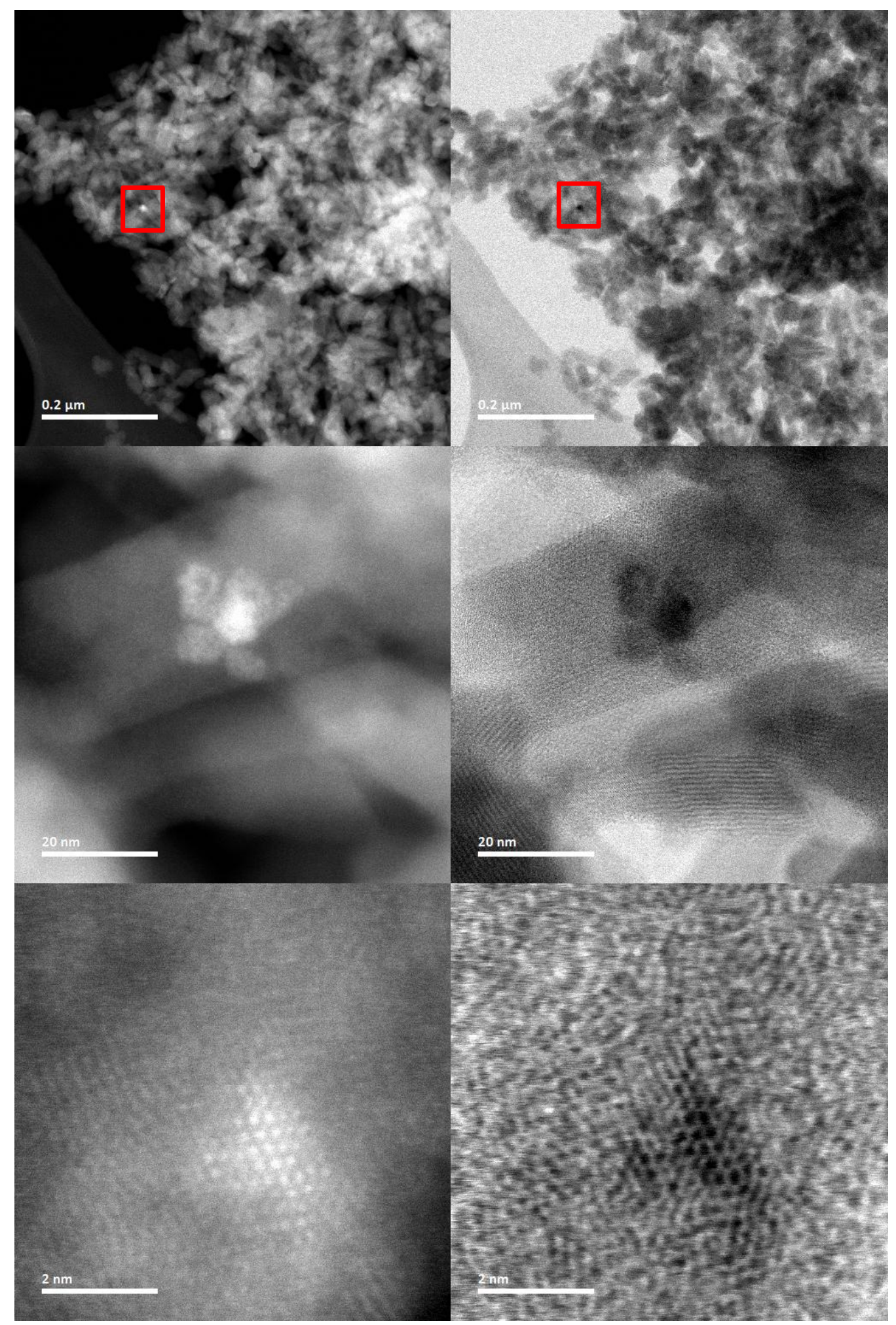

Figure S15. HAADF-STEM brightfield (left)/darkfield (right) showing a nickel particle (bright spot in brightfield and dark spot in darkfield) on CN-OA-m recovered from the experiment using method B (green LED). 


\subsubsection{Heterogeneous material generated during experiments using the UV method (photocatalyst-free and UV-light)}

The STEM image shows the solid material formed using method C (UV-light). Although the particle mainly consists of nickel, lighter elements can be additionally identified. EDX analysis (Table S20) shows the presence of carbon, indicating that agglomerated nickel species incorporate organic materials. This is in agreement with the low mass-balance observed during these reactions (e.g. Table S18, Entry 20), suggesting substrate/product degradation presumably by the high energy light source.

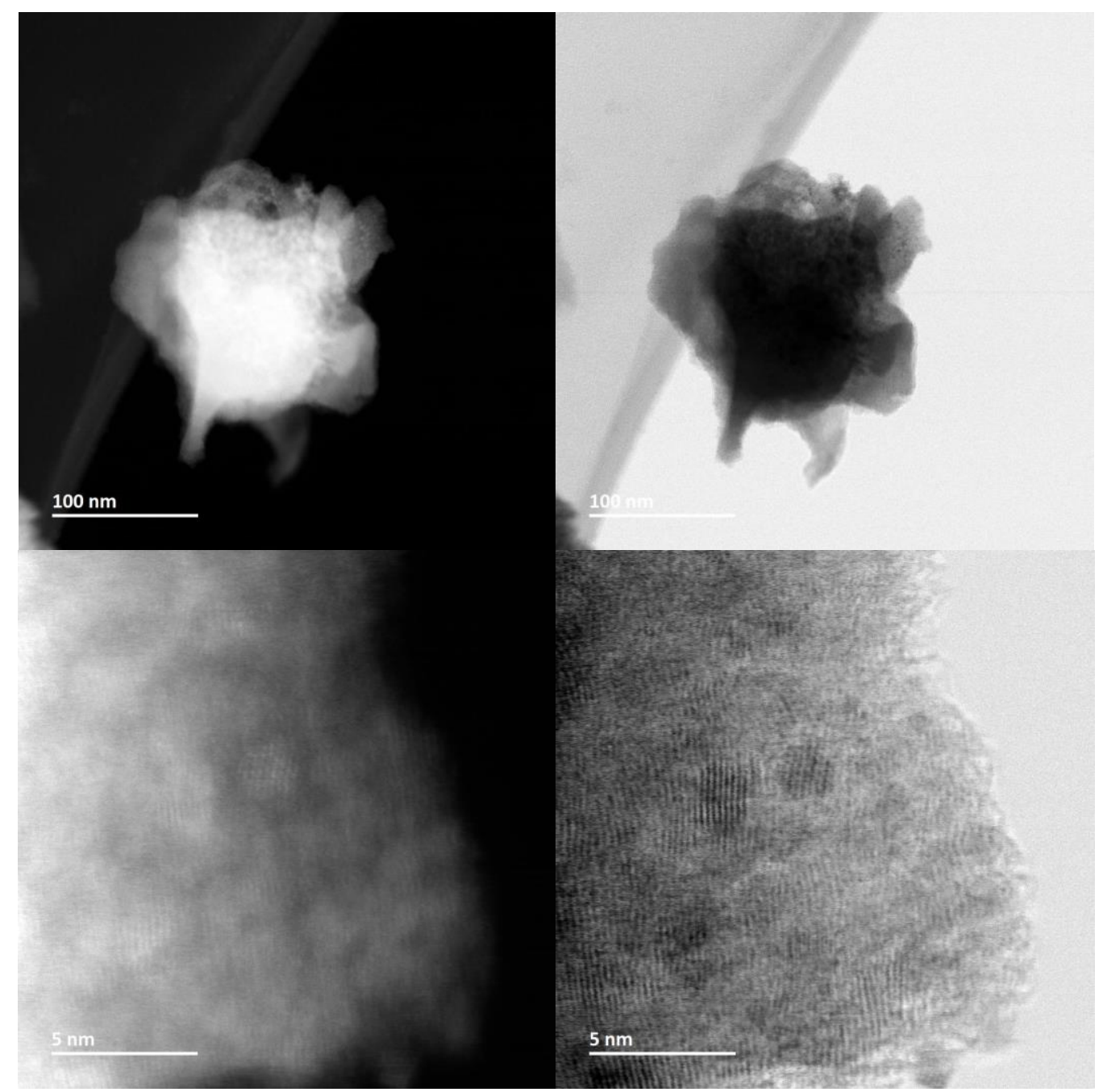

Figure S16. HAADF-STEM brightfield (left)/darkfield (right) images of nickel particles (bright spots in brightfield and dark spots in darkfield) after UV-light method (photocatalystfree). 


\subsection{Scanning electron microscopy (SEM)}

SEM images of the new and recovered CN-OA-m samples showed a porous texture that was not altered during the catalytic transformation (Figure S17).
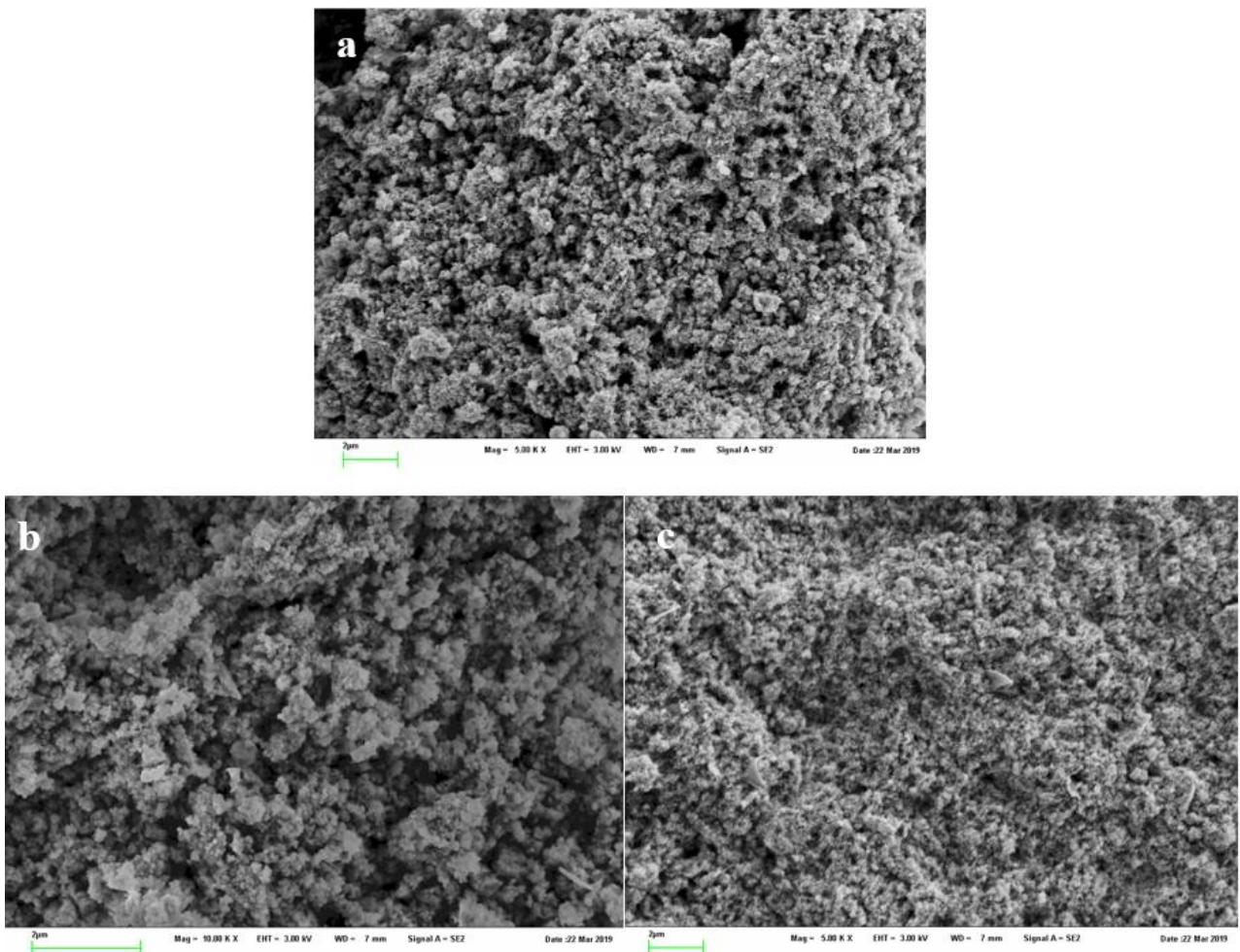

Figure S17- SEM images of CN-OA-m new (A), CN-OA-m recovered from the cross-coupling using blue light (Table S18, Entry 7) (B), and CN-OA-m recovered from the cross-coupling using green light (Table S18, Entry 8) (C). 


\subsection{Energy-dispersive X-ray spectroscopy (EDX) and inductively coupled plasma atomic emission spectroscopy (ICP-OES)}

Elemental analysis via EDX (Table S20) and ICP-OES (Table S21) analysis of the recovered CN-OA-m samples shows a 3 times higher Ni concentration for the blue light experiment. The material from the blue light experiment contains $\sim 12-14 \mathrm{w} / \mathrm{w} \% \mathrm{Ni}$ suggesting that $\sim 70 \%$ of the homogeneous nickel catalyst were deposited on the CN-OA-m during the model reaction. The material from the green light experiment contains $\sim 3-4 \mathrm{w} / \mathrm{w} \% \mathrm{Ni}$ suggesting that $\sim 70 \%$ of the homogeneous nickel catalyst were deposited on the CN-OA-m during the model reaction.

Table S20: EDX elemental composition acquired from new and recovered CN-OA-m.

\begin{tabular}{cccccc}
\hline Sample & $\% \mathrm{w} / \mathrm{w} \mathrm{N}$ & $\% \mathrm{w} / \mathrm{w} \mathrm{C}$ & $\% \mathrm{w} / \mathrm{w} \mathrm{O}$ & $\% \mathrm{w} / \mathrm{w} \mathrm{K}$ & $\% \mathrm{w} / \mathrm{w} \mathrm{Ni}$ \\
\hline CN-OA-m & 42.56 & 37.59 & 3.65 & 1.06 & 0.05 \\
$\begin{array}{c}\text { CN-OA-m from Method } \\
\quad \text { A (blue light) }\end{array}$ & 36.25 & 30.27 & 7.16 & 8.60 & 13.90 \\
$\begin{array}{c}\text { CN-OA-m from Method } \\
\text { B (green light) }\end{array}$ & 47.19 & 29.46 & 7.79 & 8.86 & 3.38 \\
$\begin{array}{c}\text { Solid from UV- } \\
\text { experiment }^{\mathbf{b}}\end{array}$ & 22.8 & 21.00 & 18.92 & - & 26.71 \\
\hline
\end{tabular}

aSample recovered from experiment described in Table S18, Entry 7. ' Sample recovered from experiment described in Table S18, Entry 8. 'Sample recovered from experiment described in Table S18, Entry 17.

Table S21: ICP-OES measurements of the nickel content on the new and recovered CN-OA-m.

\begin{tabular}{|c|c|c|}
\hline Sample & $\mathrm{Ni}[\mathrm{mg} / \mathrm{g} \mathrm{CN}]$ & $\%$ absorbed $\mathrm{Ni}$ \\
\hline CN-OA-m new & 0.69 & 0.39 \\
\hline $\begin{array}{c}\text { CN-OA-m from Method } \\
\text { A (blue light) }\end{array}$ & 126 & 71.2 \\
\hline $\begin{array}{l}\text { CN-OA-m from Method } \\
\text { B (green light) }\end{array}$ & 35.5 & 20.1 \\
\hline
\end{tabular}


8.5 Fourier-transform infrared spectroscopy (FTIR) and Ultraviolet-visible spectroscopy (UV-VIS)

FTIR spectra of the new and recovered CN-OA-m samples were identical (Figure S18).

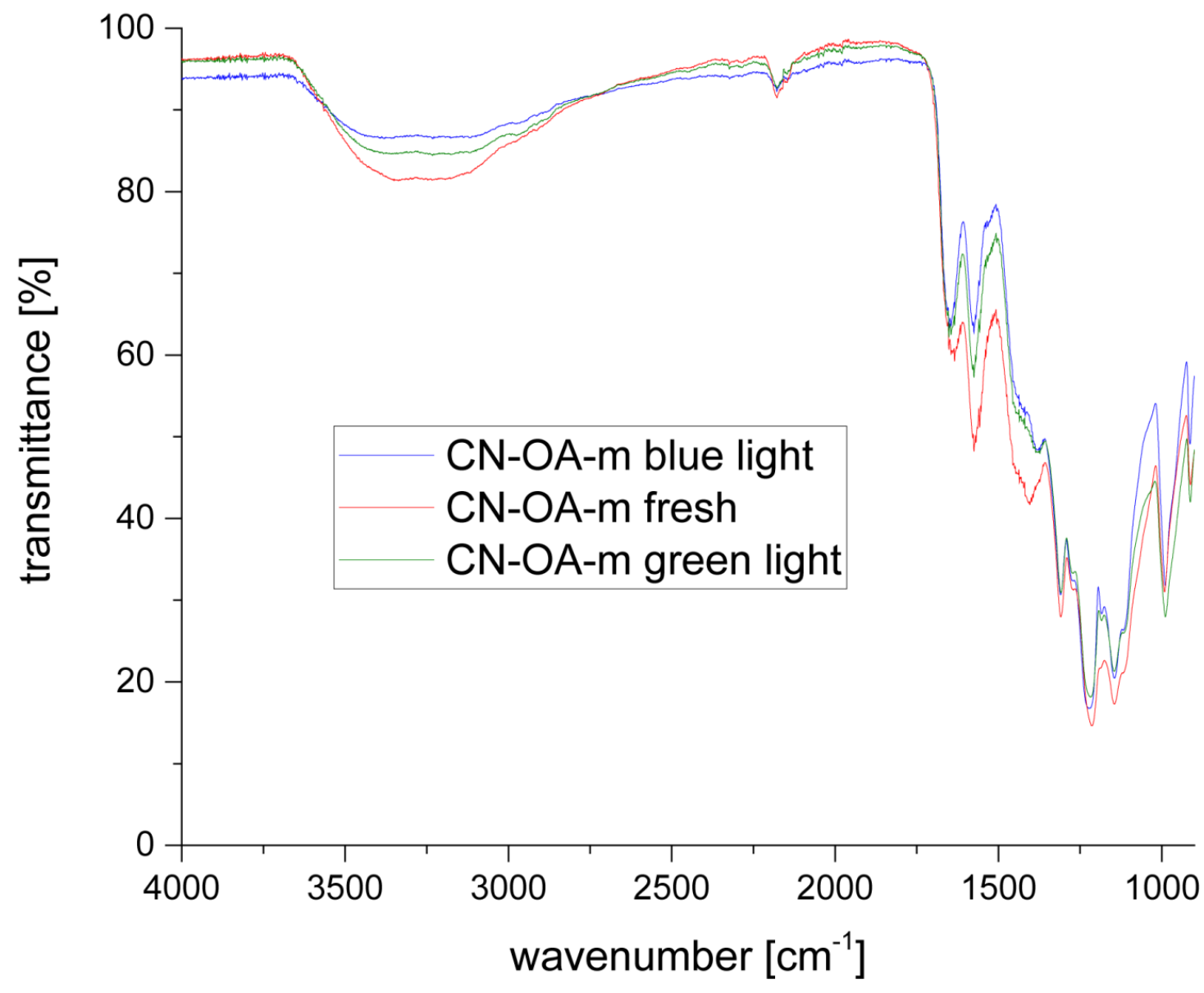

Figure S18. FTIR spectra of CN-OA-m new (red), CN-OA-m recovered from the crosscoupling using blue light (blue), and CN-OA-m recovered from the cross-coupling using green light (green). 
The UV-Vis spectra of the CN-OA-m recovered from the cross-coupling using green light and CN-OA-m recovered from the cross-coupling using blue showed an increased absorption in the visible region (>460 $\mathrm{nm}$ ) compared to a unused CN-OA-m sample.

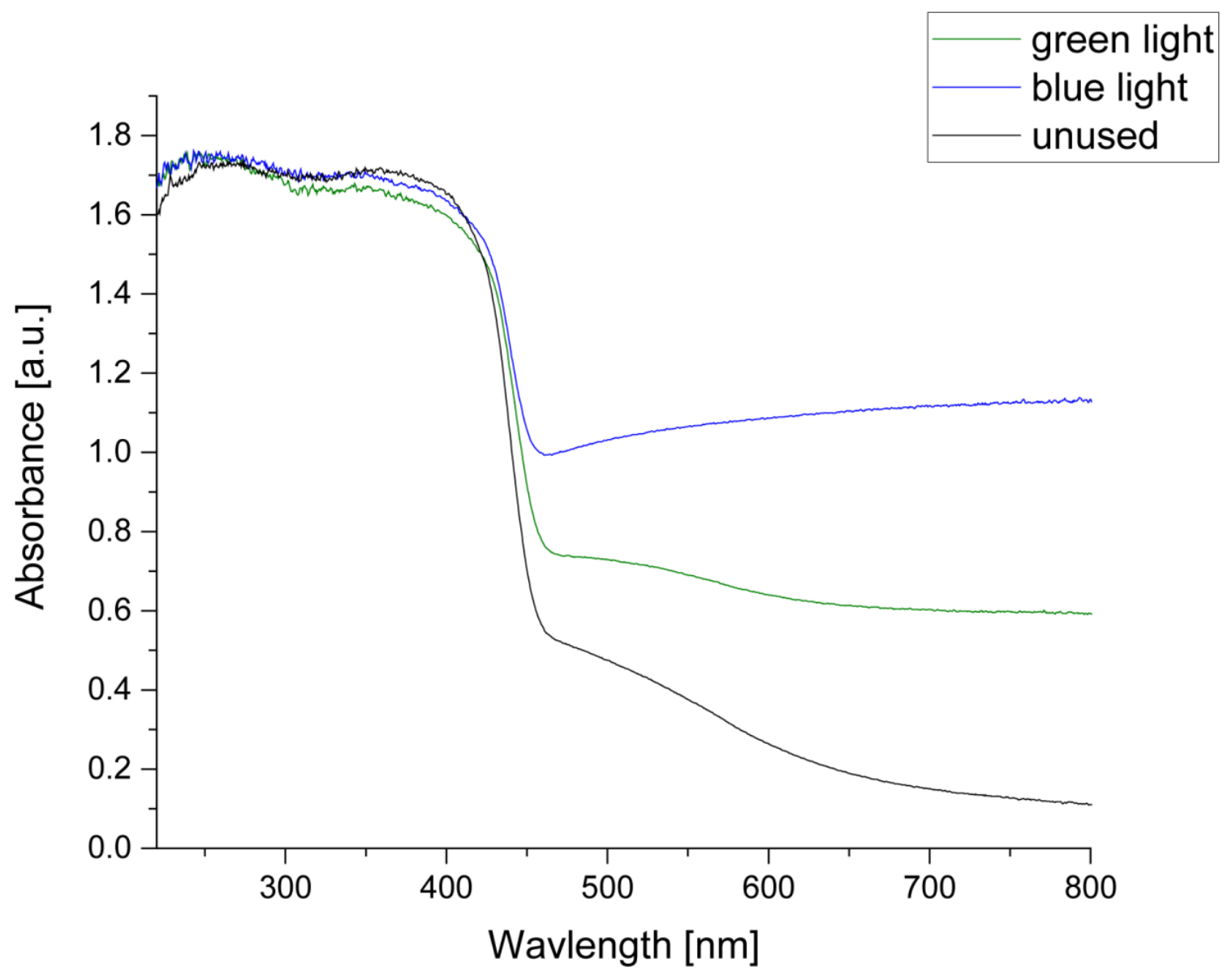

Figure S19. UV/Vis absorption spectra of CN-OA-m new (grey), CN-OA-m recovered from the cross-coupling using blue light (blue), and CN-OA-m recovered from the cross-coupling using green light (green). 


\section{Studies on the reaction of bromobenzene, 3-bromotoluene, 1-bromo- 4-tert-butylbenzene, and 4-bromoanisole with pyrrolidine.}

\section{Procedure A: Dual CN-OA-m/Ni catalysis with irradiation at $450 \mathrm{~nm}$}

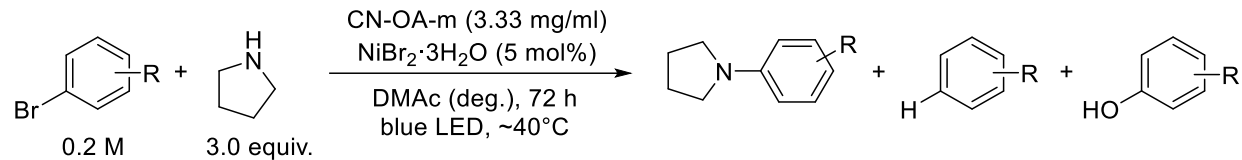

An oven dried vial $(19 \times 80 \mathrm{~mm})$ equipped with a stir bar was charged with the CN-OA-m (20 mg), aryl bromide (1.2 mmol, 1.0 equiv.) and $\mathrm{NiBr}_{2} \cdot 3 \mathrm{H}_{2} \mathrm{O}$ (16.4 mg, $60 \mu \mathrm{mol}, 5.0 \mathrm{~mol} \%$ ). Subsequently, pyrrolidine (256.0 mg, $295.6 \mu 1,3.6 \mathrm{mmol}, 3.0$ equiv.) and DMAc (anhydrous, $6 \mathrm{~mL}$ ) were added and the vial was sealed with a septum and Parafilm. The reaction mixture was sonicated for 5-10 min followed by stirring for 5 min until fine dispersion of the solids was achieved and the mixture was then degassed by bubbling $\mathrm{N}_{2}$ for $10 \mathrm{~min}$. The mixture was irradiated in the photoreactor (blue light function of RGB LED strip) at $40{ }^{\circ} \mathrm{C}$ with rapid stirring (1400 rpm). After $72 \mathrm{~h}$, one equivalent of 1,3,5-trimethoxybenzene (1.2 mmol) was added and the mixture was stirred for $5 \mathrm{~min}$. An aliquot of the reaction mixture $(\sim 300 \mu \mathrm{L})$ was filtered, diluted with DMSO- $\mathrm{d}_{6}$ and subjected to ${ }^{1} \mathrm{H}-\mathrm{NMR}$ analysis.

Procedure B: Dual CN-OA-m/Ni catalysis with irradiation at $520 \mathrm{~nm}$

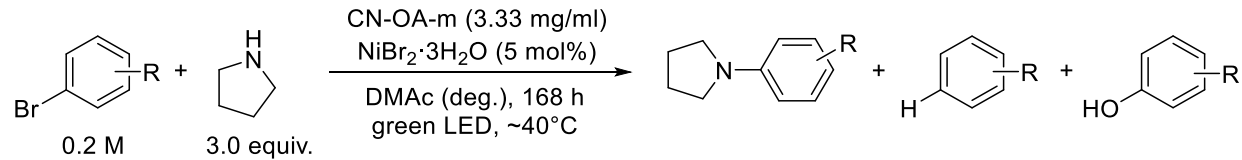

An oven dried vial $(19 \times 80 \mathrm{~mm})$ equipped with a stir bar was charged with the CN-OA-m (20 mg), aryl bromide (1.2 mmol, 1.0 equiv.) and $\mathrm{NiBr}_{2} \cdot 3 \mathrm{H}_{2} \mathrm{O}$ (16.4 mg, $60 \mu \mathrm{mol}, 5.0 \mathrm{~mol} \%$ ). Subsequently, pyrrolidine (256.0 mg, $295.6 \mu 1,3.6 \mathrm{mmol}, 3.0$ equiv.) and DMAc (anhydrous, $6 \mathrm{~mL}$ ) were added and the vial was sealed with a septum and Parafilm. The reaction mixture was sonicated for 5-10 min followed by stirring for $5 \mathrm{~min}$ until fine dispersion of the solids was achieved and the mixture was then degassed by bubbling $\mathrm{N}_{2}$ for $10 \mathrm{~min}$. The mixture was irradiated in the photoreactor (green light function of RGB LED strip) at $40{ }^{\circ} \mathrm{C}$ with rapid stirring (1400 rpm). After $168 \mathrm{~h}$, one equivalent of 1,3,5-trimethoxybenzene (1.2 mmol) was added and the mixture was stirred for $5 \mathrm{~min}$. An aliquot of the reaction mixture $(\sim 300 \mu \mathrm{L})$ was filtered, diluted with DMSO- $\mathrm{d}_{6}$ and subjected to ${ }^{1} \mathrm{H}-\mathrm{NMR}$ analysis. 


\section{Procedure C: Dual CN-OA-m/Ni catalysis with irradiation at $450 \mathrm{~nm}$ and higher concentration (1.2 M)}

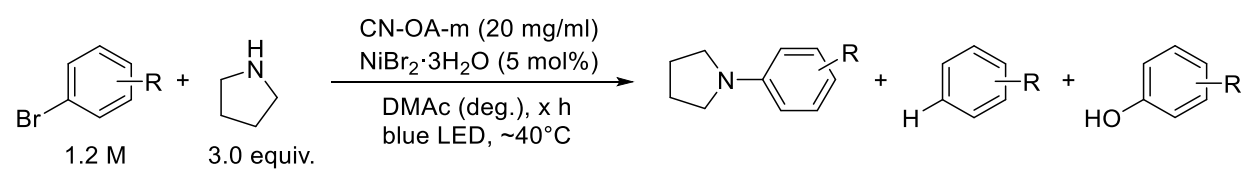

An oven dried vial $(19 \times 80 \mathrm{~mm})$ equipped with a stir bar was charged with the CN-OA-m (20 mg), aryl bromide (1.2 mmol, 1.0 equiv.) and $\mathrm{NiBr}_{2} \cdot 3 \mathrm{H}_{2} \mathrm{O}$ (16.4 mg, $60 \mu \mathrm{mol}, 5.0 \mathrm{~mol} \%$ ). Subsequently, pyrrolidine $(256.0 \mathrm{mg}, 295.6 \mu 1,3.6 \mathrm{mmol}, 3.0$ equiv.) and DMAc (anhydrous, $1 \mathrm{~mL}$ ) were added and the vial was sealed with a septum and Parafilm. The reaction mixture was sonicated for 5-10 min followed by stirring for 5 min until fine dispersion of the solids was achieved and the mixture was then degassed by bubbling $\mathrm{N}_{2}$ for $10 \mathrm{~min}$. The mixture was irradiated in the photoreactor (blue light function of RGB LED strip) at $40{ }^{\circ} \mathrm{C}$ with moderate stirring $(600 \mathrm{rpm})$. After respective reaction time, one equivalent of 1,3,5-trimethoxybenzene (202.0 mg, $1.2 \mathrm{mmol}$ ) was added and the mixture was stirred for $5 \mathrm{~min}$. An aliquot of the reaction mixture $(\sim 300 \mu \mathrm{L})$ was filtered, diluted with DMSO- $\mathrm{d}_{6}$ and subjected to ${ }^{1} \mathrm{H}-\mathrm{NMR}$ analysis. 
Table S22. Coupling of bromobenzene and pyrrolidine using methods A-C.

\begin{tabular}{|c|c|c|c|c|c|}
\hline & $+\square_{3.0 \text { equiv. }}^{\mathrm{H}}-$ & $\begin{array}{c}\mathrm{CN}-\mathrm{OA}-\mathrm{m}(20 \mathrm{mgl}) \\
\mathrm{NiBr}_{2} \cdot 3 \mathrm{H}_{2} \mathrm{O}(5 \mathrm{~mol} \%) \\
\mathrm{DMAC}(\mathrm{deg}), \sim 40^{\circ} \mathrm{C} \\
\text { Method A: } 0.2 \mathrm{M}, 72 \mathrm{~h}, 450 \mathrm{~nm} \\
\text { Method B: } 0.2 \mathrm{M}, 168 \mathrm{~h}, 520 \mathrm{~nm} \\
\text { Method C: } 1.2 \mathrm{M}, 24 \mathrm{~h}, 450 \mathrm{~nm}\end{array}$ & 28 & ${ }_{34}$ & 35 \\
\hline Entry & Procedure & Conversion $[\%]^{\mathrm{a}}$ & $28[\%]^{b}$ & $34[\%]^{b}$ & $35[\%]^{b}$ \\
\hline 1 & A & quant. & 74 & 8 & 11 \\
\hline 2 & A & quant. & 68 & 11 & 10 \\
\hline 3 & A & quant. & 67 & 11 & 12 \\
\hline 4 & A & quant. & 66 & 10 & 11 \\
\hline 5 & A & 67 & 44 & 7 & 6 \\
\hline 6 & A & 56 & 32 & 5 & 4 \\
\hline 7 & B & quant. & 94 & 4 & 3 \\
\hline 8 & B & quant. & 93 & 4 & 3 \\
\hline 9 & B & quant. & 91 & 5 & 5 \\
\hline 10 & B & quant. & 90 & 4 & 4 \\
\hline 11 & B & quant. & 88 & 4 & 5 \\
\hline 12 & B & quant. & 87 & 4 & 5 \\
\hline 13 & $\mathrm{C}$ & quant. & 86 & 8 & 4 \\
\hline 14 & $\mathrm{C}$ & quant. & 85 & 7 & 3 \\
\hline 15 & $\mathrm{C}$ & 99 & 85 & 8 & 3 \\
\hline 16 & $\mathrm{C}$ & quant. & 85 & 9 & 3 \\
\hline 17 & $\mathrm{C}$ & quant. & 84 & 8 & 3 \\
\hline 18 & $\mathrm{C}$ & quant. & 84 & 9 & 3 \\
\hline 19 & $\mathrm{C}^{\mathrm{d}}$ & quant. & 85 & 5 & 2 \\
\hline 20 & $\mathrm{C}^{\mathrm{d}}$ & quant. & 82 & 5 & 1 \\
\hline
\end{tabular}

${ }^{\mathrm{a}}$ Conversion of bromobenzene determined by ${ }^{1} \mathrm{H}-\mathrm{NMR}$ using 1,3,5-trimethoxybenzene as internal standard. ${ }^{b} \mathrm{NMR}$ yields determined by ${ }^{1} \mathrm{H}$-NMR using 1,3,5-trimethoxybenzene as internal standard. ${ }^{\mathrm{c}}$ not detected. ${ }^{\mathrm{d}}$ Carried out using $520 \mathrm{~nm}$ LEDs and $168 \mathrm{~h}$ reaction time. 
Table S23. Coupling of 3-bromotoluene and pyrrolidine using methods A-C.

\begin{tabular}{|c|c|c|c|c|c|}
\hline & {$\left[_{3.0 \text { equiv. }}^{H}-\right.$} & $\begin{array}{c}\mathrm{CN}-\mathrm{OA}-\mathrm{m}(20 \mathrm{mgl}) \\
\mathrm{NiBr}_{2} \cdot 3 \mathrm{H}_{2} \mathrm{O}(5 \mathrm{~mol} \%) \\
\mathrm{DMAc}(\mathrm{deg}), \sim 40^{\circ} \mathrm{C} \\
\text { Method A: } 0.2 \mathrm{M}, 72 \mathrm{~h}, 450 \mathrm{~nm} \\
\text { Method B: } 0.2 \mathrm{M}, 168 \mathrm{~h}, 520 \mathrm{~nm} \\
\text { Method C: } 1.2 \mathrm{M}, 48 \mathrm{~h}, 450 \mathrm{~nm}\end{array}$ & 29 & 36 & 37 \\
\hline Entry & Procedure & Conversion $[\%]^{a}$ & $29[\%]^{b}$ & $36[\%]^{b}$ & $37[\%]^{b}$ \\
\hline 1 & $\mathrm{~A}$ & quant. & 74 & 17 & 6 \\
\hline 2 & A & quant. & 72 & 17 & 6 \\
\hline 3 & A & quant. & 72 & 18 & 4 \\
\hline 4 & A & quant. & 61 & 18 & 12 \\
\hline 5 & $\mathrm{~A}$ & 64 & 31 & 12 & 9 \\
\hline 6 & A & 52 & 20 & 13 & 8 \\
\hline 7 & B & quant. & 93 & 5 & 4 \\
\hline 8 & B & quant. & 86 & 10 & 4 \\
\hline 9 & B & quant. & 85 & 10 & 5 \\
\hline 10 & $\mathrm{~B}$ & quant. & 84 & 10 & 5 \\
\hline 11 & $\mathrm{~B}$ & quant. & 84 & 10 & 7 \\
\hline 12 & B & quant. & 83 & 10 & 6 \\
\hline 13 & $\mathrm{C}$ & quant. & 85 & 14 & 2 \\
\hline 14 & $\mathrm{C}$ & quant. & 84 & 14 & 3 \\
\hline 15 & $\mathrm{C}$ & quant. & 83 & 14 & 3 \\
\hline 16 & $\mathrm{C}$ & quant. & 83 & 14 & 3 \\
\hline 17 & $\mathrm{C}$ & quant. & 82 & 15 & 3 \\
\hline 18 & $\mathrm{C}$ & quant. & 81 & 16 & 3 \\
\hline 19 & $C^{d}$ & quant. & 80 & 6 & 0 \\
\hline
\end{tabular}

${ }^{\mathrm{a}}$ Conversion of 3-bromotoluene determined by ${ }^{1} \mathrm{H}-\mathrm{NMR}$ using 1,3,5-trimethoxybenzene as internal standard.

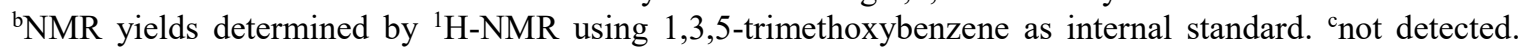
${ }^{\mathrm{d}}$ Carried out using $520 \mathrm{~nm}$ LEDs and $168 \mathrm{~h}$ reaction time. 
Table S24. Coupling of 4-bromotertbutylbenzene and pyrrolidine using methods A-C.

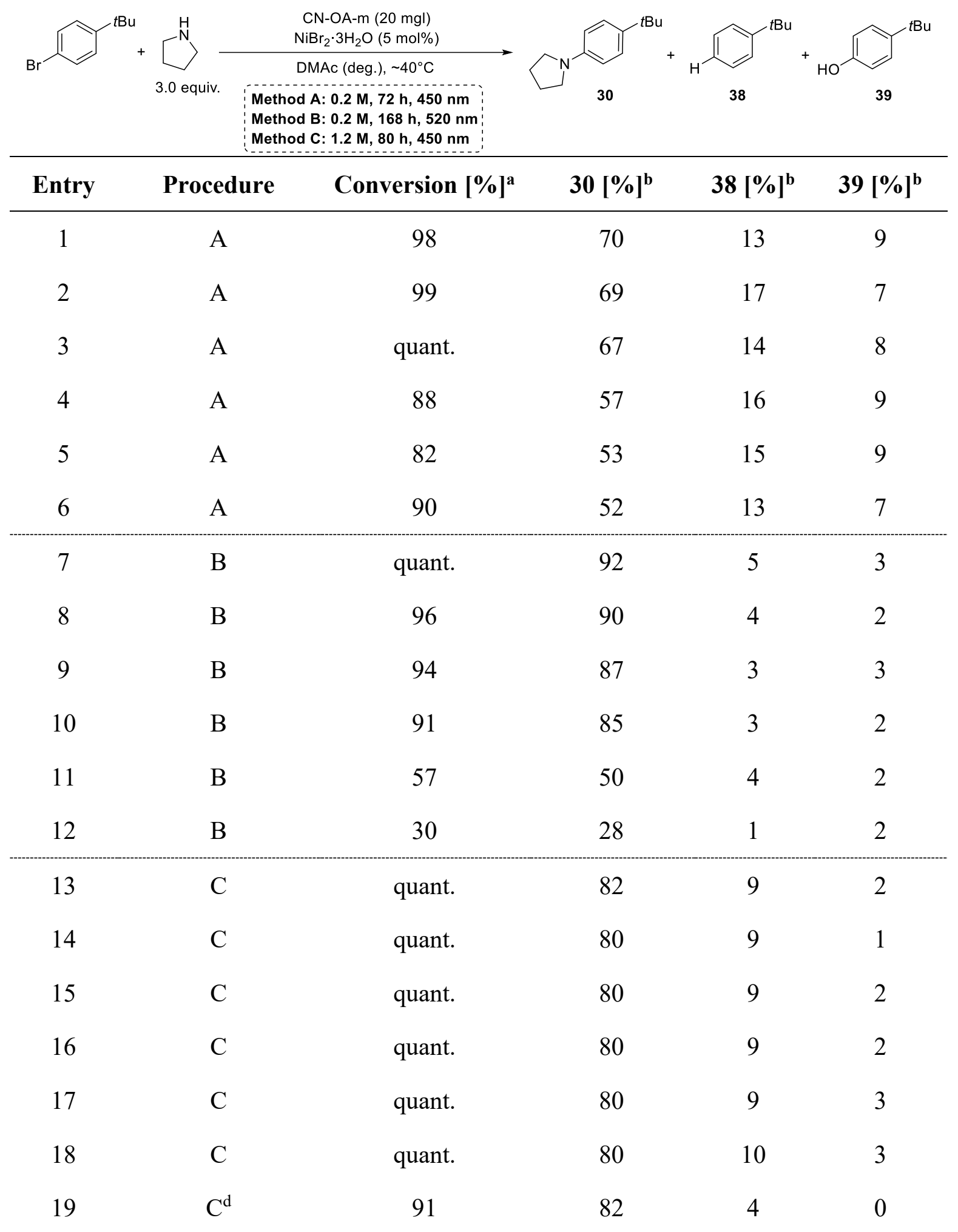

${ }^{\mathrm{a}}$ Conversion of 4-bromotertbutylbenzene determined by ${ }^{1} \mathrm{H}-\mathrm{NMR}$ using 1,3,5-trimethoxybenzene as internal standard. ${ }^{b} \mathrm{NMR}$ yields determined by ${ }^{1} \mathrm{H}-\mathrm{NMR}$ using 1,3,5-trimethoxybenzene as internal standard. ${ }^{\mathrm{c} n o t}$ detected. ${ }^{\mathrm{d} C a r r i e d}$ out using $520 \mathrm{~nm}$ LEDs and $72 \mathrm{~h}$ reaction time. 
Table S25. Coupling of 4-bromoansiole and pyrrolidine using methods A-C.

\begin{tabular}{|c|c|c|c|c|c|}
\hline \multirow[b]{2}{*}{ Entry } & $+\square_{3.0 \text { equiv. }}^{\stackrel{\mathrm{H}}{\mathrm{N}}-}$ & $\begin{array}{l}\mathrm{V}-\mathrm{OA}-\mathrm{m}(20 \mathrm{mgl}) \\
\mathrm{r}_{2} \cdot 3 \mathrm{H}_{2} \mathrm{O}(5 \mathrm{~mol} \%) \\
\mathrm{Ac}(\mathrm{deg}), \sim 40^{\circ} \mathrm{C} \\
0.2 \mathrm{M}, 72 \mathrm{~h}, 450 \mathrm{~nm} \\
0.2 \mathrm{M}, 168 \mathrm{~h}, 520 \mathrm{~nm} \\
1.2 \mathrm{M}, 96 \mathrm{~h}, 450 \mathrm{~nm}\end{array}$ & 31 & 40 & 41 \\
\hline & Procedure & Conversion $[\%]^{\mathrm{a}}$ & $31[\%]^{b}$ & $40[\%]^{b}$ & $41[\%]^{b}$ \\
\hline 1 & A & 86 & 80 & 6 & n.d. ${ }^{\mathrm{c}}$ \\
\hline 2 & A & 91 & 78 & 12 & 2 \\
\hline 3 & A & 90 & 72 & 10 & 5 \\
\hline 4 & A & 66 & 53 & 8 & 2 \\
\hline 5 & A & 43 & 32 & 4 & 2 \\
\hline 6 & A & 13 & 4 & n.d. & 2 \\
\hline 7 & $\mathrm{~B}$ & 82 & 77 & 7 & 0 \\
\hline 8 & B & 83 & 77 & 6 & 0 \\
\hline 9 & $\mathrm{~B}$ & 76 & 68 & 6 & 0 \\
\hline 10 & B & 68 & 60 & 4 & 4 \\
\hline 11 & B & 68 & 60 & 4 & 3 \\
\hline 12 & B & 58 & 52 & 4 & 2 \\
\hline 13 & $\mathrm{C}$ & quant. & 81 & 8 & 5 \\
\hline 14 & $\mathrm{C}$ & quant. & 80 & 11 & 5 \\
\hline 15 & $\mathrm{C}$ & quant. & 80 & 11 & 5 \\
\hline 16 & $\mathrm{C}$ & quant. & 80 & 8 & 4 \\
\hline 17 & $\mathrm{C}$ & quant. & 79 & 11 & 4 \\
\hline 18 & $\mathrm{C}$ & quant. & 77 & 9 & 6 \\
\hline 19 & $\mathrm{C}^{\mathrm{d}}$ & quant. & 84 & 8 & 1 \\
\hline 20 & $\mathrm{C}^{\mathrm{d}}$ & quant. & 83 & 8 & 0 \\
\hline
\end{tabular}

${ }^{\mathrm{a}}$ Conversion of 4-bromoanisole determined by ${ }^{1} \mathrm{H}$-NMR using 1,3,5-trimethoxybenzene as internal standard. ${ }^{b} \mathrm{NMR}$ yields determined by ${ }^{1} \mathrm{H}-\mathrm{NMR}$ using 1,3,5-trimethoxybenzene as internal standard. ${ }^{\mathrm{c}}$ not detected. ${ }^{\mathrm{d}}$ Carried out using $520 \mathrm{~nm}$ LEDs and $168 \mathrm{~h}$ reaction time. 


\section{Studies on the reaction of methyl 4-chlorobenzoate}

\section{Procedure A: Dual CN-OA-m/Ni catalysis with irradiation at $450 \mathrm{~nm}$}

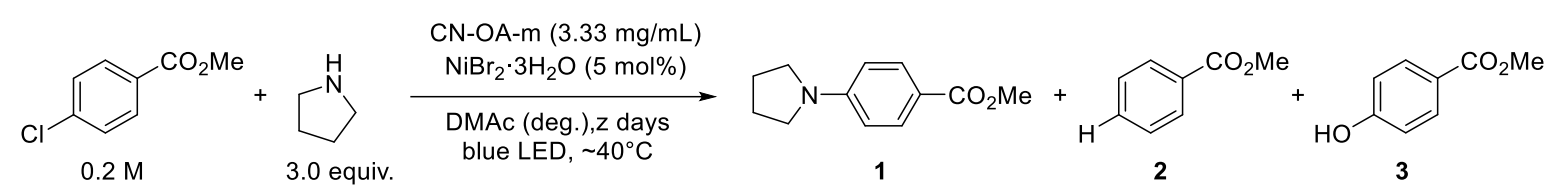

An oven dried vial $(19 \times 80 \mathrm{~mm})$ equipped with a stir bar was charged with the CN-OA-m (20 mg), methyl 4-chloromethylbenzoate (204.7 mg, $1.2 \mathrm{mmol}, 1.0$ equiv.) and $\mathrm{NiBr}_{2} \cdot 3 \mathrm{H}_{2} \mathrm{O}$ (16.4 mg, $60 \mu \mathrm{mol}, 5.0 \mathrm{~mol} \%$ ). Subsequently, pyrrolidine (64.0 mg, $295.6 \mu 1,3.6 \mathrm{mmol}, 3.0$ equiv.) and DMAc (anhydrous, $6 \mathrm{~mL}$ ) were added and the vial was sealed with a septum and Parafilm. The reaction mixture was sonicated for 5-10 min followed by stirring for 5 min until fine dispersion of the solids was achieved and the mixture was then degassed by bubbling $\mathrm{N}_{2}$ for $10 \mathrm{~min}$. The mixture was irradiated in the photoreactor (blue light of LED-band) at $40{ }^{\circ} \mathrm{C}$ with rapid stirring (1400 rpm). After respective reaction time, one equivalent of 1,3,5trimethoxybenzene $(202.0 \mathrm{mg}, 1.2 \mathrm{mmol}$ ) was added and the mixture was stirred for $5 \mathrm{~min}$. An aliquot of the reaction mixture $(\sim 300 \mu \mathrm{L})$ was filtered, diluted with DMSO-d 6 and subjected to ${ }^{1} \mathrm{H}-\mathrm{NMR}$ analysis.

\section{Procedure B: Dual CN-OA-m/Ni catalysis with irradiation at $520 \mathrm{~nm}$}

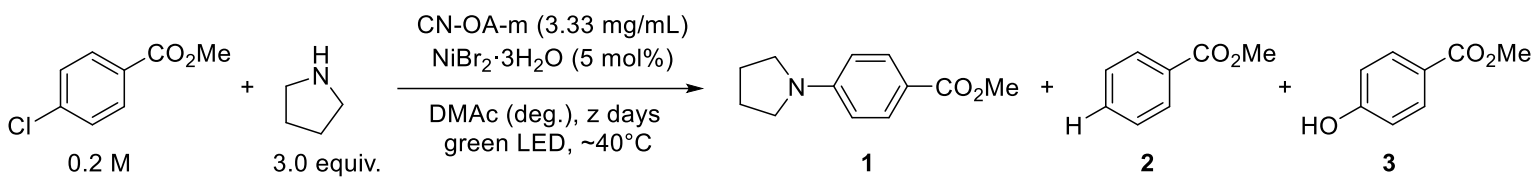

An oven dried vial $(19 \times 80 \mathrm{~mm})$ equipped with a stir bar was charged with the CN-OA-m (20 mg), methyl 4-chloromethylbenzoate (204.7 mg, $1.2 \mathrm{mmol}, 1.0$ equiv.) and $\mathrm{NiBr}_{2} \cdot 3 \mathrm{H}_{2} \mathrm{O}$ (16.4 mg, $60 \mu \mathrm{mol}, 5.0 \mathrm{~mol} \%$ ). Subsequently, pyrrolidine (64.0 mg, $295.6 \mu 1,3.6 \mathrm{mmol}, 3.0$ equiv.) and DMAc (anhydrous, $6 \mathrm{~mL}$ ) were added and the vial was sealed with a septum and Parafilm. The reaction mixture was sonicated for 5-10 min followed by stirring for $5 \mathrm{~min}$ until fine dispersion of the solids was achieved and the mixture was then degassed by bubbling $\mathrm{N}_{2}$ for $10 \mathrm{~min}$. The mixture was irradiated in the photoreactor (blue light of LED-band) at $40{ }^{\circ} \mathrm{C}$ with rapid stirring (1400 rpm). After respective reaction time, one equivalent of 1,3,5trimethoxybenzene $(202.0 \mathrm{mg}, 1.2 \mathrm{mmol}$ ) was added and the mixture was stirred for $5 \mathrm{~min}$. An aliquot of the reaction mixture $(\sim 300 \mu \mathrm{L})$ was filtered, diluted with DMSO-d $\mathrm{d}_{6}$ and subjected to ${ }^{1} \mathrm{H}-\mathrm{NMR}$ analysis. 


\section{Procedure C: Dual CN-OA-m/Ni catalysis with irradiation at $450 \mathrm{~nm}$ and higher concentration (1.2 M)}

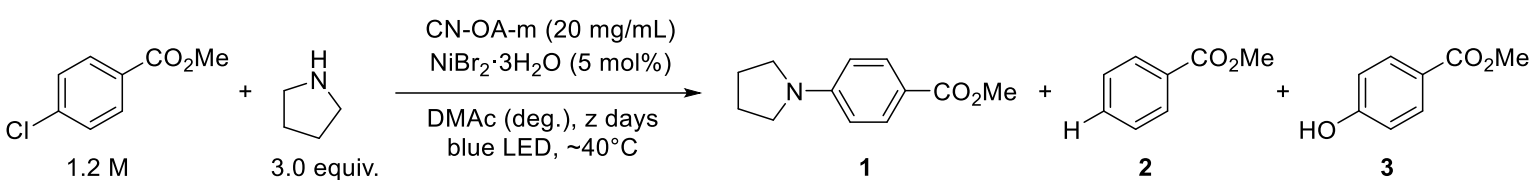

An oven dried vial $(19 \times 80 \mathrm{~mm})$ equipped with a stir bar was charged with the CN-OA-m (20 mg), methyl 4-chloromethylbenzoate (204.7 mg, $1.2 \mathrm{mmol}, 1.0$ equiv.) and $\mathrm{NiBr}_{2} \cdot 3 \mathrm{H}_{2} \mathrm{O}$ (16.4 mg, $60 \mu \mathrm{mol}, 5.0 \mathrm{~mol} \%$ ). Subsequently, pyrrolidine (64.0 mg, $295.6 \mu 1,3.6 \mathrm{mmol}, 3.0$ equiv.) and DMAc (anhydrous, $1 \mathrm{~mL}$ ) were added and the vial was sealed with a septum and Parafilm. The reaction mixture was sonicated for 5-10 min followed by stirring for $5 \mathrm{~min}$ until fine dispersion of the solids was achieved and the mixture was then degassed by bubbling $\mathrm{N}_{2}$ for $10 \mathrm{~min}$. The mixture was irradiated in the photoreactor (blue light or green function of LEDband) at $40{ }^{\circ} \mathrm{C}$ with moderate stirring $(600 \mathrm{rpm})$. After respective reaction time, one equivalent of 1,3,5-trimethoxybenzene (202.0 $\mathrm{mg}, 1.2 \mathrm{mmol}$ ) was added and the mixture was stirred for 5 min. An aliquot of the reaction mixture $(\sim 300 \mu \mathrm{L})$ was filtered, diluted with DMSO-d $\mathrm{d}_{6}$ and subjected to ${ }^{1} \mathrm{H}-\mathrm{NMR}$ analysis. 
Table S26. Coupling of methyl 4-chlorobenzoate and pyrrolidine using methods A-C.

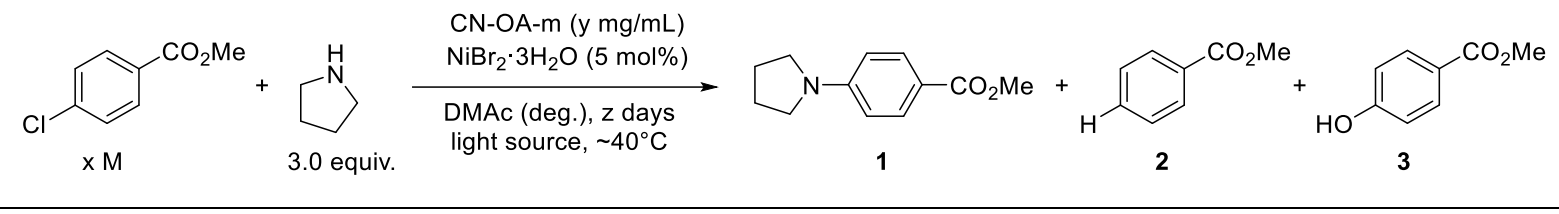

\begin{tabular}{|c|c|c|c|c|c|c|}
\hline Entry & Method & Time [days] & Conversion $[\%]^{\mathrm{a}}$ & $1[\%]^{b}$ & $2[\%]^{b}$ & $3[\%]^{b}$ \\
\hline 1 & $\mathrm{~A}$ & 3 & 47 & 37 & 2 & n.d. ${ }^{\mathrm{c}}$ \\
\hline 2 & $\mathrm{~A}$ & 7 & 78 & 65 & 7 & 3 \\
\hline 3 & $\mathrm{~A}$ & 14 & 91 & 65 & 16 & 7 \\
\hline 4 & $\mathrm{~B}$ & 3 & 59 & 41 & 1 & 12 \\
\hline 5 & $\mathrm{~B}$ & 7 & 76 & 72 & 4 & n.d. \\
\hline 6 & B & 14 & 89 & 83 & n.d. & 9 \\
\hline 7 & $\mathrm{C}$ & 1 & 79 & 75 & 3 & 1 \\
\hline 8 & $\mathrm{C}$ & 2 & 97 & 92 & 3 & 2 \\
\hline 9 & $\mathrm{C}$ & 3 & 97 & 89 & 4 & 2 \\
\hline 10 & $\mathrm{C}$ & 4 & 99 & 89 & 3 & 2 \\
\hline
\end{tabular}

${ }^{\mathrm{a}}$ Conversion of methyl 4-chlorobenzoate determined by ${ }^{1} \mathrm{H}$-NMR using 1,3,5-trimethoxybenzene as internal standard. ${ }^{b} \mathrm{NMR}$ yields determined by ${ }^{1} \mathrm{H}-\mathrm{NMR}$ using $1,3,5$-trimethoxybenzene as internal standard. ${ }^{\mathrm{c}}$ not detected 


\section{Scope and limitations}

General experimental procedure. An oven dried vial $(13 \times 95 \mathrm{~mm})$ equipped with a stir bar was charged with $\mathrm{NiBr}_{2} \cdot 3 \mathrm{H}_{2} \mathrm{O}(8.2 \mathrm{mg}, 30 \mu \mathrm{mol}, 2.5 \mathrm{~mol} \%$ ), aryl bromide (1.2 mmol, 1 equiv.) and CN-OA-m (20 mg). Subsequently, the amine (3.6 mmol, 3 equiv.) and DMAc (anhydrous, $6 \mathrm{~mL}$ ) were added and the vial was sealed with a septum and parafilm. The reaction mixture was sonicated for 5-10 min and the mixture was then degassed by bubbling $\mathrm{N}_{2}$ for $10 \mathrm{~min}$. The mixture was irradiated in the batch reactor (described above) at $40^{\circ} \mathrm{C}$ with rapid stirring $(1400$ $\mathrm{rpm})$. After the respective reaction time, one equivalent of 1,3,5-trimethoxybenzene $(202.0 \mathrm{mg}$, $1.2 \mathrm{mmol}$, internal standard) was added. An aliquot $(\sim 300 \mu \mathrm{L})$ of the reaction mixture was diluted with DMSO- $\mathrm{d}_{6}$ and subjected to ${ }^{1} \mathrm{H}-\mathrm{NMR}$ analysis. After full consumption of the arene starting material, the liquid phase was diluted with $\mathrm{H}_{2} \mathrm{O}(40 \mathrm{~mL})$ and extracted with ethyl acetate ( 3 x $30 \mathrm{~mL}$ ). The combined organic phases were washed with $\mathrm{H}_{2} \mathrm{O}(40 \mathrm{~mL}), \mathrm{NaHCO}_{3}$ solution $(40 \mathrm{ml})$ and brine $(40 \mathrm{~mL})$, dried over $\mathrm{Na}_{2} \mathrm{SO}_{4}$ and concentrated. The crude product was purified by flash column chromatography $\left(\mathrm{SiO}_{2}\right.$, Hexane/EtOAc, dichloromethane/EtOAc or dichloromethane $/ \mathrm{MeOH}$ ) on a Grace ${ }^{\mathrm{TM}}$ Reveleris ${ }^{\mathrm{TM}}$ system using a $12 \mathrm{~g}$ cartridge to afford the desired product. The final product was characterized by ${ }^{1} \mathrm{H}-\mathrm{NMR},{ }^{13} \mathrm{C}-\mathrm{NMR},{ }^{19} \mathrm{~F}-\mathrm{NMR}$ and HRMS (ESI-TOF).

\section{Unsuccessful amines}<smiles>C=CCNCC=C</smiles><smiles>CC(C)(C)N</smiles><smiles>CCNCC</smiles><smiles>CC(C)Nc1ccccc1</smiles><smiles>c1ccc(Nc2ccccc2)cc1</smiles> 


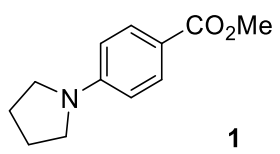

1-(4-methylbenzoate)pyrrolidine. From pyrrolidine $(256.0 \mathrm{mg}, 295.6 \mu 1,3.6 \mathrm{mmol}, 3.0$ equiv.) and 4-bromomethylbenzoate (258.0 mg, $1.2 \mathrm{mmol}, 1.0$ equiv.). Reaction time: $8 \mathrm{~h}$. Purification with flash chromatography (1. gradient $0-5 \%$ ethyl acetate in hexane; 2 . Isocratic $5 \%$ ethyl acetate in hexane) afforded the title compound (231.1 $\mathrm{mg}, 1.13 \mathrm{mmol}, 94 \%)$ as a white solid.

${ }^{1} \mathrm{H}$ NMR (400 MHz, Chloroform- $d$ ) $\delta 7.88(\mathrm{~d}, J=8.7 \mathrm{~Hz}, 2 \mathrm{H}), 6.46(\mathrm{~d}, J=8.7 \mathrm{~Hz}, 2 \mathrm{H}), 3.83$ $(\mathrm{s}, 3 \mathrm{H}), 3.40-3.09(\mathrm{~m}, 4 \mathrm{H}), 2.05-1.86(\mathrm{~m}, 4 \mathrm{H}) .{ }^{13} \mathrm{C}$ NMR $(101 \mathrm{MHz}$, Chloroform- $d) \delta=$ 167.58, 150.79, 131.32, 116.17, 110.62, 51.37, 47.47, 25.41. HRMS (ESI-TOF) m/z calcd. for $\mathrm{C}_{12} \mathrm{H}_{16} \mathrm{NO}_{2}\left[(\mathrm{M}+\mathrm{H})^{+}\right]: 206.1176$; found: 206.1158 .

These data are in full agreement with those previously published in the literature. ${ }^{18}$

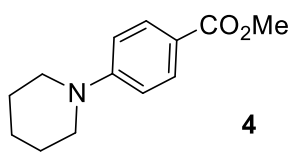

Methyl 4-(piperidin-1-yl)benzoate. From piperidine $(306.5 \mathrm{mg}, 356.4 \mu 1,3.6 \mathrm{mmol}, 3.0$ equiv.) and 4-bromomethylbenzoate (258.0 mg, $1.2 \mathrm{mmol}, 1.0$ equiv.). Reaction time: $72 \mathrm{~h}$. Double amount of $\mathrm{NiBr}_{2} \cdot 3 \mathrm{H}_{2} \mathrm{O}(16.4 \mathrm{mg}, 60 \mu \mathrm{mol}, 5.0 \mathrm{~mol} \%)$ was used. Purification with flash chromatography (1. gradient $0-5 \%$ ethyl acetate in hexane; 2 . Isocratic $5 \%$ ethyl acetate in hexane) afforded the title compound (225.8 $\mathrm{mg}, 1.03 \mathrm{mmol}, 86 \%)$ as a white solid.

${ }^{1} \mathrm{H}$ NMR (600 MHz, Chloroform- $d$ ) $\delta 7.87(\mathrm{~d}, \mathrm{~J}=9.1 \mathrm{~Hz}, 2 \mathrm{H}), 6.82(\mathrm{~d}, \mathrm{~J}=9.0 \mathrm{~Hz}, 2 \mathrm{H}), 3.83$ $(\mathrm{s}, 3 \mathrm{H}), 3.28(\mathrm{~m}, 4 \mathrm{H}), 1.67-1.56(\mathrm{~m}, 6 \mathrm{H}) .{ }^{13} \mathrm{C}$ NMR $(151 \mathrm{MHz}$, Chloroform-d) $\delta 167.18$, 154.46, 131.19, 118.61, 113.52, 51.49, 48.73, 25.35, 24.32. HRMS (ESI-TOF) m/z calcd. for $\mathrm{C}_{13} \mathrm{H}_{18} \mathrm{NO}_{2}\left[(\mathrm{M}+\mathrm{H})^{+}\right]: 220.1332$; found: 220.1340 .

These data are in full agreement with those previously published in the literature. ${ }^{19}$ 
<smiles>COC(=O)c1ccc(N2CCOCC2)cc1</smiles>

Methyl 4-morpholinobenzoate. From morpholine (313.6 mg, $313.6 \mu 1,3.6$ mmol, 3.0 equiv.) and 4-bromomethylbenzoate (258.0 mg, $1.2 \mathrm{mmol}, 1.0$ equiv.). Reaction time: $16 \mathrm{~h}$. Purification with flash chromatography (gradient $0-2 \%$ ethyl acetate in DCM; 2. Isocratic 2\% ethyl acetate in DCM) afforded the title compound (255.5 mg, $1.15 \mathrm{mmol}, 96 \%$ ) as a white solid.

${ }^{1} \mathrm{H}$ NMR (400 MHz, Chloroform- $d$ ) $\delta 7.93(\mathrm{~d}, \mathrm{~J}=9.0 \mathrm{~Hz}, 2 \mathrm{H}), 6.86(\mathrm{~d}, \mathrm{~J}=9.0 \mathrm{~Hz}, 2 \mathrm{H}), 3.92$ $3.72(\mathrm{~m}, 7 \mathrm{H}), 3.26(\mathrm{~d}, \mathrm{~J}=5.1 \mathrm{~Hz}, 4 \mathrm{H}) .{ }^{13} \mathrm{C} \mathrm{NMR}(101 \mathrm{MHz}$, Chloroform- $d) \delta 167.04,154.15$, 131.21, $120.34113 .50,66.59,51.71,47.72$. HRMS (ESI-TOF) $\mathrm{m} / \mathrm{z}$ calcd. for $\mathrm{C}_{12} \mathrm{H}_{16} \mathrm{NO}_{3}$ $\left[(\mathrm{M}+\mathrm{H})^{+}\right]: 222.1125$; found: 222.1139 .

These data are in full agreement with those previously published in the literature. ${ }^{20}$

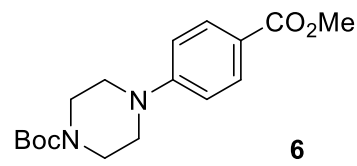

tert-Butyl 4-(4-(methoxycarbonyl)phenyl)piperazine-1-carboxylate. From tert-butyl piperazine-1-carboxylate (335.3 mg, $1.8 \mathrm{mmol}, 3.0$ equiv.) and 4-bromomethylbenzoate (129.0 mg, $0.6 \mathrm{mmol}, 1.0$ equiv.) using $5 \mathrm{~mol} \% \mathrm{NiBr}_{2} \cdot 3 \mathrm{H}_{2} \mathrm{O}(8.2 \mathrm{mg}, 60 \mu \mathrm{mol})$ and pyrrolidine (4.3 $\mathrm{mg}, 4.9 \mu \mathrm{l}, 0.06 \mathrm{mmol}, 10 \mathrm{~mol} \%$ ) as additive. Reaction time: $24 \mathrm{~h}$. Purification with flash chromatography (1. gradient 0-3\% ethyl acetate in DCM; 2. Isocratic 3\% ethyl acetate in DCM) afforded the title compound (146.2 $\mathrm{mg}, 0.45 \mathrm{mmol}, 76 \%$ ) as a white solid. The pyrrolidinecoupled side-product was formed in $10 \%$ yield, as determined by analysis of the crude mixture by ${ }^{1} \mathrm{H}$ NMR spectroscopy.

${ }^{1} \mathrm{H}$ NMR (400 MHz, Chloroform- $d$ ) $\delta 7.92(\mathrm{~d}, \mathrm{~J}=8.9 \mathrm{~Hz}, 2 \mathrm{H}), 6.85(\mathrm{~d}, \mathrm{~J}=8.9 \mathrm{~Hz}, 2 \mathrm{H}), 3.86$ (s, 3H), 3.57 (m, 4H), 3.29 (m, 4H), 1.48 (s, 9H). ${ }^{13} \mathrm{C}$ NMR (101 MHz, Chloroform- $d$ ) $\delta$ 167.48, $155.09,154.41,131.69,120.63,114.42,80.56,52.15,47.98,43.46,28.92,28.78$. HRMS (ESITOF) $\mathrm{m} / \mathrm{z}$ calcd. for $\mathrm{C}_{17} \mathrm{H}_{25} \mathrm{~N}_{2} \mathrm{O}_{4}\left[(\mathrm{M}+\mathrm{H})^{+}\right]: 321.1809$; found: 321.1818

These data are in full agreement with those previously published in the literature. ${ }^{19}$ 
<smiles>CC(=O)c1ccc(N2CCc3ccccc3C2)cc1</smiles>

Methyl 4-(3,4-dihydroisoquionolin-2(1H)-yl)benzoate. From 1,2,3,4-tetrahydroisoquinoline (479.5 mg, $456.7 \mu 1,3.6 \mathrm{mmol}, 3.0$ equiv.) and 4-bromomethylbenzoate (258.0 mg, $1.2 \mathrm{mmol}$, 1.0 equiv.). Reaction time: $16 \mathrm{~h}$. Purification with flash chromatography (1. gradient $0-5 \%$ ethyl acetate in hexane; 2 . Isocratic 5\% ethyl acetate in hexane) afforded the title compound (281.6 $\mathrm{mg}, 1.06 \mathrm{mmol}, 88 \%$ ) as a white solid.

${ }^{1} \mathrm{H}$ NMR (600 MHz, Chloroform- $d$ ) $\delta 7.97$ (d, $\left.J=9.0 \mathrm{~Hz}, 2 \mathrm{H}\right), 7.23-7.13(\mathrm{~m}, 4 \mathrm{H}), 6.86$ (d, $J$ $=9.0 \mathrm{~Hz}, 2 \mathrm{H}), 4.49(\mathrm{~s}, 2 \mathrm{H}), 3.88(\mathrm{~s}, 3 \mathrm{H}), 3.62(\mathrm{t}, J=5.9 \mathrm{~Hz}, 2 \mathrm{H}), 2.97(\mathrm{t}, J=5.8 \mathrm{~Hz}, 2 \mathrm{H}) .{ }^{13} \mathrm{C}$ NMR (151 MHz, Chloroform-d) $\delta 167.29,153.00,135.02,133.80,131.36,128.22,126.73$, 126.51, 126.37, 118.29, 112.10, 51.56, 49.01, 44.78, 29.04. HRMS (ESI-TOF) m/z calcd. for $\mathrm{C}_{17} \mathrm{H}_{18} \mathrm{NO}_{2}\left[(\mathrm{M}+\mathrm{H})^{+}\right]: 268.1332$; found: 268.1344

These data are in full agreement with those previously published in the literature. ${ }^{21}$<smiles>CC(=O)c1ccc(N(C)Cc2ccccc2)cc1</smiles>

Methyl 4-(benzyl(methyl)amino)benzoate. From $N$-methylbenzylamine (438.6 mg, $467.1 \mu 1$, $3.6 \mathrm{mmol}, 3.0$ equiv.) and 4-bromomethylbenzoate (258.0 mg, $1.2 \mathrm{mmol}, 1.0$ equiv.). Reaction time: 72 h. Purification with flash chromatography (1.gradient 0-4\% ethyl acetate in hexane; 2. Isocratic 4\% ethyl acetate in hexane) afforded the title compound (245.4 mg, $0.96 \mathrm{mmol}, 80 \%$ ) as a white solid.

${ }^{1} \mathrm{H}$ NMR (400 MHz, Chloroform- $d$ ) $\delta 7.92(\mathrm{~d}, J=9.1 \mathrm{~Hz}, 2 \mathrm{H}), 7.34$ (t, $\left.J=7.2 \mathrm{~Hz}, 2 \mathrm{H}\right), 7.28$ $(\mathrm{d}, J=7.2 \mathrm{~Hz}, 1 \mathrm{H}), 7.20(\mathrm{~d}, J=7.1 \mathrm{~Hz}, 2 \mathrm{H}), 6.71(\mathrm{~d}, J=9.1 \mathrm{~Hz}, 2 \mathrm{H}), 4.62(\mathrm{~s}, 2 \mathrm{H}), 3.86(\mathrm{~s}, 3 \mathrm{H})$, $3.12(\mathrm{~s}, 3 \mathrm{H}) .{ }^{13} \mathrm{C}$ NMR $(101 \mathrm{MHz}$, Chloroform- $d$ ) $\delta$ 167.39, 152.75, 137.79, 131.43, 128.78, 127.20, 126.46, 117.37, 110.88, 55.92, 51.52, 38.69. HRMS (ESI-TOF) m/z calcd. for $\mathrm{C}_{16} \mathrm{H}_{18} \mathrm{NO}_{2}\left[(\mathrm{M}+\mathrm{H})^{+}\right]: 256.1332$; found: 256.1344

These data are in full agreement with those previously published in the literature. ${ }^{22}$ 


Methyl 4-(butylamino)benzoate. From $n$-butylamine (263.3 mg, $355.8 \mu 1,3.6 \mathrm{mmol}, 3.0$ equiv.) and 4-bromomethylbenzoate (258.0 mg, $1.2 \mathrm{mmol}, 1.0$ equiv.) using $5 \mathrm{~mol} \%$ $\mathrm{NiBr}_{2} \cdot 3 \mathrm{H}_{2} \mathrm{O}$ (16.4 mg, $60 \mu \mathrm{mol}$,). Reaction time: $72 \mathrm{~h}$. Purification with flash chromatography (1. gradient $0-8 \%$ ethyl acetate in hexane; 2 . Isocratic $8 \%$ ethyl acetate in hexane) afforded the title compound (223.2 $\mathrm{mg}, 1.08 \mathrm{mmol}, 90 \%)$ as a white solid.

${ }^{1} \mathrm{H}$ NMR (400 MHz, Chloroform- $d$ ) $\delta 7.85(\mathrm{~d}, \mathrm{~J}=8.6 \mathrm{~Hz}, 2 \mathrm{H}), 6.52(\mathrm{~d}, \mathrm{~J}=8.6 \mathrm{~Hz}, 2 \mathrm{H}), 4.21$ (brs, 1H), $3.83(\mathrm{~s}, 3 \mathrm{H}), 3.16-3.07(\mathrm{~m}, 2 \mathrm{H}), 1.63-1.52(\mathrm{~m}, 2 \mathrm{H}), 1.41(\mathrm{~h}, \mathrm{~J}=7.3,6.9 \mathrm{~Hz}, 2 \mathrm{H})$, $0.94(\mathrm{td}, \mathrm{J}=7.3,1.0 \mathrm{~Hz}, 3 \mathrm{H}) .{ }^{13} \mathrm{C}$ NMR (101 MHz, Chloroform-d) $\delta$ 167.40, 152.24, 131.52, 117.77, 111.26, 51.46, 43.01, 31.35, 20.21, 13.84. HRMS (ESI-TOF) $\mathrm{m} / \mathrm{z}$ calcd. for $\mathrm{C}_{12} \mathrm{H}_{18} \mathrm{NO}_{2}$ $\left[(\mathrm{M}+\mathrm{H})^{+}\right]: 208.1332$; found: 208.1342 .

These data are in full agreement with those previously published in the literature. ${ }^{23}$<smiles>CC(=O)c1ccc(NC2CCCCC2)cc1</smiles>

Methyl 4-(cyclohexylamino)benzoate. From cyclohexylamine $(357.0 \mathrm{mg}, 415.4 \mu 1,3.6$ mmol, 3.0 equiv.) and 4-bromomethylbenzoate (258.0 mg, $1.2 \mathrm{mmol}, 1.0$ equiv.) using $5 \mathrm{~mol} \%$ $\mathrm{NiBr}_{2} \cdot 3 \mathrm{H}_{2} \mathrm{O}$ (16.4 mg, $60 \mu \mathrm{mol}$,). Reaction time: $72 \mathrm{~h}$. Purification with flash chromatography (1. gradient $0-5 \%$ ethyl acetate in hexane; 2 . Isocratic $5 \%$ ethyl acetate in hexane) afforded the title compound (203.2 $\mathrm{mg}, 0.87 \mathrm{mmol}, 73 \%$ ) as a white solid.

${ }^{1} \mathrm{H}$ NMR (400 MHz, Chloroform- $d$ ) $\delta 7.82(\mathrm{~d}, \mathrm{~J}=8.8 \mathrm{~Hz}, 2 \mathrm{H}), 6.51(\mathrm{~d}, \mathrm{~J}=8.9 \mathrm{~Hz}, 2 \mathrm{H}), 4.01$ (brs, 1H), 3.83 (s, 3H), $3.30(\mathrm{~m}, 1 \mathrm{H}), 2.06-2.00$ (m, 2H), $1.81-1.73(\mathrm{~m}, 2 \mathrm{H}), 1.69-1.61$ (m, 1H), $1.42-1.32(\mathrm{~m}, 2 \mathrm{H}), 1.28-1.13(\mathrm{~m}, 3 \mathrm{H}) .{ }^{13} \mathrm{C}$ NMR (101 MHz, Chloroform-d) $\delta 167.36$, 151.10, 131.60, 117.56, 111.59, 51.47, 51.24, 33.10, 25.73, 24.87. HRMS (ESI-TOF) m/z calcd. for $\mathrm{C}_{14} \mathrm{H}_{20} \mathrm{NO}_{2}\left[(\mathrm{M}+\mathrm{H})^{+}\right]$: 234.1489; found: 234.1500 .

These data are in full agreement with those previously published in the literature. ${ }^{24}$ 


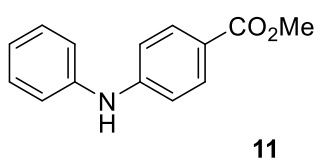

Methyl 4-(butylamino)benzoate. From aniline (335.5 mg, $329.2 \mu 1,3.6 \mathrm{mmol}, 3.0$ equiv.) and 4-bromomethylbenzoate (258.0 mg, $1.2 \mathrm{mmol}, 1.0$ equiv.) using $5 \mathrm{~mol} \% \mathrm{NiBr}_{2} \cdot 3 \mathrm{H}_{2} \mathrm{O}(8.2 \mathrm{mg}$, $60 \mu \mathrm{mol})$ and pyrrolidine $(4.3 \mathrm{mg}, 4.9 \mu \mathrm{l}, 0.06 \mathrm{mmol}, 10 \mathrm{~mol})$ as well as $N$-tertbutylisopropylamine (BIPA) (414.8 mg, $570.6 \mu 1,3.6 \mathrm{mmol}, 3.0$ equiv.) as additives Reaction time: $72 \mathrm{~h}$. Purification with flash chromatography (1. gradient $0-10 \%$ ethyl acetate in hexane; 2. Isocratic $10 \%$ ethyl acetate in hexane) afforded the title compound ( $246.7 \mathrm{mg}, 1.09 \mathrm{mmol}$, $90 \%$ ) as a white solid. The pyrrolidine-coupled side-product was formed in $2 \%$ yield, as determined by analysis of the crude mixture by ${ }^{1} \mathrm{H}$ NMR spectroscopy.

${ }^{1} \mathrm{H}$ NMR (400 MHz, Chloroform- $d$ ) $\delta 7.93(\mathrm{~d}, \mathrm{~J}=8.1 \mathrm{~Hz}, 2 \mathrm{H}), 7.34(\mathrm{~m}, 2 \mathrm{H}), 7.18(\mathrm{~d}, \mathrm{~J}=7.7$ $\mathrm{Hz}, 2 \mathrm{H}), 7.07$ (t, J = 7.4 Hz, 1H), 6.99 (d, J = 8.6 Hz, 2H), 6.19 (brs, 1H), 3.88 (s, 3H). ${ }^{13} \mathrm{C}$ NMR (101 MHz, Chloroform-d) $\delta 167.08,148.16,140.88,131.50,129.51,123.07,120.94$, 120.42, 114.56, 51.77. HRMS (ESI-TOF) $\mathrm{m} / \mathrm{z}$ calcd. for $\mathrm{C}_{14} \mathrm{H}_{14} \mathrm{NO}_{2}\left[(\mathrm{M}+\mathrm{H})^{+}\right]: 228.1019$; found: 228.1033 .

These data are in full agreement with those previously published in the literature. ${ }^{25}$

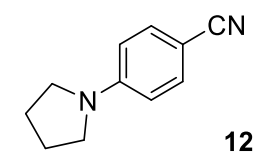

1-(4-benzonitrile)pyrrolidine. From pyrrolidine (256.0 mg, $295.6 \mu 1,3.6 \mathrm{mmol}, 3.0$ equiv.) and 4-bromobenzonitrile (218.4 mg, $1.2 \mathrm{mmol}, 1.0$ equiv.). Reaction time: $24 \mathrm{~h}$. Purification with flash chromatography (1. gradient $0-5 \%$ ethyl acetate in hexane; 2 . Isocratic $5 \%$ ethyl acetate in hexane) afforded the title compound (189.6mg, $1.11 \mathrm{mmol}, 92 \%)$ as a white solid.

${ }^{1} \mathrm{H}$ NMR (400 MHz, Chloroform- $d$ ) $\delta 7.42(\mathrm{~d}, J=8.8 \mathrm{~Hz}, 2 \mathrm{H}), 6.48(\mathrm{~d}, J=8.9 \mathrm{~Hz}, 2 \mathrm{H}), 3.32$ $3.28(\mathrm{~m}, 4 \mathrm{H}), 2.09-1.94(\mathrm{~m}, 4 \mathrm{H}) .{ }^{13} \mathrm{C}$ NMR $(101 \mathrm{MHz}$, Chloroform- $d$ ) $\delta=150.00,133.43$, 121.11, 111.47, 96.38, 47.51, 25.44. HRMS (ESI-TOF) $\mathrm{m} / \mathrm{z}$ calcd. for $\mathrm{C}_{11} \mathrm{H}_{13} \mathrm{~N}_{2}\left[(\mathrm{M}+\mathrm{H})^{+}\right]$: 173.1074; found: 173.1081 .

These data are in full agreement with those previously published in the literature. ${ }^{26}$ 


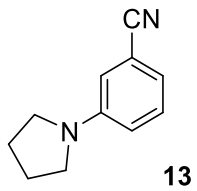

1-(3-benzonitrile)pyrrolidine. From pyrrolidine $(256.0 \mathrm{mg}, 295.6 \mu 1,3.6 \mathrm{mmol}, 3.0$ equiv.) and 3-bromobenzonitrile (218.4 mg, $1.2 \mathrm{mmol}, 1.0$ equiv.). Reaction time: $24 \mathrm{~h}$. No internal standard (1,3,5-trimethoxybenzene was used) due to poor separation from the product during flash chromatography. Purification with flash chromatography (1. gradient $0-5 \%$ ethyl acetate in hexane; 2 . Isocratic 5\% ethyl acetate in hexane) afforded the title compound (180.4 mg, 1.05 mmol, $87 \%$ ) as a white solid.

${ }^{1} \mathrm{H}$ NMR (400 MHz, Chloroform- $d$ ) $\delta 7.30-7.23(\mathrm{~m}, 1 \mathrm{H}), 6.90(\mathrm{~m}, 1 \mathrm{H}), 6.77-6.69(\mathrm{~m}, 2 \mathrm{H})$, $3.34-3.23(\mathrm{~m}, 4 \mathrm{H}), 2.13-1.99(\mathrm{~m}, 4 \mathrm{H}) .{ }^{13} \mathrm{C}$ NMR (101 MHz, Chloroform- $d$ ) $\delta 147.62,129.73$, $119.95,118.50,115.78,114.24,112.63,47.55,25.46 . H R M S$ (ESI-TOF) $\mathrm{m} / \mathrm{z}$ calcd. for $\mathrm{C}_{11} \mathrm{H}_{13} \mathrm{~N}_{2}\left[(\mathrm{M}+\mathrm{H})^{+}\right]: 173.1074$; found: 173.1080

These data are in full agreement with those previously published in the literature. ${ }^{27}$

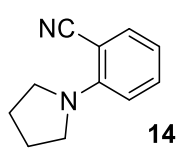

1-(2-benzonitrile)pyrrolidine. From pyrrolidine $(256.0 \mathrm{mg}, 295.6 \mu 1,3.6 \mathrm{mmol}, 3.0$ equiv.) and 2-bromobenzonitrile (218.4 mg, $1.2 \mathrm{mmol}, 1.0$ equiv.) using $5 \mathrm{~mol} \% \mathrm{NiBr}_{2} \cdot 3 \mathrm{H}_{2} \mathrm{O}(8.2 \mathrm{mg}$, $60 \mu \mathrm{mol})$. Reaction time: $72 \mathrm{~h}$. No internal standard (1,3,5-trimethoxybenzene was used) due to poor separation from the product during flash chromatography. Purification with flash chromatography (eluents: 1 . gradient $0-5 \%$ ethyl acetate in hexane; 2 . Isocratic $5 \%$ ethyl acetate in hexane) afforded the title compound (190.5 mg, $1.11 \mathrm{mmol}, 92 \%)$ as a colorless oil.

${ }^{1} \mathrm{H}$ NMR (400 MHz, Chloroform-d) $\delta 7.42(\mathrm{~m}, 1 \mathrm{H}), 7.31(\mathrm{~m}, 1 \mathrm{H}), 6.67-6.59(\mathrm{~m}, 2 \mathrm{H}), 3.63-$ $3.53(\mathrm{~m}, 4 \mathrm{H}), 2.03-1.94(\mathrm{~m}, 4 \mathrm{H}) .{ }^{13} \mathrm{C}$ NMR (101 MHz, Chloroform- $d$ ) $\delta$ 150.04, 135.72, 133.40, 121.51, 115.86, 114.24, 94.27, 49.81, 25.76. HRMS (ESI-TOF) m/z calcd. for $\mathrm{C}_{11} \mathrm{H}_{13} \mathrm{~N}_{2}$ $\left[(\mathrm{M}+\mathrm{H})^{+}\right]: 173.1074$; found: 173.1081

These data are in full agreement with those previously published in the literature. ${ }^{1}$ 


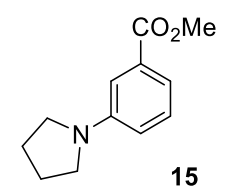

1-(3-methylbenzoate)pyrrolidine. From pyrrolidine $(256.0 \mathrm{mg}, 295.6 \mu 1,3.6 \mathrm{mmol}, 3.0$ equiv.) and 3-bromomethylbenzoate (258.0 mg, $1.2 \mathrm{mmol}, 1.0$ equiv.). Reaction time: $24 \mathrm{~h}$. No internal standard (1,3,5-trimethoxybenzene was used) due to poor separation from the product during flash chromatography. Purification with flash chromatography (1. gradient $0-5 \%$ ethyl acetate in hexane; 2 . Isocratic 5\% ethyl acetate in hexane) afforded the title compound (218.4 mg, $1.06 \mathrm{mmol}, 89 \%$ ) as a colorless oil.

${ }^{1} \mathrm{H}$ NMR (400 MHz, Chloroform- $d$ ) $\delta 7.32$ (d, $\left.J=7.6 \mathrm{~Hz}, 1 \mathrm{H}\right), 7.25(\mathrm{t}, J=7.8 \mathrm{~Hz}, 1 \mathrm{H}), 7.22$ $7.91(\mathrm{~s}, 1 \mathrm{H}), 6.71(\mathrm{~m}, 1 \mathrm{H}), 3.89(\mathrm{~s}, 3 \mathrm{H}), 3.29(\mathrm{t}, \mathrm{J}=6.6 \mathrm{~Hz}, 4 \mathrm{H}), 2.00(\mathrm{t}, \mathrm{J}=6.6 \mathrm{~Hz}, 4 \mathrm{H}) .{ }^{13} \mathrm{C}$ NMR (101 MHz, Chloroform-d) $\delta 167.89,147.78,130.73,129.02,116.39,115.93,112.38$, 52.00, 47.70, 25.48. HRMS (ESI-TOF) $\mathrm{m} / \mathrm{z}$ calcd. for $\mathrm{C}_{12} \mathrm{H}_{16} \mathrm{NO}_{2}\left[(\mathrm{M}+\mathrm{H})^{+}\right]: 206.17556$; found: 206.1185 .

These data are in full agreement with those previously published in the literature. ${ }^{20}$

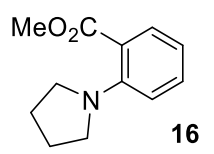

1-(2-methylbenzoate)pyrrolidine. From pyrrolidine $(256.0 \mathrm{mg}, 295.6 \mu 1,3.6 \mathrm{mmol}, 3.0$ equiv.) and 2-bromomethylbenzoate (258.0 mg, $1.2 \mathrm{mmol}, 1.0$ equiv.) using $5 \mathrm{~mol} \%$ $\mathrm{NiBr}_{2} \cdot 3 \mathrm{H}_{2} \mathrm{O}(8.2 \mathrm{mg}, 60 \mu \mathrm{mol})$. Reaction time: $72 \mathrm{~h}$. No internal standard $(1,3,5-$ trimethoxybenzene was used) due to poor separation from the product during flash chromatography. Purification with flash chromatography (1. gradient $0-5 \%$ ethyl acetate in hexane; 2. Isocratic 5\% ethyl acetate in hexane) afforded the title compound (87.2 $\mathrm{mg}, 0.42$ mmol, $35 \%$ ) as a colourless oil.

${ }^{1} \mathrm{H}$ NMR (400 MHz, Chloroform- $d$ ) $\delta 7.57(\mathrm{~m}, 1 \mathrm{H}), 7.31(\mathrm{t}, J=8.7 \mathrm{~Hz}, 1 \mathrm{H}), 6.79(\mathrm{~m}, 1 \mathrm{H}), 6.71$ $(\mathrm{t}, J=7.4 \mathrm{~Hz}, 1 \mathrm{H}), 3.88(\mathrm{~s}, 3 \mathrm{H}), 3.28-3.19(\mathrm{~m}, 4 \mathrm{H}), 1.99-1.88(\mathrm{~m}, 4 \mathrm{H}) .{ }^{13} \mathrm{C} \mathrm{NMR}(101 \mathrm{MHz}$, Chloroform- $d$ ) $\delta 169.57,147.93,131.79,131.08,117.09,115.63,113.95,52.00,50.87,25.88$. HRMS (ESI-TOF) m/z calcd. for $\mathrm{C}_{12} \mathrm{H}_{16} \mathrm{NO}_{2}\left[(\mathrm{M}+\mathrm{H})^{+}\right]$: 206.17556; found: 206.1185 .

These data are in full agreement with those previously published in the literature. ${ }^{28}$ 


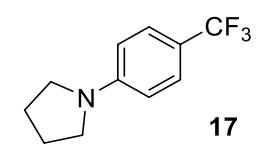

1-(4-(trifluoromethyl)phenyl)pyrrolidine. From pyrrolidine $(256.0 \mathrm{mg}, 295.6 \mu 1,3.6 \mathrm{mmol}$, 3.0 equiv.) and 4-bromobenzotrifluoride (270.0 mg, $168.0 \mu 1,1.2 \mathrm{mmol}, 1.0$ equiv.). Reaction time: $8 \mathrm{~h}$. Purification with flash chromatography (1. gradient $0-3 \%$ ethyl acetate in hexane; 2 . Isocratic 3\% ethyl acetate in hexane) afforded the title compound (238.2 mg, $1.11 \mathrm{mmol}, 92 \%$ ) as a white solid.

${ }^{1} \mathrm{H}$ NMR (400 MHz, Chloroform- $d$ ) $\delta 7.48(\mathrm{~d}, J=8.7 \mathrm{~Hz}, 2 \mathrm{H}), 6.58(\mathrm{~d}, J=8.7 \mathrm{~Hz}, 2 \mathrm{H}), 3.37$ $3.27(\mathrm{~m}, 4 \mathrm{H}), 2.10-2.00(\mathrm{~m}, 4 \mathrm{H}) .{ }^{13} \mathrm{C}$ NMR $(101 \mathrm{MHz}$, Chloroform- $d$ ) $\delta 149.76,126.38(\mathrm{q}, J$ $=3.7 \mathrm{~Hz}), 125.42(\mathrm{q}, J=269.9 \mathrm{~Hz}), 116.56(\mathrm{q}, J=32.5 \mathrm{~Hz}), 110.84,47.53,25.48 .{ }^{19} \mathrm{~F} \mathrm{NMR}$ (376 MHz, Chloroform- $d$ ) $\delta-60.58(\mathrm{~s}, 3 \mathrm{~F})$. HRMS (ESI-TOF) $\mathrm{m} / \mathrm{z}$ calcd. for $\mathrm{C}_{11} \mathrm{H}_{13} \mathrm{~F}_{3} \mathrm{~N}$ $\left[(\mathrm{M}+\mathrm{H})^{+}\right]: 216.0922$; found: 216.1008.

These data are in full agreement with those previously published in the literature. ${ }^{29}$

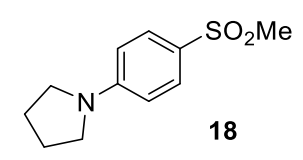

1-(4-(methylsulfonyl)phenyl)pyrrolidine. From pyrrolidine $(256.0 \mathrm{mg}, 295.6 \mu 1,3.6 \mathrm{mmol}$, 3.0 equiv.) and 4-bromopheyl methylsulfone (282.1 mg, $1.2 \mathrm{mmol}, 1.0$ equiv.). Reaction time: 24 h. Purification with flash chromatography (1. gradient $0-2 \%$ ethyl acetate in DCM; 2. Isocratic 2\% ethyl acetate in DCM) afforded the title compound (251.0 mg, $1.11 \mathrm{mmol}, 93 \%)$ as a white solid.

${ }^{1} \mathrm{H}$ NMR (600 MHz, Chloroform- $d$ ) $\delta 7.65$ (d, $\left.J=8.9 \mathrm{~Hz}, 2 \mathrm{H}\right), 6.51(\mathrm{~d}, J=9.0 \mathrm{~Hz}, 2 \mathrm{H}), 3.30$ $3.24(\mathrm{~m}, 4 \mathrm{H}), 2.94(\mathrm{~s}, 3 \mathrm{H}), 2.05-1.93(\mathrm{~m}, 4 \mathrm{H}) .{ }^{13} \mathrm{C}$ NMR (151 MHz, Chloroform-d) $\delta$ 150.89, 129.02, 125.04, 110.98, 47.61, 45.13, 25.39. HRMS (ESI-TOF) $\mathrm{m} / \mathrm{z}$ calcd. for $\mathrm{C}_{11} \mathrm{H}_{16} \mathrm{NO}_{2} \mathrm{~S}$ $\left[(\mathrm{M}+\mathrm{H})^{+}\right]: 226.0897$; found: 226.0907.

These data are in full agreement with those previously published in the literature. ${ }^{30}$ 


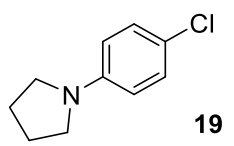

1-(4-chlorophenyl)pyrrolidine. From pyrrolidine (256.0 mg, $295.6 \mu 1,3.6 \mathrm{mmol}, 3.0$ equiv.) and 4-bromochlorobenzene (229.7 mg, $1.2 \mathrm{mmol}, 1.0$ equiv.). Reaction time: $24 \mathrm{~h}$. Purification with flash chromatography (1. gradient $0-2 \%$ ethyl acetate in hexane; 2 . Isocratic $2 \%$ ethyl acetate in hexane) afforded the title compound (196.8 $\mathrm{mg}, 1.08 \mathrm{mmol}, 90 \%)$ as a white solid.

${ }^{1} \mathrm{H}$ NMR (600 MHz, Chloroform- $\left.d\right) \delta 7.17$ (d, $\left.J=8.9 \mathrm{~Hz}, 2 \mathrm{H}\right), 6.48(\mathrm{~d}, J=8.9 \mathrm{~Hz}, 2 \mathrm{H}), 3.28-$ $3.18(\mathrm{~m}, 4 \mathrm{H}), 2.06-1.97(\mathrm{~m}, 4 \mathrm{H}) .{ }^{13} \mathrm{C}$ NMR (151 MHz, Chloroform- $d$ ) $\delta 146.49,128.81$, 120.04, 112.61, 47.73, 25.48. HRMS (ESI-TOF) $\mathrm{m} / \mathrm{z}$ calcd. for $\mathrm{C}_{10} \mathrm{H}_{13} \mathrm{ClN}\left[(\mathrm{M}+\mathrm{H})^{+}\right]$: 182.0731; found: 182.0738 .

These data are in full agreement with those previously published in the literature. ${ }^{18}$

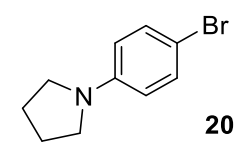

1-(4-bromophenyl)pyrrolidine. From pyrrolidine (256.0 mg, $295.6 \mu 1,3.6 \mathrm{mmol}, 3.0$ equiv.) and 1,4-dibromobenzene (283.1 mg, $1.2 \mathrm{mmol}, 1.0$ equiv.). Reaction time: $24 \mathrm{~h}$. Purification with flash chromatography (1. gradient $0-2 \%$ ethyl acetate in hexane; 2 . Isocratic $2 \%$ ethyl acetate in hexane) afforded the title compound (218.4 $\mathrm{mg}, 0.97 \mathrm{mmol}, 80 \%)$ as a white solid.

${ }^{1} \mathrm{H}$ NMR (400 MHz, Chloroform- $d$ ) $\delta 7.28$ (d, $\left.J=8.9 \mathrm{~Hz}, 2 \mathrm{H}\right), 6.42(\mathrm{~d}, J=8.9 \mathrm{~Hz}, 2 \mathrm{H}), 3.29$ $3.16(\mathrm{~m}, 4 \mathrm{H}), 2.05-1.96(\mathrm{~m}, 4 \mathrm{H}) .{ }^{13} \mathrm{C}$ NMR $(101 \mathrm{MHz}$, Chloroform- $d$ ) $\delta 146.82,131.68$, 113.19, 107.08, 47.68, 25.50. HRMS (ESI-TOF) $\mathrm{m} / \mathrm{z}$ calcd. for $\mathrm{C}_{10} \mathrm{H}_{13} \mathrm{BrN}\left[(\mathrm{M}+\mathrm{H})^{+}\right]$: 226.0226; found: 226.0231 .

These data are in full agreement with those previously published in the literature. ${ }^{31}$ 


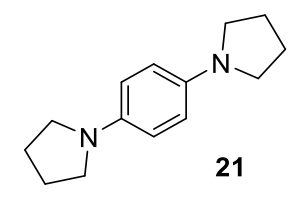

1-di(4-pyrrolidin-1yl)benzene. From pyrrolidine ( $853.3 \mathrm{mg}, 985.3 \mu 1,12.0 \mathrm{mmol}, 10$ equiv.) and 1,4-dibromobenzene (283.1 mg, $1.2 \mathrm{mmol}, 1.0$ equiv.). Reaction time: $144 \mathrm{~h}$. Purification with flash chromatography (1. gradient $0-5 \%$ ethyl acetate in hexane; 2 . Isocratic $5 \%$ ethyl acetate in hexane) afforded the title compound (157.3 $\mathrm{mg}, 0.73 \mathrm{mmol}, 61 \%$ ) as a white solid. For analysis via NMR spectroscopy, the final product was treated with deuterated trifluoro acetic acid in $\mathrm{D}_{2} \mathrm{O}$.

${ }^{1} \mathrm{H}$ NMR (400 MHz, deuterium oxide) $\delta 7.17(\mathrm{~s}, 4 \mathrm{H}), 3.20(\mathrm{~m}, 8 \mathrm{H}), 1.68(\mathrm{~m}, 8 \mathrm{H}) .{ }^{13} \mathrm{C}$ NMR (101 MHz, deuterium oxide) $\delta 143.24,126.02,61.01,25.62$. HRMS (ESI-TOF) $\mathrm{m} / \mathrm{z}$ calcd. for $\mathrm{C}_{14} \mathrm{H}_{21} \mathrm{~N}_{2}\left[(\mathrm{M}+\mathrm{H})^{+}\right]: 217.1700$; found: 217.1709

These data are in full agreement with those previously published in the literature. ${ }^{32}$

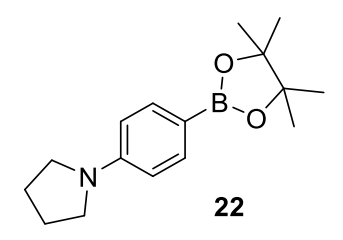

1-(4-(4,4,5,5-tetramethyl-1,3,2-dioxaborolan-2yl)phenyl)pyrrolidine. From pyrrolidine (256.0 mg, $295.6 \mu 1,3.6 \mathrm{mmol}, 3.0$ equiv.) and 4-bromomethyl-phenylboronic acid pinacol ester (339.6 mg, $1.2 \mathrm{mmol}, 1.0$ equiv.). Reaction time: $48 \mathrm{~h}$. No internal standard $(1,3,5-$ trimethoxybenzene was used) due to poor separation from the product during flash chromatography. Purification with flash chromatography (1. gradient $0-10 \%$ ethyl acetate in hexane; 2 . Isocratic $2 \%$ ethyl acetate in hexane) afforded the title compound (284.3 $\mathrm{mg}, 1.04$ mmol, $87 \%$ ) as a white solid.

${ }^{1} \mathrm{H}$ NMR (400 MHz, Chloroform- $d$ ) $\delta 7.70$ (d, $\left.J=8.6 \mathrm{~Hz}, 2 \mathrm{H}\right), 6.55$ (d, $\left.J=8.6 \mathrm{~Hz}, 2 \mathrm{H}\right), 3.39$ $3.17(\mathrm{~m}, 4 \mathrm{H}), 2.13-1.92(\mathrm{~m}, 4 \mathrm{H}), 1.35(\mathrm{~s}, 12 \mathrm{H}) .{ }^{13} \mathrm{C}$ NMR (101 MHz, Chloroform- $d$ ) $\delta$ 150.00, 136.24, 113.94, 110.93, 83.06, 47.40, 25.46, 24.88. HRMS (ESI-TOF) $\mathrm{m} / \mathrm{z}$ calcd. for $\mathrm{C}_{16} \mathrm{H}_{25} \mathrm{BNO}_{2}\left[(\mathrm{M}+\mathrm{H})^{+}\right]: 274.1973$; found: 274.1987.

These data are in full agreement with those previously published in the literature. ${ }^{33}$ 
<smiles>O=C(c1ccccc1)c1ccc(N2CCCC2)cc1</smiles>

phenyl(4-(pyrrolidin-1-yl)phenyl)methanone. From pyrrolidine (256.0 mg, $295.6 \mu 1,3.6$ mmol, 3.0 equiv.) and 4-bromobenzophenone (313.3 mg, $1.2 \mathrm{mmol}, 1.0$ equiv.). Reaction time: 48 h. Purification with flash chromatography (1. gradient $0-5 \%$ ethyl acetate in hexane; 2. Isocratic 5\% ethyl acetate in hexane) afforded the title compound (281.9 mg, $1.12 \mathrm{mmol}, 93 \%$ ) as a white solid.

${ }^{1} \mathrm{H}$ NMR (600 MHz, Chloroform- $\left.d\right) \delta 7.78(\mathrm{~d}, J=8.9 \mathrm{~Hz}, 2 \mathrm{H}), 7.72-7.66(\mathrm{~m}, 2 \mathrm{H}), 7.49(\mathrm{t}, J$ $=7.4 \mathrm{~Hz}, 1 \mathrm{H}), 7.45-7.37(\mathrm{~m}, 2 \mathrm{H}), 6.51(\mathrm{~d}, J=8.9 \mathrm{~Hz}, 2 \mathrm{H}), 3.38-3.27(\mathrm{~m}, 4 \mathrm{H}), 2.02-1.95$ (m, 4H). ${ }^{13} \mathrm{C}$ NMR $(151 \mathrm{MHz}$, Chloroform- $d$ ) $\delta 195.01,150.88,139.51,132.90,130.95,129.37$, 127.97, 124.20, 110.63, 47.58, 25.42. HRMS (ESI-TOF) m/z calcd. for $\mathrm{C}_{17} \mathrm{H}_{17} \mathrm{NO}\left[(\mathrm{M}+\mathrm{H})^{+}\right]$: 252.1383; found: 252.1394 .

These data are in full agreement with those previously published in the literature. ${ }^{34}$

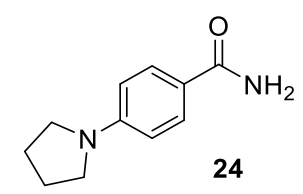

1-(4-benzamide)pyrrolidine. From pyrrolidine (256.0 mg, $295.6 \mu 1,3.6 \mathrm{mmol}, 3.0$ equiv.) and 4-bromobenzamide (240.0 mg, $1.2 \mathrm{mmol}, 1.0$ equiv.). Reaction time: $72 \mathrm{~h}$. Purification with flash chromatography (1. gradient 0-5\% methanol in DCM; 2. Isocratic 5\% methanol in DCM) afforded the title compound (175.0 $\mathrm{mg}, 0.92 \mathrm{mmol}, 77 \%)$ as a white solid.

${ }^{1} \mathrm{H}$ NMR (400 MHz, DMSO-d6) $\delta 7.69$ (d, J = 8.8 Hz, 2H), 7.58 - 7.52 (brs, 1H), 6.86 - 6.80 (brs, 1H), 6.47 (d, J = 8.8 Hz, 2H), 3.23 (s, 4H), 1.92 (s, 4H). ${ }^{13} \mathrm{C}$ NMR (101 MHz, DMSO-d 6 ) $\delta 168.05,149.49,129.08,120.24,110.47,47.22,25.01$. HRMS (ESI-TOF) $\mathrm{m} / \mathrm{z}$ calcd. for $\mathrm{C}_{11} \mathrm{H}_{15} \mathrm{~N}_{2} \mathrm{O}\left[(\mathrm{M}+\mathrm{H})^{+}\right]:$191.1179; found: 191.1188 .

These data are in full agreement with those previously published in the literature. ${ }^{35}$ 


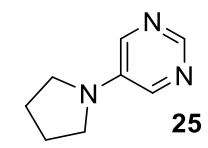

5-(4-pyrrolidin-1yl)pyrimidine. From pyrrolidine ( $256.0 \mathrm{mg}, 295.6 \mu 1,3.6 \mathrm{mmol}, 3.0$ equiv.) and 5-bromopyrimidine (190.8 mg, $1.2 \mathrm{mmol}, 1.0$ equiv.) using $5 \mathrm{~mol} \% \mathrm{NiBr}_{2} \cdot 3 \mathrm{H}_{2} \mathrm{O}(16.4 \mathrm{mg}$, $60 \mu \mathrm{mol}$ ). Reaction time: $72 \mathrm{~h}$. Purification with flash chromatography (1. gradient $0-50 \%$ ethyl acetate in hexane with $1 \% \mathrm{Et}_{3} \mathrm{~N} ; 2$. Isocratic $50 \%$ ethyl acetate in hexane with $1 \% \mathrm{Et}_{3} \mathrm{~N}$ ) afforded the title compound (141.3 $\mathrm{mg}, 0.95 \mathrm{mmol}, 79 \%)$ as a colorless solid.

${ }^{1} \mathrm{H}$ NMR (400 MHz, Chloroform- $d$ ) $\delta 8.47$ (s, 1H), 7.97 (s, 2H), 3.32 - $3.16(\mathrm{~m}, 4 \mathrm{H}), 2.06$ $1.90(\mathrm{~m}, 4 \mathrm{H}) .{ }^{13} \mathrm{C}$ NMR (101 MHz, Chloroform- $d$ ) $\delta$ 146.60, 141.09, 139.35, 46.84, 25.27. HRMS (ESI-TOF) m/z calcd. for $\mathrm{C}_{8} \mathrm{H}_{12} \mathrm{~N}_{3}\left[(\mathrm{M}+\mathrm{H})^{+}\right]$: 150.1026 ; found: 150.1033 .

These data are in full agreement with those previously published in the literature. ${ }^{36}$

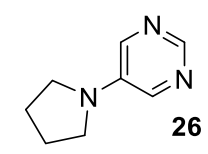

3-(pyrrolidin-1yl)pyridine. From pyrrolidine (256.0 mg, $295.6 \mu 1,3.6 \mathrm{mmol}, 3.0$ equiv.) and 3-bromopyridine (189.6 mg, $115.6 \mu \mathrm{l}, 1.2 \mathrm{mmol}, 1.0$ equiv.) using $5 \mathrm{~mol} \% \mathrm{NiBr}_{2} \cdot 3 \mathrm{H}_{2} \mathrm{O}(16.4$ $\mathrm{mg}, 60 \mu \mathrm{mol})$. Reaction time: $72 \mathrm{~h}$. Purification with flash chromatography (1. gradient $0-40 \%$ ethyl acetate in hexane with $1 \% \mathrm{Et}_{3} \mathrm{~N} ; 2$. Isocratic $40 \%$ ethyl acetate in hexane with $1 \% \mathrm{Et}_{3} \mathrm{~N}$ ) afforded the title compound (135.2 $\mathrm{mg}, 0.91 \mathrm{mmol}, 76 \%)$ as a colorless oil.

${ }^{1} \mathrm{H}$ NMR (400 MHz, Chloroform- $d$ ) $\delta 7.96-7.81(\mathrm{~m}, 2 \mathrm{H}), 7.03(\mathrm{~m}, 1 \mathrm{H}), 6.72(\mathrm{~m}, 1 \mathrm{H}), 3.21$ $(\mathrm{m}, 4 \mathrm{H}), 2.00-1.87(\mathrm{~m}, 4 \mathrm{H}) .{ }^{13} \mathrm{C}$ NMR (101 MHz, Chloroform-d) $\delta$ 143.68, 136.74, 134.23, 123.49, 117.60, 47.19, 25.32. HRMS (ESI-TOF) $\mathrm{m} / \mathrm{z}$ calcd. for $\mathrm{C}_{9} \mathrm{H}_{13} \mathrm{~N}_{2}\left[(\mathrm{M}+\mathrm{H})^{+}\right]: 149.1074$; found: 149.1081

These data are in full agreement with those previously published in the literature. ${ }^{37}$ 


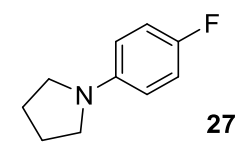

1-(4-fluorophenyl)pyrrolidine. From pyrrolidine $(256.0 \mathrm{mg}, 295.6 \mu 1,3.6 \mathrm{mmol}, 3.0$ equiv.) and 4-bromofluorobenzene (210.0 mg, $131.8 \mu 1,1.2 \mathrm{mmol}, 1.0$ equiv.) using $5 \mathrm{~mol} \%$ $\mathrm{NiBr}_{2} \cdot 3 \mathrm{H}_{2} \mathrm{O}(16.4 \mathrm{mg}, 60 \mu \mathrm{mol})$. Reaction time: $72 \mathrm{~h}$. Purification with flash chromatography (1. gradient $0-3 \%$ ethyl acetate in hexane; 2 . Isocratic $3 \%$ ethyl acetate in hexane) afforded the title compound (128.8 $\mathrm{mg}, 0.78 \mathrm{mmol}, 65 \%$ ) as a white solid.

${ }^{1} \mathrm{H}$ NMR (400 MHz, Chloroform- $d$ ) $\delta 6.99-6.89(\mathrm{~m}, 2 \mathrm{H}), 6.52-6.44$ (m, 2H), $3.30-3.19$ (m, 4H), $2.05-1.96(\mathrm{~m}, 4 \mathrm{H}) .{ }^{13} \mathrm{C}$ NMR (101 MHz, Chloroform-d) $\delta 154.81$ (d, $\left.J=233.3 \mathrm{~Hz}\right)$, 144.78, $115.48(\mathrm{~d}, J=22.0 \mathrm{~Hz}), 112.05(\mathrm{~d}, J=7.1 \mathrm{~Hz}), 48.10,25.50 .{ }^{19} \mathrm{~F}$ NMR $(564 \mathrm{MHz}$, Chloroform- $d$ ) $\delta-131.00(\mathrm{~s}, 1 \mathrm{~F})$. HRMS (ESI-TOF) $\mathrm{m} / \mathrm{z}$ calcd. for $\mathrm{C}_{10} \mathrm{H}_{13} \mathrm{FN}\left[(\mathrm{M}+\mathrm{H})^{+}\right]$: 166.1027 ; found: 166.1033 .

These data are in full agreement with those previously published in the literature. ${ }^{31}$

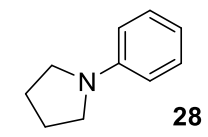

1-phenylpyrrolidine. From pyrrolidine (256.0 mg, $295.6 \mu 1,3.6 \mathrm{mmol}, 3.0$ equiv.) and bromobenzene (188.4 mg, $125.6 \mu \mathrm{l}, 1.2 \mathrm{mmol}, 1.0$ equiv.). using $5 \mathrm{~mol} \% \mathrm{NiBr}_{2} \cdot 3 \mathrm{H}_{2} \mathrm{O}(16.4$ $\mathrm{mg}, 60 \mu \mathrm{mol})$. Reaction time: $72 \mathrm{~h}$. Purification with flash chromatography (1. gradient $0-2 \%$ ethyl acetate in hexane; 2 . Isocratic $2 \%$ ethyl acetate in hexane) afforded the title compound (136.9 mg, $0.93 \mathrm{mmol}, 77 \%$ ) as a colourless oil.

${ }^{1} \mathrm{H}$ NMR (400 MHz, Chloroform- $d$ ) $\delta 7.35(\mathrm{~m}, 2 \mathrm{H}), 6.78(\mathrm{t}, J=7.3 \mathrm{~Hz}, 1 \mathrm{H}), 6.69(\mathrm{~d}, J=8.0$ $\mathrm{Hz}, 2 \mathrm{H}), 3.43-3.30(\mathrm{~m}, 4 \mathrm{H}), 2.13-2.05(\mathrm{~m}, 4 \mathrm{H}) .{ }^{13} \mathrm{C}$ NMR (101 MHz, Chloroform- $\left.d\right) \delta$ 148.04, 129.25, 115.49, 111.77, 47.71, 25.61. HRMS (ESI-TOF) $\mathrm{m} / \mathrm{z}$ calcd. for $\mathrm{C}_{10} \mathrm{H}_{14} \mathrm{~N}$ $\left[(\mathrm{M}+\mathrm{H})^{+}\right]:$148.1121; found: 148.1122 .

These data are in full agreement with those previously published in the literature. ${ }^{18}$ 


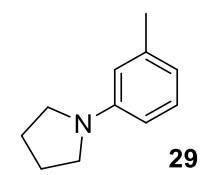

1-(m-tolyl)pyrrolidine. From pyrrolidine $(256.0 \mathrm{mg}, 295.6 \mu 1,3.6 \mathrm{mmol}, 3.0$ equiv.) and 3bromotoluene (188.4 mg, $145.6 \mu 1,1.2 \mathrm{mmol}, 1.0$ equiv.) using $5 \mathrm{~mol} \% \mathrm{NiBr}_{2} \cdot 3 \mathrm{H}_{2} \mathrm{O}(16.4 \mathrm{mg}$, $60 \mu \mathrm{mol})$. Reaction time: 72 h. Purification with flash chromatography (1. gradient $0-2 \%$ ethyl acetate in hexane; 2 . Isocratic $2 \%$ ethyl acetate in hexane) afforded the title compound (134.0 mg, $0.93 \mathrm{mmol}, 69 \%$ ) as a colorless oil.

${ }^{1} \mathrm{H}$ NMR (400 MHz, Chloroform- $d$ ) $\delta$ 7.24-7.16 (t, $\left.J=8.8 \mathrm{~Hz}, 1 \mathrm{H}\right), 6.58(\mathrm{~d}, J=7.4 \mathrm{~Hz}, 1 \mathrm{H})$, $6.51-6.44(\mathrm{~m}, 2 \mathrm{H}), 3.35(\mathrm{~m}, 4 \mathrm{H}), 2.41(\mathrm{~s}, 3 \mathrm{H}), 2.11-2.00(\mathrm{~m}, 4 \mathrm{H}) .{ }^{13} \mathrm{C}$ NMR $(101 \mathrm{MHz}$, Chloroform- $d$ ) $\delta 148.13,138.86,129.09,116.44,112.45,108.99,47.68,25.56,21.98$. HRMS (ESI-TOF) $\mathrm{m} / \mathrm{z}$ calcd. for $\mathrm{C}_{11} \mathrm{H}_{16} \mathrm{~N}\left[(\mathrm{M}+\mathrm{H})^{+}\right]$: 162.1278; found: 162.1282.

These data are in full agreement with those previously published in the literature. ${ }^{29}$

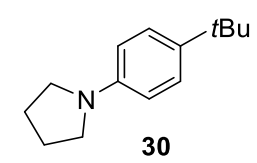

1-(4-(tert-butyl)phenyl)pyrrolidine. From pyrrolidine $(256.0 \mathrm{mg}, 295.6 \mu 1,3.6 \mathrm{mmol}, 3.0$ equiv.) and 4-bromotertbutylbenzene ( $255.7 \mathrm{mg}, 208.8 \mu 1,1.2 \mathrm{mmol}, 1.0$ equiv.) using $5 \mathrm{~mol} \%$ $\mathrm{NiBr}_{2} \cdot 3 \mathrm{H}_{2} \mathrm{O}(16.4 \mathrm{mg}, 60 \mu \mathrm{mol})$. Reaction time: $72 \mathrm{~h}$. Purification with flash chromatography (1. gradient $0-3 \%$ ethyl acetate in hexane; 2 . Isocratic 3\% ethyl acetate in hexane) afforded the title compound (203.2 $\mathrm{mg}, 1.00 \mathrm{mmol}, 83 \%$ ) as a white solid.

${ }^{1} \mathrm{H}$ NMR (400 MHz, Chloroform-d) $\delta 7.37$ (d, J = 7.0 Hz, 2H), 6.64 (d, J = 7.0 Hz, 2H), 3.42 $3.30(\mathrm{~m}, 4 \mathrm{H}), 2.11-2.02(\mathrm{~m}, 4 \mathrm{H}), 1.40(\mathrm{~s}, 9 \mathrm{H}) .{ }^{13} \mathrm{C}$ NMR (101 MHz, Chloroform- $d$ ) $\delta$ 145.94, 138.03, 125.99, 111.43, 47.79, 33.82, 31.70, 25.56. HRMS (ESI-TOF) $\mathrm{m} / \mathrm{z}$ calcd. for $\mathrm{C}_{14} \mathrm{H}_{22} \mathrm{~N}$ $\left[(\mathrm{M}+\mathrm{H})^{+}\right]:$204.1747; found: 204.1759 .

These data are in full agreement with those previously published in the literature. ${ }^{18}$ 


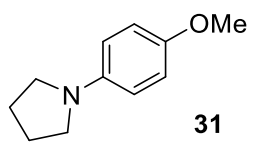

1-(4-methoxyphenyl)pyrrolidine. From pyrrolidine $(256.0 \mathrm{mg}, 295.6 \mu 1,3.6 \mathrm{mmol}, 3.0$ equiv.) and 4-bromoanisole (224.4 mg, $150.2 \mu \mathrm{l}, 1.2 \mathrm{mmol}, 1.0$ equiv.) using $5 \mathrm{~mol} \%$ $\mathrm{NiBr}_{2} \cdot 3 \mathrm{H}_{2} \mathrm{O}(16.4 \mathrm{mg}, 60 \mu \mathrm{mol})$. Reaction time: $72 \mathrm{~h}$. No internal standard $(1,3,5-$ trimethoxybenzene was used) due to poor separation from the product during flash chromatography. Purification with flash chromatography (1. gradient $0-5 \%$ ethyl acetate in hexane; 2. Isocratic 5\% ethyl acetate in hexane) afforded the title compound (154.7 $\mathrm{mg}, 0.87$ mmol, $73 \%$ ) as a white solid.

${ }^{1} \mathrm{H}$ NMR (400 MHz, Chloroform- $d$ ) $\delta 6.88(\mathrm{~d}, \mathrm{~J}=8.1 \mathrm{~Hz}, 2 \mathrm{H}), 6.57(\mathrm{~d}, \mathrm{~J}=8.1 \mathrm{~Hz}, 2 \mathrm{H}), 3.78$ (s, 3H), $3.32-3.18(\mathrm{~m}, 4 \mathrm{H}), 2.07-1.94(\mathrm{~m}, 4 \mathrm{H}) .{ }^{13} \mathrm{C}$ NMR (101 MHz, Chloroform- $d$ ) $\delta$ 150.75, 143.25, 115.01, 112.59, 56.01, 48.24, 25.41.HRMS (ESI-TOF) $\mathrm{m} / \mathrm{z}$ calcd. for $\mathrm{C}_{11} \mathrm{H}_{16} \mathrm{NO}$ $\left[(\mathrm{M}+\mathrm{H})^{+}\right]: 178.1227$; found: 178.1236

These data are in full agreement with those previously published in the literature. ${ }^{18}$ 


\section{References}

1 Yu, P. \& Morandi, B. Nickel-Catalyzed Cyanation of Aryl Chlorides and Triflates Using Butyronitrile: Merging Retro-hydrocyanation with Cross-Coupling. Angew. Chem. Int. Ed. 56, 15693-15697 (2017).

2 Wang, J., Zhao, J. \& Gong, H. Nickel-catalyzed methylation of aryl halides/tosylates with methyl tosylate. Chem. Commun. 53, 10180-10183 (2017).

3 Mori, A., Mizusaki, T., Ikawa, T., Maegawa, T., Monguchi, Y. \& Sajiki, H. Mechanistic Study of a $\mathrm{Pd} / \mathrm{C}$-Catalyzed Reduction of Aryl Sulfonates Using the $\mathrm{Mg}-\mathrm{MeOH}-$ NH4OAc System. Chem. Eur. J. 13, 1432-1441 (2007).

4 Brown, H. C., Kanth, J. V. B., Dalvi, P. V. \& Zaidlewicz, M. Molecular Addition Compounds. 15. Synthesis, Hydroboration, and Reduction Studies of New, Highly Reactive tert-Butyldialkylamine-Borane Adducts. J. Org. Chem. 64, 6263-6274 (1999).

5 Kawamata, Y., Vantourout, J. C., Hickey, D. P., Bai, P., Chen, L., Hou, Q., Qiao, W., Barman, K., Edwards, M. A., Garrido-Castro, A. F., deGruyter, J. N., Nakamura, H., Knouse, K., Qin, C., Clay, K. J., Bao, D., Li, C., Starr, J. T., Garcia-Irizarry, C., Sach, N., White, H. S., Neurock, M., Minteer, S. D. \& Baran, P. S. Electrochemically Driven, Ni-Catalyzed Aryl Amination: Scope, Mechanism, and Applications. J. Am. Chem. Soc. 141, 6392-6402 (2019).

6 Lim, C.-H., Kudisch, M., Liu, B. \& Miyake, G. M. C-N Cross-Coupling via Photoexcitation of Nickel-Amine Complexes. J. Am. Chem. Soc. 140, 7667-7673 (2018).

7 Corcoran, E. B., Pirnot, M. T., Lin, S., Dreher, S. D., DiRocco, D. A., Davies, I. W., Buchwald, S. L. \& MacMillan, D. W. C. Aryl amination using ligand-free Ni(II) salts and photoredox catalysis. Science 353, 279-283 (2016).

8 Du, Y., Pearson, R. M., Lim, C.-H., Sartor, S. M., Ryan, M. D., Yang, H., Damrauer, N. H. \& Miyake, G. M. Strongly Reducing, Visible-Light Organic Photoredox Catalysts as Sustainable Alternatives to Precious Metals. Chem. Eur. J. 23, 10962-10968 (2017).

9 Liu, Y.-Y., Liang, D., Lu, L.-Q. \& Xiao, W.-J. Practical heterogeneous photoredox/nickel dual catalysis for $\mathrm{C}-\mathrm{N}$ and $\mathrm{C}-\mathrm{O}$ coupling reactions. Chem. Commun. 55, 4853-4856 (2019). 
10 Ghosh, I., Khamrai, J., Savateev, A., Shlapakov, N., Antonietti, M. \& König, B. Organic semiconductor photocatalyst can bifunctionalize arenes and heteroarenes. Science $\mathbf{3 6 5}$, 360-366 (2019).

11 Zhang, G., Li, G., Lan, Z.-A., Lin, L., Savateev, A., Heil, T., Zafeiratos, S., Wang, X. \& Antonietti, M. Optimizing Optical Absorption, Exciton Dissociation, and Charge Transfer of a Polymeric Carbon Nitride with Ultrahigh Solar Hydrogen Production Activity. Angew. Chem. Int. Ed. 56, 13445-13449 (2017).

12 (https://www.sigmaaldrich.com (Germany; 2019 October 16).).

13 https://www.bauhaus.info/led-baender/tween-light-ledband/p/22517610?gclid=EAIaIQobChMIoLWto9zl3wIVTZSyCh3YDweqEAQYASA BEgJmRfD_BwE\&s_kwcid=AL!5677!3!190027496787!!!g!462716337331!\&pla_prp aid=462716337331\&ef_id=EAIaIQobChMIoLWto9zl3wIVTZSyCh3YDweqEAQYA SABEgJmRfD_BwE:G:s\&pla_adgrid=41635814775\&pla_campid=225980581\&pla_p rch=online\&pla_prid=22517610\&cid=PSEGoo225980581_41635814775\&pla_adt=pl a (Germany; 2019 October 16).

14 Goettmann, F., Fischer, A., Antonietti, M. \& Thomas, A. Chemical Synthesis of Mesoporous Carbon Nitrides Using Hard Templates and Their Use as a Metal-Free Catalyst for Friedel-Crafts Reaction of Benzene. Angew. Chem. Int. Ed. 45, 4467-4471 (2006).

15 Shalom, M., Guttentag, M., Fettkenhauer, C., Inal, S., Neher, D., Llobet, A. \& Antonietti, M. In Situ Formation of Heterojunctions in Modified Graphitic Carbon Nitride: Synthesis and Noble Metal Free Photocatalysis. Chem. Mater. 26, 5812-5818 (2014).

16 Zhang, J., Sun, J., Maeda, K., Domen, K., Liu, P., Antonietti, M., Fu, X. \& Wang, X. Sulfur-mediated synthesis of carbon nitride: Band-gap engineering and improved functions for photocatalysis. Energy Environ. Sci. 4, 675-678 (2011).

17 Savateev, A., Pronkin, S., Epping, J. D., Willinger, M. G., Wolff, C., Neher, D., Antonietti, M. \& Dontsova, D. Potassium Poly(heptazine imides) from Aminotetrazoles: Shifting Band Gaps of Carbon Nitride-like Materials for More Efficient Solar Hydrogen and Oxygen Evolution. ChemCatChem 9, 167-174 (2017).

18 Hamid, M. H. S. A., Allen, C. L., Lamb, G. W., Maxwell, A. C., Maytum, H. C., Watson, A. J. A. \& Williams, J. M. J. Ruthenium-Catalyzed N-Alkylation of Amines 
and Sulfonamides Using Borrowing Hydrogen Methodology. J. Am. Chem. Soc. 131, 1766-1774 (2009).

19 Sandtorv, A. H. \& Stuart, D. R. Metal-free Synthesis of Aryl Amines: Beyond Nucleophilic Aromatic Substitution. Angew. Chem. Int. Ed. 55, 15812-15815 (2016).

20 Urgaonkar, S., Xu, J.-H. \& Verkade, J. G. Application of a New Bicyclic Triaminophosphine Ligand in Pd-Catalyzed Buchwald-Hartwig Amination Reactions of Aryl Chlorides, Bromides, and Iodides. J. Org. Chem. 68, 8416-8423 (2003).

21 Lin, S.-X., Sun, G.-J. \& Kang, Q. A visible-light-activated rhodium complex in enantioselective conjugate addition of $\alpha$-amino radicals with Michael acceptors. Chem. Commun. 53, 7665-7668 (2017).

22 Wolfe, J. P. \& Buchwald, S. L. Scope and Limitations of the Pd/BINAP-Catalyzed Amination of Aryl Bromides. J. Org. Chem. 65, 1144-1157 (2000).

23 Xie, X., Zhang, T. Y. \& Zhang, Z. Synthesis of Bulky and Electron-Rich MOP-type Ligands and Their Applications in Palladium-Catalyzed C-N Bond Formation. J. Org. Chem. 71, 6522-6529 (2006).

24 Liu, K.-J., Zeng, X.-L., Zhang, Y., Wang, Y., Xiao, X.-S., Yue, H., Wang, M., Tang, Z. $\&$ He, W.-M. Palladium-Catalyzed Reductive Coupling of Nitroarenes with Phenolsleading to N-Cyclohexylanilines. Synthesis 50, 4637-4644 (2018).

25 Suárez-Pantiga, S., Hernández-Ruiz, R., Virumbrales, C., Pedrosa, M. R. \& Sanz, R. Reductive Molybdenum-Catalyzed Direct Amination of Boronic Acids with Nitro Compounds. Angew. Chem. Int. Ed. 58, 2129-2133 (2019).

26 Desmarets, C., Schneider, R. \& Fort, Y. Nickel(0)/Dihydroimidazol-2-ylidene Complex Catalyzed Coupling of Aryl Chlorides and Amines. J. Org. Chem. 67, 3029-3036 (2002).

27 Wolfe, J. P., Tomori, H., Sadighi, J. P., Yin, J. \& Buchwald, S. L. Simple, Efficient Catalyst System for the Palladium-Catalyzed Amination of Aryl Chlorides, Bromides, and Triflates. J. Org. Chem. 65, 1158-1174 (2000).

28 Yoshida, H., Morishita, T. \& Ohshita, J. Direct Access to Anthranilic Acid Derivatives via CO2 Incorporation Reaction Using Arynes. Org. Lett. 10, 3845-3847 (2008).

29 Brenner, E., Schneider, R. \& Fort, Y. Nickel-catalysed couplings of aryl chlorides with secondary amines and piperazines. Tetrahedron 55, 12829-12842 (1999). 
30 Johnson, T. C., Elbert, Bryony L., Farley, A. J. M., Gorman, T. W., Genicot, C., Lallemand, B., Pasau, P., Flasz, J., Castro, J. L., MacCoss, M., Dixon, D. J., Paton, R. S., Schofield, C. J., Smith, M. D. \& Willis, M. C. Direct sulfonylation of anilines mediated by visible light. Chem. Sci. 9, 629-633 (2018).

31 Hollmann, D., Bähn, S., Tillack, A., Parton, R., Altink, R. \& Beller, M. A novel saltfree ruthenium-catalyzed alkylation of aryl amines. Tetrahedron Lett. 49, 5742-5745 (2008).

$32 \mathrm{Ju}$, Y. \& Varma, R. S. An Efficient and Simple Aqueous N-Heterocyclization of Aniline Derivatives: Microwave-Assisted Synthesis of N-Aryl Azacycloalkanes. Org. Lett. 7, 2409-2411 (2005).

33 Lim, S., Song, D., Jeon, S., Kim, Y., Kim, H., Lee, S., Cho, H., Lee, B. C., Kim, S. E., Kim, K. \& Lee, E. Cobalt-Catalyzed C-F Bond Borylation of Aryl Fluorides. Org. Lett. 20, 7249-7252 (2018).

34 Wolfe, J. P. \& Buchwald, S. L. Palladium-Catalyzed Amination of Aryl Triflates. J. Org. Chem. 62, 1264-1267 (1997).

35 Lakshminarayana, N., Prasad, Y. R., Gharat, L., Thomas, A., Narayanan, S., Raghuram, A., Srinivasan, C. V. \& Gopalan, B. Synthesis and evaluation of some novel dibenzo[b,d]furan carboxylic acids as potential anti-diabetic agents. Eur. J. Med. Chem. 45, 3709-3718 (2010).

36 Charles, M. D., Schultz, P. \& Buchwald, S. L. Efficient Pd-Catalyzed Amination of Heteroaryl Halides. Org. Lett. 7, 3965-3968 (2005).

37 Maiti, D., Fors, B. P., Henderson, J. L., Nakamura, Y. \& Buchwald, S. L. Palladiumcatalyzed coupling of functionalized primary and secondary amines with aryl and heteroaryl halides: two ligands suffice in most cases. Chem. Sci. 2, 57-68 (2011). 
12. Copies of NMR spectra
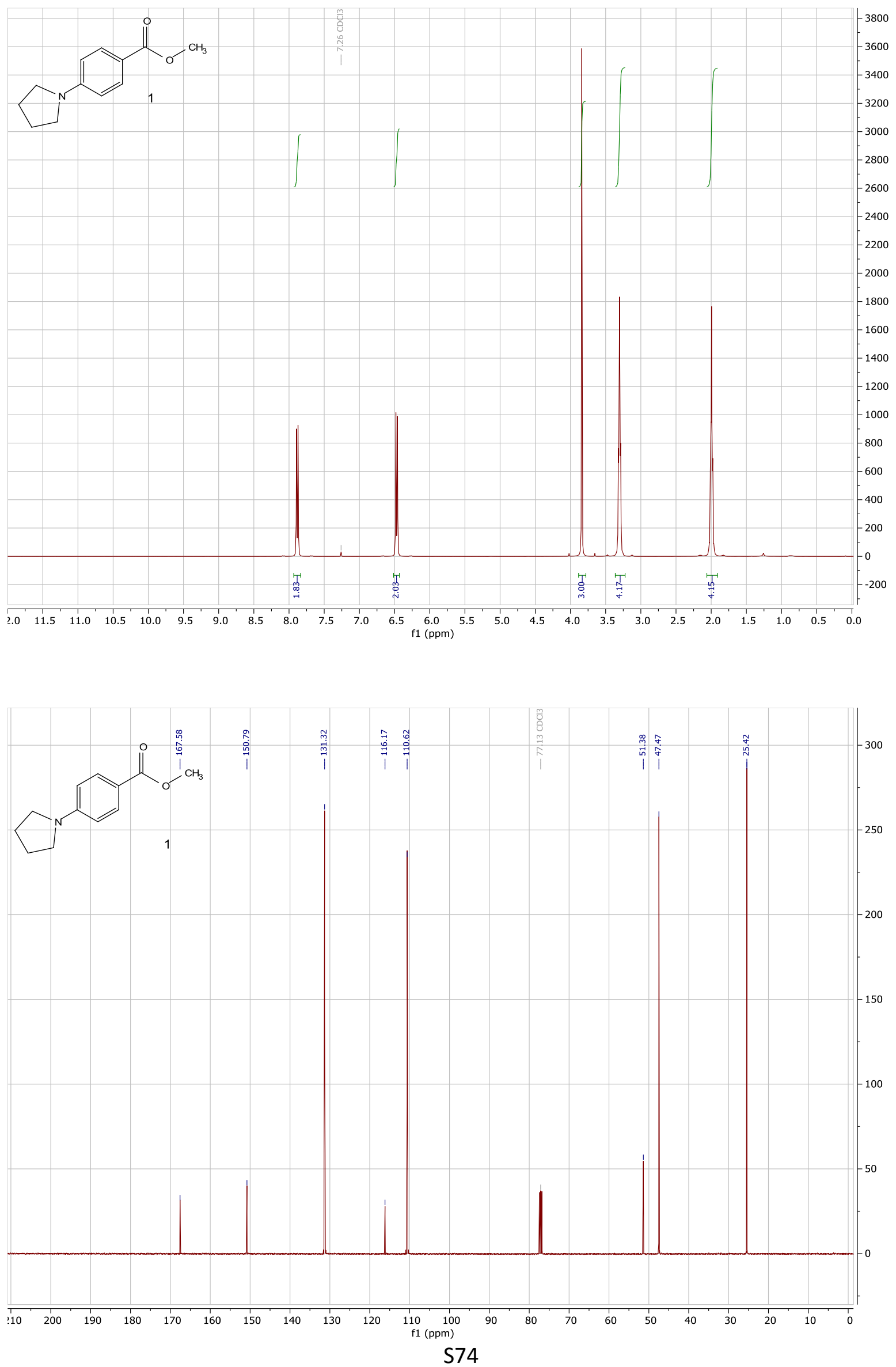

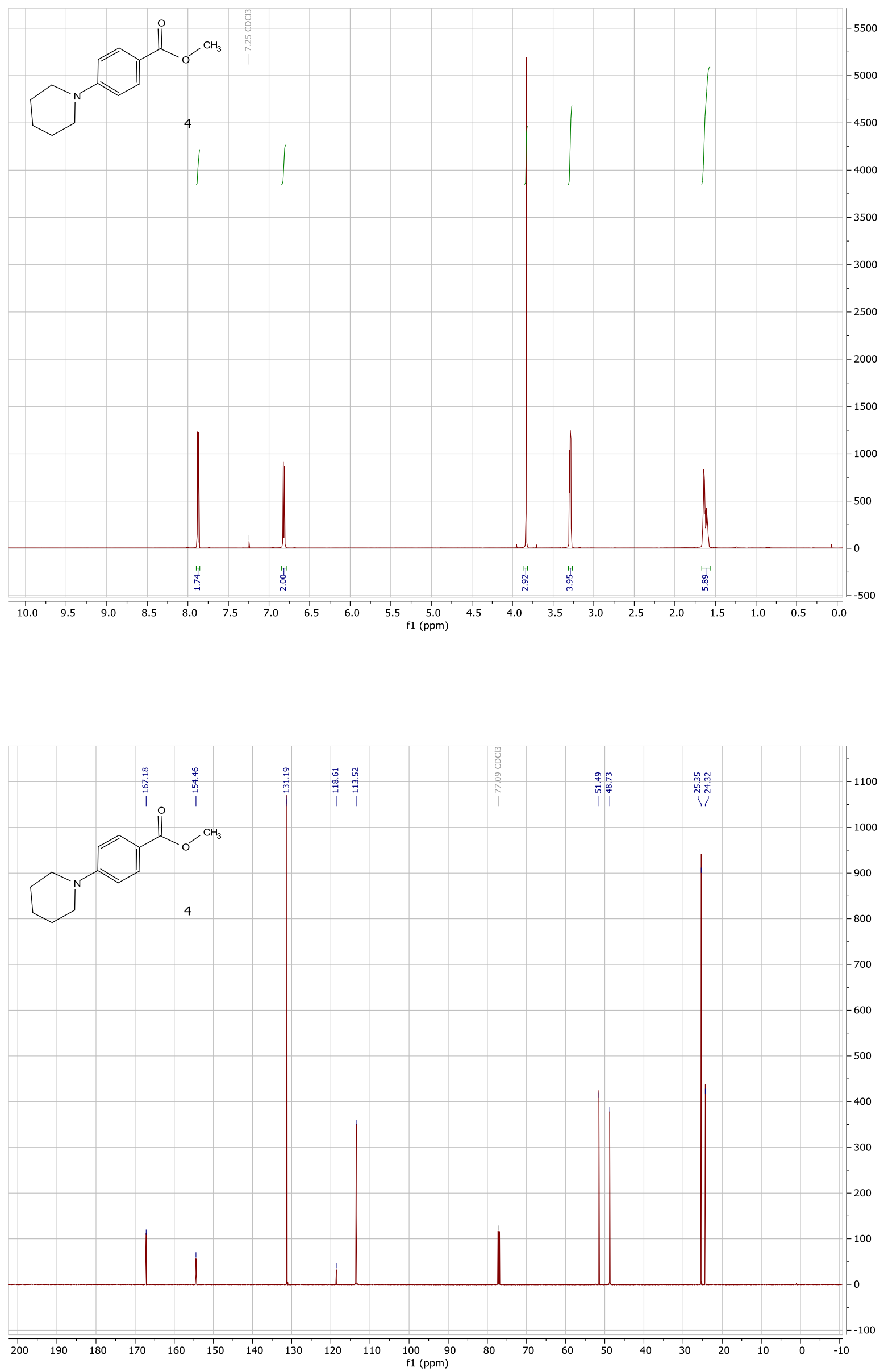

S75 

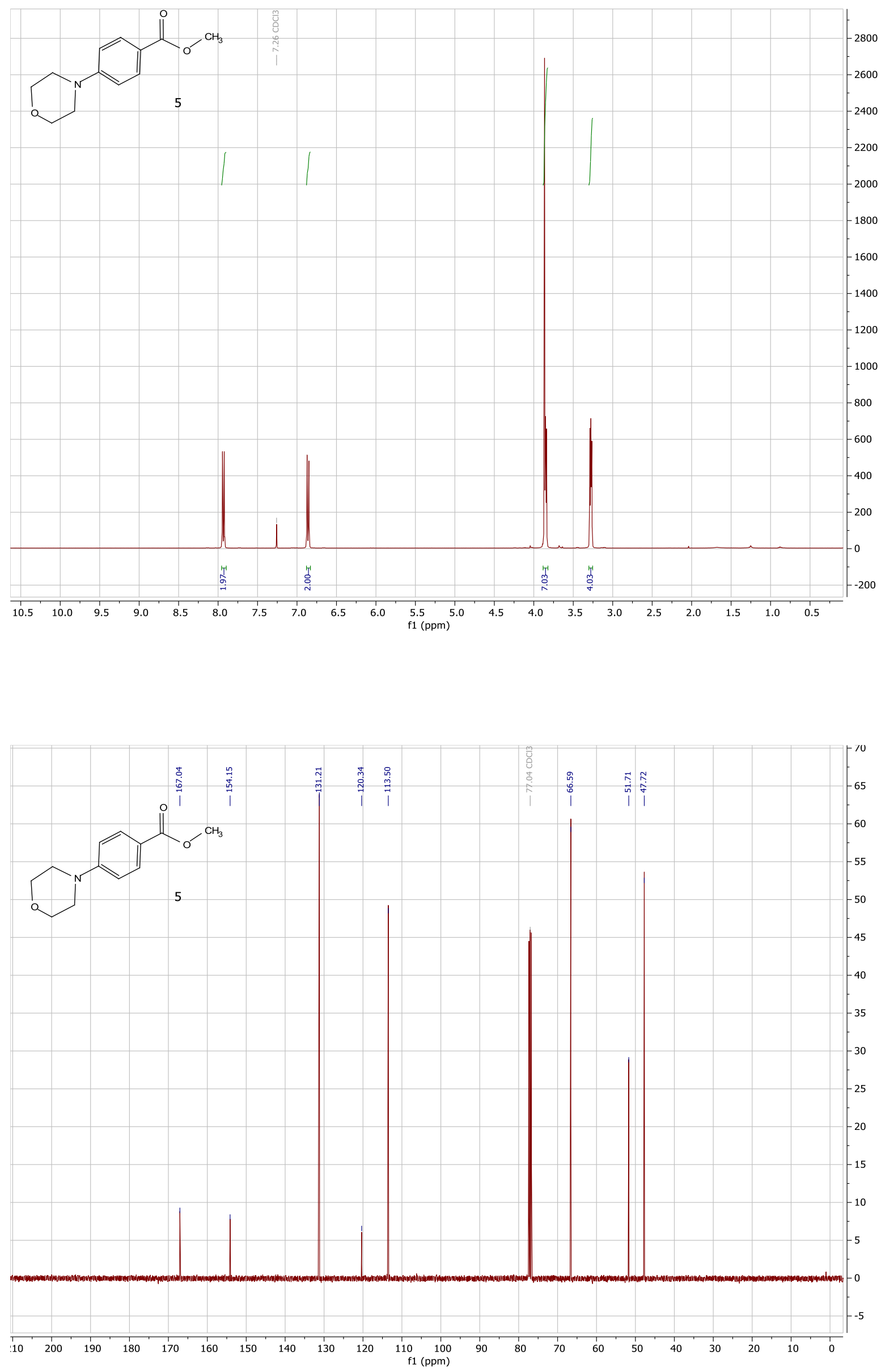

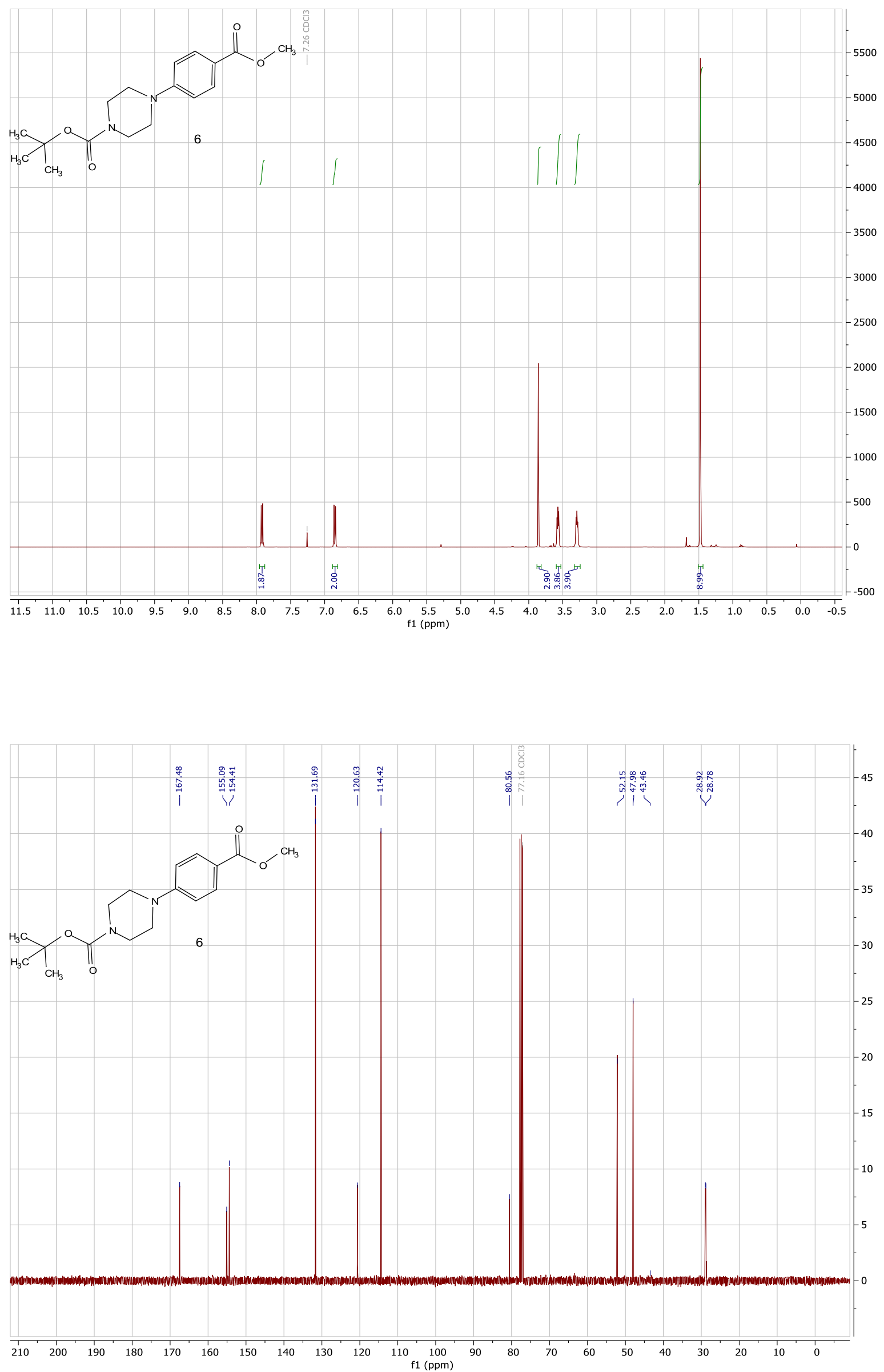

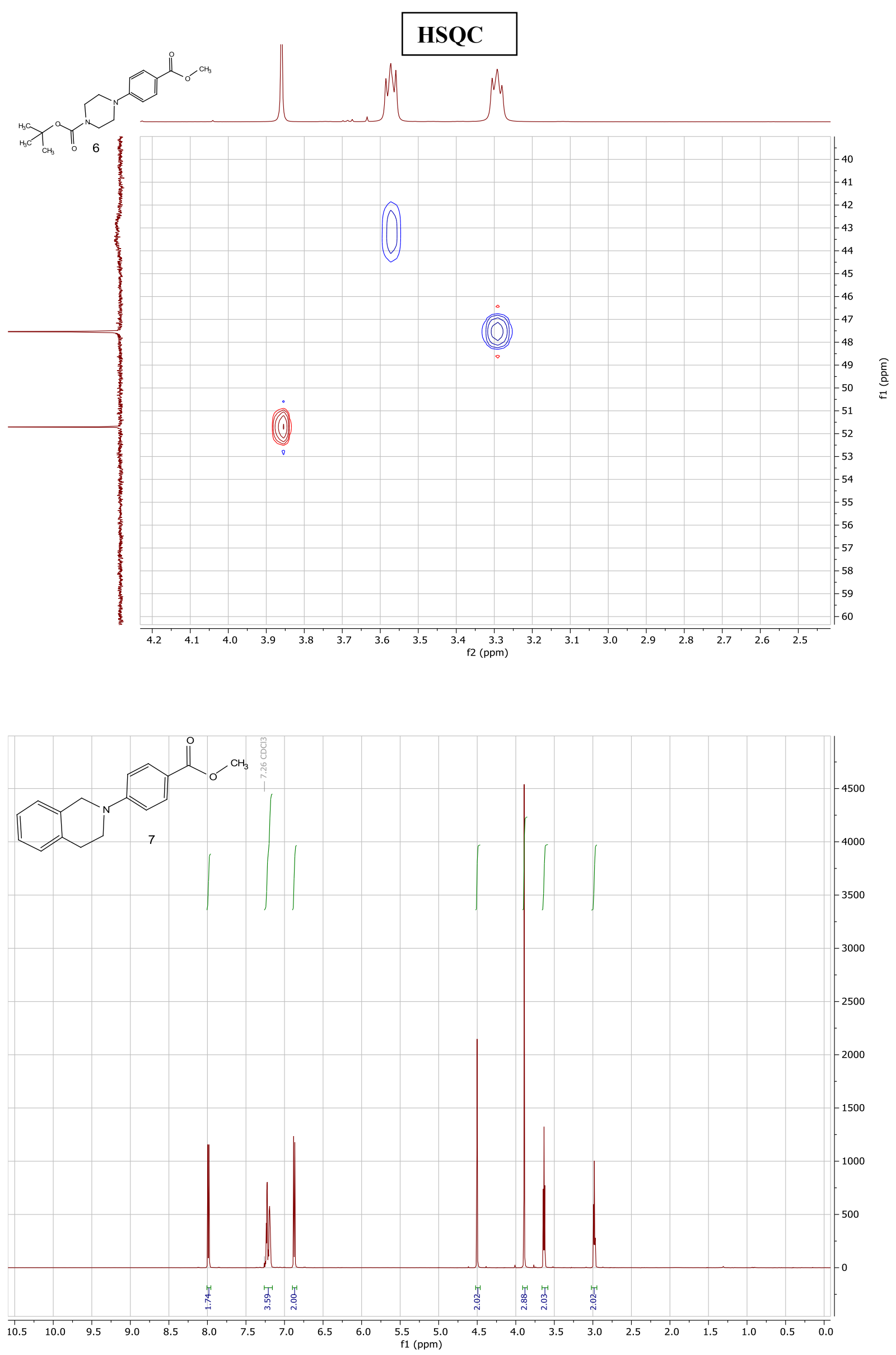

S78 

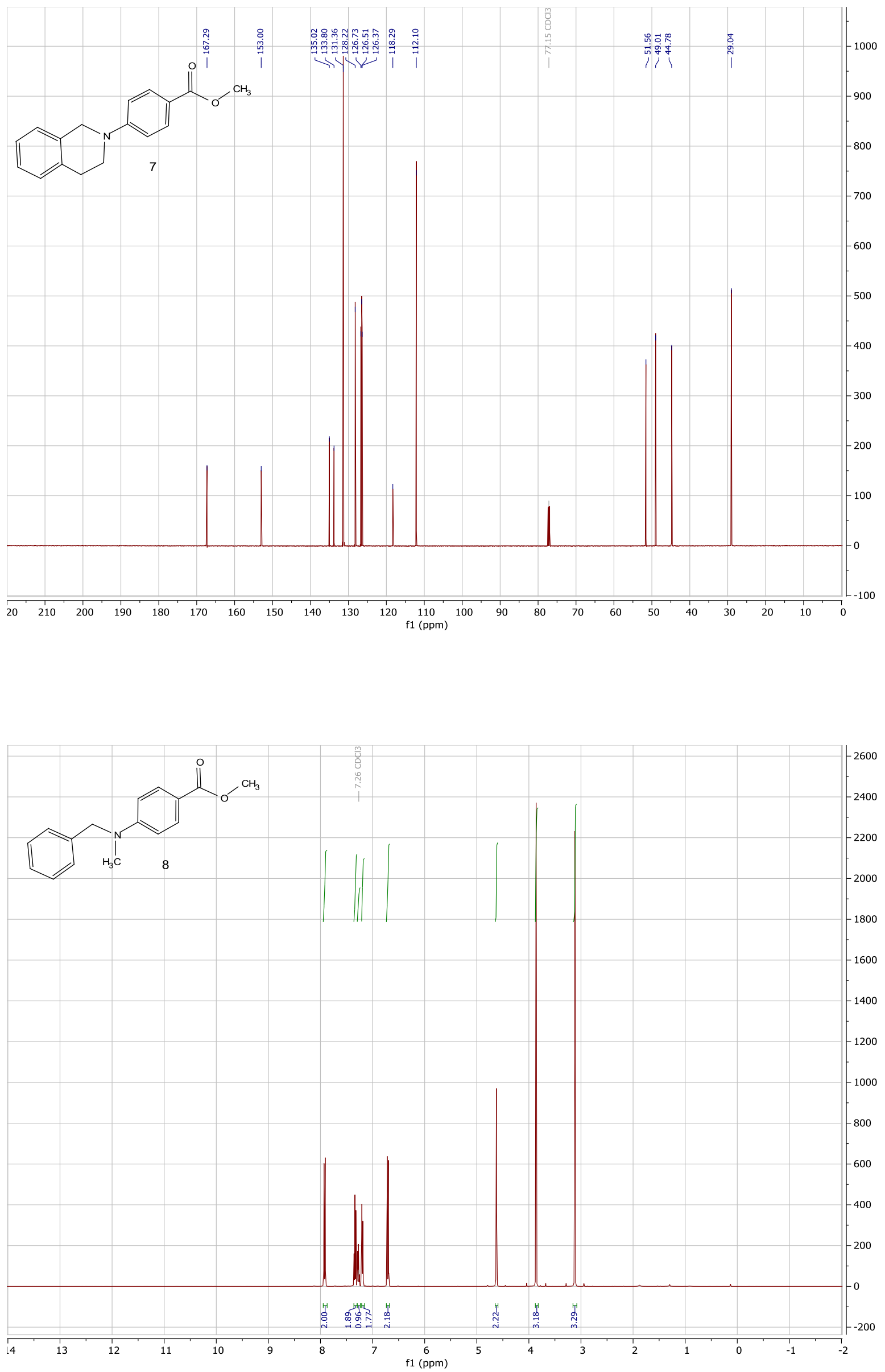

S79 

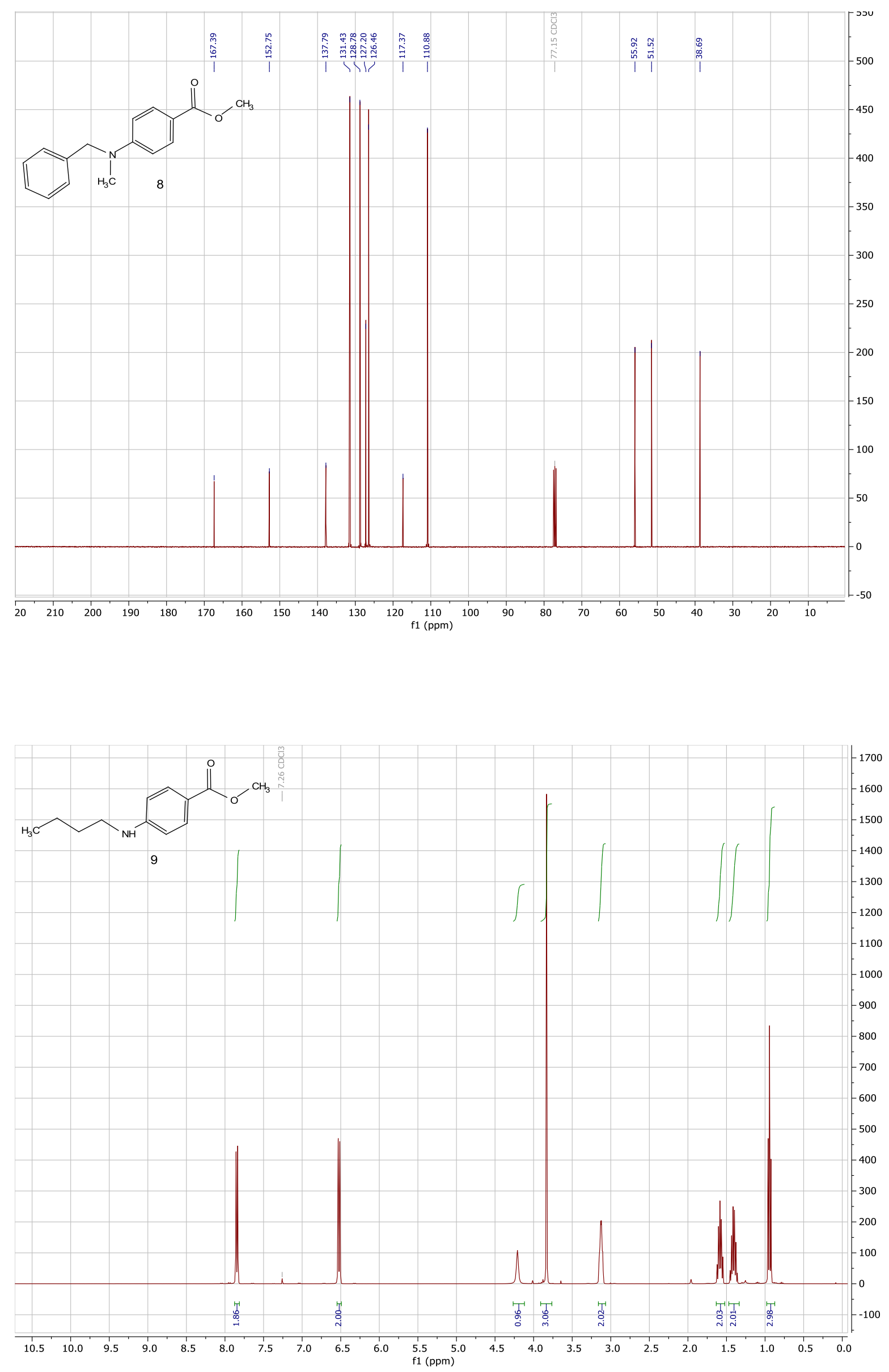

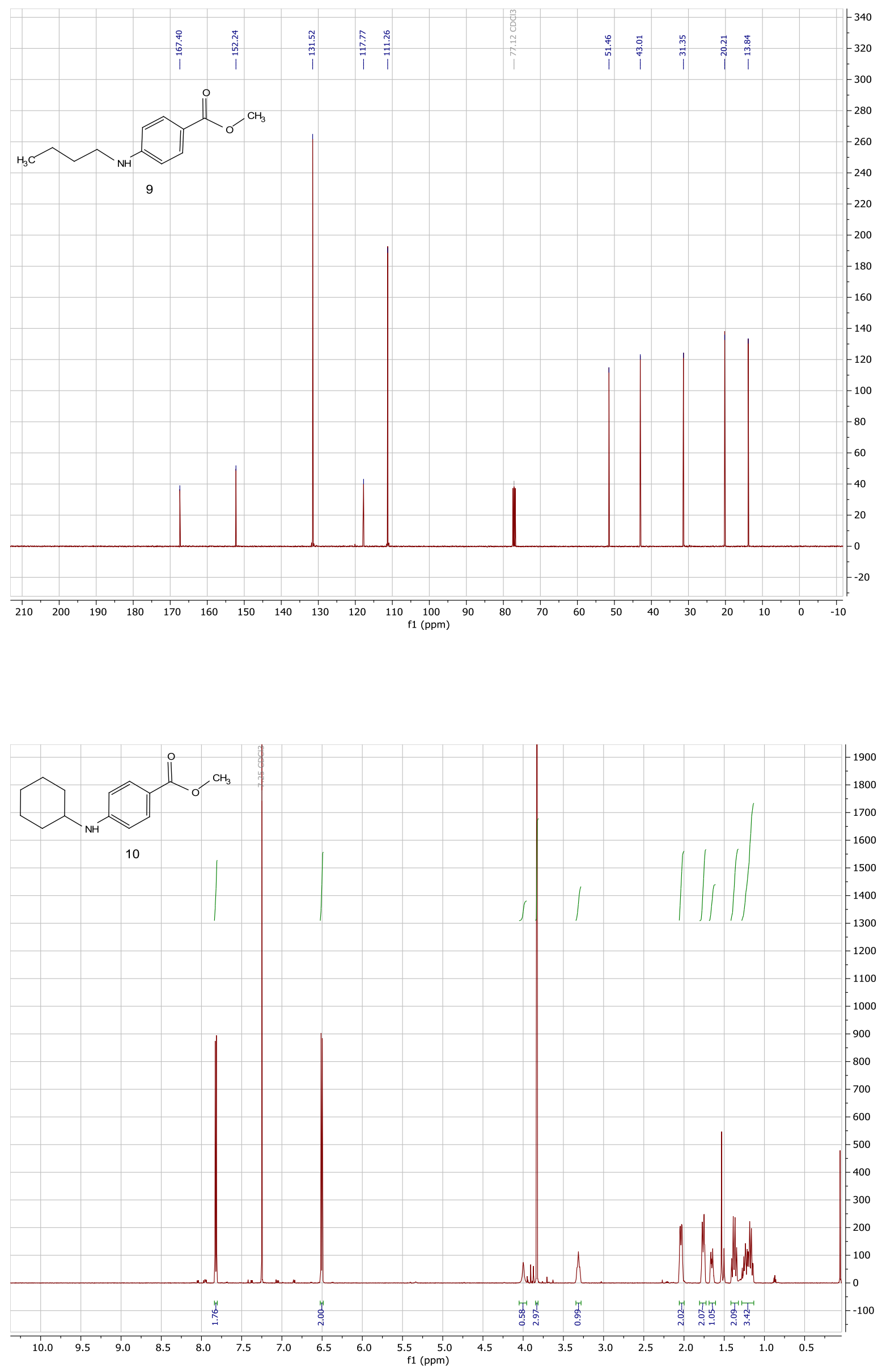

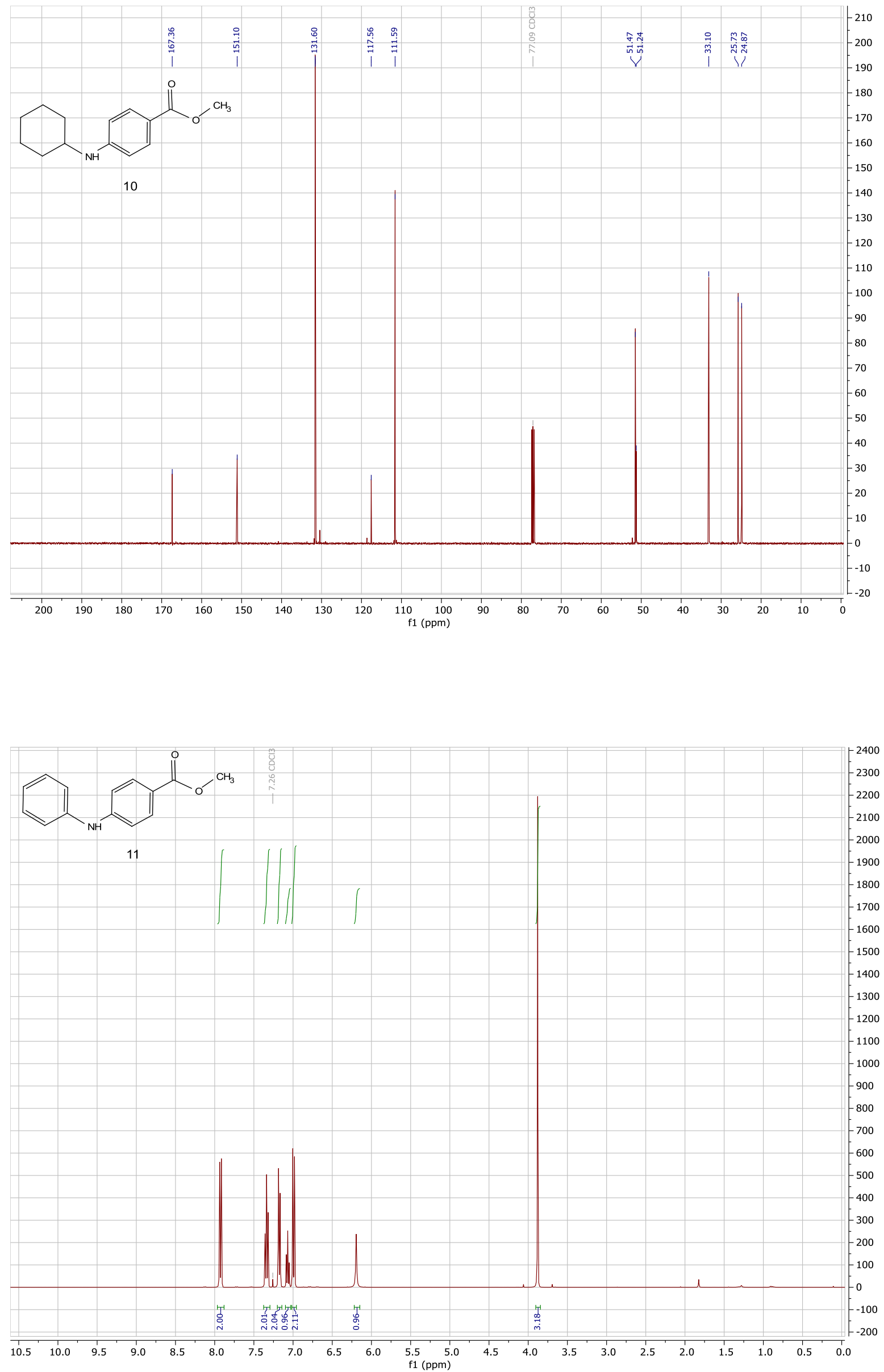

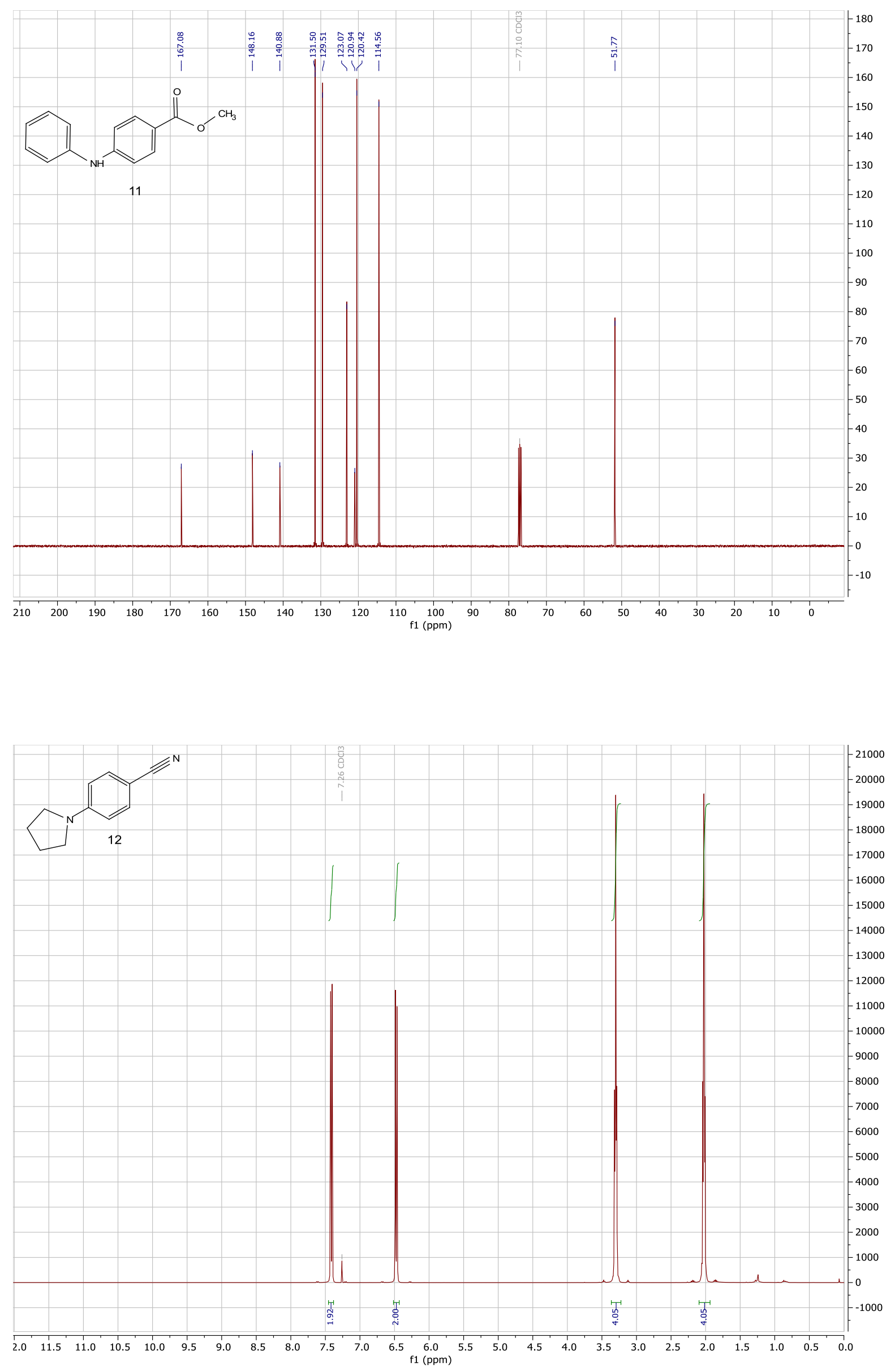

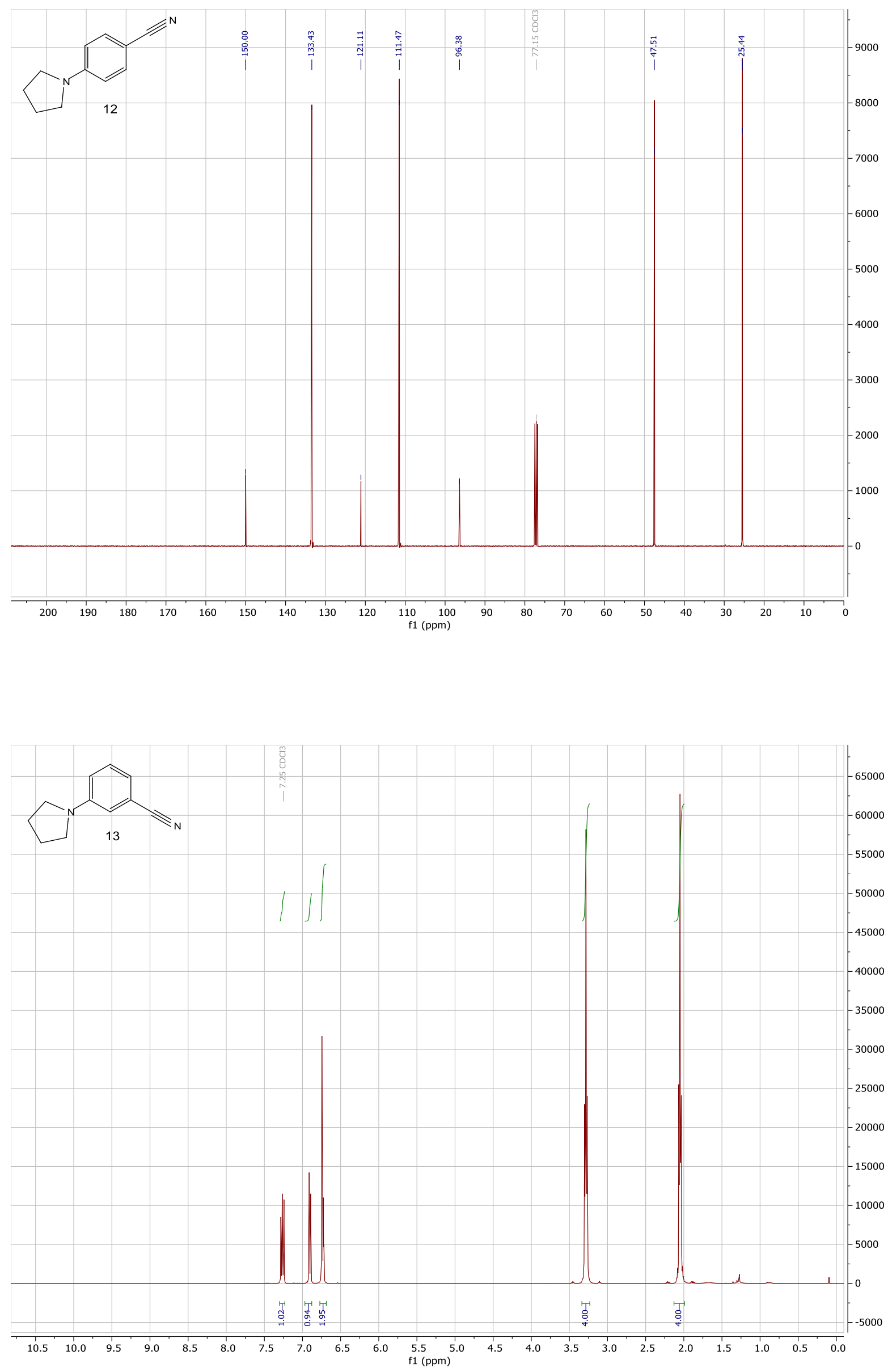

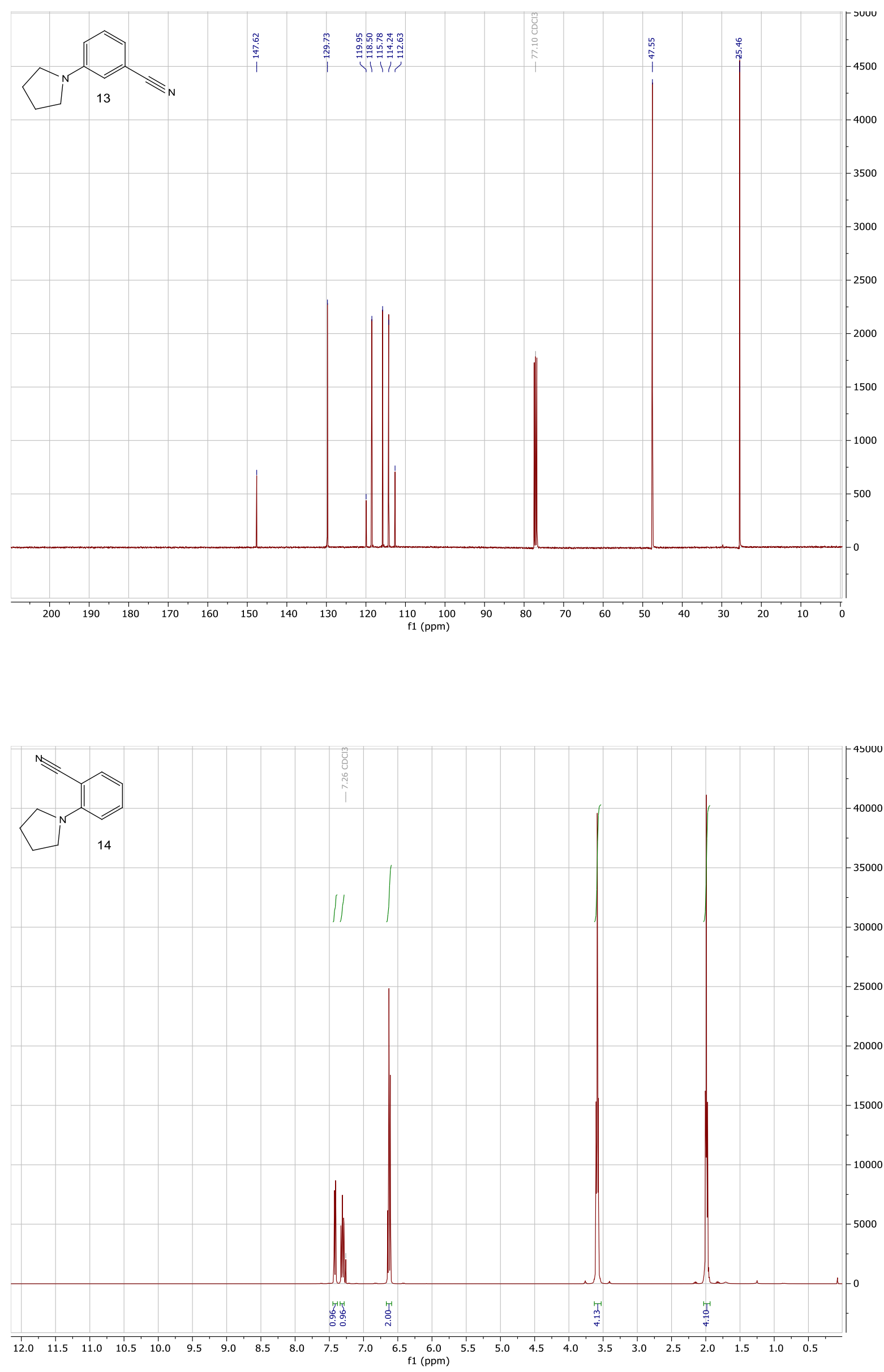

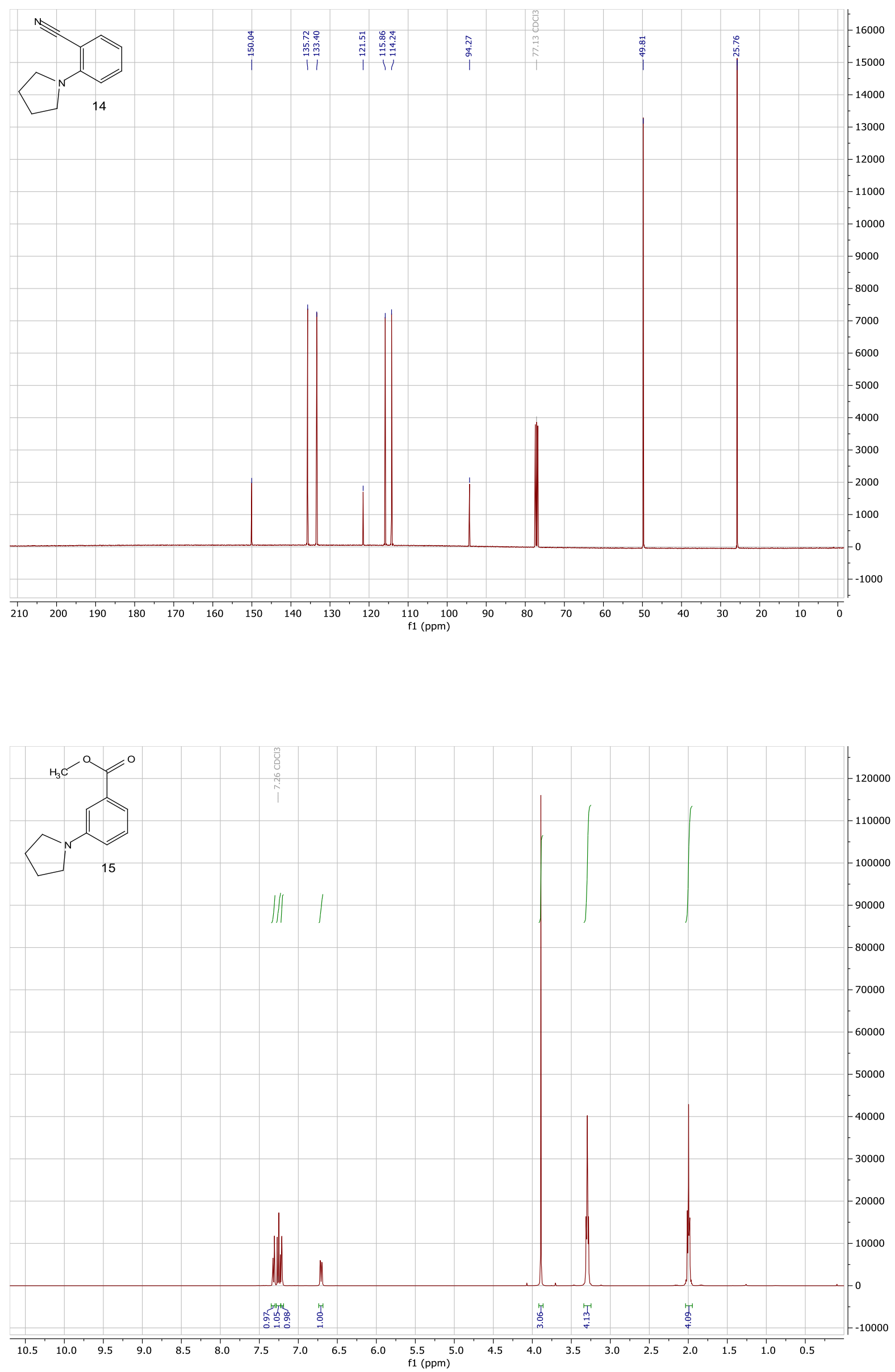

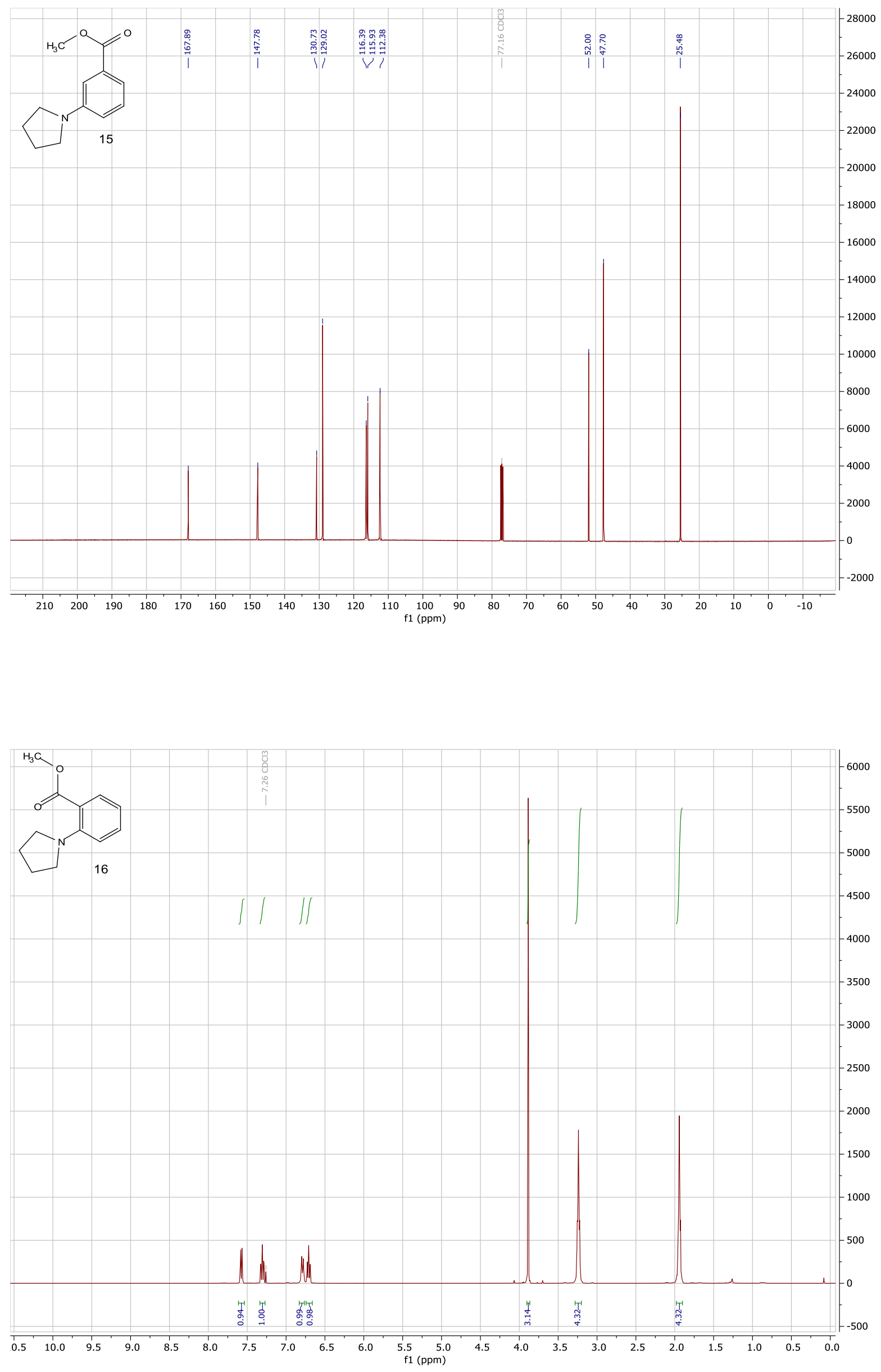

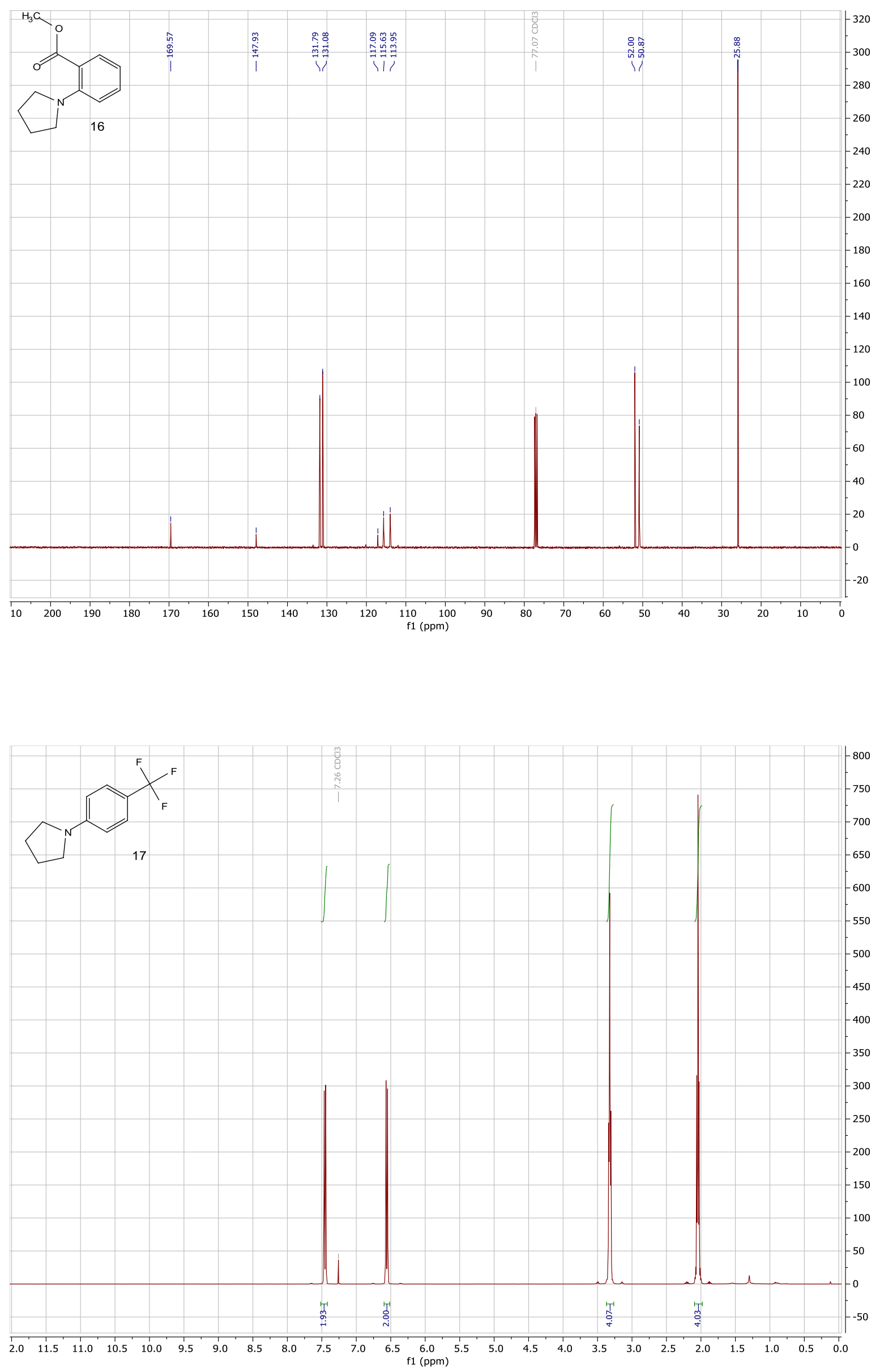

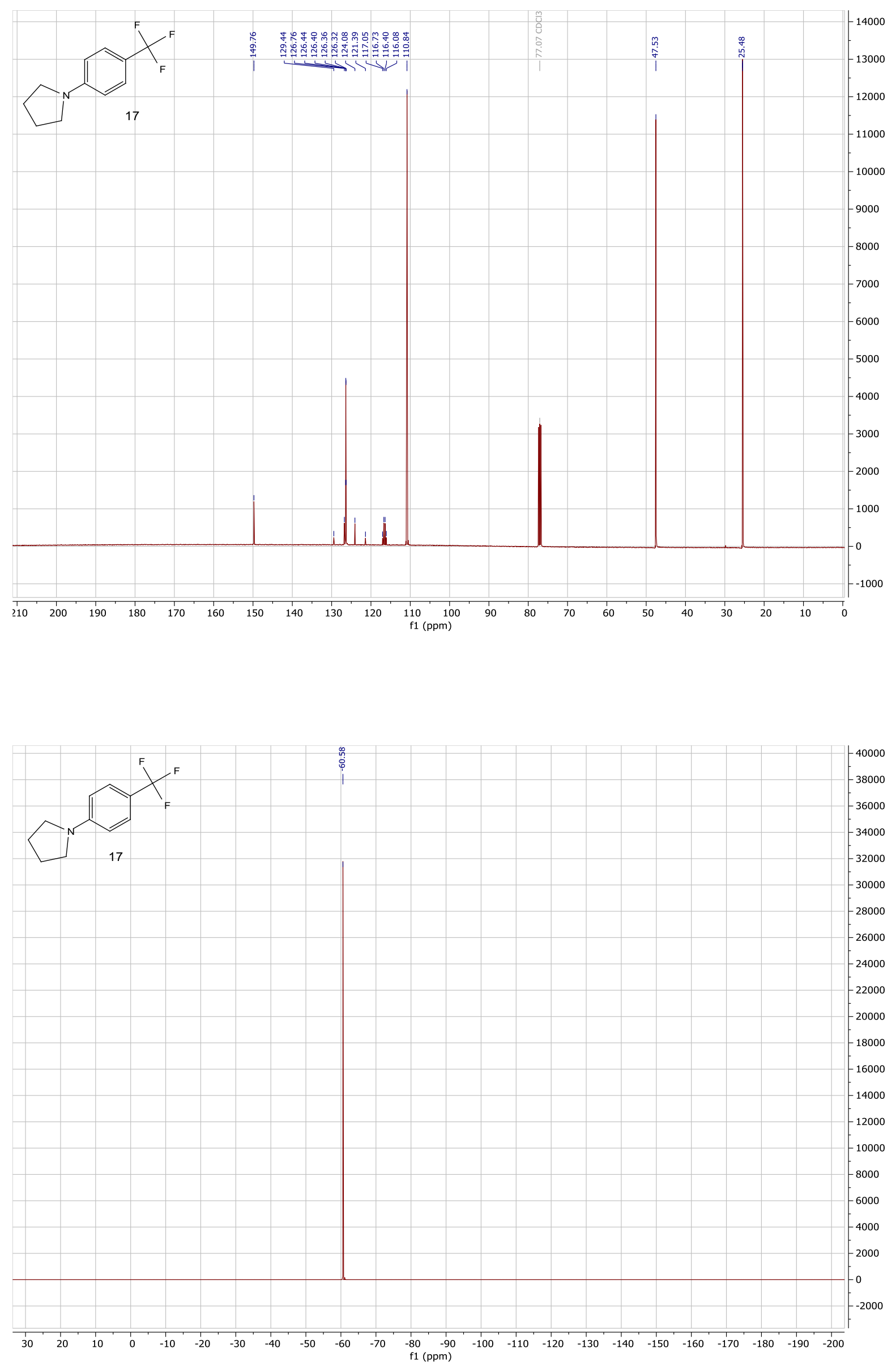

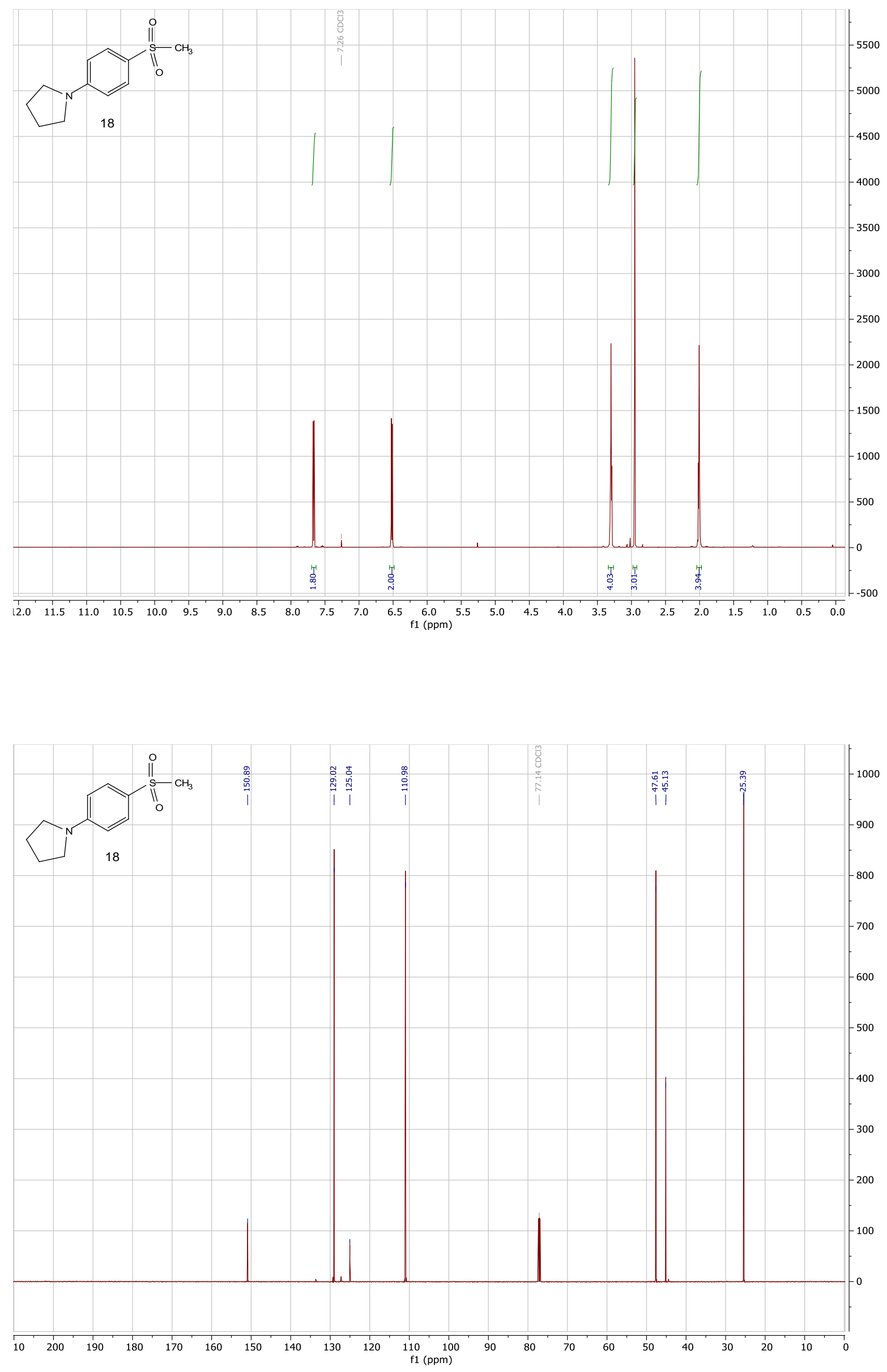

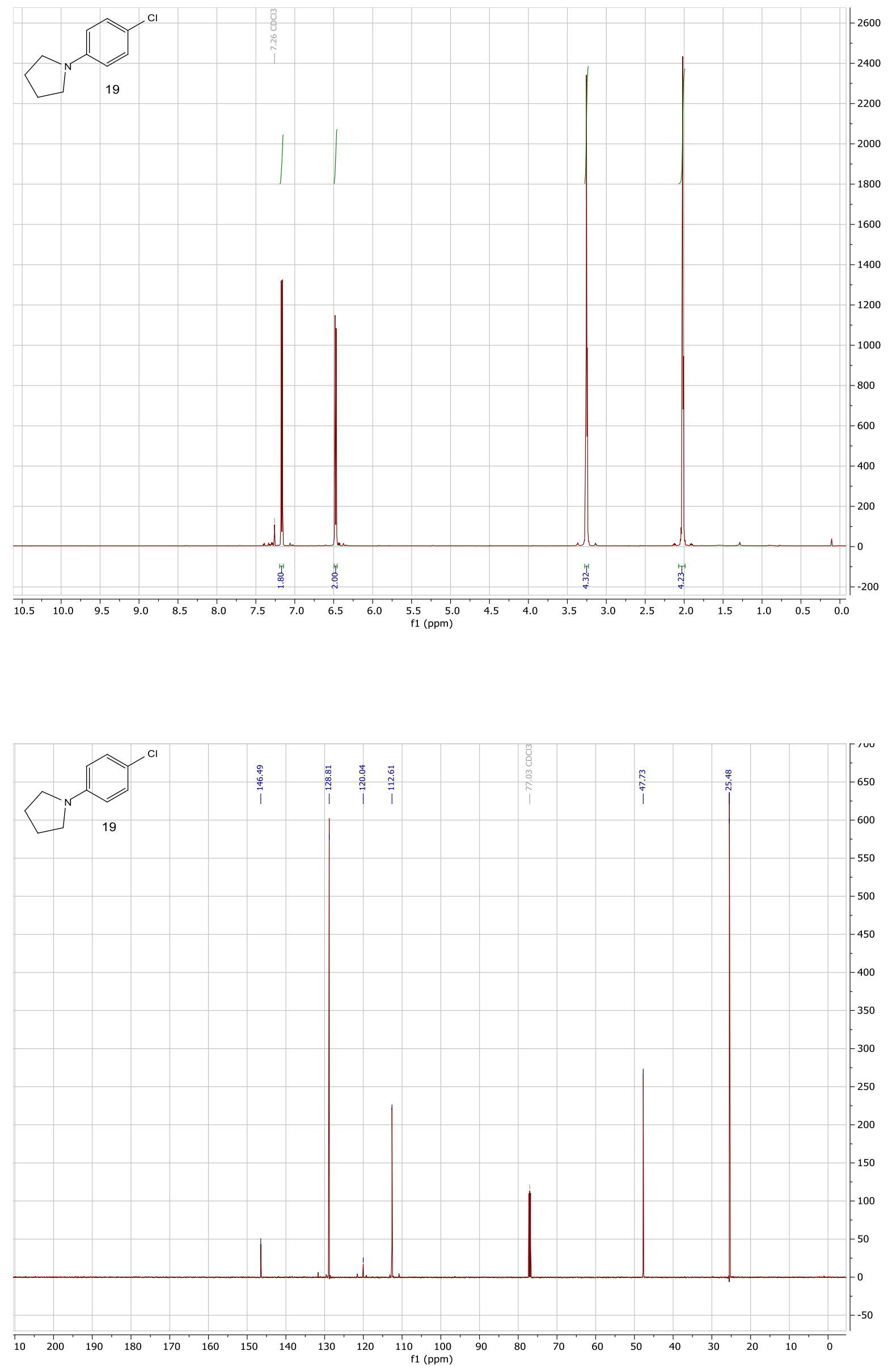

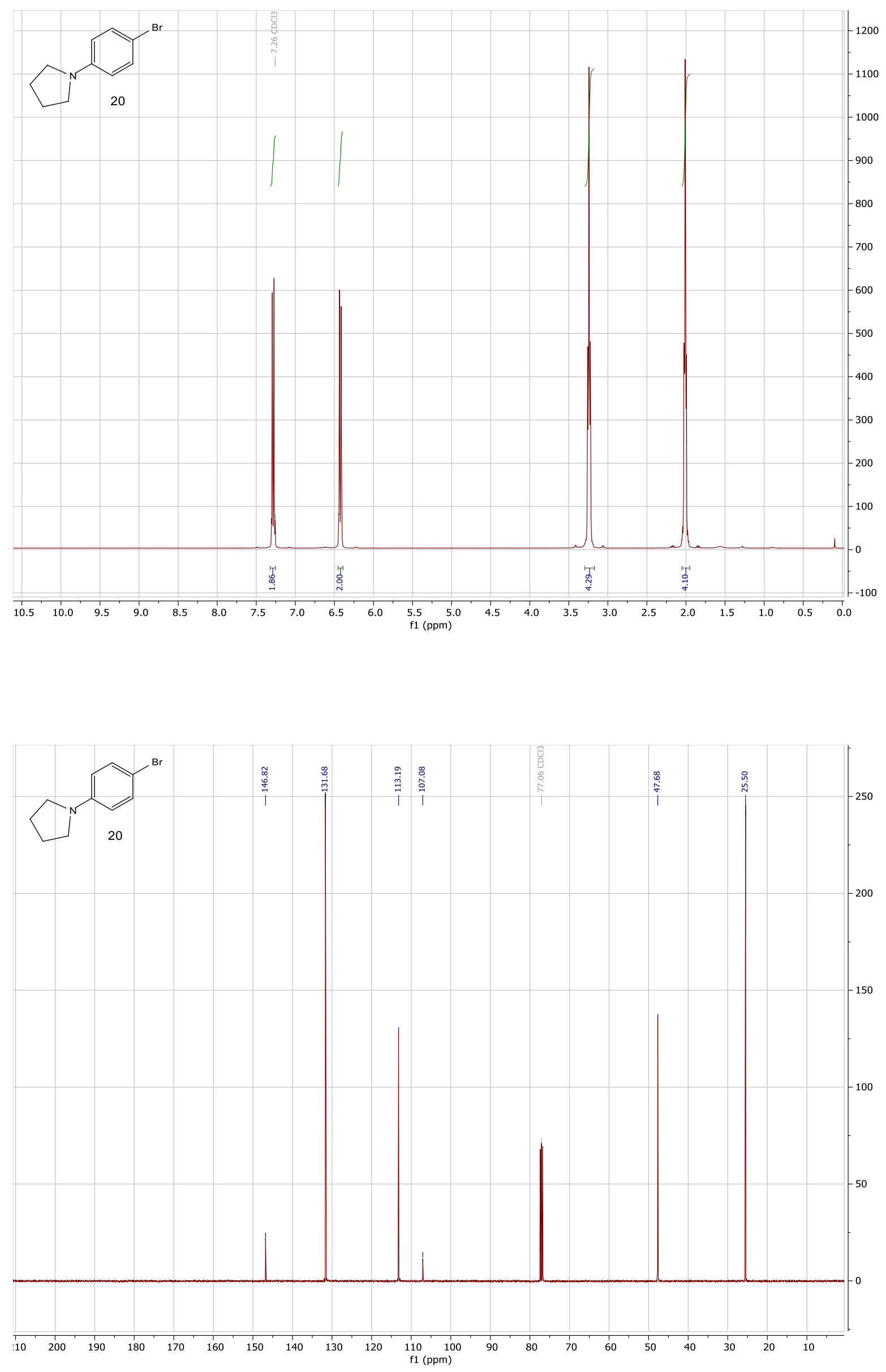

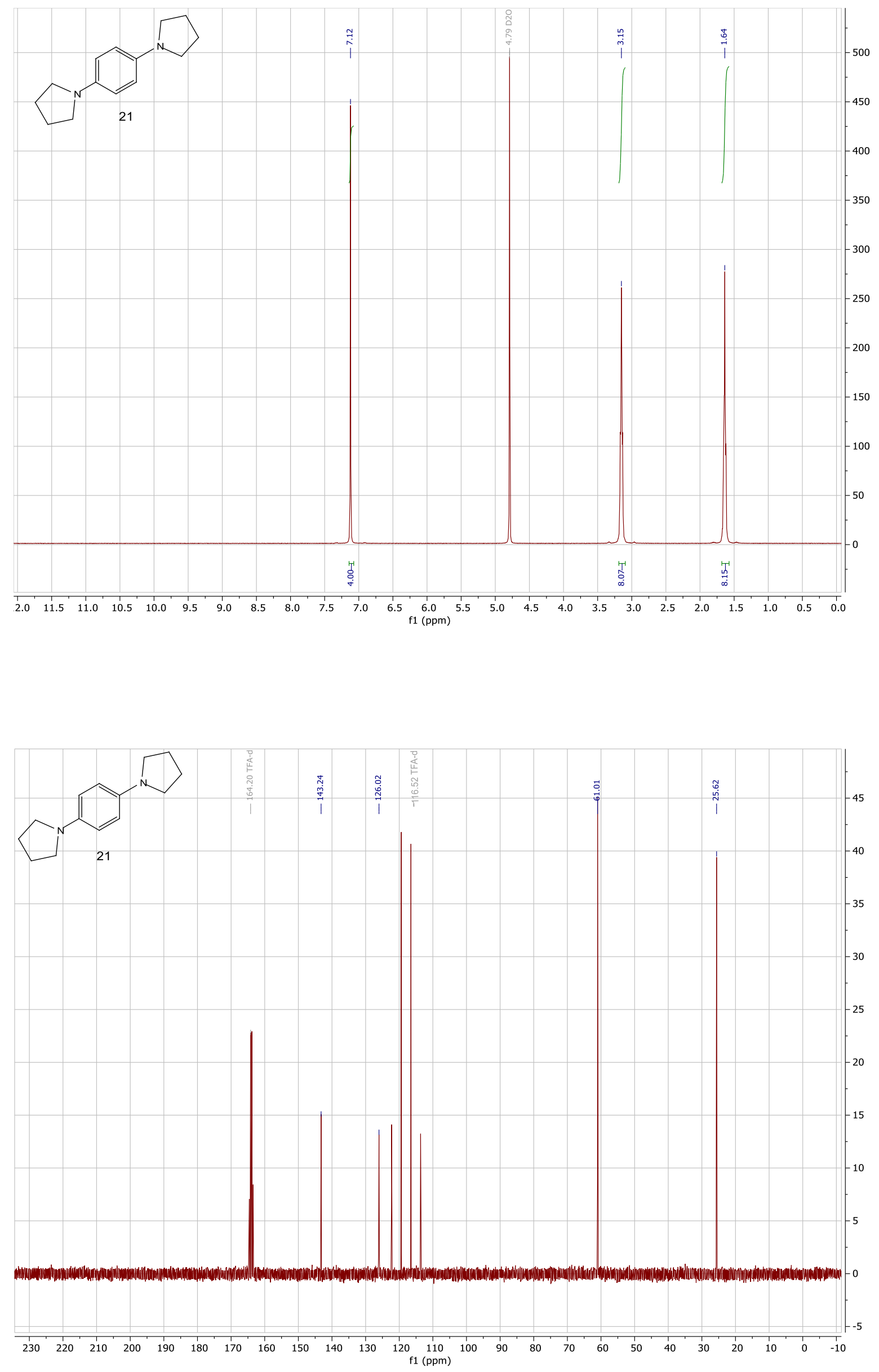

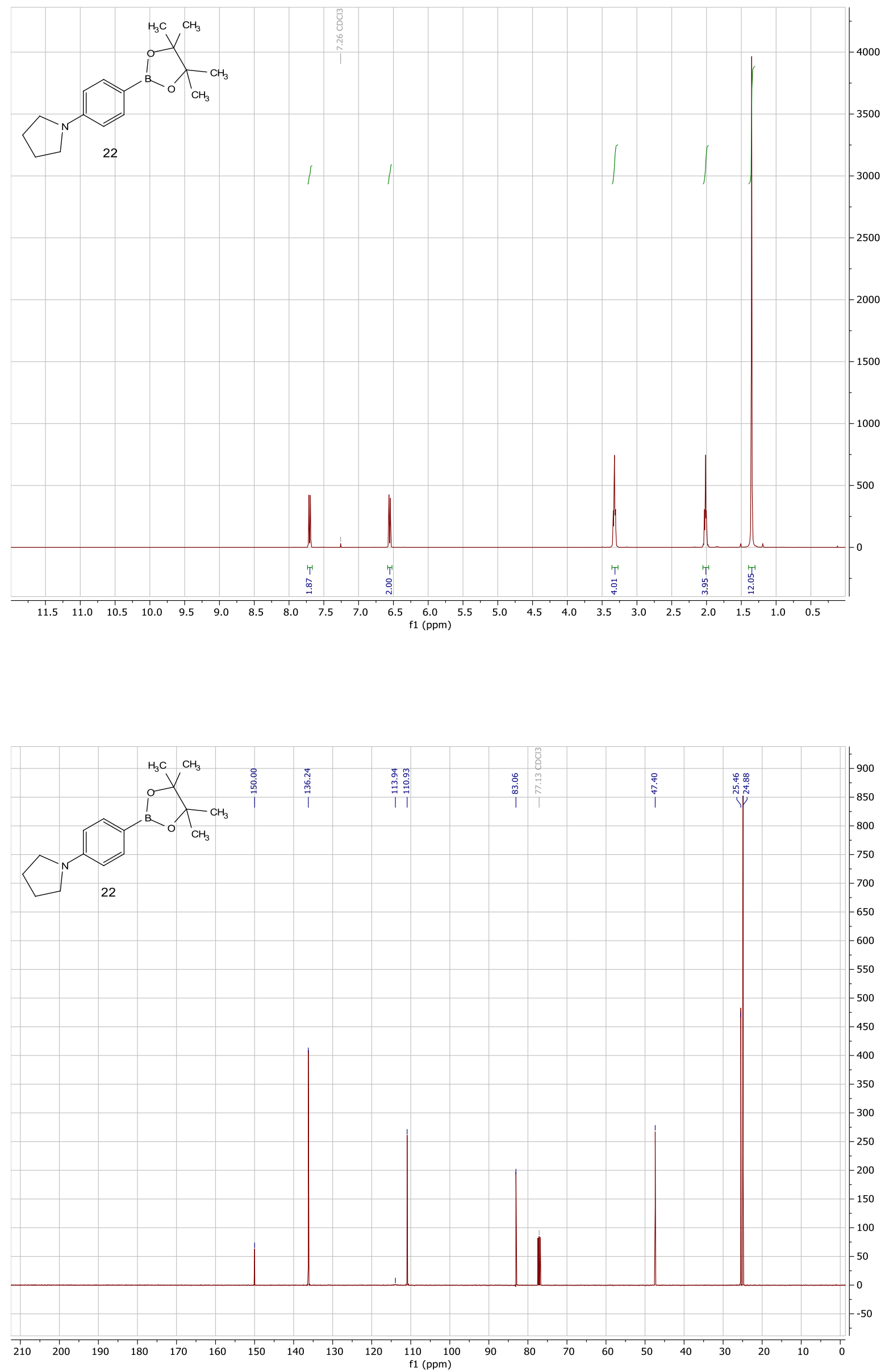

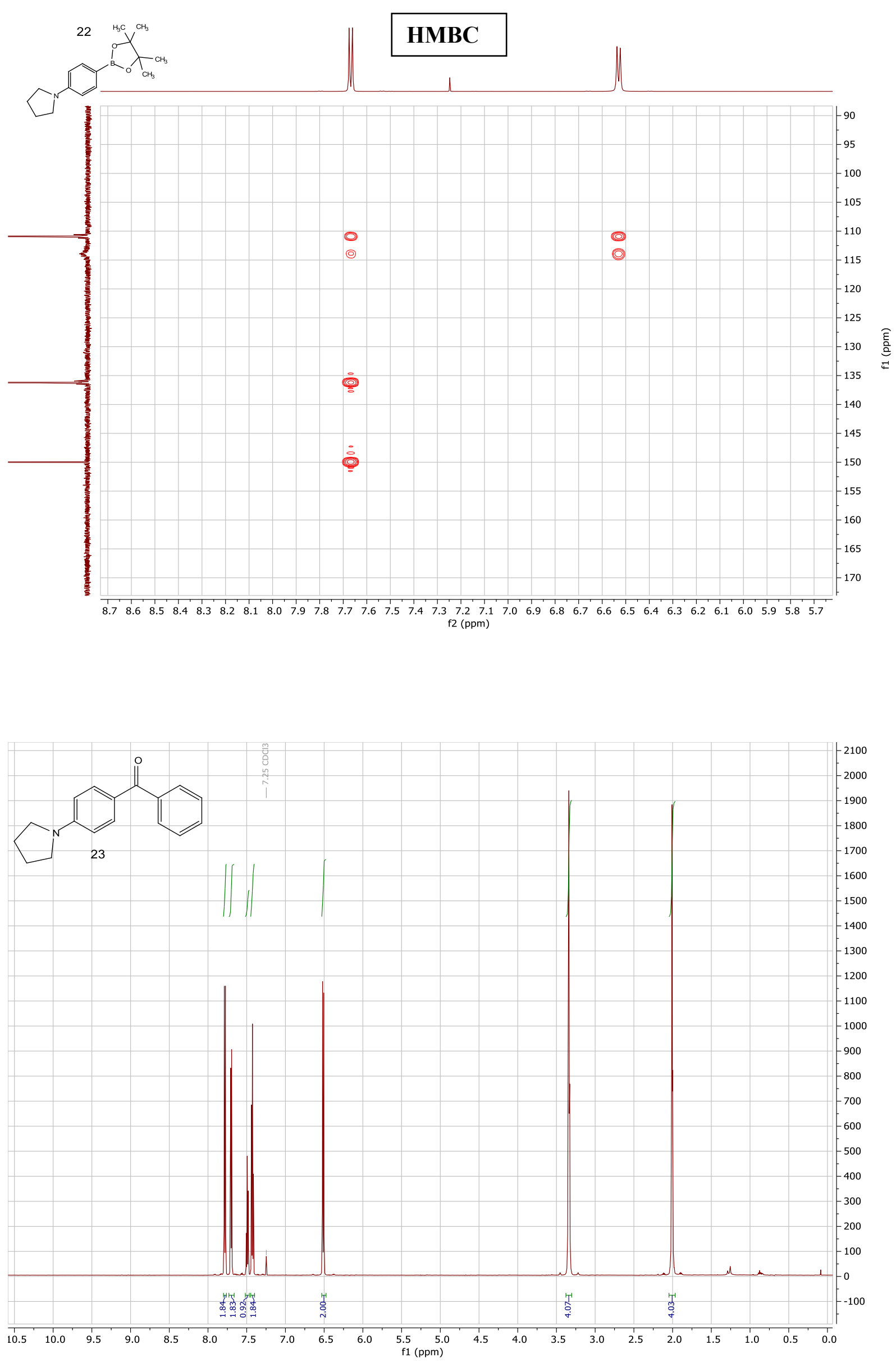

S95 

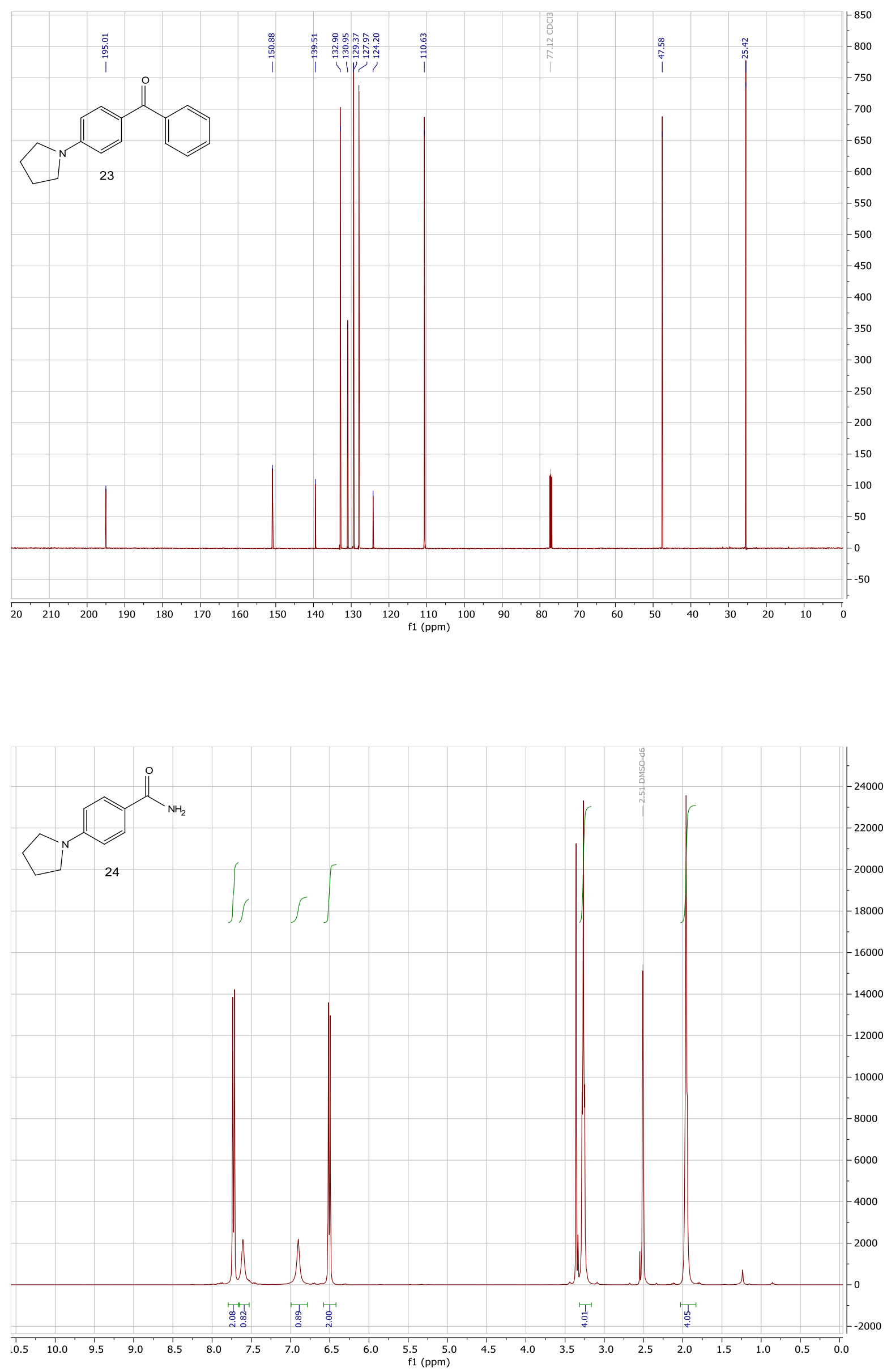

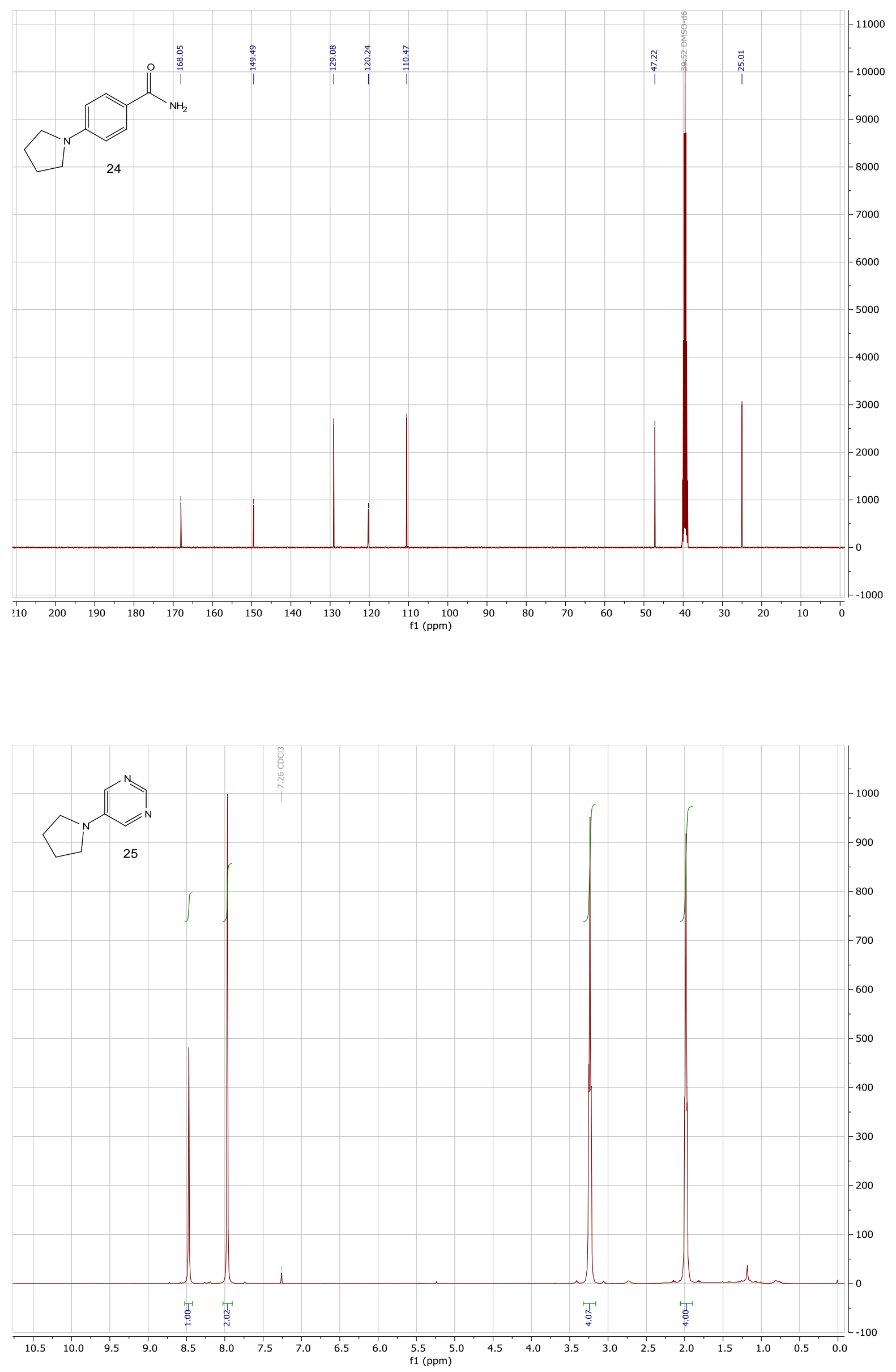

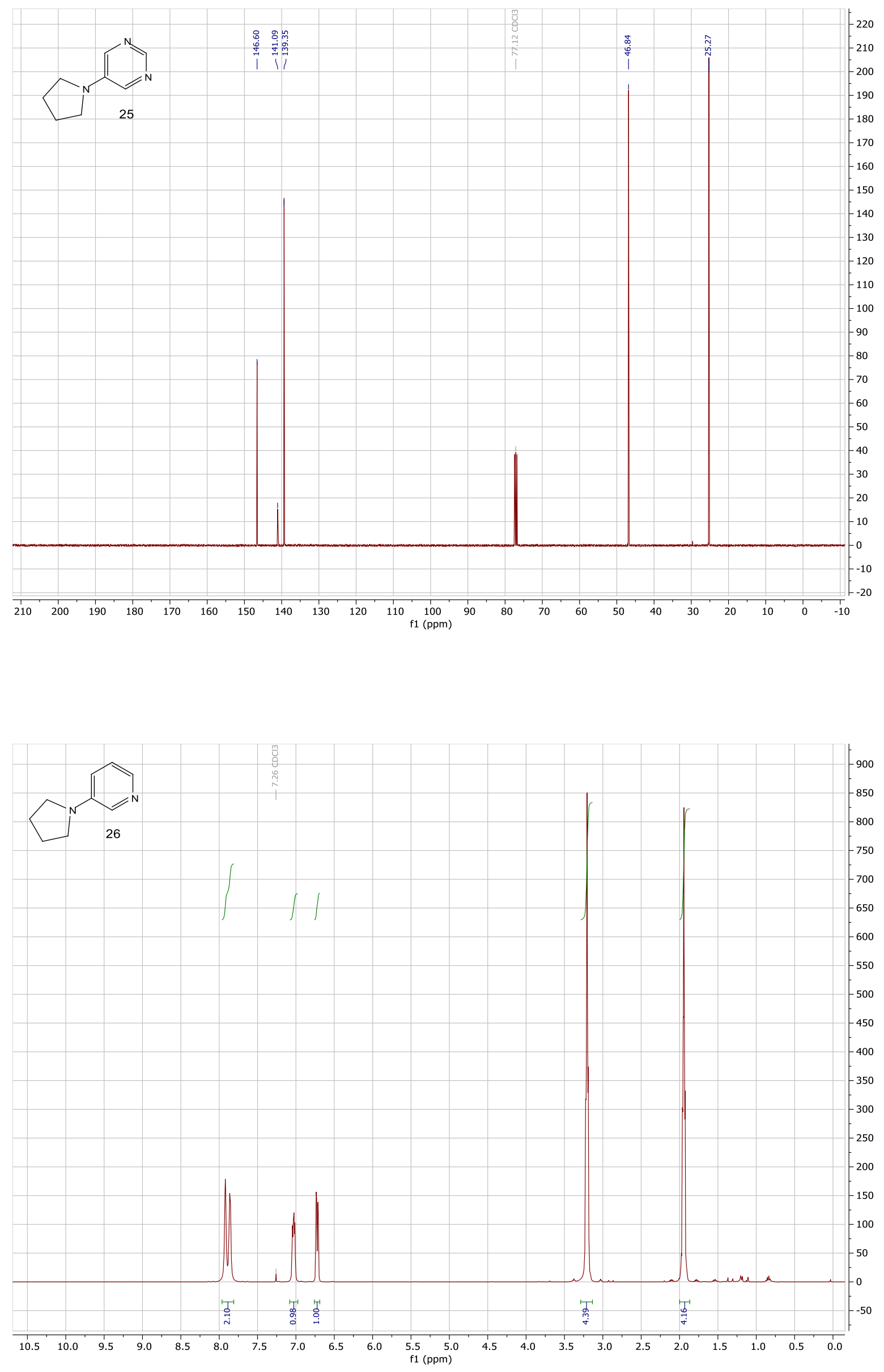

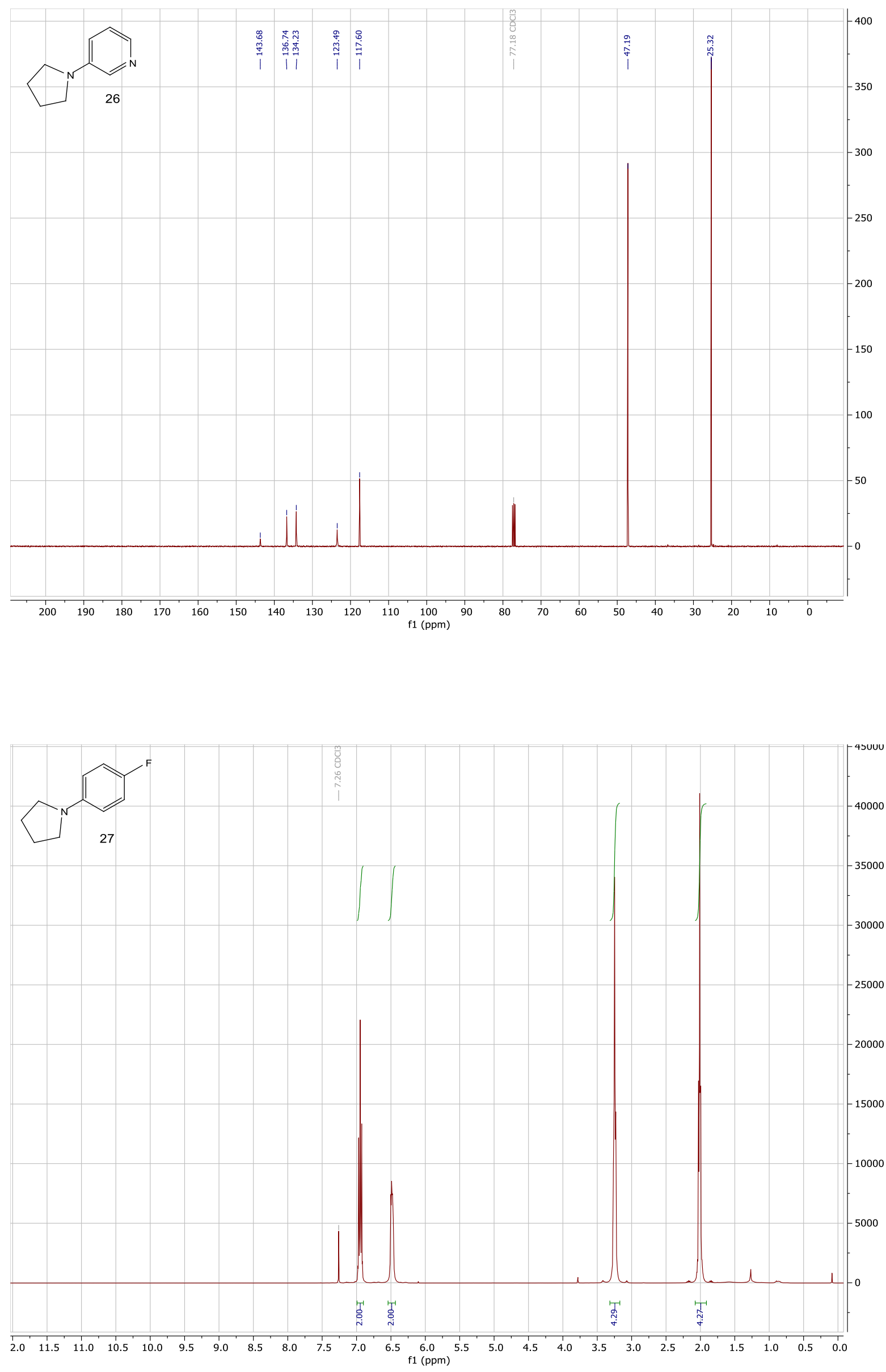

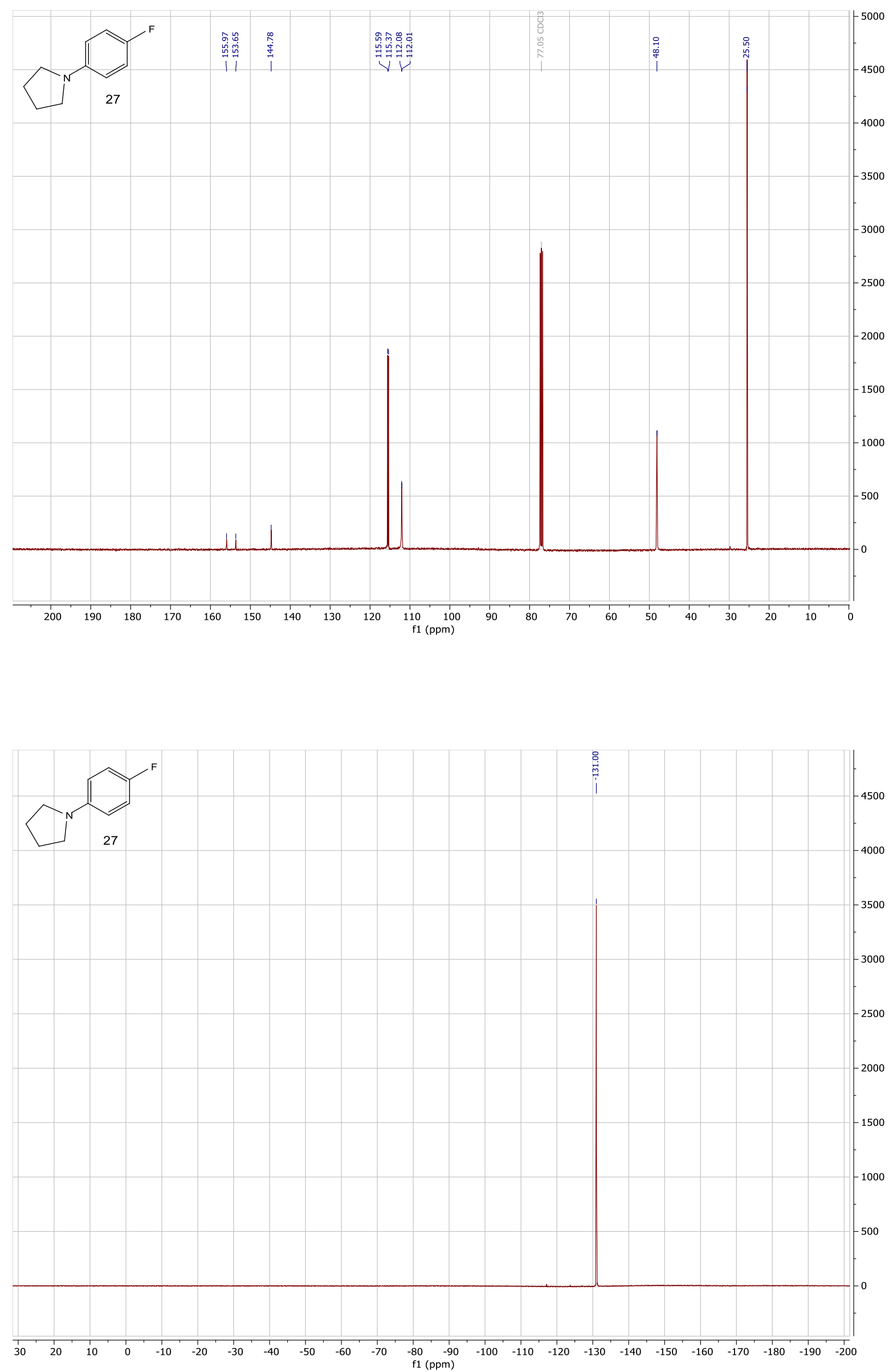

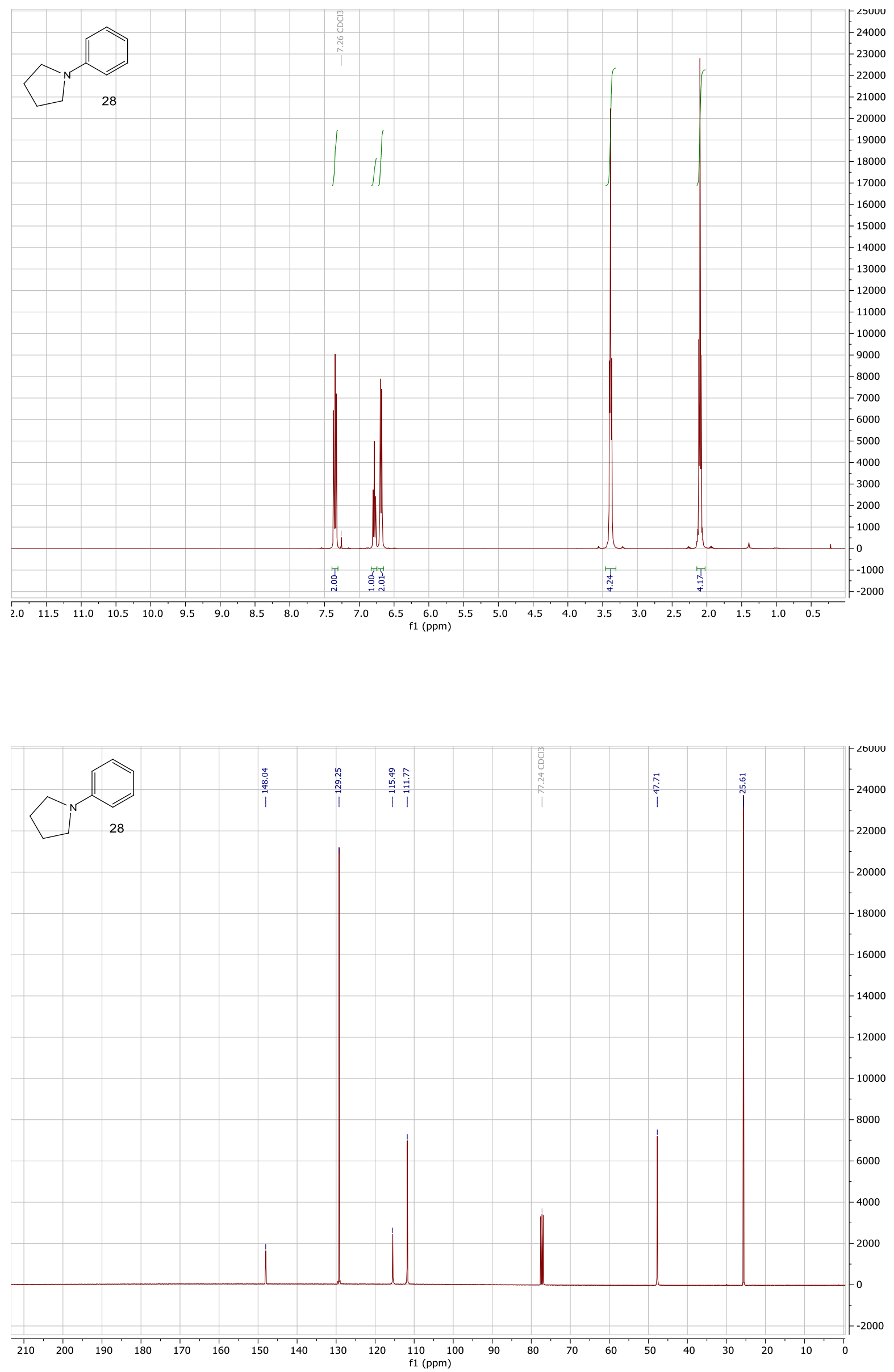

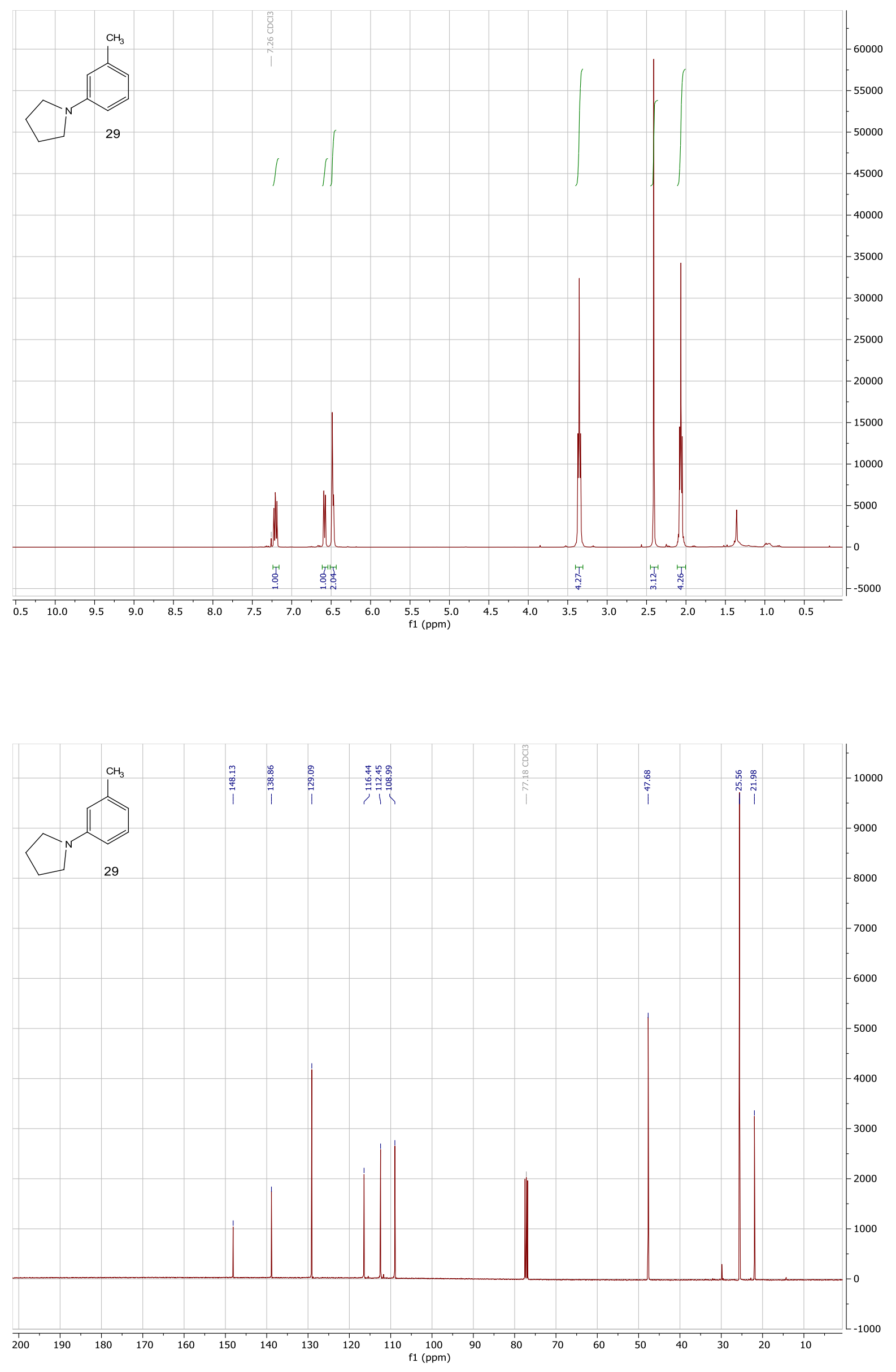

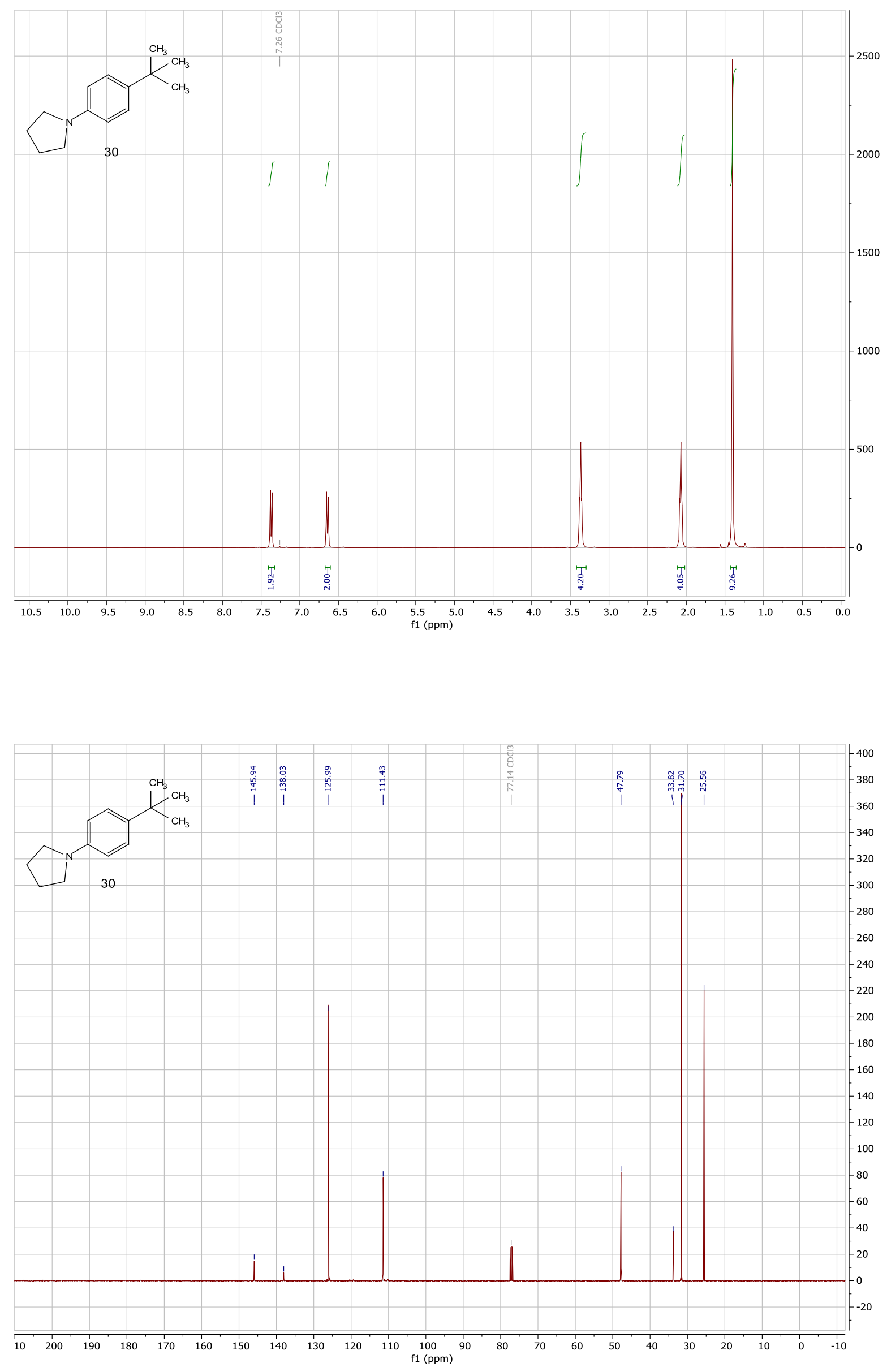

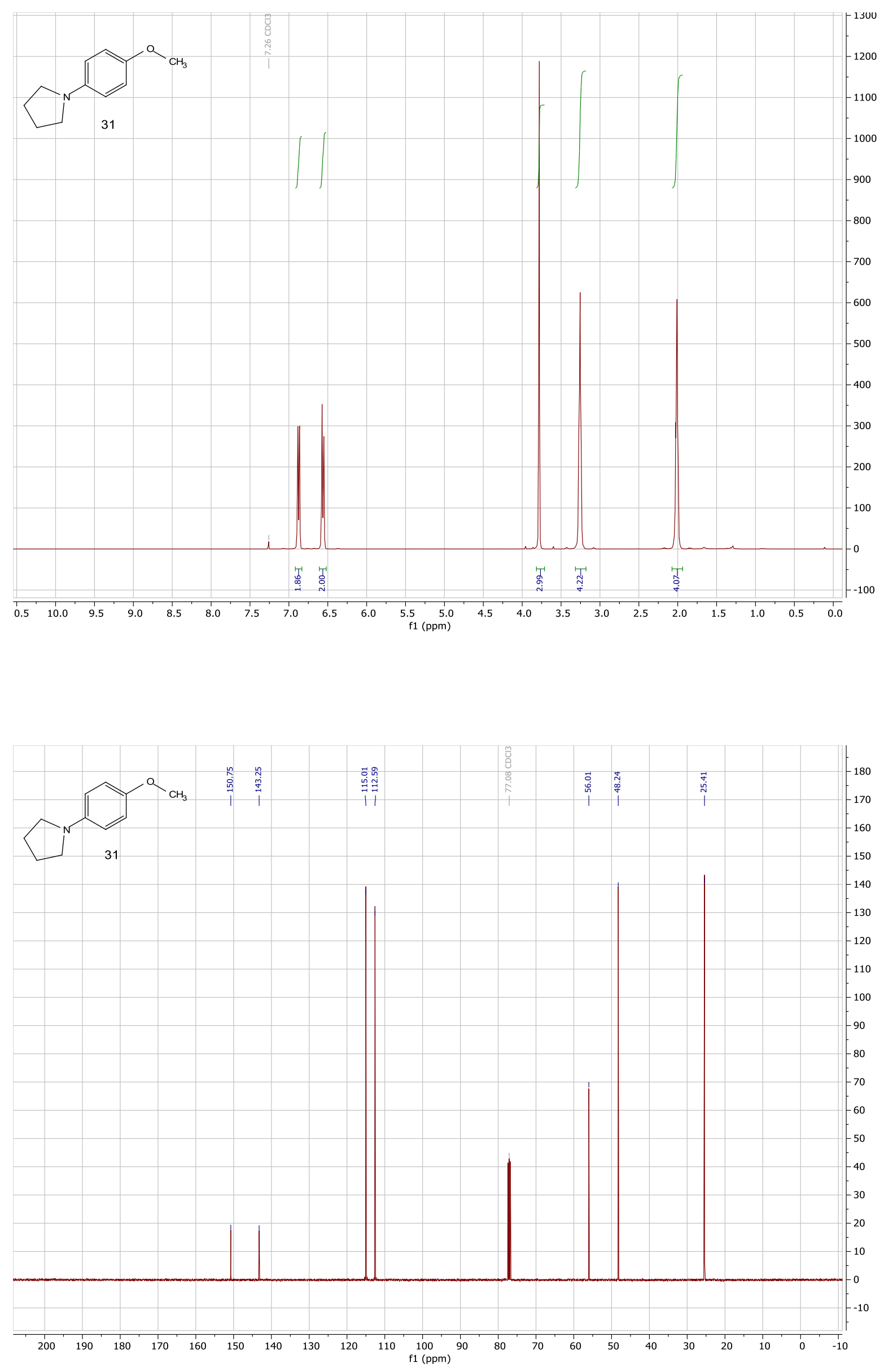
